\title{
FIRE LOADS AND DESIGN FIRES FOR MID-RISE BUILDINGS
}

\author{
A thesis submitted to \\ the Faculty of Graduate and Postdoctoral Affairs \\ in Partial Fulfillment of the requirements for the degree \\ Master of Applied Science in Civil Engineering
}

by

Naki Ocran

Department of Civil and Environmental Engineering

Carleton University

Ottawa-Carleton Institute of Civil and Environmental Engineering

August, 2012

C2012 Naki Ocran 
Library and Archives

Canada

Published Heritage

Branch

395 Wellington Street

Ottawa ON K1A ON4

Canada
Bibliothèque et

Archives Canada

Direction du

Patrimoine de l'édition

395 , rue Wellington

Ottawa ON K1A ON4

Canada
Your file Votre référence

ISBN: $978-0-494-93514-9$

Our file Notre référence

ISBN: 978-0-494-93514-9
NOTICE:

The author has granted a nonexclusive license allowing Library and Archives Canada to reproduce, publish, archive, preserve, conserve, communicate to the public by telecommunication or on the Internet, loan, distrbute and sell theses worldwide, for commercial or noncommercial purposes, in microform, paper, electronic and/or any other formats.

The author retains copyright ownership and moral rights in this thesis. Neither the thesis nor substantial extracts from it may be printed or otherwise reproduced without the author's permission.
AVIS:

L'auteur a accordé une licence non exclusive permettant à la Bibliothèque et Archives Canada de reproduire, publier, archiver, sauvegarder, conserver, transmettre au public par télécommunication ou par l'Internet, prêter, distribuer et vendre des thèses partout dans le monde, à des fins commerciales ou autres, sur support microforme, papier, électronique et/ou autres formats.

L'auteur conserve la propriété du droit d'auteur et des droits moraux qui protege cette thèse. $\mathrm{Ni}$ la thèse ni des extraits substantiels de celle-ci ne doivent être imprimés ou autrement reproduits sans son autorisation.
In compliance with the Canadian Privacy Act some supporting forms may have been removed from this thesis.

While these forms may be included in the document page count, their removal does not represent any loss of content from the thesis.
Conformément à la loi canadienne sur la protection de la vie privée, quelques formulaires secondaires ont été enlevés de cette thèse.

Bien que ces formulaires aient inclus dans la pagination, il n'y aura aucun contenu manquant. 


\section{Abstract}

This study which involves the development of fire loads and design fires for residential and non-residential mid-rise buildings is part of NEWBuildS" "Rationalization of Life Safety - Code Requirements for Mid-rise Buildings" project. The project is focused on analysing the code requirements that relate to fire resistance and the use of automatic sprinklers for mid-rise buildings built with combustible or non-combustible construction. The ultimate goal of the project is to come up with alternative solutions and, potentially, trigger changes in the code requirements for mid-rise buildings.

A review, compilation, and analysis of fire load survey data was conducted from available literature for residential and office buildings. A web survey of floor areas was also conducted for floor areas of mid-rise buildings. Fire loads and fuel packages for midrise buildings were developed based on previous surveys as well as the web survey. The fire load data in conjunction with statistical data was used to select fire scenarios from which design fire scenarios were chosen.

The fire characteristics of the selected fuel packages, such as heat release rate, and production of toxic gases, were analyzed using the two-zone fire risk analysis model, CUrisk, in order to develop appropriate design fires for mid-rise buildings. 
To Daddy, Mama, Uncle Paul, and Uncle Seth. 


\section{Acknowledgements}

My first thanks goes to my parents and two uncles without whose financial support and encouragement I would never have made it this far. I would also like to thank my brother who pushes me to be the best I can be and my sister who thinks I can and should follow my dreams.

I would like to thank my supervisor Dr. Zalok and my co-supervisor Dr. Hadjisophocleous for their guidance and valuable support throughout the writing of my thesis and for the numerous meetings we had where I was able to get information that propelled me forward in finishing my thesis. I would also like to thank them for teaching Materials in Fire and Fire Modelling courses respectively from which I learned a lot of what I needed to carry out my research and write my thesis. My sincere appreciation goes to NEWBuildS for funding my research.

My special thanks go to Xiao $\mathrm{Li}$, a colleague and Ph.D. candidate who helped me to understand and use CUrisk, and who met with me several times to help fine-tune my model.

I am also grateful for Dr. Jim Mehaffey, Dr. Braimah, Dr. Noureddine Benichou, and Dr. Craft whose courses I enjoyed tremendously, and for all members of NEWBuildS. My thanks to Dr. Craft for meeting with me during the initial stages of my thesis and for the pointers he provided. 


\section{Table of Contents}

\begin{tabular}{lr} 
Abstract & ii \\
\hline Acknowledgements & iv \\
Table of Contents & $\mathbf{v}$ \\
List of Tables & viii \\
\hline List of Figures & x \\
Chapter 1: Introduction & 1
\end{tabular}

1.1 Introduction...................................................................................

1.1.1 Combustible versus Non-combustible Construction ...............................2

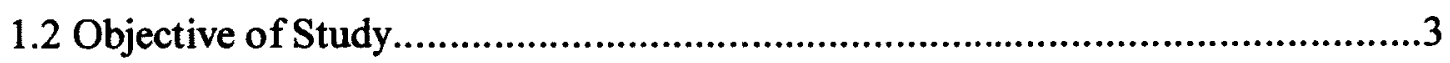

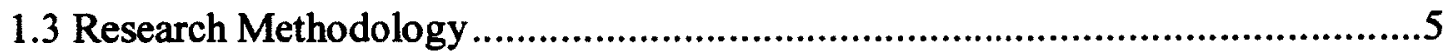

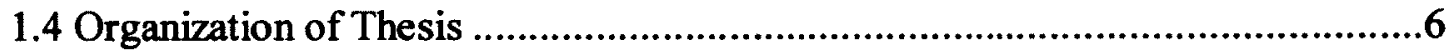

$\begin{array}{ll}\text { Chapter 2: Literature Review } & 7\end{array}$

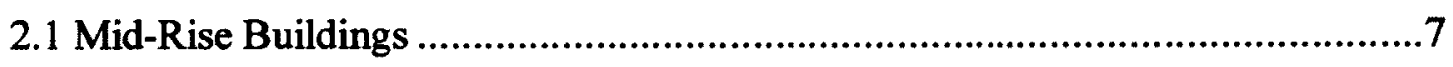

2.1.1 Fire Safety in Wood-Frame Mid-rise Buildings...................................8

2.2 Fire Load Surveys and Fire Loads ......................................................11

2.3 Fire Scenarios and Design Fires .....................................................22

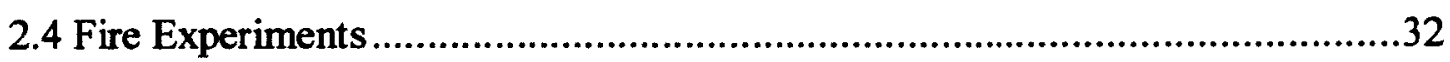

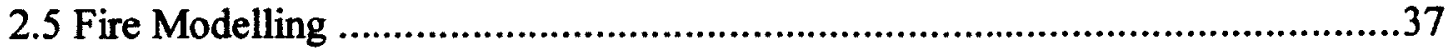

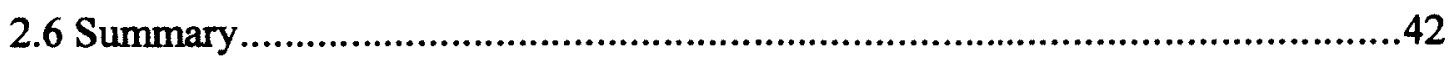

Chapter 3: Fire Load Survey Data 44

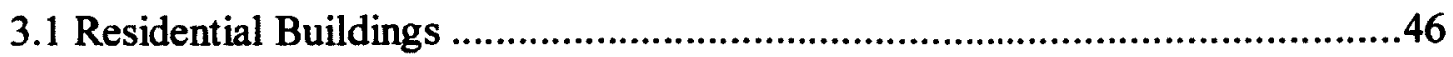




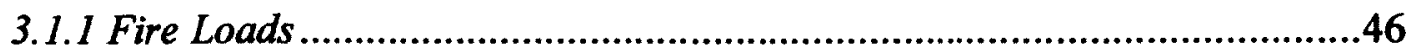

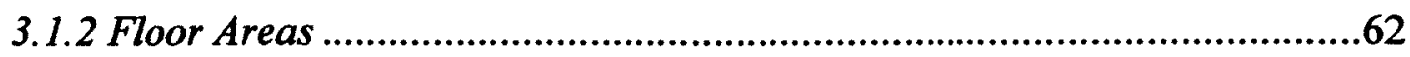

3.1.3 Summary of Fire Loads and Fire Load Densities .....................................71

3.1.4 Area of Openings........................................................................................73

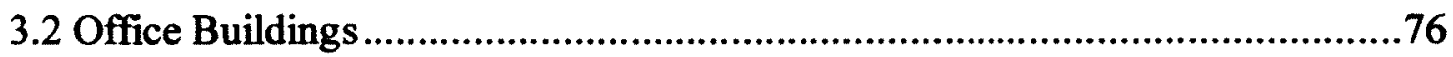

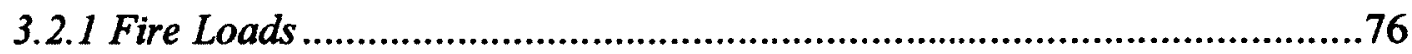

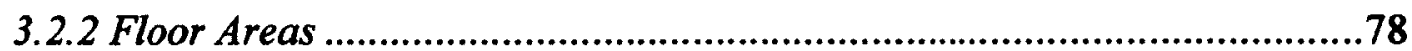

3.2.3 Summary of Fire Loads and Fire Load Densities .....................................80

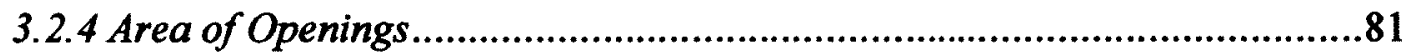

Chapter 4: Statistics of Fire Events $\quad 82$

4.1 Residential Building Fires ........................................................................82

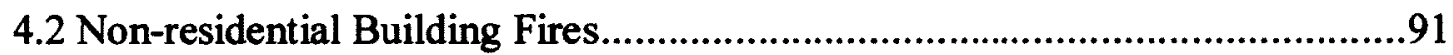

4.3 Fire Statistics in Buildings with and without Sprinklers ..................................94

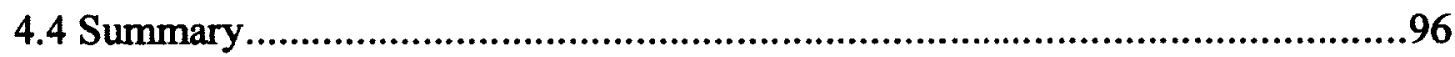

Chapter 5: Fuel Packages and Fire Scenerios $\quad 97$

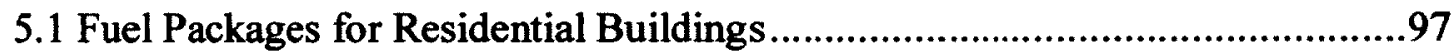

5.2 Fuel Packages for Office Buildings ..............................................................99

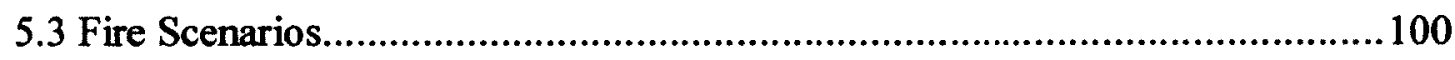

$\begin{array}{ll}\text { Chapter 6: CUrisk Fire Modelling } & 103\end{array}$

6.1 Building Description ..................................................................................103

6.2 Building Fire Safety Features ...................................................................111

6.3 Fire Simulation Theory........................................................................111

6.4 Simulated Fire Scenarios...........................................................................114

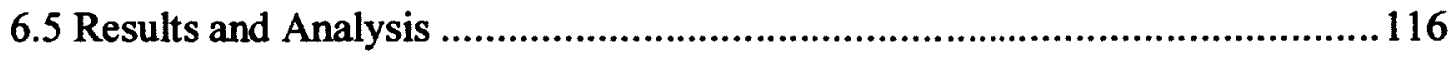

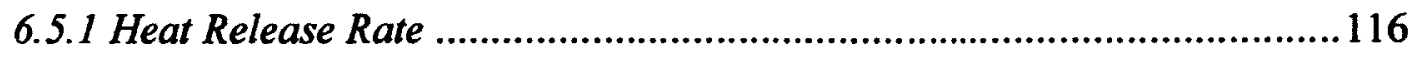

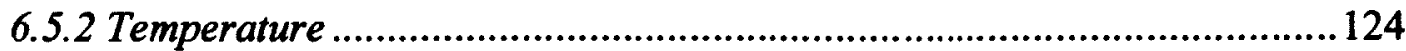

6.5.3 Smoke Interface Height ........................................................................132 
6.5.4 Oxygen Levels

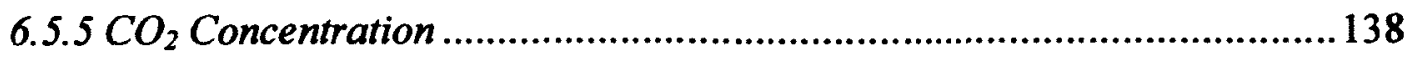

6.5.6 CO and Soot Concentrations ....................................................... 141

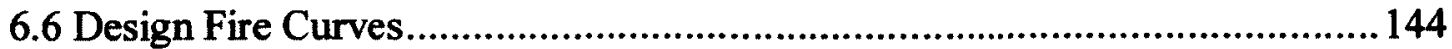

6.6.1 Design Fire Curves for Living Rooms ........................................... 145

6.6.2 Design Fire Curves for Bedrooms................................................. 147

6.6.3 Design Fire Curves for Kitchens................................................... 149

Chapter 7: Conclusions and Recommendations 150

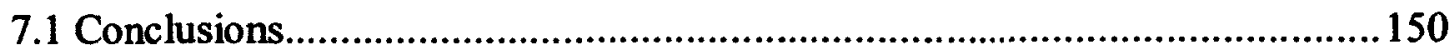

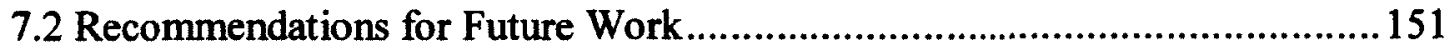

References $\quad 153$

$\begin{array}{ll}\text { Appendix A } & 157\end{array}$ 


\section{List of Tables}

Table 1: Floor area, fire load density, and total fire load for all 168 surveyed stores [10]

Table 2: Number of samples and characteristics of fire load density for major groupings [10]

Table 3: Influence of room use on fire load density [14].....................................18

Table 4: Influence of floor level on fire load density [14] ......................................18

Table 5: Fire load survey results [12] ....................................................................20

Table 6: Areas of window openings for surveyed hotels and motels [16].................22

Table 7: Fire load density for guest rooms in motels and hotels [16] .......................22

Table 8: Categories of $\mathrm{t}^{2}$ fires and their growth constants [18]...............................31

Table 9: Influence of geographic location and building height of fire load (extracted from [11])

Table 10: Residential fire load density .48

Table 11: Total fire load density in different motel and hotel categories [16]. .49

Table 12: Mean values of fire load and fire load density for the various homes [25].52

Table 13: Mean values of fire load and fire load density for various homes [26].......56

Table 14: Mean values for fire load and fire load density for basements in various home categories [26]

Table 15: Fire load and fire load density for various rooms $[15] \ldots \ldots \ldots \ldots \ldots \ldots \ldots \ldots \ldots \ldots . . .59$

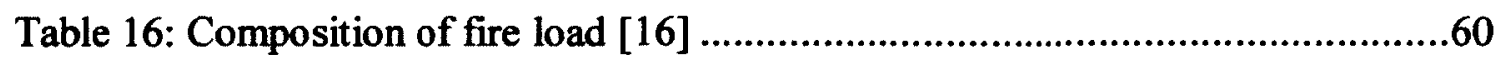

Table 17: Mean fire load density for residences in the United States [27] .................62

Table 18: Floor areas for survey of motels and hotels [16]

Table 19: Mean floor areas for main floor living room survey (extracted from [25] and [26]) 
Table 20: Mean floor areas for basement living room survey (extracted from [25] and [26]) .66

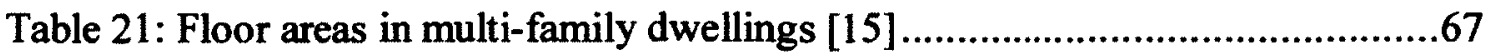

Table 22: Mean floor areas for residences in the United States ..............................67

Table 23: Floor areas for various spaces in mid-rise buildings.................................69

Table 24: Summary of fire load densities for residential buildings............................72

Table 25: Summary of fire loads for residential buildings .......................................73

Table 26: Window areas for main floor living rooms [25] [26]...............................75

Table 27: Window areas for basement living rooms [25] [26] ................................75

Table 28: Fire load densities for offices in various regions of the United States [11] 77

Table 29: Home fires in the United States in 1996, by property type [33] ................85

Table 30: Fire events in motels/hotels by building height and height of fire origin

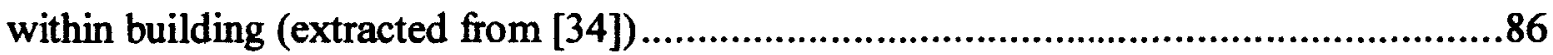

Table 31: Sources of ignition in reported residential fires in the United States in 1996Percent of total [33]

Table 32: NFPA estimates 1993-1997 annual averages - first item/materials ignited in home fires (in decreasing order of deaths per 100 fires) [33]

Table 33: Outcomes of fire events in hotels/motels and care homes for the aged of all construction types with and without sprinklers for the period 1980 - 1998 [34] .95

Table 34: Calculated maximum heat release rates and assumed growth rates. 112

Table 35: Maximum expected post-flashover temperatures, time to flashover, and HRR at flashover 114

Table 36: Observed and predicted time to flashover for various scenarios 124 


\section{List of Figures}

Figure 1: Stages of fire development in a room without active suppression (modified

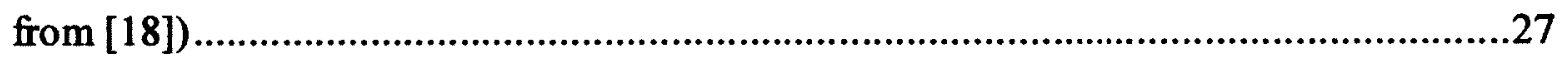

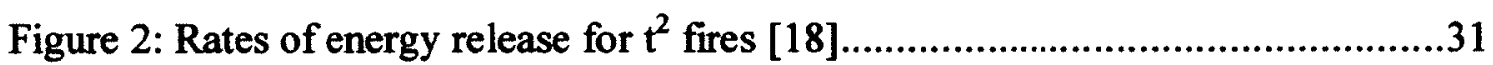

Figure 3: Layout of instrumentation in the test room [16] ........................................33

Figure 4: Section view of instrumentation at window opening [16] ..........................34

Figure 5: A schematic of the fire risk assessment system model [23].......................40

Figure 6: Furniture in main floor living room [25]...............................................52

Figure 7: Frequency distribution of total fire load for living rooms [25] ...................53

Figure 8: Frequency distribution of fire load density for living rooms [25] ..............53

Figure 9: Frequency distribution of fire load density for basement living rooms [25]54

Figure 10: Frequency distribution of floor areas for 45 mid-rise buildings.................70

Figure 11: Annual fire losses in ontario from 2006 to 2010 [35]............................84

Figure 12: Non-residential building fires and fire losses by property type (2006) [47]

Figure 13: Probability chart developed from fire statistics..................................... 101

Figure 14: Dimensions for various spaces within apartment ...................................104

Figure 15: First floor plan with location of compartments ......................................105

Figure 16: Second floor plan with location of compartments....................................106

Figure 17: Third floor plan with location of compartments......................................107

Figure 18: Fourth floor plan with location of compartments ...................................108

Figure 19: Fifth floor plan with location of compartments.....................................109

Figure 20: Sixth floor plan with location of compartments ....................................110

Figure 21: HRR curve for Group one Scenario one ..............................................119

Figure 22: HRR curve for Group two Scenario one ...............................................119 
Figure 23: HRR curve for Group one Scenario two 120

Figure 24: HRR curve for Group two Scenario two 120

Figure 25: HRR curve for Group one Scenario three 121

Figure 26: HRR curve for Group two Scenario three

Figure 27: HRR curve for Group one Scenario four 122

Figure 28: HRR curve for Group two Scenario four 122

Figure 29: HRR curve for Group one Scenario five 123

Figure 30: HRR curve for Group two Scenario five 123

Figure 31: Upper layer temperature for compartments in apartment of fire origin for Group one Scenario one 127

Figure 32: Upper layer temperature for compartments in apartment of fire origin for Group two Scenario one 127

Figure 33: Upper layer temperature for compartments in apartment of fire origin for Group one Scenario two 128

Figure 34: Upper layer temperature for compartments in apartment of fire origin for Group two Scenario two 128

Figure 35: Upper layer temperature for compartments in apartment of fire origin for Group one Scenario three. 129

Figure 36: Upper layer temperature for compartments in apartment of fire origin for Group two Scenario three 129

Figure 37: Upper layer temperature for compartments in apartment of fire origin for Group one Scenario four. 130

Figure 38: Upper layer temperature for compartments in apartment of fire origin for Group two Scenario four. 130

Figure 39: Upper layer temperature for compartments in apartment of fire origin for Group one Scenario five 131

Figure 40: Upper layer temperature for compartments in apartment of fire origin for Group two Scenario five 
Figure 41: Upper layer temperature for selected compartments outside apartment of fire origin for Group two Scenario one.

Figure 42: Interface Height for Group one Scenario one for selected compartments .134

Figure 43: Interface height for Group two Scenario two for selected compartments 134 Figure 44: Interface Height for Group two Scenario five for selected compartments 135

Figure 45: Oxygen concentration in upper layer for selected compartments for Group one Scenario one

Figure 46: Oxygen concentration in upper layer for selected compartments for Group two Scenario two.

Figure 47: Oxygen concentration in upper layer for Group two Scenario five for selected compartments. 138

Figure 48: $\mathrm{CO}_{2}$ concentration in upper layer for Group one Scenario one for selected compartments

Figure 49: $\mathrm{CO}_{2}$ concentration in upper layer for Group two Scenario two for selected compartments

Figure 50: $\mathrm{CO}_{2}$ concentration in upper layer for Group two Scenario five for selected compartments 140

Figure 51: CO concentration in upper layer for Group one Scenario one for selected compartments

Figure 52: CO concentration in upper layer for Group two Scenario two for selected compartments

Figure 53: CO concentration in upper layer for Group two Scenario five for selected compartment 142

Figure 54: Soot concentration in upper layer for Group one Scenario one for selected compartments

Figure 55: Soot concentration in upper layer for Group two Scenario two for selected compartments 
Figure 56: Soot concentration in upper layer for Group two Scenario four for selected

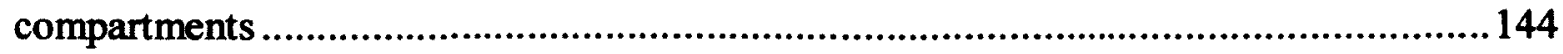

Figure 57: Design HRR curve for living room with closed main doors................... 145

Figure 58: Design HRR curve for living room with open main doors .....................146

Figure 59: Design HRR curve for a secondary bedroom ........................................148

Figure 60: Design HRR curve for a primary bedroom ..........................................148

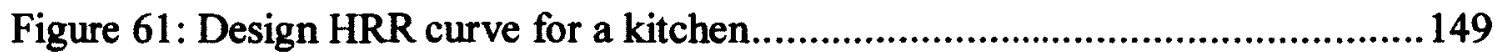




\section{Chapter 1: Introduction}

\subsection{Introduction}

Beginning with the 2005 edition of the National Building Code of Canada (NBCC), which introduced objective-based codes, engineers are finally permitted to implement innovative engineering solutions that meet at least the minimum performance requirements of the acceptable solutions defined in the code. Designers are no longer restricted to the limited number of acceptable solutions provided by prescriptive-based codes and its allowable equivalencies.

In spite of the changes that have been put forward so far, there are still restrictions on building area and height for some building occupancies as well as restrictive fire resistance requirements among other things. The stringency of the various restrictions and requirements depend on occupancy classification, but combustible construction is still not allowed beyond a limit for each classification even if fire protection measures are increased. For example, according to the prescriptive requirements in Division B, Sections 3.2.2.42 to 3.2.2.48 of NBCC 2005 [1], the highest possible residential building permitted to be built of combustible construction should not exceed four storeys. There are currently major efforts by the wood industry, the federal and provincial government, and other bodies to push the limits of the code to increase the current allowable heights on combustible construction [2]. 


\subsubsection{Combustible versus Non-combustible Construction}

A combustible material is defined by the National Building Code as any material that fails to meet the criteria of CAN/ULC-S114-05 "Standard Method of test for determination of non-combustibility in Building Materials" [1]. A non-combustible material on the other hand passes this test which involves the subjection of three $38 \mathrm{~mm} \mathrm{x}$ $38 \mathrm{~mm} \times 50 \mathrm{~mm}$ (high) samples of the material to 750 degree Celsius furnace for 15 minutes. The material is said to have passed the test if the mean maximum temperature rise of the samples does not exceed a temperature rise of over 36 degree Celsius higher than the mean temperature of the furnace during the test, there is no flaming of any of the three samples during the last 14.5 minutes of the test, and maximum mass loss of any of the three samples during the test does not exceed $20 \%$ [3]. Non-combustible construction according to NBCC 1.1.3.2 [1] is the type of construction in which the structural members and other building assemblies are made of non-combustible materials.

Building elements and assemblies in both combustible and non-combustible construction must meet various fire-resistance rating requirements. Fire-resistance ratings are assigned to building elements in whole number of hours or parts of hours based on a test or some other approval system [4]. Building elements, whether or not they are made in part or entirely by non-combustible materials, must pass the same test to receive a particular rating. Also the performance of a building in a real fire scenario depends on the fire severity and the inherent fire resistance of its structural elements and assemblies, and not necessarily on the combustibility of assemblies. 
Currently buildings made of combustible construction are hindered from exceeding six storeys in height because of the prescriptive requirement of a 2-hour fire-resistance rating among other things that are required for buildings beyond this height. No explanation is provided for this requirement. The 2-hour fire-resistance rating implies that the building assembly should be able to perform its intended function without collapse for at least two hours when subjected to the fire resistance test; combustible assemblies currently do not meet this criterion. During a real fire scenario though, fire characteristics such as temperature and duration which depend on fire load and ventilation conditions, determine the ability of a building element to withstand the fire, and not building height.

To implement performance-based design, it is necessary to show that the proposed solutions meet at least the minimum performance requirements of the acceptable solutions defined in the code. Design fires, the characteristics of which depend on the type, amount, and arrangement of combustible materials in the room of fire origin and ventilation, are used in evaluating fire protection designs. It is necessary to perform fire load surveys to determine the fire load density, types, and distribution of combustible materials, and building characteristics that can realistically be expected in mid-rise buildings. This will help to choose appropriate fire scenarios and design fires to facilitate the analysis of the code requirements related to mid-rise buildings and determine the level of safety provided by these requirements.

\subsection{Objective of Study}

This research forms part of a project that is focused on analysing the code requirements that relate to fire resistance and the use of automatic sprinklers for mid-rise buildings 
with large floor areas, built with combustible or non-combustible construction. The ultimate goal of the project is to come up with alternative solutions and, potentially, trigger changes in the code requirements for mid-rise buildings. The objectives of the project as stated in the project proposal are:

- To determine the level of safety provided by building code requirements that impose limitations on the building area and number of storeys.

- To determine the level of safety provided by the fire resistance requirements of the code including combustible versus non-combustible construction.

- To evaluate the contribution of code requirements to the code objectives and to find alternative solutions and/or develop new code requirements.

- To develop appropriate design fires for mid-rise buildings.

A design fire is an idealization of a real fire. It is a quantitative description of the assumed course of a particular fire based on appropriate fire scenarios and is characterized by heat release rate, fire size, quantities of fire gases, temperature of hot gases, and time to key events such as flashover [5]. The characteristics of a design fire are affected by the type, amount, and distribution of combustible materials in a room and room characteristics such as wall lining and ventilation. The main objectives of this research are:

- To develop fuel packages and fire loads for residential and non-residential midrise buildings;

- To determine the fire characteristics of these selected fuel packages, such as heat release rate, and production of toxic gases; 
- And finally, to develop design fires for mid-rise buildings.

\subsection{Research Methodology}

Achieving the objectives of this research will require a thorough review of available literature on:

- mid-rise buildings built with both combustible and non-combustible construction;

- fire load surveys and fire loads;

- fire scenarios and design fires;

- statistical data on fires in residential, office, commercial, and mixed use buildings;

- fire simulations using the fire risk analysis model, CUrisk;

- fire experiments.

The literature review will provide valuable information and data about fire loads for mid-rise buildings and this will help with the development of fuel packages for the same. The fire load data considered will be those related to mid-rise residential and office buildings. The fire load data in conjunction with statistical data will be used to select fire scenarios from which design fire scenarios can be chosen. The fire loads and information from fire statistics will then be used as input to perform simulations using the two-zone fire risk analysis model, CUrisk, in order to determine the characteristics of design fires for mid-rise buildings. 


\subsection{Organization of Thesis}

This thesis is organized into seven chapters.

- Chapter 1 gives in introduction to the project, explains the objective of this study, and outlines the methodology to achieve these objectives.

- Chapter 2 presents literature reviews on mid-rise buildings. Fire loads surveys and fire loads for residential, office and commercial buildings of all heights are also discussed. Literature on fire scenarios and design fires, fire experiments, and fire modelling is also reviewed and presented.

- Chapter 3 discusses fire loads, floor areas, and area of openings for both residential and office buildings.

- Chapter 4 discusses statistics of fire events for both residential and non-residential building fires, as well as fire statistics in buildings with and without sprinklers.

- Chapter 5 is a compilation of fuel packages for residential and office buildings. Fire scenarios for mid-rise buildings are also presented in this chapter.

- Chapter 6 discusses modelling a six-storey building using CUrisk. In this chapter, the characteristics of the building as well as the simulated fire scenarios are described. The results of the modelling are also presented and design fire curves developed.

- Chapter 7 presents the conclusions and recommendations for future work. 


\section{Chapter 2: Literature Review}

\subsection{Mid-Rise Buildings}

Mid-rise buildings are a building alternative which help communities and cities to meet housing requirements [6]; relatively small building footprints are used to provide accommodation for a large number of people and uses. Mid-rise buildings, as the name suggests, are classified in-between low-rise and high-rise buildings. There is currently no clear definition as to the number of storeys or height that qualifies a building to be classified as mid-rise. The city of Toronto considers mid-rise as buildings from four to twelve storeys [6]. The Canadian province of British Columbia (BC) defines a mid-rise residential wood-frame building as one less than 18 metres to the top floor [7]. With the assumption that each storey is approximately 3 metres, a mid-rise residential wood-frame building will have a maximum of six storeys. For the purposes of this project, mid-rise buildings will be considered as buildings from four to eight storeys since the project aims to push the limits of the code with respect to wood-frame mid-rise buildings, and the current proposals being put forth for wood-frame buildings especially in the provinces of British Columbia and Quebec involve buildings of these heights [2].

The development of new building technologies such as Cross Laminated Timber (CLT) has enabled the building of higher and higher wooden buildings. According to a 
report on the history and use of mid-rise buildings [2], an eight storey CLT building has been constructed in Europe, a continent which has used wood-frame mid-rise buildings since 1995 . In the summer of 2008 , a nine-storey wood frame building was constructed in the United Kingdom to become the world's tallest wood-frame residential building. The United States has also amended their building codes over the past seven years to allow for the construction of more mid-rise buildings using wood technologies [2]. The code allowed an increase from four to five storeys for wood-frame buildings; this has enabled the building of higher hybrid buildings up to eight storeys in height that incorporate wood mezzanine floors and/or concrete floors. The first six-storey wood-frame mid-rise building in Canada has been built in British Columbia. It consists of four storeys of wood frame construction and a wood mezzanine built on a concrete basement to give a total of six floors [2]. There are several more projects in the pipeline awaiting code changes and approvals.

\subsubsection{Fire Safety in Wood-Frame Mid-rise Buildings}

The use of wood-frame in the construction of mid-rise buildings has been restricted over the years due primarily to fire safety concerns. Wood-frame residential buildings, according to the current Canadian national building code are not permitted to exceed four storeys. In performance-based design, engineers and designers have the task of proving that their alternative solutions have at least the same level of performance as the acceptable solutions presented by the code. In this light, it should therefore be possible to construct wood-frame buildings beyond a height of four storeys, as long as the designer can prove that the higher building is as safe if not safer. In January 2009, GHL 
Consultants Limited, at the request of Building Safety and Policy Branch (BSPB) of the Ministry of Housing and Social Development, presented a technical report [8] regarding the proposed changes to the British Columbia (BC) building code to allow for the construction of five- and six-storey wood frame buildings. The report identified the process and technical risks relating to the code changes for five- and six-storey woodframe buildings in BC, with the focus on fire safety. Five- and six-storey wood-frame buildings were compared to four-storey wood-frame and six-storey light steel-frame buildings of residential occupancy which are $1 \mathrm{~h}$ fire rated buildings defined in subsection 3.2.2 of Division B of NBCC 2005 [1]. The proposed five- and six-storey buildings were analysed under the following fire safety risks:

- Risk of ignition - It was concluded that this risk was unlikely to increase if the total gross floor area of $7200 \mathrm{~m}^{2}$ defined under article 3.2.2.45 of NBCC 2005 is adhered to. This will imply a maximum of $1440 \mathrm{~m}^{2}$ per floor for five-storey buildings and $1200 \mathrm{~m}^{2}$ for six-storey buildings. The likely sources of ignition are managed by maintaining the same gross volume in wood-frame construction.

- Risk of fire spread beyond point of origin - Two forms of spread were identified; through the interior of the building and through the exterior via unprotected openings. The BC code addresses fire spread from compartment to compartment by implementing sprinklers and fire separations which work independent of building height. If these are used in the proposed five- and six-storey buildings, increase in interior fire spread is unlikely. Regarding exterior fire spread, noncombustible cladding or limited types of combustible cladding was suggested 
since the use of combustible cladding will serve to increase spread. Also it was recommended that fire stopping should be used appropriately where needed.

- Risk of fire spread to neighbouring buildings - the spread of fire from one building to another is usually by radiation from the burning building and is based on the distance of separation and window sizes. Sprinklers serve to reduce the temperature and therefore radiation. Fire separations confine the fire to compartment of origin thereby reducing emitting size and number surfaces. If recommended exterior claddings are used, the risk of spread to neighbouring buildings is not likely to increase.

- Risk of failure of sprinklers - Since sprinklers are installed and operate per floor area, the risk of failure of sprinklers will be no greater for a five- or six-storey wood-frame building than for a four-storey wood-frame or six-storey light steelframe building. The installation of sprinklers in large concealed spaces and crawl spaces was also recommended.

- Risk of occupants not able to recognize fire - This is not expected to increase if detection systems and alarms are appropriately installed.

- Risk of occupants not able to evacuate building - If maximum allowable area of $7200 \mathrm{~m}^{2}$ is maintained, occupant load is not expected to change. The time to travel to an exit will decrease with the smaller floor areas, there will also be less queuing at exits because there will be less people per floor. Even though travel within stairwell will increase, this will be balanced out by the shortened time to 
get to an exit. Also occupants will be protected due to fire separation requirements for stairwell walls just like in a six-storey steel-frame building.

The same kind reasoning and analysis can be applied to determine the feasibility of constructing higher mid-rise buildings in different parts of Canada.

\subsection{Fire Load Surveys and Fire Loads}

Loads are elements which cause stresses in a structure. They are due to the structure's self-weight and also due to external loads such as wind, earthquake, and items moved in for occupant use such as furniture. The ability of the structure to resist the loads applied on it is called resistance [9]. Fire loads have to do with the amounts and weights of combustible materials in a building. Fire load is often expressed as Fire Load Density (FLD) (usually per meter squared of floor area) and is given by equation 2.1 [4]. Fire load density is defined as the amount of energy that can be released per meter squared of floor area due to the complete combustion of all combustible materials in the compartment as well as the combustible parts of the space [5]. It is given by [4]:

$$
e_{f}=E / A_{f}
$$

Where

$$
e_{f}=\text { fire load density }\left(\mathrm{MJ} / \mathrm{m}^{2}\right)
$$

$E=$ the maximum possible energy that can be released by complete combustion of fuel (see equations 2.2 and 2.3) (MJ)

$$
A_{f}=\text { floor area of room }\left(\mathrm{m}^{2}\right)
$$

For dry fuels; 


$$
E=M \Delta H_{c}
$$

For fuels containing moisture;

$$
E=M \Delta H_{c, n}
$$

Where

$$
\begin{aligned}
M & =\text { mass of fuel }(\mathrm{kg}) \\
\Delta H_{c} & =\text { net calorific value of dry fuel }(\mathrm{MJ} / \mathrm{kg}) \\
\Delta H_{c, n} & =\text { net calorific value of fuel containing moisture }(\mathrm{MJ} / \mathrm{kg})
\end{aligned}
$$

Very often the fire compartment contains many types of combustible materials in varying proportions. Each of these fuels must be accounted for in calculating the total fire load density as shown in equation 2.4 [10];

$$
Q=\sum k_{i} M_{i} H_{c_{i}}
$$

Where

$$
\begin{aligned}
& Q=\text { total fire load in a compartment (MJ) } \\
& k_{i}=\text { proportion of content } i \text { that can burn } \\
& M_{i}=\text { mass of content } i \text { in the compartment }(\mathrm{kg}) \\
& M_{c_{t}}=\text { calorific value of content } i(\mathrm{MJ} / \mathrm{kg})
\end{aligned}
$$

Sometimes, fire load density is expressed per square metre of total bounding surfaces of the room [4]. Fire severity, which is a measure of the intensity or temperature of a fire which could cause the collapse of a structure or some other type of failure, depends on the duration of a fire, which in turn depends on the fire load density of a compartment.

Fire load surveys are used to establish the types, amounts, and distribution of the combustible contents of compartments. Other important information gathered during fire 
load surveys are the physical features and ambient environment of the building, occupant characteristics, and potential sources of ignition. Fire and live load surveys have been conducted since 1891 but since construction practices, building materials, and building contents change over time, there is a need to continually update fire load data through fire load surveys [11]. Design fire loads are determined in a manner similar to design loads for wind or earthquakes in order that the design fire selected is a representation of an extreme value of the likely fire scenarios [4]. The design fire load is usually chosen as a value between the $80^{\text {th }}$ and $95^{\text {th }}$ percentile. According to Buchanan [4], the design fire load should be the load which has a less than $10 \%$ probability of being exceeded in the 50 year life of the building. During fire load surveys, both fixed and movable fire loads should be considered [4]. Fixed fire loads are combustible materials such as built-in structural elements, floor coverings, cupboards, shelves, doors, door and window frames, and windowsills [5]. Moveable fire loads are items that are brought into the compartment for occupant use. They are items that can easily be moved in and out of the compartment such as books and papers, computers, and furniture [5]. Fire loads depend on such things as occupancy type, building characteristics, and use of space. A study by Culver [11] involved the investigation of the characteristics of fire loads in office buildings. The author considered things such as location (in the United States), height (2- 49 floors), age (2-73 years), occupancy characteristics, room use, and room size, and found that some of these factors also affect the fire load of a building.

Fire load surveys are conducted using several methods which include the weighing method, inventory method, combination of weighing and inventory, questionnaires, and 
web-site review. The combination of weighing and inventory was considered the best survey method since it combines best practices from both the inventory and the weighing methods and thus minimizes the degree of uncertainty and error [12].

In fire load surveys, the following assumptions are usually made to simplify the estimation of fire loads [13]:

- Combustible materials are distributed uniformly throughout the building

- All combustible materials in the fire compartment would be involved in a fire

- All combustible materials in the compartment of fire origin would undergo complete combustion during a fire

Zalok et al. [10] present the results of a survey conducted in Ottawa and Gatineau to characterize fire loads in commercial premises. A total of 168 commercial businesses with a total floor area of $17,127 \mathrm{~m}^{2}$ were surveyed. The floor area of the surveyed stores ranged from 3.25 to $1707 \mathrm{~m}^{2}$. These included restaurants, travel agencies, pharmacies, and retail stores selling clothing, shoes, food, alcohol, computers, and computer supplies. The area of clothing stores surveyed was about $30 \%$ of the total area, restaurants $13 \%$, storage areas $9 \%$, art and crafts supplies $5 \%$, and fast-food outlets $4 \%$. The survey was conducted using a combination of the weighing and inventory methods. Five types of combustible materials usually found in commercial establishments, and usually having different calorific values, were selected based on the results of the survey. The five groups selected were textiles, plastics, wood/paper, food, and miscellaneous items which included all combustible materials not included in the first four groups such as alcohol products, rubber, tobacco products, etc. 
It was found that high values of fire load have low occurrence. The fire load densities were found to have a mean of $747 \mathrm{MJ} / \mathrm{m}^{2}$, a maximum of $5305 \mathrm{MJ} / \mathrm{m}^{2}$, a minimum of 56 $\mathrm{MJ} / \mathrm{m}^{2}$, and a standard deviation of $833 \mathrm{MJ} / \mathrm{m}^{2}$. The total fire load of all fixed and movable combustibles ranged from $1126 \mathrm{MJ}$ to $511,413 \mathrm{MJ}$ with a mean of 52,339 MJ. Tables 1 and 2 present a summary of the results from the Zalok et al. [10] study. Table 1 shows the floor area, fire load density, and the total fire load for all 168 surveyed establishments. Table 2 shows the number of samples and characteristics of the fire load density of the major groupings of surveyed stores.

Table 1: Floor area, fire load density, and total fire load for all 168 surveyed stores [10]

\begin{tabular}{lcccc}
\hline & Mean & Range & Standard Deviation & 95 $^{\text {th }}$ percentile \\
\hline Floor area $\left(\mathrm{m}^{2}\right)$ & 102 & $3.25-1707$ & 183 & 333 \\
Fire load density $\left(\mathrm{MJ} / \mathrm{m}^{2}\right)$ & 747 & $56-5305$ & 833 & 2050 \\
Total fire load $(\mathrm{MJ})$ & 52339 & $1126-511413$ & 77166 & 167383 \\
\hline
\end{tabular}

Table 2: Number of samples and characteristics of fire load density for major groupings [10]

\begin{tabular}{lcccccc}
\hline \multirow{2}{*}{ Group } & No. of & \multicolumn{5}{c}{ Fire load density $\left(\mathbf{M J} / \mathbf{m}^{\mathbf{2}}\right)$} \\
\cline { 3 - 7 } & samples & $\begin{array}{c}\mathbf{9 5}^{\mathbf{6}} \\
\text { percentile }\end{array}$ & Mean & $\begin{array}{c}\text { Standard } \\
\text { deviation }\end{array}$ & Maximum & Minimum \\
\hline All stores & 168 & 2050 & 747 & 833 & 5305 & 56 \\
Shoe storage areas & 3 & - & 2547 & - & 4896 & 686 \\
Storage areas & 43 & 4289 & 1196 & 1208 & 4899 & 56 \\
Fast-food outlets & 18 & 881 & 526 & 320 & 1592 & 151 \\
Clothing stores & 14 & 661 & 393 & 164 & 755 & 142 \\
Restaurants & 11 & 582 & 298 & 190 & 625 & 84 \\
Kitchens & 8 & 553 & 314 & 161 & 602 & 149 \\
\hline
\end{tabular}


In 1973, a survey of offices [11] was conducted by the General Services Administration (GSA), the National Academy of Sciences (NAS), and the National Bureau of Standards (NBS) to collect fire load data, identify the building characteristics and occupancy characteristics that affect the magnitude of these loads, and develop mathematical models for predicting future loads. Factors of interest included location, height, age, occupancy characteristics, room use, and room size. Twenty-three private and government office buildings, ranging in height from two to forty-nine storeys, and in age from two to seventy-three years, were surveyed throughout the United States. The loads were obtained by converting the weight of items to equivalent weights of combustible materials having a calorific value of $3820 \mathrm{~kJ} / \mathrm{kg}$ and then dividing the total equivalent weights in each room by the area of the room. The total equivalent weights of enclosed combustible materials were included in calculating the fire loads. Based on the results obtained, the maximum fire load was found to be $106.6 \mathrm{psf}\left(520.5 \mathrm{~kg} / \mathrm{m}^{2}\right)$; the minimum was found to be $0.3 \mathrm{psf}\left(1.5 \mathrm{~kg} / \mathrm{m}^{2}\right)$; and a calculated mean of $7.7 \mathrm{psf}$ ( 37.6 $\left.\mathrm{kg} / \mathrm{m}^{2}\right)$. The standard deviations ranged from $5.5 \mathrm{psf}\left(26.9 \mathrm{~kg} / \mathrm{m}^{2}\right)$ to $7.4 \mathrm{psf}\left(36.1 \mathrm{~kg} / \mathrm{m}^{2}\right)$ for various regions. The author found that the data did not show any definite relationship between fire load and building height, between fire loads in government and private office buildings, nor between fire loads and building age. Conflicting results were obtained for occupancy duration; survey showed no significant change in the mean values for a given time interval considering a number of buildings with several tenants, but previous data shows $70 \%$ change for the NBS building. Also, room use affected the fire load, with file rooms, storage rooms, and libraries having relatively higher fire loads. 
A survey of office buildings was also carried out by Kumar and Rao [14] in Kanpur, India. The survey involved 388 rooms in eight office buildings with total floor area of about $11,720 \mathrm{~m}^{2}$. The buildings were up to four storeys in height and were surveyed using the inventory method. The measured masses in a compartment were multiplied by the respective calorific value of the weighed items, and then summed to obtain the total fire load of that compartment. No derating factors were applied to enclosed combustible materials. The maximum fire load was $1860 \mathrm{MJ} / \mathrm{m}^{2}$, observed in the storage and file rooms. The minimum fire loads were observed in the corridors. The mean fire load for all the rooms was found to be $348 \mathrm{MJ} / \mathrm{m}^{2}$ with a standard deviation of $262 \mathrm{MJ} / \mathrm{m}^{2}$. The 95 th percentile was $1030 \mathrm{MJ} / \mathrm{m}^{2}$. Table 3 shows the influence of room use on fire load as observed in the survey. The mean fire load, maximum fire load, and standard deviation appear to decrease with increase in room floor area. As can be observed in Table 4, the data showed no definite relationship between fire load and floor level. The maximum fire load density observed on the third floor however was about half the maximum fire load observed on first floor. Wood and paper were observed to contribute $98.7 \%$ of fire loads in office buildings. 
Table 3: Infuence of room use on fire load density [14]

\begin{tabular}{|c|c|c|c|c|c|}
\hline \multirow[b]{2}{*}{ Room Use } & \multirow[b]{2}{*}{$\begin{array}{l}\text { Number of } \\
\text { rooms }\end{array}$} & \multirow[b]{2}{*}{$\begin{array}{l}\text { Total floor } \\
\text { area }\left(\mathrm{m}^{2}\right)\end{array}$} & \multicolumn{3}{|c|}{ Fire Load Density $\left(\mathrm{MJ} / \mathrm{m}^{2}\right)$} \\
\hline & & & $\begin{array}{l}\text { Maximum } \\
\text { load }\end{array}$ & Mean load & $\begin{array}{c}\text { Standard } \\
\text { deviation of load }\end{array}$ \\
\hline Reception & 19 & 246.7 & 1540 & 637 & 349 \\
\hline Storage and file & 40 & 1217.9 & 1860 & 601 & 372 \\
\hline Technical & 21 & 623.8 & 1240 & 434 & 302 \\
\hline Clerical & 84 & 3617.8 & 1760 & 432 & 200 \\
\hline General & 108 & 2802.6 & 1080 & 300 & 191 \\
\hline Corridor & 36 & 1922.2 & 1150 & 153 & 140 \\
\hline Conference & 8 & 575.5 & 317 & 189 & 39 \\
\hline Lavatory & 62 & 461.9 & 762 & 146 & 143 \\
\hline Miscellaneous & 10 & 251.4 & 862 & 278 & 270 \\
\hline All rooms & 388 & 11719.8 & 1860 & 348 & 262 \\
\hline
\end{tabular}

Table 4: Influence of floor level on fire load density [14]

\begin{tabular}{ccccc}
\hline & Floor area & \multicolumn{3}{c}{ Fire Load Density $\left.\mathbf{( M J} / \mathbf{m}^{\mathbf{2}}\right)$} \\
\cline { 3 - 5 } & $\left.\mathbf{m}^{\mathbf{2}}\right)$ & $\begin{array}{c}\text { Maximum } \\
\text { Flood level }\end{array}$ & Mean load & $\begin{array}{c}\text { Standard deviation of } \\
\text { load }\end{array}$ \\
\hline Ground floor & 2434.5 & 643 & 370 & 173 \\
First floor & 3415.4 & 566 & 306 & 79 \\
Second floor & 3553.5 & 633 & 347 & 106 \\
Third floor & 2316.4 & 372 & 304 & 27 \\
\hline
\end{tabular}

A survey was conducted by Bwalya et al. [15] of floor areas and combustible contents in 515 multi-family dwellings including semi-detached houses, town houses, and low-rise apartments. $74 \%$ of all homes surveyed were town houses. The homes ranged from 1 year to 83 years. The objectives of the project were to quantify the combustible contents of multi-family dwellings and to determine the similarities in combustible contents and 
configurations between semi-detached houses, town houses, and low-rise apartments. The survey focused on the contents which were not part of the building structure of rooms in which fires were most likely to start such as living rooms, bedrooms, and kitchens. The data was collected from real estate websites. This internet-based survey was considered relatively less energy and time consuming and also helped to avoid privacy concerns involved in physically entering homes. The disadvantages of this method as listed by the author are:

- photographs often do not show all the furnishings and relevant details of a room

- rooms are often tidy in photographs; in real life, there is often some clutter in various parts of a house

- the calculated fire load densities may not be accurate since they are based on estimates rather than physically weighing items

According to the author, results of the survey conducted in Ottawa compared well with those for other Canadian provinces. Kitchens, with mean fire load density of $807 \mathrm{MJ} / \mathrm{m}^{2}$, were found to have significantly higher fire load densities than other rooms due to relatively small floor areas and heavy wooden cabinets. Primary and secondary bedrooms had mean fire load density of $534 \mathrm{MJ} / \mathrm{m}^{2}$ and $594 \mathrm{MJ} / \mathrm{m}^{2}$ respectively. Basement living rooms were found to have the lowest mean fire load density of $288 \mathrm{MJ} / \mathrm{m}^{2}$. It was observed that wood-based products formed a large portion of the total combustible mass in every room. Most living rooms had hardwood and laminate flooring, kitchens had mostly vinyl flooring, while bedrooms and basement living rooms had mostly carpeting. 
In a project [12] to validate the fire load survey methodology proposed in the NFPA (draft) Standard 557, the author conducts a survey of 103 offices in five office buildings. The survey was carried out in the Canadian cities of Ottawa and Gatineau from November 2010 to April 2011. The buildings included both private and federal government buildings. The survey was conducted using the weighing method, the inventory method, the combination method, and the questionnaire method. The offices surveyed consisted of 27 enclosed offices and 76 cubicles. The fire loads were calculated by converting the measured masses into energy units using the respective calorific values of the measured items. The author found that the inventory method gave higher fire load density in most cases, and the weighing method gave the least. A summary of the fire load densities obtained are presented in Table 5. The author concluded that the combination method is the best survey method since it combines best practices from both methods thereby minimizing uncertainty and error in predicting fire load density. The combination method gave a mean fire load density for offices of $557 \mathrm{MJ} / \mathrm{m}^{2}$ with a standard deviation of $286 \mathrm{MJ} / \mathrm{m}^{2}$.

Table 5: Fire load survey results [12]

\begin{tabular}{lcccc}
\hline & $\begin{array}{c}\text { Sample } \\
\text { Size }\end{array}$ & $\begin{array}{c}\text { Inventory } \\
\mathbf{M e t h o d} \\
\left(\mathbf{M J} / \mathbf{m}^{\mathbf{2}}\right)\end{array}$ & $\begin{array}{c}\text { Weighing } \\
\text { Method } \\
\left(\mathbf{M J} / \mathbf{m}^{2}\right)\end{array}$ & $\begin{array}{c}\text { Combination } \\
\text { Method } \\
\left(\mathbf{M J} / \mathbf{m}^{2}\right)\end{array}$ \\
\hline Mean & 103 & 852 & 530 & 557 \\
$\mathbf{8 0}^{\text {th }}$ percentile & 103 & 1572 & 871 & 1077 \\
$90^{\text {th }}$ percentile & 103 & 1805 & 996 & 1182 \\
$9^{\text {th }}$ percentile & 103 & 2090 & 1188 & 1282 \\
Standard Deviation & 103 & $\mathbf{4 8 4}$ & 257 & 286 \\
\hline
\end{tabular}


Chen [16] conducted a research project to develop design fires for motels and hotels. The fire load survey conducted in 2007 involved 10 motels and 12 hotels in the Canadian cities of Ottawa and Gatineau. The motels that were surveyed consisted of low-rise buildings of one- or two-storeys, and one three-storey building. The surveyed hotels were mostly 2- to 5-star buildings ranging from 6 years to 100 years old and 3- to 24-storeys. The inventory method was used since the author had pre-weighed most of the items found in the rooms. The author surveyed 25 motel rooms with a total floor area of $567 \mathrm{~m}^{2}$ which represented 315 motel guest rooms with a total floor area of $7108 \mathrm{~m}^{2}$ which had similar layouts and contents. Also, 36 hotel rooms with a total floor area of $1094 \mathrm{~m}^{2}$ were surveyed representing 2041 similar rooms with floor area of $58,395 \mathrm{~m}^{2}$. The survey focused only on guest rooms and suites. A summary of the areas of window openings for the surveyed hotels and motels have been compiled in Table 6 according to the results presented by the author. As can be seen from the table, rooms in hotels or motels with one bed have similar window sizes to those with two beds. The author found that a mean of $33 \%$ with a standard deviation of $5.12 \%$ of floor area was occupied by furniture and equipment in bedrooms with one bed, and a mean of $40.3 \%$ with a standard deviation of $5.69 \%$ for those with two beds. Table 7 shows a summary of the moveable and total fire load densities for the surveyed motels and hotels. 
Table 6: Areas of window openings for surveyed hotels and motels [16].

\begin{tabular}{lcccccc}
\hline & & \multicolumn{5}{c}{ Area of window opening $\mathbf{~ m}^{2}$} \\
\cline { 4 - 7 } & of beds & Minimum & Maximum & Mean & $\begin{array}{c}\mathbf{9 5}^{\text {th }} \\
\text { Percentile }\end{array}$ & $\begin{array}{c}\text { Standard } \\
\text { Deviation }\end{array}$ \\
\cline { 5 - 7 } Motel & 1 & 1.65 & 3.79 & 2.54 & 3.34 & 0.60 \\
Motel & 2 & 1.65 & 3.79 & 2.51 & 2.41 & 0.60 \\
Standard hotels & 1 & 2.03 & 6.60 & 3.98 & 6.39 & 1.56 \\
Luxury hotels & 1 & 3.13 & 10.00 & 5.92 & 9.18 & 2.55 \\
Suite hotels & 1 & 1.32 & 3.00 & 1.87 & 2.80 & 0.76 \\
Standard hotels & 2 & 2.03 & 6.00 & 2.95 & 5.20 & 1.42 \\
Luxury hotels & 2 & 3.13 & 10.00 & 5.26 & 9.34 & 3.06 \\
Suite hotels & 2 & 1.59 & 2.67 & 1.98 & 2.57 & 0.60 \\
\hline
\end{tabular}

Table 7: Fire load density for guest rooms in motels and hotels [16]

\begin{tabular}{lcccccccc}
\hline & \multicolumn{2}{c}{ Moveable Fire Load Density } & & \multicolumn{3}{c}{ Total Fire Load Density } \\
\cline { 2 - 4 } & $\begin{array}{c}\text { Motels } \\
\left(\mathrm{MJ} / \mathrm{m}^{2}\right)\end{array}$ & $\begin{array}{c}\text { Hotels } \\
\left(\mathrm{MJ} / \mathrm{m}^{2}\right)\end{array}$ & $\begin{array}{c}\text { All Rooms } \\
\left(\mathrm{MJ} / \mathrm{m}^{2}\right)\end{array}$ & & $\begin{array}{c}\text { Motels } \\
\left(\mathrm{MJ} / \mathrm{m}^{2}\right)\end{array}$ & $\begin{array}{c}\text { Hotels } \\
\left(\mathrm{MJ} / \mathrm{m}^{2}\right)\end{array}$ & $\begin{array}{c}\text { All Rooms } \\
\left(\mathrm{MJ} / \mathrm{m}^{2}\right)\end{array}$ \\
\hline Minimum & 202 & 145 & 145 & & 371 & 279 & 279 \\
Maximum & 569 & 571 & 571 & & 736 & 848 & 848 \\
Mean & 383 & 391 & 388 & & 535 & 560 & 550 \\
$80 \%$ & 436 & 453 & 453 & & 605 & 638 & 632 \\
$95 \%$ & 501 & 544 & 539 & & 712 & 776 & 753 \\
$\begin{array}{l}\text { Standard } \\
\text { deviation }\end{array}$ & 89 & 105 & 98 & & 100 & 123 & 115 \\
\hline
\end{tabular}

\subsection{Fire Scenarios and Design Fires}

Design fires are needed in the fire safety design of buildings. Methods of obtaining design fires include development from surveys and data, hand calculations, published curves or parametric fire equations [4]. Performance-based fire protection analysis and design is one of the building blocks in the process of building design, construction, and 
operation [17]. It is important to incorporate fire protection from the conceptual stage of any building design. There is the need to specify a design fire or several design fires when analysing the fire safety protection of a building in performance-based design. The design fires chosen should be appropriate for the fire safety design objectives set at the beginning of the project.

The Society of Fire Protection Engineers (SFPE) engineering guide to PerformanceBased Fire Protection [17] provides an outline for the performance-based design process. The first step is to clearly define the scope of the project. Next, the goals for fire protection which is an important element in the design of any building should be identified. The goals may include levels of protection for people and property, protection of equipment and continuity of operation, and environmental protection among other things. Design objectives should then be set by refining the goals into values that are quantifiable in engineering terms. For example, the consequence of a fire should be quantified in monetary terms. The performance criteria are developed through a further refinement of the design objectives. This involves the setting of numerical values to which expected performance of trial designs will later be compared. Design alternatives that will meet the performance criteria need to be developed and analyzed; the first step in this process is to identify possible fire scenarios and select appropriate design fire scenarios. In performance-based design, there is the need for computational tools which rely on the development of design fires [18] for various occupancies.

Design fire is an idealization of real fires that may occur in a building. A design fire is a quantitative description of properties of a fire based on data or reasonable assumptions 
about the type, amount and distribution of combustible materials within a compartment, ignition sources and methods, growth, spread, decay, and extinction of the fire within a compartment [18]. The properties of a design fire include the heat release rate, effluent from the fire, and temperature. These properties vary with time, increasing rapidly following flashover. The first step to developing a design fire is to identify fire scenarios from which design fire scenarios can be selected.

A design fire scenario as defined by ISO/TR-13387-2 is "a specific fire scenario on which an analysis will be conducted. It includes a description of the impact of the fire on building features, occupants, fire safety systems and would typically define the ignition source and process, the growth of the fire on the first item ignited, the spread of fire, the interaction of the building occupants and the interaction with the features and fire safety system within the building" [15]. A fire scenario is a set of conditions that are thought to be threatening to a building, its occupants, and contents. It describes the factors which are critical to the outcome of a fire including fire protection features, ignition sources, the amount, type, and distribution of combustible materials, ventilation conditions, condition of building structure, and occupants among other things [17]. Each fire scenario is described by a unique set of events that influence the ignition, development, and spread of fire in a particular compartment [5]. Any change to the events of a fire scenario is likely to give rise to a different outcome, thereby creating a different fire scenario. A fire scenario should describe the characteristics of the fire, building, and occupants [17]. Building characteristics are the physical features, contents, and ambient environment of 
the building. These as stated in the SFPE engineering guide to performance-based fire protection are:

- Architectural features

- Structural components

- Fire protection systems

- Building services/processes

- Operational characteristics

- Fire department response characteristics

- Environmental factors

Occupant characteristics describe the ability of occupants in a building to respond and evacuate during a fire event. These as stated in the SFPE engineering guide to performance-based fire protection [17] are:

- Number of occupants

- Distribution throughout the building

- Alertness (asleep or awake)

- Focal point

- Physical and mental capabilities

- Role

- Familiarity

- Social affiliation

- Physical and physiological condition 
Fire characteristics as stated in the SFPE engineering guide to performance-based fire protection [17] are:

- Ignition sources

- Growth

- Flashover

- Full development

- Extinction

Design fire scenarios on which further analysis will be conducted are chosen from the list of developed fire scenarios. Design fire scenarios are chosen using engineering judgement [17] and available data on which fires are most probable and which will have the most impact.

A fire develops through different stages from ignition to extinction as shown in Figure 1. Some of the things that affect the development of a fire are the form of the ignition source, the type of fuel first ignited, ventilation and conditions of ventilation openings and equipment, location of the fire, compartment geometry, lining and contents, and form of intervention [17]. 


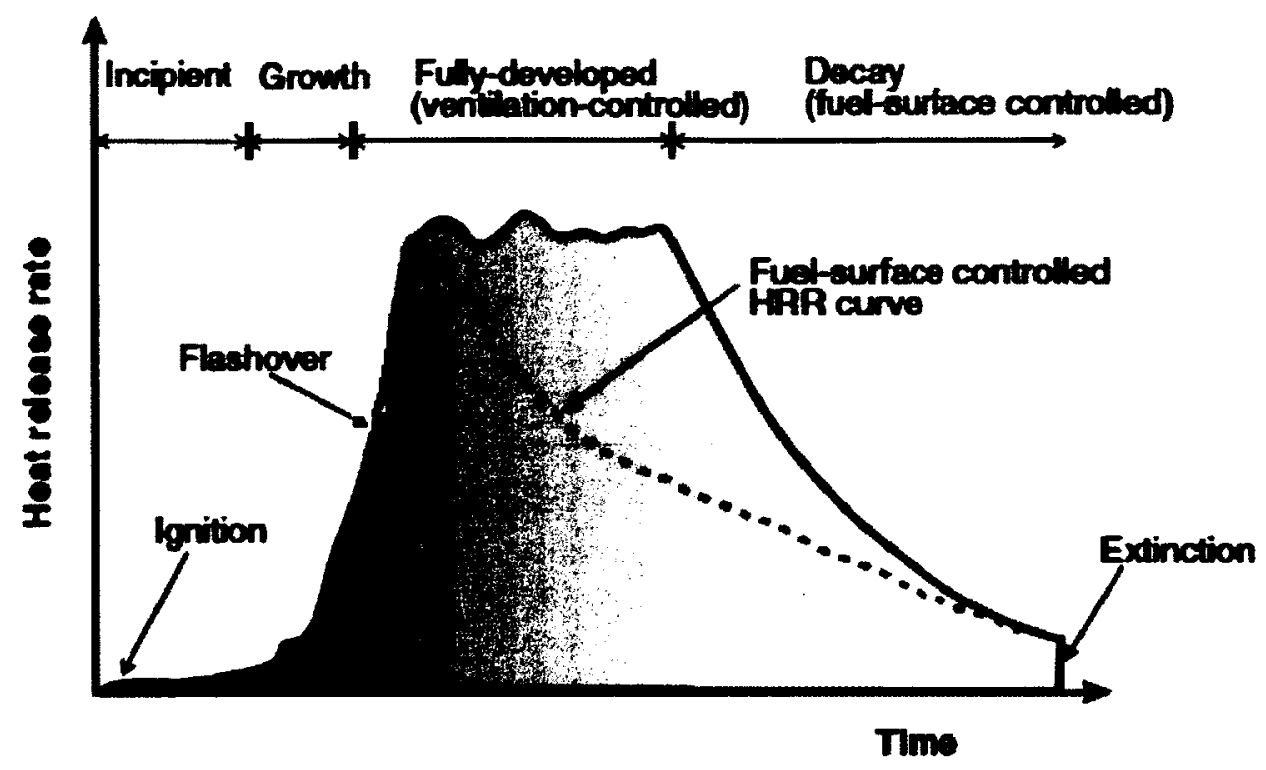

Figure 1: Stages of fire development in a room without active suppression (modified from [18])

For ignition to occur there has to be fuel, oxygen, and an ignition source. In a building compartment, there is usually no shortage of combustible materials or oxygen; the limiting factor is often the ignition source. The ignition source has to be strong enough and have sufficient contact time to raise the temperature of the fuel to its ignition temperature. Therefore in identifying sources of ignition to include in fire scenarios, one needs to consider the temperature, energy, and time, and area of contact with potential fuels. Ignition sources should be chosen carefully as some ignition sources with a low frequency of occurrence may have the greatest devastating effects on the building should a fire occur [17]. 
After ignition a fire starts to grow as rapidly developing flames or as a smouldering fire. The growth characteristics determine time to detection, when conditions become untenable, the effectiveness of suppression and evacuation efforts [5]. The period of growth includes an incipient phase. The duration of the incipient stage depends on factors such as the strength and location of the ignition source, ventilation, and the thermal properties of the item first ignited. The growth of the fire also depends on the types, amounts, and distribution of combustible materials in the fire compartment. As the fire grows, the room heats up and a smoke layer begins to develop on the upper level of the room. At some point, the amount of heat radiated to the bottom of the room is high enough to ignite all combustible materials in the compartment; this phenomenon is called flashover. Flashover is defined in several ways [15]:

- The transition from growth to a fully developed fire;

- The transition from one combustible item burning to all combustible items burning;

- The point at which the hot layer temperature reaches $500^{\circ} \mathrm{C}$ to $600^{\circ} \mathrm{C}$;

- The point at which the heat flux at the floor of the compartment reaches 15 to 20 $\mathrm{kW} / \mathrm{m}^{2}$.

Flashover is characterised by a rapid increase in heat release rate, temperature, smoke production, and toxicity until further increase is inhibited by ventilation [18]. Some of the factors that affect whether or not flashover occurs in a compartment are the total surface area of the compartment, the area and height of ventilation openings, the heat release rate of burning item/items, the rate of air flow into the compartment, and the thermal 
properties of room boundaries. It is possible to not reach flashover if burning is taking place in a large compartment [4], or there is a limited supply of oxygen or fuel [19]. There are various expressions in literature to calculate the critical value of heat release necessary to cause flashover [4].

After flashover occurs, the fire progresses rapidly into a fully-developed stage at which point the heat release rate is maximum and steady burning occurs. The peak heat release rate depends on the available fuel and burning area [17]. The maximum heat release rate and duration of the fully-developed fire govern the response and possible failure of structural elements [5]. A fully-developed fire is usually ventilation-controlled, and involves the whole room with the exit of flames through ventilation opening which may lead to fire spread. Decay and extinction of a fire occur when there is a depletion of fuel or lack of oxygen to sustain the fire.

The stages of a fire may also be divided into pre-flashover and post-flashover. The pre-flashover stage involves ignition and growth phases leading up to flashover. During this stage in the fire, the main concern is occupant safety. Pre-flashover is characterised by a continuous increase of heat release rate, temperature, smoke production, and toxicity in the fire compartment [15]. It is usually expressed as a power law correlation which is a function of time as shown in equation 2.5 [18]. The expression leads to a curve commonly known as a t-squared fire curve when $p$ is set equal to 2 .

$$
\dot{Q}=\alpha t^{p}
$$

Where,

$$
\dot{Q}=\text { heat release rate }(\mathrm{kW})
$$


$p=$ positive exponent (usually having a value of 2 but may be determined experimentally);

$t=$ time after effective ignition (s);

$\alpha=$ fire growth coefficient $\left(\mathrm{kW} / \mathrm{s}^{2}\right)$.

The growth coefficient takes on a value depending on the growth rate of the fire which in turn depends on the materials involved in the fire. It is calculated as:

$$
\alpha=\frac{\dot{Q}_{0}}{t_{o}{ }^{2}}
$$

Where,

$$
\begin{aligned}
& \dot{Q}_{o}=\text { is the reference heat release rate (usually taken to be } 1055 \mathrm{~kW} \text { ) } \\
& t_{o}=\text { is the time to reach } \dot{Q}_{o}
\end{aligned}
$$

A fire may be described as having a slow, medium, fast, or ultra fast growth rates as illustrated in Figure 2. The time to reach the reference heat release rate and the materials involved for the various growth rates are shown in Table 8.

In the post-flashover stage of a fire, conditions in the compartment become untenable. The main concern at this point is the safety of fire fighters, property protection, and structural stability of the building and therefore the temperature history is important [18]. Post-flashover fires are usually ventilation controlled, and combustion rate depends on the condition of ventilation openings. Glass will typically break following flashover allowing more oxygen into the compartment [4]. Buchanan [4] provides information on estimating temperatures during post-flashover fires. 


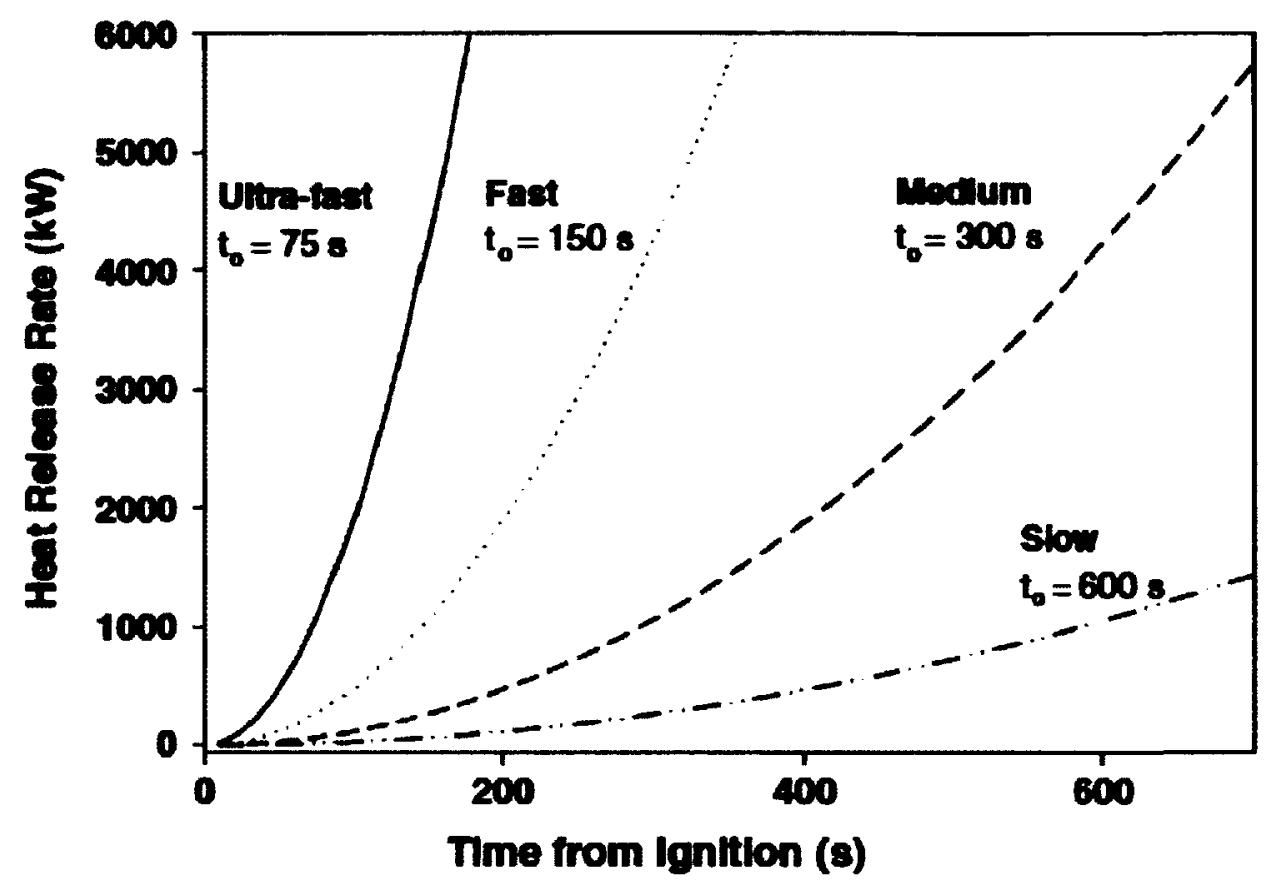

Figure 2: Rates of energy release for $t^{2}$ fires [18].

Table 8: Categories of $t^{2}$ fires and their growth constants [18]

\begin{tabular}{lccc}
\hline $\begin{array}{l}\text { Growth } \\
\text { Rate }\end{array}$ & Design Fire Scenario & $\begin{array}{c}\text { Value of } \\
\boldsymbol{\alpha}\end{array}$ & $\begin{array}{c}\text { Characteristic } \\
\text { time, }_{\mathbf{0}} \text { (s) }\end{array}$ \\
\hline Slow & Floor coverings & 0.00293 & 600 \\
Medium & $\begin{array}{c}\text { Shop counters, office furniture, furniture } \\
\text { items with small amounts of plastic }\end{array}$ & 0.0117 & 300 \\
Fast & $\begin{array}{c}\text { Bedding, displays and padded work- } \\
\text { station partitioning }\end{array}$ & 0.0466 & 150 \\
& $\begin{array}{c}\text { Upholstered furniture and stacked } \\
\text { furniture near combustible linings, } \\
\text { lightweight furnishings, packing material } \\
\text { in rubbish pile, non-fire-retarded plastic } \\
\text { foam storage, cardboard of plastic boxes } \\
\text { in vertical storage arrangement }\end{array}$ & 0.1874 & 75 \\
\hline
\end{tabular}


Bwalya [18] describes heat release rate as the single most important variable that quantitatively defines a design fire. The heat release rate of various furniture items has been measured in a furniture calorimeter using the oxygen consumption principle under fully-ventilated conditions. Published data of these values are available in literature. Heat release density is the heat release rate of a fire divided by the base area of the fuel package. It is important in estimating the peak heat release rate of similar fuel packages occupying different base areas [18].

\subsection{Fire Experiments}

Fire experiments are carried out in order to determine the burning characteristics of room fires and the combustible materials contained therein. Through experiments, it is possible to determine the time varying properties that define a particular fire which include heat release rate, fire effluent, mass loss rate, temperature, and heat flux. These experiments are set up and conducted based on information about building contents and characteristics gathered from fire loads surveys, and also from statistics about fire events and losses. In 2008, two full-scale tests were conducted by Chen [16] at the National Research Council of Canada/ Carleton University (NRCC/Carleton) Fire Research Lab based on the data obtained from fire load surveys conducted in 10 motels and 12 hotels in Ottawa and Gatineau, Canada. The tests were carried out to help develop design fires for motels and hotels. The two tests were set up to simulate fires scenarios in bedrooms with one and two beds respectively. The fire load densities used in these tests were lower than the mean values observed during the fire load survey. For both tests, the test room was built on a $15.2 \mathrm{~cm}$ thick concrete slab and measured $3.77 \mathrm{~m} \times 4.17 \mathrm{~m} \times 2.37 \mathrm{~m}$, with a window 
opening of $1.5 \mathrm{~m} \times 1.5 \mathrm{~m}$ and a $2.0 \mathrm{~m} \times 0.9 \mathrm{~m}$ door. A hood was built above the window to collect exhaust gases. The door was closed during the tests. The walls and roof were constructed with lightweight steel frame. The interior and exterior sides of the walls were lined with one layer each of cement board. The ceiling was lined on the interior with two layers of Type-X gypsum board and the exterior with plywood. The floor of the test room was covered with one layer of cement board.

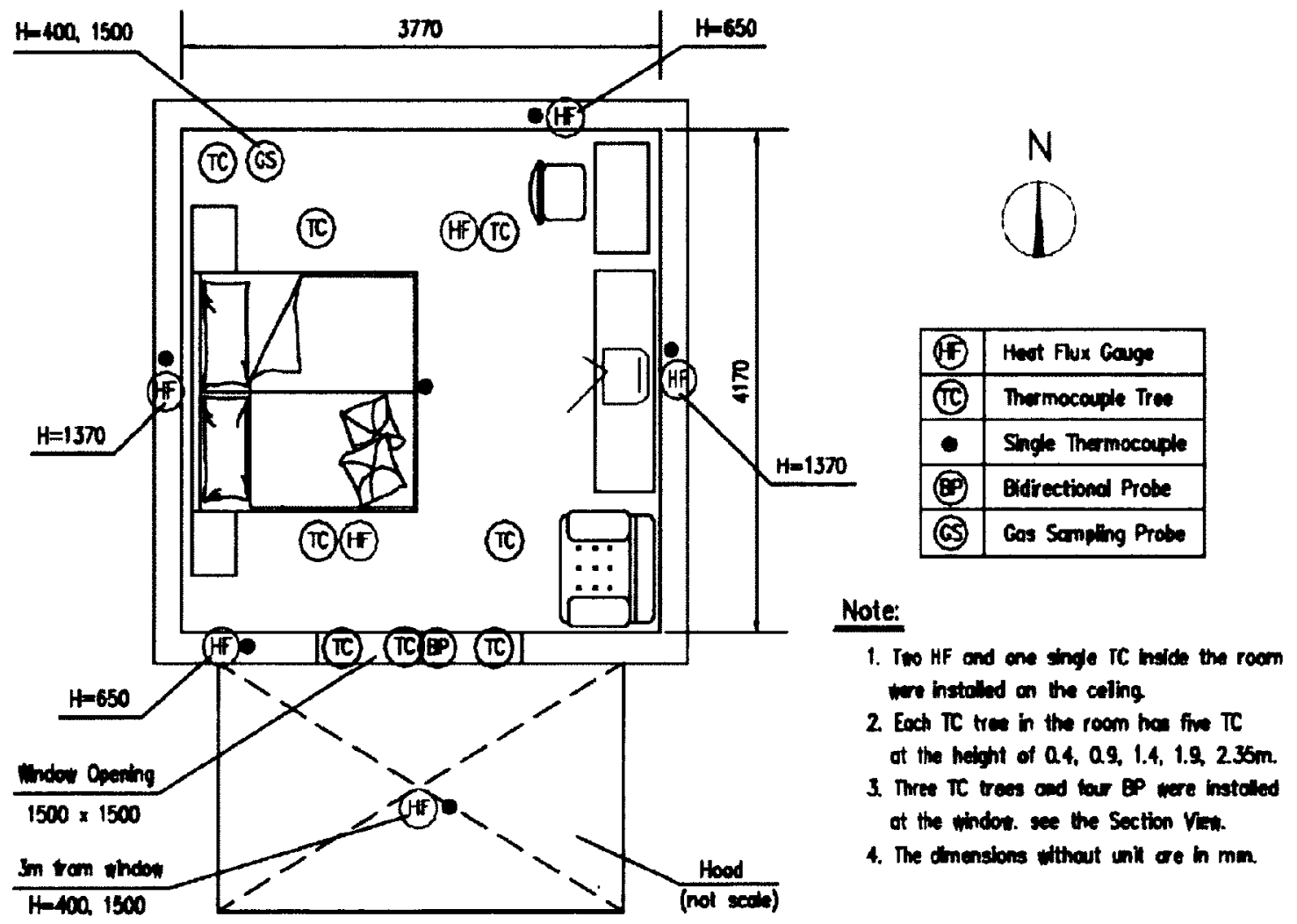

Figure 3: Layout of instrumentation in the test room [16] 


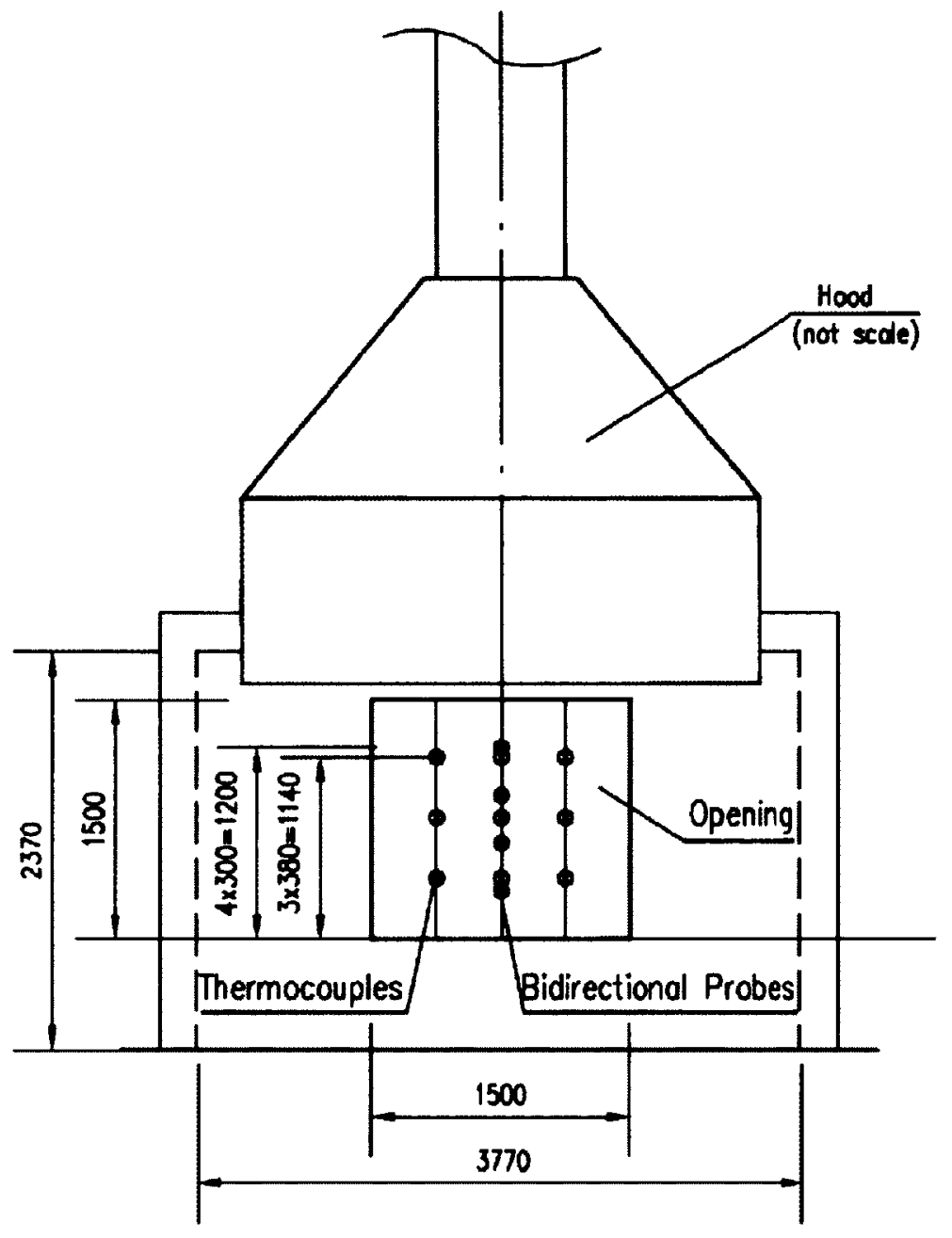

Figure 4: Section view of instrumentation at window opening [16]

The heat release rate was measured using the classical principle of oxygen consumption which uses the concept that for many organic materials, the same amount of heat is produced per unit mass of oxygen consumed in a fire. An exhaust duct was connected to the hood over the window to facilitate the collection of exhaust gases. The mass flow rate, gas temperature, pressure, and the concentrations of oxygen, carbon monoxide, and carbon dioxide which are needed to calculate the heat release rate were measured in the 
exhaust duct. Instrumentation in the test room consisted of eight thermocouple trees having five thermocouples each, five single thermocouples, six heat flux gauges, four bidirectional probes, and two gas sampling probes located as shown in Figure 3 and Figure 4. Thermocouples which are able to measure between -200 and $1200^{\circ} \mathrm{C}$ were used and the temperature was recorded directly by a data acquisition system. The bidirectional probes were in the window opening to monitor the movement of gas and air through the opening. The two gas sampling probes were installed at two different heights to monitor the gas concentrations in the different layers in the room. The two test rooms were set up with furnishings similar to those found during the survey.

During the tests, exhaust fans were used to collect the fire gases into the hood to be analysed. A propane burner set to a flow of $6.6 \mathrm{~L} / \mathrm{min}$, placed beside the beds and close to the window, was used as the ignition source. In another fire experiment by Zalok [5], the ignition source was a $75 \mathrm{~kW}$ propane burner running for four minutes to simulate fire starting from a large waste paper basket. Observations made during the test were recorded by hand and by infrared cameras, a digital video camera, digital still cameras, and by a data acquisition system.

The propane burner was turned off 50 seconds after the start of both tests. For the first test involving one bed, flames reached the ceiling in 195 seconds, smoke began to flow out of the window after 210 seconds, flames began to come out of the window at 240 seconds at which time the room reaches flashover. Decay started at 780 seconds, flames were observed coming out of the door around 1500 seconds, and the test was terminated at 1785 seconds. For the second test involving two beds, flames reached the ceiling in 
140 seconds, smoke began to flow out of the window after 160 seconds, flames began to come out of the window at 180 seconds at which time the room reached flashover. Decay started at 900 seconds, and the test was terminated at 1325 seconds. The fire in the second test developed faster than in the first test but the second test had a higher peak heat release rate of $4809 \mathrm{~kW}$, while the second test reached a peak of $3735 \mathrm{~kW}$. The expected maximum heat release rate was calculated from equation 2.7 [16] below to be 4.13 MW. The actual measured heat release rates were higher for the first test with one double bed and lower for the test with two single beds.

$$
\dot{Q}=1.5 A \sqrt{H}
$$

Where, $\quad \dot{Q}=$ heat release rate of the fire (MW)

$$
\begin{aligned}
& A=\text { total area of openings }\left(\mathrm{m}^{2}\right) \\
& H=\text { weighted height of the openings }(\mathrm{m})
\end{aligned}
$$

The heat release rate curves were followed to provide design fire curves for the two tests. A second set of design curves was obtained by applying a safety factor of 1.15 to the heat release rate of the fully developed stage of the fire.

The peak temperatures for most of the thermocouples in the first test occurred at 600 seconds, at the same time that the heat release rate began to decline, this point however did not correspond to the peak heat release rate. Temperatures as high as $1091^{\circ} \mathrm{C}$ were observed during the tests. The peak heat fluxes were observed to correspond to the time of the peak heat release rate. The gas analysis probes were located $0.5 \mathrm{~m}$ and $1.5 \mathrm{~m}$ from the floor, $0.9 \mathrm{~m}$ from the north wall. The mole percentage oxygen levels were observed to drop to zero 300 seconds into the test and stayed at zero for 250 seconds. Maximum 
carbon dioxide levels were recorded at $17.9 \%$ for the first test and $18.3 \%$ for the second test. Carbon monoxide could not be measured accurately because the levels exceeded the range of the measuring device. The results for full scale fire experiments provide data for the validation of computer simulations.

\subsection{Fire Modelling}

Several fire modelling software currently exist which facilitate the simulations of fires in buildings to help with fire safety research and design. The computer models that exist include network models, zone models, and field models or computational fluid dynamics (CFD) models. Network models are used to calculate fire spread, flows through buildings, and occupant evacuation; two-zone models usually work by dividing the space into a hot upper layer and a cold lower layer; field models divide the space into small control volumes for which the fundamental equations for mass, momentum, energy, and species concentration are solved [16].

With network models, the building is modelled as a series of nodes and links, with the nodes representing compartments and the links representing paths or connections between compartments. These connections include such things as doors, windows, cracks and spaces between compartments through which air can flow. Where there are staircases, elevator shafts, or chutes connecting more than one floor, each floor is represented by a node. Flow from one compartment to another depends on the size, shape, and pressure difference across the flow path. CONTAM [20] is a network model software used for indoor air quality analysis, and to calculate airflows and contaminant concentrations. 
The Fire Dynamics Simulator (FDS) is a CFD model that facilitates the modelling of fire-driven fluid flow. The FDS software solves numerically a form of the Navier-Stokes equations which are appropriate for low-speed, thermally-driven flow of smoke and heat from fires [21]. It works by dividing the given fire compartment into control volumes in which conservation of mass, momentum, and energy equations are solved. FDS has relatively fast computational speed and modest computational hardware requirements [16]. The FDS software is often used in combination with Smokeview before, during, and after modelling to visualize the defined boundaries, obstructions, and fire phenomena. Smokeview is an easier and faster way to setup and edit FDS input files, and monitor the progress of a simulation. With smokeview, one is able to create or edit blockages by specifying size and location of materials, and their properties [22].

CFAST is an example of a two-zone model. Prior to flashover a space can be idealised into two zones; the lower zone or layer consisting of cold fresh air that is being entrained into the fire, and an upper zone or layer consisting of hot fire gases. CFAST allows for the prediction of the levels of fire gases, pressure, and temperature in the spaces in a building during a fire. It uses a system of ordinary differential equations derived from conservation of mass and energy, and the ideal gas law. CUrisk [23] is another two-zone model software, which is currently being developed at Carleton University. It is primarily a risk assessment model composed of several coordinated submodels which include ignition and fire growth, smoke movement, boundary failure, fire spread, smoke and fire detection, occupant response and evacuation, fire department response and action, and economic loss. This model may be used in combination with 
other models such as CFAST, EXIT, and WALL2D. Figure 5 shows a diagram of the steps in running the model. The direct inputs to the system model include annual fire frequency, population of the building, number of fire scenarios, probability of each scenario, design life of the building in years, number of rooms of fire origin, statistical probability of smoldering fire, statistical probability of non-flashover flaming fire, statistical probability of flashover fire, statistical probability of door being open, statistical probability of door being closed, number and location of sprinklers, and the reliability and effectiveness of sprinkler suppression. The following are the various submodels that make up CUrisk:

- Fire Scenarios Sub-model - this sub-model gives a number of fire scenarios and the probability of each. The sub-model consists of events which include the ignition of the fire at a specific location; the development of the fire into a smouldering or flaming fire, and whether or not the fire develops into a flashover fire; the specification of an appropriate design fire based on the contents and characteristics of the fire room; weather conditions at the time of the fire; the presence or absence and response of notification and fire fighting capabilities; and the possibility of boundary failure and fire spread to other compartments.

- Design Fire Sub-model - this sub-model provides the fire growth sub-model with fuel composition in a compartment, species generation and depletion rates, and nominal heat release rate based on the characteristics of the compartment as well as the amount and distribution of combustible materials contained therein. 


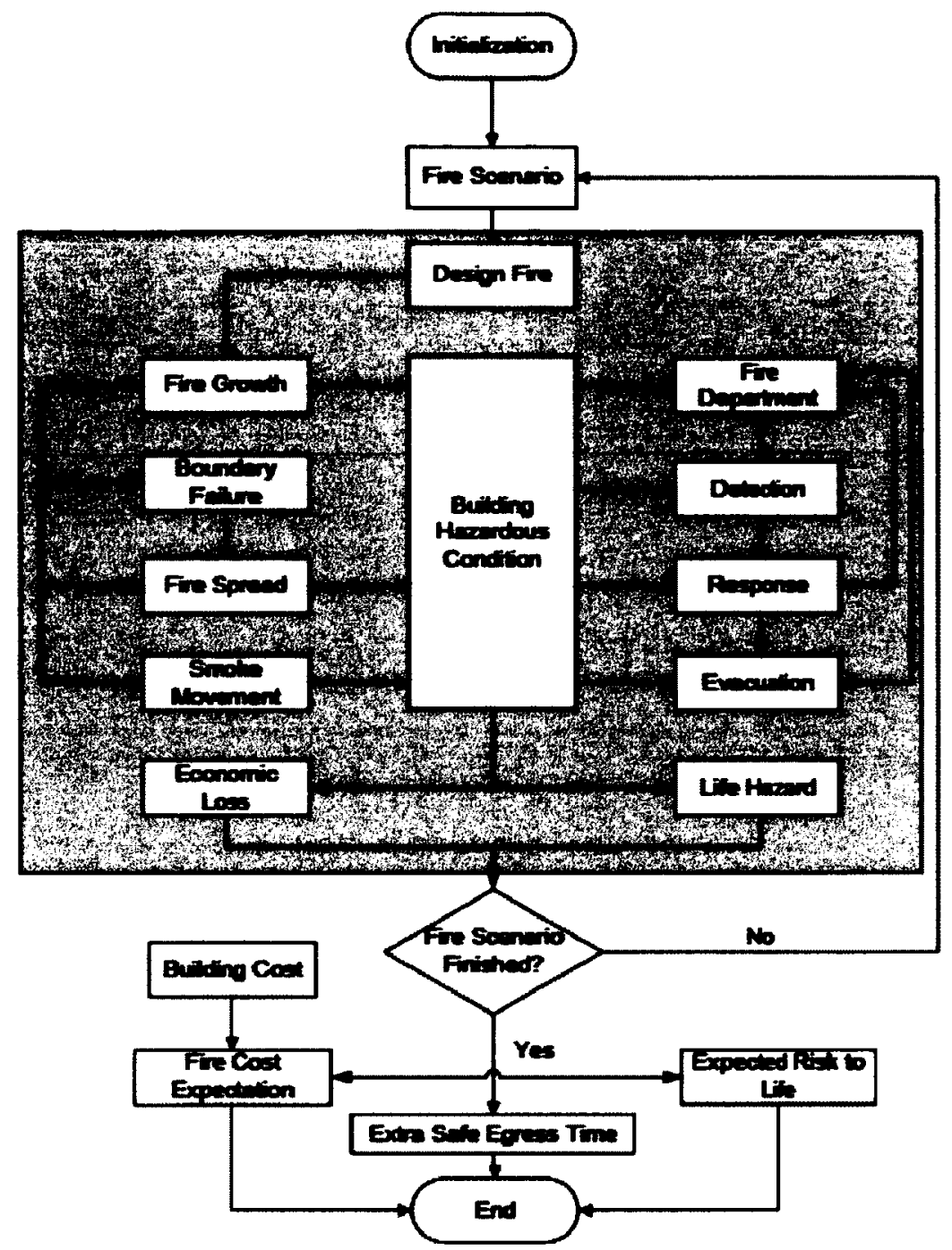

Figure 5: A schematic of the fire risk assessment system model [23]

- Fire Growth Sub-model - this model uses inputs from the design fire sub-model to predict fire conditions in the fire compartment. It adjusts the nominal heat release and calculates the production of fire gases and smoke, calculates the temperatures of the gas layers, as well as mass flow rates based on the real conditions of combustion in the fire compartment. 
- Smoke Movement Sub-model - this sub-model calculates the smoke temperature, concentration of the various species generated, the height of the smoke layer, radiant heat flux to the boundaries of each compartment, and visibility. This helps to predict tenability in each compartment.

- Boundary Failure Sub-model - this sub-model uses input from the fire growth sub-model to calculate the probability of boundary failure and provides input for the fire spread sub-model.

- Fire Spread Sub-model - this sub-model calculates fire spread to other compartments based on the boundary failure time. The boundary failure time depends on the fire severity and the fire resistance of the boundaries in the fire compartment.

- Smoke and Fire Detection Sub-model - this sub-model calculates the time to detection of fire or smoke using input from the hazardous conditions sub-model; time to activation of a fire or smoke detection system depends on some pre-set activation conditions.

- Fire Department Response and Action Sub-model - this model determines the time it will take the fire department to respond to the fire and rescue occupants. It depends on environmental conditions, the characteristics of the fire department and the properties of the building.

- Hazardous Condition Sub-model - this sub-model predicts temperature and species concentrations of gas layers, interface height, radiation flux, and temperature to help determine unsafe conditions in the various compartments. 
The other sub-models which make up CUrisk are Building Cost, Economic Loss, Occupant Response, Occupant Evacuation, Life Hazard, Expected Risk to Life, and the Fire Cost Expectation Sub-models.

Due to the size of the building to be simulated, and the number of compartments CUrisk will be used. CUrisk also has a relatively low computation time (depending on building size) and also allows for easy entry and modification of input data. One of the drawnbacks of using this software however is that one is not able to directly input fire loads and fire load densities.

\subsection{Summary}

Mid-rise buildings are classified as buildings of heights in-between low-rise and high-rise buildings. For the purposes of this project, mid-rise buildings have been defined as buildings from four- to eight-storeys. With the development of new wood building technologies, there is finally the opportunity to construct higher buildings made of combustible construction than previously allowed. Adequate fire safety in mid-rise buildings of combustible construction may be achieved adhering to the total gross floor area of $7200 \mathrm{~m}^{2}$ required by the prescriptive codes, by properly implementing passive and active fire control systems, and by using non-combustible exterior cladding among other things.

To evaluate and establish the adequacy of fire safety measures implemented in midrise buildings, it is important to develop design fires for these buildings. In order to develop a design fire, fire scenarios first have to be identified from which appropriate ones may be selected as design fire scenarios. Fire scenarios should describe the 
characteristics of the fire, building, and occupants. To develop design fires, one needs knowledge about the types, amounts, and distribution of combustible materials found in a compartment of fire origin. These fire loads are determined by carrying out fire load surveys or using data from literature of surveys that have already been performed. Fire load surveys also help to determine the physical features and ambient environment of the building, occupant characteristics, and potential sources of ignition. Potential sources of ignition and other characteristics that influence the development, progression, and effects of a fire are determined through the review of statistics of fire events.

Various researchers have carried out fire load surveys on different types of occupancies and their data is available for use in this research. The surveys were conducted using different methods including web surveys, the inventory, weighing, and a combination of inventory and weighing methods.

CUrisk will be used to facilitate the development of the design fires for mid-rise buildings. It will be used to model a typical fire compartment in a mid-rise building to obtain heat release rates and the production rates of toxic gases. 


\section{Chapter 3: Fire Load Survey Data}

The push for higher wood-frame buildings has made it necessary to develop design fires for mid-rise buildings in order to facilitate the analysis of the code requirements related to mid-rise buildings and to determine the level of safety provided by these requirements. To develop design fires for a particular category of structures, it is usually the practice to perform a fire load survey for that category of building if there is no data available in literature. After a thorough literature review, it was discovered that no fire load surveys have been performed specifically for mid-rise buildings. Most of the available surveys have usually focussed on particular occupancies such as fire load surveys for residential buildings, offices, or commercial buildings without any conscious consideration for building height.

The best way of obtaining fire loads for mid-rise buildings for this project would have been to conduct a survey of mid-rise buildings. The challenges with doing this however include the fact that it would be time consuming to obtain permission from building owners and conduct the survey. There are also privacy concern issues that will need to be overcome. Also, a large number of buildings will need to be surveyed to establish a meaningful data set for realistic analyses. The obvious alternative is to use data available 
from surveys that have already been conducted. The first step was to establish the appropriateness of this data for the objectives of this project.

Culver [11] conducted a survey of offices to collect fire load data, identify the building characteristics and occupancy characteristics that affect the magnitude of these loads, and develop mathematical models for predicting future loads. The author concluded that the data did not show any definite relationship between fire load and building height as can be seen from Table 9. This conclusion was based on the survey of twenty-three private and government office buildings, ranging in height from two to forty-nine storeys.

Table 9: Influence of geographic location and building height of fire load (extracted from [11])

\begin{tabular}{lccccccc}
\hline \multirow{2}{*}{$\begin{array}{l}\text { Census } \\
\text { Region (USA) }\end{array}$} & $\begin{array}{c}\text { Height group } \\
\text { (No. of storeys) }\end{array}$ & No. of & No. of & & \multicolumn{4}{c}{ Total fire load (psf) } \\
\cline { 7 - 9 } bldgs & rooms & max & min & mean & Std dev \\
\hline \multirow{2}{*}{ North-east } & $1-5$ & 2 & 36 & 19.2 & 0.9 & 5.1 & 4.2 \\
& $6-10$ & 1 & 11 & 17.5 & 1.4 & 6.2 & 4.3 \\
North-central & $1-5$ & 3 & 41 & 24.0 & 0.5 & 6.2 & 4.3 \\
& $6-10$ & 0 & - & - & - & - & - \\
South & $1-5$ & 2 & 29 & 39.9 & 1.1 & 8.1 & 7.9 \\
& $6-10$ & 2 & 79 & 45.3 & 1.6 & 7.7 & 6.5 \\
\multirow{2}{*}{ West } & $1-5$ & 2 & 37 & 33.3 & 1.0 & 8.6 & 7.5 \\
& $6-10$ & 2 & 60 & 29.0 & 1.5 & 5.5 & 4.0 \\
\hline
\end{tabular}

Similarly Kumar and Rao [14] found no definite relationship between fire load and floor level (refer to Table 4).

Chen [16] observed that the mean, $80^{\text {th }}$, and $95^{\text {th }}$ percentile fire load density obtained for the motels which were low rise buildings and the hotels which included mid-rise and 
high-rise buildings were close in value (refer to Table 7). This seems to suggest that fire load density is not influenced significantly by building height. The author also came to this same conclusion in his literature review.

In general, height of a building does not affect aesthetic contents found in rooms for particular uses. For example, the combustible contents found in a kitchen such as cabinets, food containers and utensils will be present whether the kitchen is in an 8-storey apartment building or a single family home. In the same way items present in a 6-storey office will more than likely be present in a 1-storey office building used for the same purpose. In light of these facts, it should then be possible to make use of the data currently available for various building occupancies to establish design fires for mid-rise buildings. The thing to bear in mind though is the variation in floor area for the different rooms in different buildings of different heights. This is because a small room with a particular fire load density will have a smaller fire load overall, than a large room with the same fire load density. Rooms with larger fire loads and comparable fire growth and ventilation characteristics will most likely result in more severe fires of longer duration than rooms with relatively less fire loads [15].

\subsection{Residential Buildings}

\subsubsection{Fire Loads}

According to the Acceptable Solution of the New Zealand Building Code, the design value for residential occupancy is $400 \mathrm{MJ} / \mathrm{m}^{2}$, but this value is considered to be too low for safe design [4]. An extensive fire load survey project was conducted from 1967 to 
1969 under the guidance of the Swiss Fire Prevention Association for Industry and Trade. The average fire load densities obtained were reported in the Design Guide- Structural Fire Safety [24]. The fire load densities were developed using at least 10-15 samples but usually $\mathbf{2 0}$ or more samples were available for analysis. Even though only average values are provided, correlations are provided for estimating the standard deviation, $80^{\text {th }}$ and $90^{\text {th }}$ percentile, and isolated peak values as follows:

Coefficient of variations $=30 \%-50 \%$ of the given average value

$90^{\text {th }}$ percentile value $\quad=(1.35-1.65) \mathrm{x}$ average value

$80^{\text {th }}$ percentile value $\quad=(1.25-1.50) \mathrm{x}$ average value

Isolated peak value $\quad=2 \times$ average value

Table 10 shows the fire load density obtained for some residential occupancies. The mean values are obtained directly for the Design Guide- Structural Fire Safety [24]; the remaining values are calculated as directed above using the highest values in each category. The mean fire load density for residential occupancies was found to range from 300 to $500 \mathrm{MJ} / \mathrm{m}^{2}$. The $80^{\text {th }}$ percentile of the fire loads was calculated to range from 450 to $750 \mathrm{MJ} / \mathrm{m}^{2}$, the $90^{\text {th }}$ percentile from 495 to $825 \mathrm{MJ} / \mathrm{m}^{2}$, and the peak values from 600 to $1000 \mathrm{MJ} / \mathrm{m}^{2}$. For family dwellings the mean value was found to be $500 \mathrm{MJ} / \mathrm{m}^{2}$ with calculated standard deviation, $80^{\text {th }}$, and $90^{\text {th }}$ percentile values of $250 \mathrm{MJ} / \mathrm{m}^{2}, 750 \mathrm{MJ} / \mathrm{m}^{2}$, and $825 \mathrm{MJ} / \mathrm{m}^{2}$ respectively. Since the raw data is not available for this survey, it is not possible to produce frequency graphs of the types and amounts of the combustible materials found, but the average values will serve as a bench mark for comparing values obtained by other researchers in developing the needed fire loads. 
Table 10: Residential fire load density

\begin{tabular}{lccccc}
\hline Occupancy & $\begin{array}{c}\text { Mean } \\
\text { FLD } \\
\left(\mathbf{M J} / \mathbf{m}^{2}\right)\end{array}$ & $\begin{array}{c}\text { Standard } \\
\text { deviation } \\
\left(\mathbf{M J} / \mathbf{m}^{2}\right)\end{array}$ & $\begin{array}{c}\mathbf{8 0}^{\text {th }} \\
\text { Percentile } \\
\left(\mathbf{M J} / \mathbf{m}^{2}\right)\end{array}$ & $\begin{array}{c}\mathbf{9 0}^{\text {th }} \\
\text { Percentile } \\
\left(\mathbf{M J} / \mathbf{m}^{2}\right)\end{array}$ & $\begin{array}{c}\text { Isolated peak } \\
\text { values } \\
\left(\mathbf{M J} / \mathbf{m}^{2}\right)\end{array}$ \\
\hline Children's home & 400 & 200 & 600 & 660 & 800 \\
Homes & 500 & 250 & 750 & 825 & 1000 \\
Homes for aged & 400 & 200 & 600 & 660 & 800 \\
Hotel & 300 & 150 & 450 & 495 & 600 \\
Youth hostel & 300 & 150 & 450 & 495 & 600 \\
\hline
\end{tabular}

More recently in 2007, a fire load survey was carried involving 10 motels and 12 hotels [16]. The motels were low-rise buildings of one or two storeys, and one threestorey building, while the hotels were mostly high-rise buildings ranging between threeand twenty-four storeys. The survey was conducted in guest rooms and suite guest rooms which had either one or two beds. The author found that the mean total fire load density for motels was $535 \mathrm{MJ} / \mathrm{m}^{2}$, that for hotels was $560 \mathrm{MJ} / \mathrm{m}^{2}$, and that for all surveyed guest rooms was $550 \mathrm{MJ} / \mathrm{m}^{2}$. All of these values are greater than the mean value obtained for hotels in the Design Guide- Structural Fire Safety [24] but very close to the value of 500 $\mathrm{MJ} / \mathrm{m}^{2}$ obtained for homes. It should be noted that guest luggage was not included in the calculation of the fire loads. Table 7 shows a summary of the moveable and total fire load densities. The $95^{\text {th }}$ percentile values obtained were $712 \mathrm{MJ} / \mathrm{m}^{2}$ for motels, $776 \mathrm{MJ} / \mathrm{m}^{2}$ for hotels, and $753 \mathrm{MJ} / \mathrm{m}^{2}$ for all the surveyed guest rooms; these values are higher than the peak values suggested for hotels and also higher than the suggested $90^{\text {th }}$ percentile values [24]. The surveyed hotels were classified as standard hotels (3-star and below), luxury hotels (above 3.5 star), and hotel suites (one or two bedroom with living room). The 
combustibles in motels and hotels were found to consist of wood, plastic, textile, paper, mattress, and sofa. It was found that wood usually contributed the most to the fire load density, ranging from $44.7 \%$ to $73.8 \%$. The next highest contributor to the total fire load was mattress. Table 11 shows the total fire load density of the various combustible materials by room type and hotel category. Suite refers to a group of rooms in a hotel which have a door separating the living room and bedroom(s); living room refers a space in a suite separated from the bedroom(s) by a door; and bedroom and living room refers to a suite with no door separating the living room and bedroom(s).

Table 11: Total fire load density in different motel and hotel categories [16]

\begin{tabular}{|c|c|c|c|c|c|c|c|c|}
\hline & & $\begin{array}{c}\text { Wood } \\
\left(\mathrm{MJ} / \mathrm{m}^{2}\right)\end{array}$ & $\begin{array}{c}\text { Plastic } \\
\left(\mathrm{MJ} / \mathrm{m}^{2}\right)\end{array}$ & $\begin{array}{c}\text { Textile } \\
\left(\mathrm{MJ} / \mathrm{m}^{2}\right)\end{array}$ & $\begin{array}{c}\text { Paper } \\
\left(\mathrm{MJ} / \mathrm{m}^{2}\right)\end{array}$ & $\begin{array}{l}\text { Mattress } \\
\left(\mathrm{MJ} / \mathrm{m}^{2}\right)\end{array}$ & $\begin{array}{c}\text { Sofa } \\
\left(\mathrm{MJ} / \mathrm{m}^{2}\right)\end{array}$ & $\begin{array}{c}\text { Total } \\
\left(\mathrm{MJ} / \mathrm{m}^{2}\right)\end{array}$ \\
\hline \multirow{3}{*}{$\begin{array}{l}\text { Motel } \\
\text { (lbed) }\end{array}$} & mean & 306.7 & 23.4 & 26.5 & 6.8 & 127.6 & 15.1 & 506 \\
\hline & 95th percentile & 444.7 & 33.4 & 52.9 & 21.5 & 163 & 60.6 & 636.8 \\
\hline & contribution $(\%)$ & 60.6 & 4.6 & 5.2 & 1.3 & 25.2 & 3 & 100 \\
\hline \multirow{3}{*}{$\begin{array}{l}\text { Motel } \\
\text { (2beds) }\end{array}$} & mean & 274.9 & 20.4 & 27.8 & 7.5 & 220 & 14.8 & 565.5 \\
\hline & 95th & 377.9 & 29.8 & 39.2 & 18.6 & 247.7 & 48.2 & 714.9 \\
\hline & contribution $(\%)$ & 48.6 & 3.6 & 4.9 & 1.3 & 38.9 & 2.6 & 100 \\
\hline \multirow{3}{*}{$\begin{array}{l}\text { Standard } \\
\text { hotel } \\
\text { (1 bed) }\end{array}$} & mean & 341.5 & 17.3 & 39.2 & 15.7 & 137.2 & 39.5 & 590.3 \\
\hline & 95th & 538.1 & 25.6 & 53.3 & 22.4 & 161.1 & 66 & 758.2 \\
\hline & contribution (\%) & 57.8 & 2.9 & 6.6 & 2.7 & 23.2 & 6.7 & 100 \\
\hline \multirow{3}{*}{$\begin{array}{l}\text { Standard } \\
\text { hotel } \\
\text { (2beds) }\end{array}$} & mean & 300.1 & 16 & 45.2 & 16.7 & 199.7 & 23 & 600.5 \\
\hline & 95th & 476 & 24.9 & 54.6 & 21.1 & 246.8 & 38.8 & 795.4 \\
\hline & contribution (\%) & 50 & 2.7 & 7.5 & 2.8 & 33.2 & 3.8 & 100 \\
\hline \multirow{3}{*}{$\begin{array}{l}\text { Luxury } \\
\text { hotel } \\
\text { (1bed) }\end{array}$} & mean & 315.1 & 13 & 43.5 & 17.4 & 120.1 & 33.5 & 542.6 \\
\hline & 95th & 347.8 & 16.2 & 56.1 & 19.4 & 130 & 41.9 & 593.8 \\
\hline & contribution $(\%)$ & 58.1 & 2.4 & 8 & 3.2 & 22.1 & 6.2 & 100 \\
\hline Luxury & mean & 296.4 & 13.1 & 46.5 & 17.2 & 159 & 34.7 & 567 \\
\hline
\end{tabular}




\begin{tabular}{|c|c|c|c|c|c|c|c|c|}
\hline \multirow{2}{*}{$\begin{array}{l}\text { hotel } \\
\text { (2beds) }\end{array}$} & 95th & 319.1 & 16.1 & 61.6 & 19.1 & 171.4 & 44.1 & 604.1 \\
\hline & contribution (\%) & 52.3 & 2.3 & 8.2 & 3 & 28 & 6.1 & 100 \\
\hline \multirow{3}{*}{$\begin{array}{l}\text { Suite } \\
\text { (1 bed) }\end{array}$} & mean & 383.6 & 11.3 & 33.3 & 20.5 & 214.8 & 0 & 690.9 \\
\hline & 95th & 516.9 & 18.6 & 37.7 & 28.4 & 233.5 & 0 & 756.8 \\
\hline & contribution $(\%)$ & 57.8 & 1.7 & 5 & 3.1 & 32.4 & 0 & 100 \\
\hline \multirow{3}{*}{$\begin{array}{l}\text { Suite } \\
\text { (2beds) }\end{array}$} & mean & 308.8 & 19.8 & 44 & 23.2 & 295.1 & 0 & 690.9 \\
\hline & 95th & 372.2 & 24.9 & 47 & 25.5 & 304.6 & 0 & 756.8 \\
\hline & contribution $(\%)$ & 44.7 & 2.9 & 6.4 & 3.4 & 42.7 & 0 & 100 \\
\hline \multirow{3}{*}{$\begin{array}{l}\text { Living } \\
\text { room }\end{array}$} & mean & 296 & 24.1 & 26 & 14.3 & 0 & 40.6 & 401 \\
\hline & 95th & 431.4 & 29.9 & 58.2 & 18.8 & 0 & 69.4 & 541.5 \\
\hline & contribution (\%) & 73.8 & 6 & 6.5 & 3.6 & 0 & 10.1 & 100 \\
\hline \multirow{3}{*}{$\begin{array}{l}\text { Living } \\
\text { room } \\
\text { and } \\
\text { bedroom }\end{array}$} & mean & 316.4 & 14 & 31.6 & 12.6 & 71.6 & 35.5 & 481.7 \\
\hline & 95th & 419.2 & 21.9 & 41.8 & 16.1 & 77 & 39.8 & 596 \\
\hline & contribution (\%) & 65.7 & 2.9 & 6.6 & 2.6 & 14.9 & 7.4 & 100 \\
\hline
\end{tabular}

A pilot survey [25] was conducted of combustible contents of living rooms located on the main floor and basement levels of residential buildings. The survey was conducted by the National Research Council (NRC) using a web-based questionnaire. The questionnaires were distributed to employees of the Institute for Research in Construction (IRC) at NRC. The author recognised that lower income families may be underrepresented in the selected samples. Also that the information obtained from this survey was qualitative in nature since the actual weight of the items in homes are unknown. Items such as paper products, toys, and other small miscellaneous items were not included in the fire load. The fire loads in this report were calculated with the highest weight and heat of combustion values found for each grouping of furniture in order to capture the worst case scenario. The survey included 74 homes which consisted mostly 
(45\%) of 2-storey detached houses. Table 12 shows a summary of the mean values obtained for the various categories of homes represented, as well as, the number of samples for each group. The mean fire load density was calculated based on an average floor area of $22 \mathrm{~m}^{2}$ found through the survey. For all of the building types except duplexes, the mean fire load density is close to the reported value [24] of $500 \mathrm{MJ} / \mathrm{m}^{2}$.

Upholstery furniture was found to contribute the most towards the fire load found in the living rooms. Other combustible items of furniture and electronics found in the main floor living rooms include tables, computers, televisions, racks, and bookcases. The typical items found in living rooms in the buildings surveyed were sofa, loveseat, recliner/chair, TV, bookcase, entertainment unit, coffee table, and side table. These items were present in at least $40 \%$ of homes. Figure 6 shows the number of each of the combustible items found in the surveyed homes, as well as, the total fire load contributed by the total number of each item. Figure 7 provides the frequency distribution of the total fire load observed for living rooms on the main floor. The mean was found to be 10,000 MJ with a standard deviation of $3000 \mathrm{MJ}$. Very high and very low fire loads were found to be less prevalent. Figure 8 shows the frequency distribution of the fire load density obtained for living rooms on the main floor level. The mean fire load density for the 74 surveyed homes was $600 \mathrm{MJ} / \mathrm{m}^{2}$ with a standard deviation of $200 \mathrm{MJ} / \mathrm{m}^{2}$. The fire load densities obtained ranged from $200 \mathrm{MJ} / \mathrm{m}^{2}$ to $1300 \mathrm{MJ} / \mathrm{m}^{2}$. Again, very high and very low values were less prevalent. 
Table 12: Mean values of fire load and fire load density for the various homes [25]

\begin{tabular}{lccc}
\hline Home type & $\begin{array}{c}\text { Mean fire } \\
\text { load (MJ) }\end{array}$ & $\begin{array}{c}\text { Mean fire load } \\
\text { density based on } \\
\text { floor area of 22 } \mathbf{~ m}^{2} \\
\text { (MJ/m }\end{array}$ & $\begin{array}{c}\text { Number of } \\
\text { samples }\end{array}$ \\
\hline Apartment & 12000 & 550 & 6 \\
3 storey town home & 11000 & 500 & 5 \\
2 storey semi-detached & 10000 & 450 & 4 \\
2 storey detached & 11000 & 500 & 33 \\
3 storey detached & 11000 & 500 & 4 \\
2 storey town home & 10000 & 450 & 6 \\
Bungalow & 10000 & 450 & 13 \\
Duplex & 7000 & 300 & 2 \\
\hline
\end{tabular}

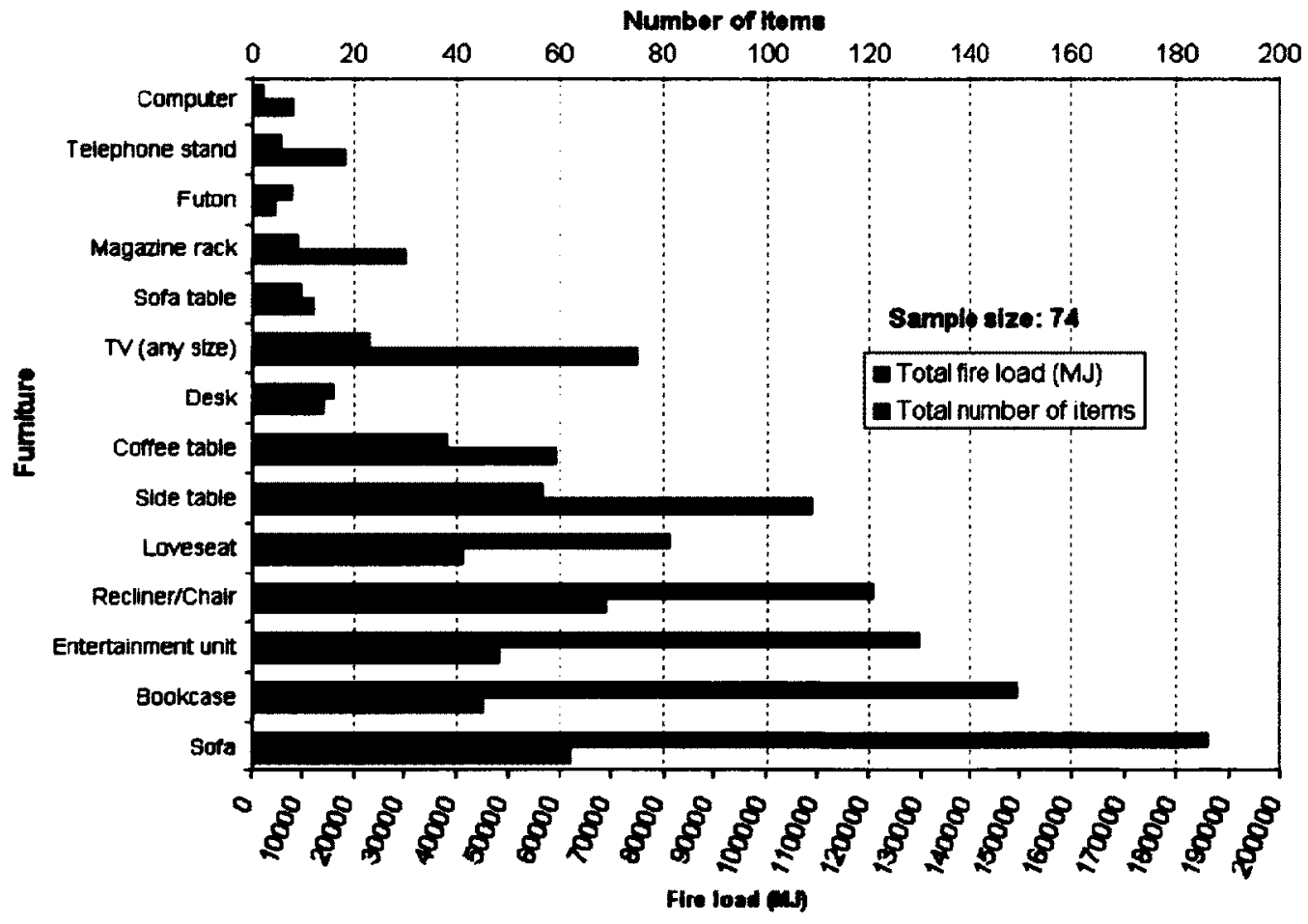

Figure 6: Furniture in main foor living room [25] 


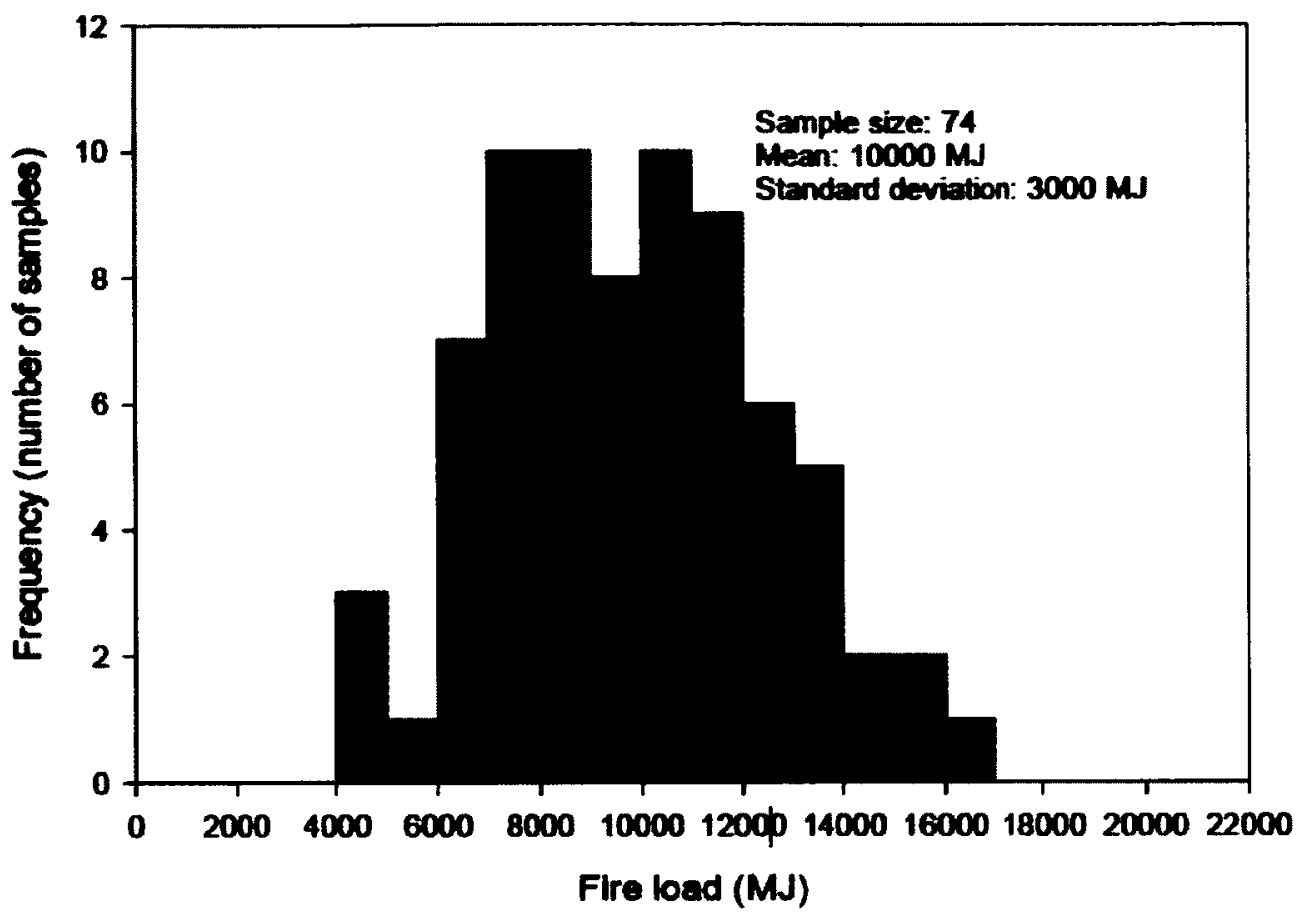

Figure 7: Frequency distribution of total fire load for living rooms [25]

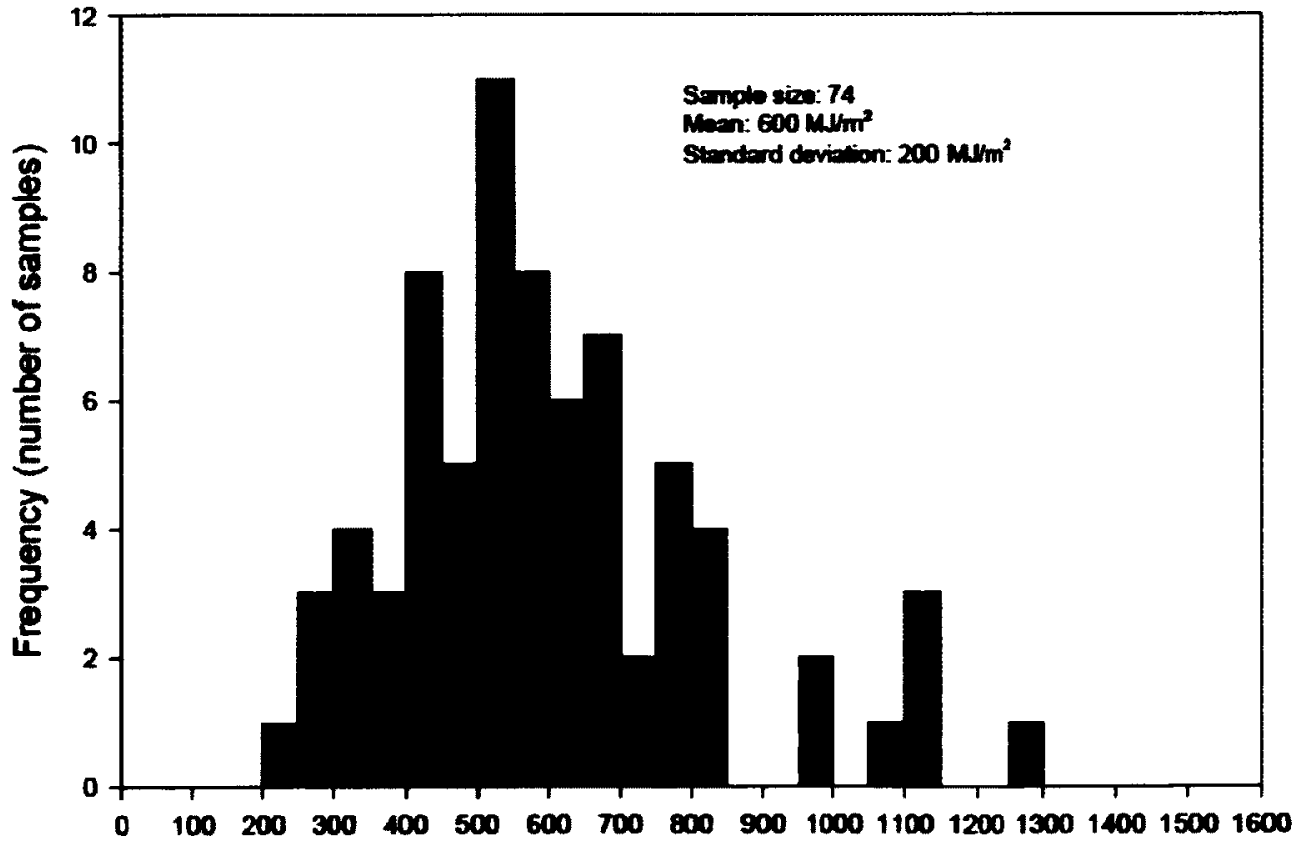

Fire load density $\left(\mathrm{MJ} / \mathrm{m}^{2}\right)$

Figure 8: Frequency distribution of fire load density for living rooms [25] 


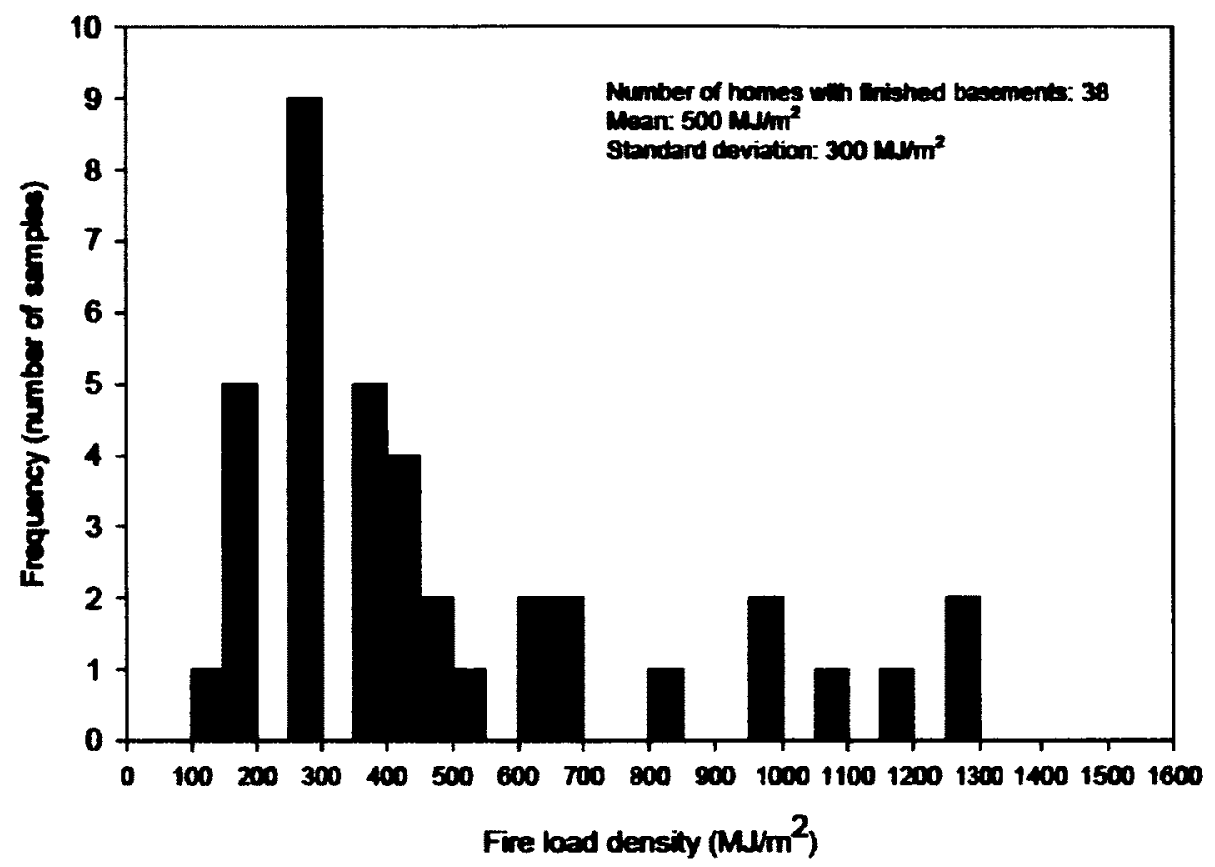

Figure 9: Frequency distribution of fire load density for basement living rooms [25]

Basement living rooms tended to have fewer items in terms of numbers, but a greater variety of items. It should also be noted that the sample size for basement living rooms was much smaller than that for main level living rooms since not all homes had finished basements. The items found in the basement were sofa, entertainment unit, loveseat, desk, side table, bed, futon, computer, and air hockey table. Bedroom furniture and recreational equipment were only found in basement living rooms and none in the main level living rooms. Basement living rooms also had a wider range of fire loads; $1000 \mathrm{MJ}$ to $20,000 \mathrm{MJ}$ compared to $4000 \mathrm{MJ}$ to $17,000 \mathrm{MJ}$ for main level living rooms. The average fire load was found to be $11,000 \mathrm{MJ}$ with a standard deviation of $4000 \mathrm{MJ}$. Figure 9 shows the frequency distribution of fire load density for basement living rooms. 
Of the 38 finished basements, the mean was found to be $500 \mathrm{MJ} / \mathrm{m}^{2}$ with a standard deviation of $300 \mathrm{MJ} / \mathrm{m}^{2}$.

An extended survey was later conducted by Bwalya [26] as a follow up to the pilot survey. This time there were 598 respondents providing an opportunity for better analysis and more realistic conclusions. Again two-storey detached homes were the largest proportion (38\%) of homes surveyed. Unlike in the pilot survey where the fire loads were calculated using the highest weights and heat of combustion of items, the fire loads this time were selected randomly from low, medium, and high values in an attempt to give an impartial representation of reality. Table 13 provides a summary of the mean fire load, the mean fire load density, the standard deviation of the fire load density, and the number of samples for main floor living rooms in each home category. The fire loads and fire load densities found were much lower than previously, with values around $7500 \mathrm{MJ}$ and $400 \mathrm{MJ} / \mathrm{m}^{2}$ respectively. These lower values stand to reason since in the pilot survey only the highest values of weight and heat of combustion were used in calculating the fire loads as opposed to random values in this survey. The mean fire load was found to be $7750 \mathrm{MJ}$ with a standard deviation of $3610 \mathrm{MJ}$ and a $95^{\text {th }}$ percentile value of $13,610 \mathrm{MJ}$. The fire load densities ranged from about $50 \mathrm{MJ} / \mathrm{m}^{2}$ to $1600 \mathrm{MJ} / \mathrm{m}^{2}$, with higher values being less prevalent. The fire load density had a mean of $410 \mathrm{MJ} / \mathrm{m}^{2}$ with a standard deviation of $230 \mathrm{MJ} / \mathrm{m}^{2}$ and $95^{\text {th }}$ percentile value of $790 \mathrm{MJ} / \mathrm{m}^{2}$. It was also found that fire load density decreased with increasing floor area since furnishings in both small and large living rooms were similar. The items found to be typical of living rooms in the pilot survey were also found to be typical during the extended survey. According to the 
author's calculations, living rooms contain an average of six of the items in Figure 6 with a standard deviation of two items.

Of the homes that were surveyed, $60 \%$ had finished basement living rooms. $36 \%$ of the basement ceilings had ceiling tiles, $35 \%$ had drywall, $9 \%$ had unfinished ceilings, $1 \%$ had plywood, and $19 \%$ had other types of ceiling. Also, most (63\%) of the basement floors had carpet, $10 \%$ had an area rug on concrete, $7 \%$ hardwood flooring, $7 \%$ vinyl, $4 \%$ painted concrete, $4 \%$ area rug on hardwood floor, $3 \%$ bare concrete, and $2 \%$ ceramic flooring. It was found that basements had an average of 9 items with a standard deviation of 4 items; this is higher than that for main floor living rooms. The $95^{\text {th }}$ percentile was 16 items.

Table 13: Mean values of fire load and fire load density for various homes [26]

\begin{tabular}{lcccc}
\hline Housing category & $\begin{array}{c}\text { Mean fire } \\
\text { load (MJ) }\end{array}$ & $\begin{array}{c}\text { Mean fire } \\
\text { load density } \\
\left(\mathbf{M J} / \mathbf{m}^{\mathbf{2}}\right)\end{array}$ & $\begin{array}{c}\text { Standard } \\
\text { deviation } \\
\left(\mathbf{M J} / \mathbf{m}^{\mathbf{2}}\right)\end{array}$ & $\begin{array}{c}\text { Number } \\
\text { of samples }\end{array}$ \\
\hline 2 storey detached & 7800 & 390 & 160 & 231 \\
Bungalow & 7790 & 410 & 270 & 118 \\
Apartment & 7920 & 440 & 272 & 64 \\
2 storey town home & 8300 & 490 & 240 & 58 \\
2 storey semi-detached & 7920 & 440 & 300 & 29 \\
3 storey detached & 8190 & 390 & 240 & 28 \\
3 storey town home & 6290 & 370 & 240 & 14 \\
Duplex & 8360 & 440 & 190 & 12 \\
\hline
\end{tabular}

The items found during this survey were similar to the ones found during the pilot survey. The fire load for basements in this survey ranged from $1000 \mathrm{MJ}$ to about 21,000 
MJ. The mean fire load for basement living rooms was $8400 \mathrm{MJ}$ with a standard deviation of $3700 \mathrm{MJ}$ and a $95^{\text {th }}$ percentile value of $14,900 \mathrm{MJ}$. The fire load density ranged from about $50 \mathrm{MJ} / \mathrm{m}^{2}$ to $1700 \mathrm{MJ} / \mathrm{m}^{2}$. The mean was found to be $360 \mathrm{MJ} / \mathrm{m}^{2}$ with a standard deviation of $200 \mathrm{MJ} / \mathrm{m}^{2}$, and $95^{\text {th }}$ percentile of $700 \mathrm{MJ} / \mathrm{m}^{2}$. Again, lower values of fire load and fire load density were found to be more prevalent. Table 14 shows the mean values of fire load and fire load density for basements in the various home categories.

Table 14: Mean values for fire load and fire load density for basements in various home categories [26]

\begin{tabular}{lcccc}
\hline Housing category & $\begin{array}{c}\text { Mean fire } \\
\text { load (MJ) }\end{array}$ & $\begin{array}{c}\text { Mean fire } \\
\text { load density } \\
\left(\mathbf{M J} / \mathbf{m}^{2}\right)\end{array}$ & $\begin{array}{c}\text { Standard } \\
\text { deviation } \\
\left(\mathbf{M J} / \mathbf{m}^{2}\right)\end{array}$ & $\begin{array}{c}\text { Number } \\
\text { of samples }\end{array}$ \\
\hline 2 storey detached & 8500 & 340 & 190 & 140 \\
Bungalow & 10200 & 350 & 210 & 89 \\
2 storey town home & 8610 & 410 & 260 & 35 \\
2 storey semi-detached & 10750 & 430 & 240 & 16 \\
3 storey detached & 10150 & 350 & 230 & 14 \\
Duplex & 8060 & 310 & 140 & 6 \\
3 storey town home & 6200 & 310 & 120 & 4 \\
\hline
\end{tabular}

Results for the NRC-IRC project [15] initiated to study fires in low-rise multi-suite residential dwellings including semi-detached houses, town houses, low-rise apartments, and residential care homes are presented in Table 15 . The survey was conducted using a web-based approach for multi-family residential dwellings and the traditional approach for residential care dwellings. $74 \%$ of these homes were town houses, $10 \%$ semidetached, $8 \%$ low-rise apartments, $3 \%$ high-rise apartments, $2 \%$ duplexes, and $3 \%$ other 
homes. The fire load survey was conducted for rooms where fires are most likely to start, such as the living room, bedrooms, and kitchen. It was found that the main floor of the homes surveyed typically had the kitchen, dining room, and living room interconnected without floor to ceiling wall separations. The main floor of a typical two-storey home had the kitchen, the dining room, and the living rooms; the second floor had the bedrooms, bathrooms and closets; and the basement had a living room or the space was divided into several rooms for various uses. Since the photographs did not show clothing, some assumptions were made; primary bedrooms were assumed to contain $138 \mathrm{~kg}$ of clothing, secondary bedrooms were assumed to contain $92 \mathrm{~kg}$ of clothing. In residential care homes, it was assumed that each resident had $23 \mathrm{~kg}$ of clothing. The kitchen had the highest mean fire load density of $807 \mathrm{MJ} / \mathrm{m}^{2}$ while the basement living room had the lowest of $288 \mathrm{MJ} / \mathrm{m}^{2}$. The bedrooms had fire load densities around $550 \mathrm{MJ} / \mathrm{m}^{2}$ which is close to the values obtained for motels and hotels bedrooms [16] and the CIB values. A value of $412 \mathrm{MJ} / \mathrm{m}^{2}$ was obtained for main living room, this value is consistent with those obtained for the extended survey of living rooms [26] discussed earlier. 
Table 15: Fire load and fire load density for various rooms [15Error! Reference source not found.]

\begin{tabular}{lccccccc}
\hline Room & $\begin{array}{c}\text { Mean } \\
\text { FLD } \\
\left(\mathbf{M J} / \mathbf{m}^{2}\right)\end{array}$ & $\begin{array}{c}\text { Standard } \\
\text { Deviation } \\
\left(\mathbf{M J} / \mathbf{m}^{2}\right)\end{array}$ & $\begin{array}{c}\text { Minimum } \\
\left(\mathbf{M J} / \mathbf{m}^{2}\right)\end{array}$ & $\begin{array}{c}\text { Maximum } \\
\left(\mathbf{M J} / \mathbf{m}^{2}\right)\end{array}$ & $\begin{array}{c}\text { 95th } \\
\text { Percentille }\end{array}$ & $\begin{array}{c}\text { Sample } \\
\text { Size }\end{array}$ & $\begin{array}{c}\text { Mean } \\
\text { FL } \\
(\mathbf{M J})\end{array}$ \\
\hline $\begin{array}{l}\text { Kitchen } \\
\text { Secondary } \\
\text { bedroom }\end{array}$ & 807 & 123 & 420 & 1244 & 940 & 515 & 7908 \\
$\begin{array}{l}\text { Primary } \\
\text { Bedroom }\end{array}$ & 594 & 146 & 107 & 1000 & 846 & 129 & 6237 \\
$\begin{array}{l}\text { Living } \\
\text { Room }\end{array}$ & 412 & 127 & 106 & 897 & 610 & 397 & 7251 \\
$\begin{array}{l}\text { Dining } \\
\text { Room } \\
\text { Basement }\end{array}$ & 393 & 132 & 119 & 901 & 576 & 292 & 3812 \\
$\begin{array}{l}\text { Living } \\
\text { Room }\end{array}$ & 288 & 96 & 103 & 633 & 450 & 130 & 6682 \\
\hline
\end{tabular}

Unlike with the survey of living rooms [26], the author [15] finds that the variation of fire load with floor area is somewhat random. The combustible contents found during this fire load survey were put into three groups; wood and paper (cellulose-based) (W), synthetic plastics $(\mathrm{P})$, and textiles $(\mathrm{T})$. Wood-based materials were found to form a large portion of the fire load in every room, especially in kitchens, dining rooms, and living rooms. Table 16 provides a summary of the composition of the fire loads. The bedrooms had a higher proportion of textiles which included clothes and bedding material.

Items found in living rooms in this survey are comparable to those found in the survey of living rooms discussed earlier [26], with a wider variety of items found in the basement living rooms than in main floor living rooms. Items found in dining rooms include chairs, dining table, window coverings, books, dining display unit, hutch, area 
rug, side table, wooden shelves, upholstered chairs, and plastic storage bins. Items found in the bedrooms included night table, window covering, dresser bed, books, side table, stuffed toys, wooden shelves, wardrobe, upholstered chair, drawer chest, entertainment unit, plastic storage bins; many of these items were also found in the survey of hotels and motels [16]. For bedrooms and basement living rooms, carpet was the most common flooring; in kitchens, it was vinyl; and in main floor living rooms, it was hardwood flooring.

Table 16: Composition of fire load [16]

\begin{tabular}{lccccccc}
\hline \multirow{2}{*}{ Room } & \multicolumn{3}{c}{ Percent Weight (kg) } & & \multicolumn{3}{c}{ Percent FL (MJ) } \\
\cline { 2 - 4 } \cline { 7 - 8 } \cline { 7 - 8 } Kitchen & W & P & T & & W & P & T \\
Living Room & 86.5 & 13.5 & $<<1 \%$ & & 80.2 & 19.8 & $<<1 \%$ \\
Dining Room & 65.8 & 32.9 & 1.4 & & 57.4 & 41.4 & 1.2 \\
Primary bedroom & 72.6 & 26.6 & 0.8 & & 65 & 34 & 0.8 \\
Secondary bed room & 42.3 & 26.4 & 31.4 & & 37.8 & 34.1 & 28.1 \\
$\begin{array}{l}\text { Basement living } \\
\text { room }\end{array}$ & 61 & 29.8 & 30.3 & & 35.2 & 38 & 26.8 \\
\hline
\end{tabular}

The survey of the residential care dwellings involved four buildings with a total of 22 bedrooms and 31 single beds. The buildings were a combination of two duplexes to form a residential care home; a single family dwelling located in a residential neighborhood; a modified two-storey single family dwelling with accommodation for 16 residents, and; a town house with home care residents on the main and basement level and the owner on the upper floor. A mean fire load density of $593 \mathrm{MJ} / \mathrm{m}^{2}$ with a standard deviation of 109 $\mathrm{MJ} / \mathrm{m}^{2}$ was found for the surveyed facilities. The maximum fire load density was found 
to be $786 \mathrm{MJ} / \mathrm{m}^{2}$ and a minimum of $379 \mathrm{MJ} / \mathrm{m}^{2}$. This mean value compares favorably with the mean obtained for secondary bedrooms in low-rise multi-suite residential dwellings. Hardwood flooring was reported in $95 \%$ of the residential care dwellings and this contributed significantly to the fire load. Other items that contributed to the fire load were stuffed toys of which there were over 250 per 100 rooms, single beds, night table, shoes chairs, computer workstation, and other items found in bedrooms in multi-suite residences.

Table 17 shows a summary of the results of a survey [27] conducted with the support of the Central Housing Committee in the Unites States. The mean fire load densities in the report were presented in $\mathrm{lb} / \mathrm{ft}^{2}$. These values were modified to give the equivalent weight of a material with calorific value of $8,000 \mathrm{Btu} / \mathrm{lb}(18.6 \mathrm{MJ} / \mathrm{kg})$. The values provided in the table in $\mathrm{MJ} / \mathrm{m}^{2}$ were therefore modified from $\mathrm{lb} / \mathrm{ft}^{2}$ using the value 18.6 $\mathrm{MJ} / \mathrm{kg}$ in order to make comparison to earlier values feasible. A mean of $799 \mathrm{MJ} / \mathrm{m}^{2}$ was obtained for all the residences surveyed. This value is much higher than any of the values obtained in any of the other surveys previously discussed. The hallway had the highest mean fire load density followed by the bedroom, whereas in previous surveys it was found that the kitchen or storage room had the highest fire load density. The mean fire load density for bedrooms of $944 \mathrm{MJ} / \mathrm{m}^{2}$ is also almost twice the value of about 500 $\mathrm{MJ} / \mathrm{m}^{2}$ obtained for bedrooms in previous surveys. Basements were found to have a fire load density of $91 \mathrm{MJ} / \mathrm{m}^{2}$; also much lower than in other surveys. It is worth noting that this survey though was presented in a report issued as far back as 1942, and this might 
account for the observed discrepancies since combustible materials in buildings have changed a lot since then.

Table 17: Mean fire load density for residences in the United States [27]

\begin{tabular}{lccc}
\hline \multirow{2}{*}{ Room } & \multicolumn{3}{c}{ Mean fire load density } \\
\cline { 2 - 4 } & $\mathbf{l b} / \mathbf{f t}^{\mathbf{2}}$ & $\mathbf{k g} / \mathbf{m}^{\mathbf{2}}$ & $\mathbf{M J} / \mathbf{m}^{\mathbf{2}}$ \\
\hline Entire apartment & 8.8 & 43.0 & 799 \\
or residence & 10.5 & 51.3 & 954 \\
Hallway & 1.0 & 4.9 & 91 \\
Basement & 7.0 & 34.2 & 636 \\
Bathroom & 6.8 & 33.2 & 618 \\
Kitchen & 10.4 & 50.8 & 944 \\
Bedroom & 7.2 & 35.2 & 654 \\
Dining & 7.2 & 35.2 & 654 \\
Storeroom & 8.1 & 39.5 & 736 \\
Living room & & & \\
\hline
\end{tabular}

\subsubsection{Floor Areas}

The fire load density alone is not enough to determine the severity of a fire in a particular room; it is important also to have information about floor areas. As previously mentioned a large room with a particular fire load density will have a larger fire load and most likely lead to a more severe fire of longer duration, than a small room with the same fire load density and the same ventilation characteristics. During fire load surveys, one of the important parameters that are measured is floor area. The fire load density is calculated by dividing the fire load obtained for a room by the floor area of that room. In the same vein, the fire load densities can be multiplied by the areas of the rooms they were obtained from to obtain the fire loads for those rooms. Since one of the assumptions of 
this research is that similar items will be found in rooms of similar uses regardless of building height, the fire loads obtained can be applied to floor areas found for mid-rise buildings to determine the fire load density for the same.

Table 18 provides a summary of the floor areas found for the hotels and motels surveyed by Chen [16]. In all cases, guest rooms with two beds have larger floor areas than those with one bed. Also hotel suite bedrooms have relatively small floor areas compared to the other rooms since they have a separate living room to accommodate things such as couches and chairs. The luxury hotel guest rooms generally had larger floor areas than the other guest rooms.

Table 18: Floor areas for survey of motels and hotels [16]

\begin{tabular}{|c|c|c|c|c|c|}
\hline & \multicolumn{5}{|c|}{ Floor Area $\left(\mathbf{m}^{2}\right)$} \\
\hline & Minimum & Maximum & Mean & $\begin{array}{l}\text { Standard } \\
\text { deviation }\end{array}$ & $\begin{array}{c}95^{\text {th }} \\
\text { Percentile }\end{array}$ \\
\hline Motel (1 bed) & 15.5 & 33.2 & 20.4 & 5.67 & 29.4 \\
\hline Motel ( 2 beds) & 15.7 & 33.2 & 22.9 & 4.75 & 29.8 \\
\hline $\begin{array}{l}\text { Standard hotel } \\
\text { (1 bed) }\end{array}$ & 17.0 & 29.4 & 22.8 & 4.41 & 28.3 \\
\hline $\begin{array}{l}\text { Standard hotel } \\
\text { ( } 2 \text { beds) }\end{array}$ & 20.3 & 32.9 & 26 & 5.32 & 31.9 \\
\hline $\begin{array}{l}\text { Luxury hotel } \\
\text { (1 bed) }\end{array}$ & 20.1 & 32.8 & 26.2 & 4.83 & 32.1 \\
\hline $\begin{array}{l}\text { Luxury hotel } \\
\text { ( } 2 \text { beds) }\end{array}$ & 26.0 & 32.8 & 28.4 & 2.92 & 32.2 \\
\hline $\begin{array}{l}\text { Hotel Suite } \\
\text { (1 bed) }\end{array}$ & 11.2 & 15.0 & 13.2 & 1.96 & 15.0 \\
\hline $\begin{array}{l}\text { Hotel suite } \\
\text { ( } 2 \text { beds) }\end{array}$ & 11.2 & 17.2 & 14.6 & 3.07 & 17.0 \\
\hline
\end{tabular}


In the pilot fire load survey [25] of living rooms conducted by NRC, the floor area values obtained were compared to values obtained from The Grape Vine Home Marketing Consultants' website [15]. It was found that living room floor areas were similar in both cases, ranging from $10 \mathrm{~m}^{2}$ to $40 \mathrm{~m}^{2}$ with most ranging from $15 \mathrm{~m}^{2}$ to 25 $\mathrm{m}^{2}$. The pilot survey yielded an average floor area of $22 \mathrm{~m}^{2}$ while the website survey yielded an average of $20 \mathrm{~m}^{2}$. Floor areas which were less than $10 \mathrm{~m}^{2}$ and greater $40 \mathrm{~m}^{2}$ obtained in the survey were considered unrealistic and these affected the fire load density values obtained. The follow up extended survey [26] with a larger sample size conducted by the same author yielded a slightly lower mean floor area of $21 \mathrm{~m}^{2}$ with a standard deviation of $8 \mathrm{~m}^{2}$. Table 19 gives a summary of the mean floor areas obtained for main floor living rooms in the various types of homes surveyed, and the number of samples in each category for both the pilot and extended surveys. For the pilot survey, bungalows had the highest mean floor area of $26 \mathrm{~m}^{2}$ per room and duplexes had the least of $9 \mathrm{~m}^{2}$ per room. In the extended survey however, three-storey detached homes had the highest floor area per room. The extended survey yielded values closer to the overall mean than the pilot survey. There did not appear to be any correlation between building height and floor area in this survey. 
Table 19: Mean floor areas for main floor living room survey (extracted from [25] and [26])

\begin{tabular}{|c|c|c|c|c|}
\hline \multirow[b]{2}{*}{ Home } & \multicolumn{2}{|c|}{ Pilot survey } & \multicolumn{2}{|c|}{ Extended Survey } \\
\hline & $\begin{array}{l}\text { Living room } \\
\operatorname{area}\left(\mathbf{m}^{2}\right)\end{array}$ & $\begin{array}{c}\text { Number of } \\
\text { samples }\end{array}$ & $\begin{array}{l}\text { Living room } \\
\text { area }\left(\mathbf{m}^{2}\right)\end{array}$ & $\begin{array}{c}\text { Number of } \\
\text { samples }\end{array}$ \\
\hline Bungalow & 26 & 13 & 19 & 118 \\
\hline Apartment & 24 & 6 & 18 & 64 \\
\hline 3 storey town home & 23 & 5 & 17 & 14 \\
\hline 2 storey detached & 22 & 33 & 20 & 231 \\
\hline 2 storey town home & 22 & 6 & 17 & 58 \\
\hline $\begin{array}{l}2 \text { storey semi- } \\
\text { detached }\end{array}$ & 17 & 4 & 18 & 29 \\
\hline 3 storey detached & 15 & 4 & 21 & 28 \\
\hline Duplex & 9 & 2 & 19 & 12 \\
\hline
\end{tabular}

The floor area of basement living rooms were found to vary greatly, ranging from 5 $\mathrm{m}^{2}$ to $80 \mathrm{~m}^{2}$ for the pilot survey and from $10 \mathrm{~m}^{2}$ to $70 \mathrm{~m}^{2}$ for the extended survey. Again areas below $10 \mathrm{~m}^{2}$ and those above $45 \mathrm{~m}^{2}$ were deemed unrealistic. The mean was obtained as $28 \mathrm{~m}^{2}$ for the pilot survey and $27 \mathrm{~m}^{2}$ for the extended survey, with standard deviations of $9 \mathrm{~m}^{2}$ and $13 \mathrm{~m}^{2}$ respectively (after excluding the unrealistic values). These values were much greater than those for main floor living rooms. Table 20 provides a summary of the mean values obtained. For both the pilot survey and the extended survey, only about $60 \%$ of the surveyed homes had finished basement living rooms, and about $60 \%$ of those had a door on the main floor leading to the basement. For the pilot survey duplexes were again found to have the least floor area and bungalows, the greatest. The extended survey for basement living rooms showed a wider variation of floor areas than 
with main floor living rooms, with bungalows having the highest mean floor area and two-storey town homes having the least.

Table 20: Mean floor areas for basement living room survey (extracted from [25] and [26])

\begin{tabular}{lcccccc}
\hline & \multicolumn{2}{c}{ Pilot survey } & & \multicolumn{2}{c}{ Extended Survey } \\
\cline { 2 - 3 } \cline { 5 - 6 } Home & $\begin{array}{c}\text { Living room } \\
\text { area }\left(\mathbf{m}^{2}\right)\end{array}$ & $\begin{array}{c}\text { Number of } \\
\text { samples }\end{array}$ & & $\begin{array}{c}\text { Living room } \\
\text { area (m }\end{array}$ & $\begin{array}{c}\text { Number of } \\
\text { samples }\end{array}$ \\
\hline Bungalow & 37 & 11 & & 30 & 89 \\
2 storey detached & 33 & 18 & & 25 & 140 \\
3 storey town home & 32 & 3 & & 20 & 4 \\
2 Storey semi-detached & 24 & 4 & & 25 & 16 \\
2 storey town home & 14 & 6 & & 21 & 35 \\
3 storey detached & 14 & 2 & & 29 & 14 \\
Duplex & 7 & 1 & & 26 & 6 \\
\hline
\end{tabular}

Table 21 provides the results of the floor areas for the NRC-IRC project initiated to study fires in low-rise multi-suite residential dwellings that included semi-detached houses, town houses, low rise apartments, and residential care homes [15]. It was observed that basement living rooms generally had larger floor areas than main floor living rooms, as well as, other rooms in the surveyed homes. This is consistent with the observations made with the pilot [25] and extended [26] surveys of living rooms. As previously mentioned, the main floor of the homes surveyed typically had the kitchen, dining room, and living room interconnected without floor to ceiling wall separation. The floor areas of the interconnected spaces were found to range from $22 \mathrm{~m}^{2}$ to $62 \mathrm{~m}^{2}$, with a mean of $34.8 \mathrm{~m}^{2}$ and a standard deviation of $7.6 \mathrm{~m}^{2}$. 
Table 21: Floor areas in multi-family dwellings [15]

\begin{tabular}{lccccc}
\hline Room & $\begin{array}{c}\text { Average Area } \\
\left(\mathbf{m}^{2}\right)\end{array}$ & $\begin{array}{c}\text { Standard } \\
\text { Deviation } \\
\left(\mathbf{m}^{\mathbf{2}}\right)\end{array}$ & $\begin{array}{c}\text { Minimum } \\
\left(\mathbf{m}^{\mathbf{2}}\right)\end{array}$ & $\begin{array}{c}\text { Maximum } \\
\left(\mathbf{m}^{\mathbf{2}}\right)\end{array}$ & $\begin{array}{c}\text { Sample } \\
\text { Size }\end{array}$ \\
\hline Kitchen & 9.8 & 3.6 & 3.6 & 28.2 & 515 \\
Dining room & 9.7 & 2.3 & 4.2 & 21.2 & 415 \\
Main living room & 17.6 & 4.3 & 6.1 & 33.2 & 494 \\
Basement living room & 23.2 & 9 & 6.7 & 64.7 & 295 \\
Primary bedroom & 16.6 & 3.7 & 7.2 & 27.3 & 521 \\
Secondary bedroom 1 & 10.5 & 2 & 6.1 & 26.5 & 514 \\
Secondary bedroom 2 & 9.5 & 2.2 & 6 & 21.7 & 402 \\
Residential care home & 11.0 & - & - & - & - \\
bedrooms & & & & & \\
\hline
\end{tabular}

The survey conducted with the support of the Central Housing Committee in the Unites States [27] yielded floor areas that are comparable to those obtained by other researchers. Table 22 provides a summary of the mean floor areas for the various spaces in the surveyed homes.

Table 22: Mean floor areas for residences in the United States

\begin{tabular}{lcc}
\hline \multirow{2}{*}{ Room } & \multicolumn{2}{c}{ Mean floor area } \\
\cline { 2 - 3 } & $\mathbf{f t}^{2}$ & $\mathbf{m}^{2}$ \\
\hline Entire apt & 628 & 58.3 \\
Hallway & 41 & 3.8 \\
Basement & 783 & 72.7 \\
Bathroom & 43 & 4.0 \\
Kitchen & 119 & 11.1 \\
Bedroom & 128 & 11.9
\end{tabular}




\begin{tabular}{lll} 
Dining & 165 & 15.3 \\
Storeroom & 274 & 25.5 \\
Living room & 209 & 19.4 \\
\hline
\end{tabular}

A web-based floor area survey was conducted on two real estate websites [28] [29] in order to determine typical floor areas for mid-rise buildings and compare these values to floor areas reported for fire load surveys analyzed in this thesis. The survey involved forty-five buildings ranging in height from four- to eight-storeys. Figure 10 shows a frequency distribution of the floor areas found for various spaces in the surveyed buildings. $91 \%$ of the surveyed dwellings had specially designated dining room space, $73 \%$ had a second bedroom, and $40 \%$ had a study area. Each of the surveyed buildings had at least one bedroom, a kitchen, and a living room. Table 23 shows a summary of the results obtained for this survey. The floor area of the surveyed living rooms ranged from $7.3 \mathrm{~m}^{2}$ to $31.8 \mathrm{~m}^{2}$ with a mean of $17.4 \mathrm{~m}^{2}$ and standard deviation of $5.2 \mathrm{~m}^{2}$. This range and mean compares favorably with the results obtained for main floor living rooms in the NRC-IRC project initiated to study fires in low-rise multi-suite residential dwellings [15] (Table 21) and also with survey conducted with the support of the Central Housing Committee in the Unites States [27]. This web survey yielded a slightly lower range than that obtained in the pilot [25] and extended [26] surveys by Bwalya. However the mean values obtained in the extended survey are close to that obtained for this web survey. A mean floor area of $13.5 \mathrm{~m}^{2}$ was obtained for primary bedrooms which had a minimum floor area of $8.5 \mathrm{~m}^{2}$ and a maximum of $18.2 \mathrm{~m}^{2} .69 \%$ of the surveyed primary bedrooms had areas between $10 \mathrm{~m}^{2}$ and $15 \mathrm{~m}^{2}$. The mean value is close to those obtained for hotel 
suite bedrooms (Table 18) and in the United States survey (Table 22), but lower than the values obtained in the NRC-IRC project involving low-rise multi-suite residential dwellings [15] (Table 21). The maximum value of $18.2 \mathrm{~m}^{2}$ is much lower than that obtained in any of the previously discussed surveys (except hotel suites). The floor area of secondary bedrooms had a mean of $10.6 \mathrm{~m}^{2}$ with a standard deviation of $1.9 \mathrm{~m}^{2}$, and a maximum value of $13.9 \mathrm{~m}^{2}$. This mean is close to the mean of $11.0 \mathrm{~m}^{2}$ obtained for secondary bedrooms in residential care facilities (Table 21).

Table 23: Floor areas for various spaces in mid-rise buildings

\begin{tabular}{lccccc}
\hline Room & $\begin{array}{c}\text { Average Area } \\
\left(\mathbf{m}^{2}\right)\end{array}$ & $\begin{array}{c}\text { Standard } \\
\text { Deviation } \\
\left(\mathbf{m}^{2}\right)\end{array}$ & $\begin{array}{c}\text { Minimum } \\
\left(\mathbf{m}^{2}\right)\end{array}$ & $\begin{array}{c}\text { Maximum } \\
\left(\mathbf{m}^{2}\right)\end{array}$ & Sample Size \\
\hline Study & 5.1 & 2.4 & 1.9 & 10.2 & 18.0 \\
Dining & 8.8 & 2.9 & 2.9 & 14.7 & 41.0 \\
Living room & 17.4 & 5.2 & 7.3 & 31.8 & 45.0 \\
Bedroom 1 & 13.5 & 2.4 & 8.5 & 18.2 & 45.0 \\
Bedroom 2 & 10.6 & 1.4 & 8.6 & 13.9 & 33.0 \\
Kitchen & 8.3 & 1.9 & 4.0 & 12.3 & 45.0 \\
\hline
\end{tabular}

The minimum, maximum, and mean floor areas obtained for kitchens were $4.0 \mathrm{~m}^{2}$, $12.3 \mathrm{~m}^{2}$, and $8.3 \mathrm{~m}^{2}$ respectively with a standard deviation of $1.9 \mathrm{~m}^{2}$. Most $(76 \%)$ of the floor area values obtained were between $5 \mathrm{~m}^{2}$ and $10 \mathrm{~m}^{2}$. The maximum value for kitchens was much lower than that obtained for the survey of multi-suite residential dwellings [15] (Table 21). Floor areas for dining rooms were found to have a mean of 8.8 $\mathrm{m}^{2}$ with $60 \%$ of the floor areas falling between $5 \mathrm{~m}^{2}$ and $10 \mathrm{~m}^{2}$. 


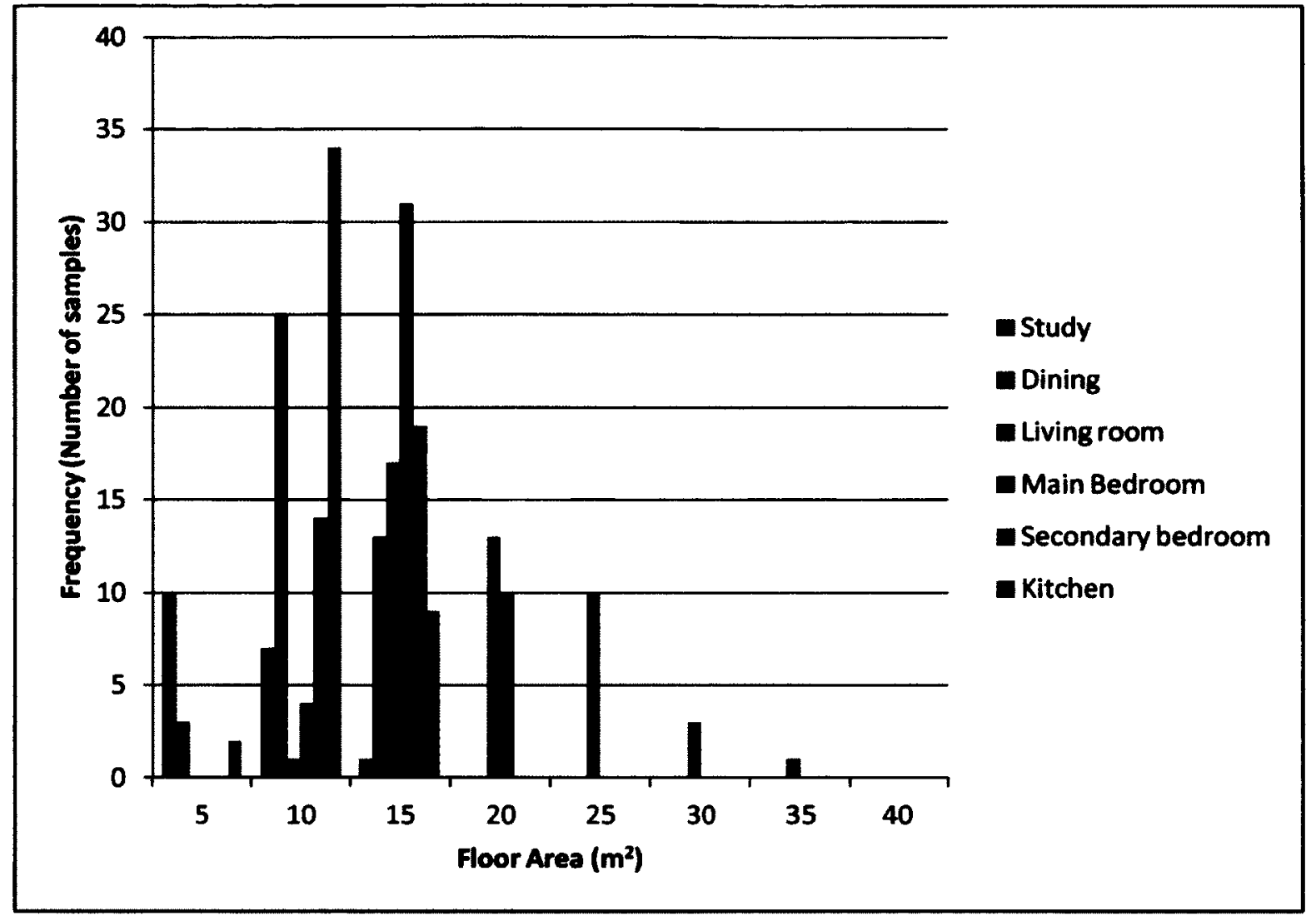

Figure 10: Frequency distribution of floor areas for $\mathbf{4 5}$ mid-rise buildings

The floor area results obtained for the web survey of mid-rise buildings compared to others reported by researchers suggests that in general, spaces in mid-rise buildings tend to have smaller floor areas than spaces in low-rise buildings, especially two- and threestorey single family dwellings which may be free standing or built side-by-side as multifamily dwellings or multiplexes. The mean values obtained in the web survey of mid-rise buildings are close to those obtained by other researchers, but the maximum values tended to be much lower for mid-rise buildings. This is most likely because various rooms and spaces in two- and three-storey single family dwellings are spread between the 
floors; the living room, dining room, kitchen and study area may be located on the main floor while the bedrooms are located on the upper floors. In mid-rise buildings however, each floor usually accommodates all the necessary spaces such as living room, kitchen, and bedrooms. Additionally each floor may have several apartments, leaving limited space to accommodate the needed rooms. Also, the higher a building is, the less footprint it is allowed to occupy by the code [1].

\subsubsection{Summary of Fire Loads and Fire Load Densities}

The mean fire load densities found for residential buildings by various authors ranged from $370 \mathrm{MJ} / \mathrm{m}^{2}$ to $550 \mathrm{MJ} / \mathrm{m}^{2}$. The mean floor areas ranged from $17 \mathrm{~m}^{2}$ to $24 \mathrm{~m}^{2}$ per room and the mean fire loads from $6290 \mathrm{MJ}$ to $13,200 \mathrm{MJ}$ per room. Where the fire loads were not provided directly by the author, they were calculated by multiplying the fire load densities by the floor areas reported. In the same way to calculate average floor areas, the fire loads were divided by the fire load densities provided. The mean fire load densities for living rooms ranged from $288 \mathrm{MJ} / \mathrm{m}^{2}$ to $600 \mathrm{MJ} / \mathrm{m}^{2}$, the mean fire loads from $6682 \mathrm{MJ}$ to $13,200 \mathrm{MJ}$, and the mean floor areas from $17.6 \mathrm{~m}^{2}$ to $23.2 \mathrm{~m}^{2}$. Bedrooms, including those in residences, motels and hotels, and residential care homes, had mean fire load densities ranging from $534 \mathrm{MJ} / \mathrm{m}^{2}$ to $944 \mathrm{MJ} / \mathrm{m}^{2}$, mean fire loads ranging from $6237 \mathrm{MJ}$ to $12,264 \mathrm{MJ}$, and floor areas from $10.5 \mathrm{~m}^{2}$ to $21.9 \mathrm{~m}^{2}$. Dining rooms were reported to have a mean fire load density of $393 \mathrm{MJ} / \mathrm{m}^{2}$, mean fire load of $3812 \mathrm{MJ}$, and mean floor area of $9.7 \mathrm{~m}^{2}$. Kitchens were found to have a rather high mean fire load density of $807 \mathrm{MJ} / \mathrm{m}^{2}$, a mean fire load of $7909 \mathrm{MJ}$, and floor area of $9.8 \mathrm{~m}^{2}$. The $95^{\text {th }}$ percentile fire load ranged from 450 to $790 \mathrm{MJ} / \mathrm{m}^{2}$ for living rooms and 712 
$\mathrm{MJ} / \mathrm{m}^{2}$ to $846 \mathrm{MJ} / \mathrm{m}^{2}$ for bedrooms. The $95^{\text {th }}$ percentile fire load density was found to be $940 \mathrm{MJ} / \mathrm{m}^{2}$ for kitchens, and $576 \mathrm{MJ} / \mathrm{m}^{2}$ for dining rooms. The $95^{\text {th }}$ percentile fire load ranged from $10,440 \mathrm{MJ}$ to $17,380 \mathrm{MJ}$ for living rooms and $8883 \mathrm{MJ}$ to $16,994 \mathrm{MJ}$ for bedrooms. The $95^{\text {th }}$ percentile fire load was found to be $5587 \mathrm{MJ}$ for dining rooms, and $9212 \mathrm{MJ}$ for kitchens. Where the fire load was not reported directly by the author, it was estimated by multiplying the mean floor area by the $95^{\text {th }}$ percentile of the fire load density. The peak fire load density values were reported to range from $633 \mathrm{MJ} / \mathrm{m}^{2}$ to $1700 \mathrm{MJ} / \mathrm{m}^{2}$ for living rooms and from $738 \mathrm{MJ} / \mathrm{m} 2$ to $1000 \mathrm{MJ} / \mathrm{m}^{2}$ for bedrooms. The peak fire load density was found to be $1244 \mathrm{MJ} / \mathrm{m}^{2}$ for kitchens, and $901 \mathrm{MJ} / \mathrm{m}^{2}$ for dining rooms. The peak fire load ranged from $14,686 \mathrm{MJ}$ to $35,700 \mathrm{MJ}$ for living rooms and $10,500 \mathrm{MJ}$ to $18,571 \mathrm{MJ}$ for bedrooms. The peak fire load density was found to be $8740 \mathrm{MJ}$ for dining rooms, and $12,191 \mathrm{MJ}$ for kitchens. This information is presented in Table 24 and Table 25.

Table 24: Summary of fire load densities for residential buildings

\begin{tabular}{lccc}
\hline & \multicolumn{3}{c}{ Fire Load Density $\left(\mathrm{MJ} / \mathrm{m}^{2}\right)$} \\
\cline { 2 - 4 } & Mean & $95^{\text {th }}$ Percentile & Maximum \\
\hline All residential buildings & $\begin{array}{c}370-550 \\
(\text { per room) }\end{array}$ & - & - \\
Living room & $288-600$ & $450-790$ & $633-1700$ \\
Bedroom & $534-944$ & $712-846$ & $738-1000$ \\
Dining room & 393 & 576 & 901 \\
Kitchens & 807 & 940 & 1244 \\
\hline
\end{tabular}


Table 25: Summary of fire loads for residential buildings

\begin{tabular}{lccc}
\hline & \multicolumn{3}{c}{ Fire Load (MJ) } \\
\cline { 2 - 4 } & Mean & $9^{\text {th }}$ Percentile & Maximum \\
\hline All residential buildings & $\begin{array}{c}6290-13200 \\
\text { (per room) }\end{array}$ & - & - \\
Living room & $6682-13200$ & $10440-17380$ & $14686-35700$ \\
Bedroom & $6237-12264$ & $8883-16994$ & $10500-18571$ \\
Dining room & 3812 & 5587 & 8746 \\
Kitchens & 7909 & 9212 & 12191 \\
\hline
\end{tabular}

It was found through a web survey that floor areas for various compartments in midrise residential buildings are generally smaller than floor areas in low-rise buildings. This conclusion was based on the finding that the mean values obtained in the web survey of mid-rise buildings were close to those obtained by other researchers, but the maximum values were found to be much lower for mid-rise buildings.

\subsubsection{Area of Openings}

As part of the fire load survey the various researchers measured the area of openings. The rate of burning of combustible materials in a room depends on the number, size, and shape of openings. It is assumed that at flashover window glass in closed windows will break allowing the inflow of oxygen and therefore a rapid increase in burning rate, temperature, and fire gases. The amount of oxygen that can enter the fire compartment is limited by the window sizes.

A summary of the areas of window openings for the surveyed hotels and motels [16] are compiled in Table 6 according to the results presented by Chen. As can be seen from the table, rooms in hotels or motels with one bed have similar window sizes to those with 
two beds. The mean area of window openings for motels, standard hotels, luxury hotels, and hotel suites with one bed were found to be $2.54 \mathrm{~m}^{2}, 3.98 \mathrm{~m}^{2}, 5.92 \mathrm{~m}^{2}$, and $1.87 \mathrm{~m}^{2}$ respectively. Those with two beds were found to be $2.51 \mathrm{~m}^{2}, 2.95 \mathrm{~m}^{2}, 5.26 \mathrm{~m}^{2}$, and 1.98 $\mathrm{m}^{2}$ respectively.

Table 26 and Table 27 give the results of window measurements obtained during the pilot [25] and extended [26] surveys conducted by NRC. In general, the windows in the basement were much smaller than those in the main floor living room. Most main floor living rooms had an average of two windows while basements had between two and four windows on average. Basement living rooms have been estimated by a previous survey to have an average window area of $0.6 \mathrm{~m}^{2}[15]$ and this agrees well with the values presented in Table 27. The measurement of window sizes during the survey of multifamily dwellings yielded an average of $3.1 \mathrm{~m}^{2}$, a minimum of $1.1 \mathrm{~m}^{2}$, and a maximum of $8.0 \mathrm{~m}^{2}$ for living rooms with a standard deviation of $1.2 \mathrm{~m}^{2}$. An average of $1.7 \mathrm{~m}^{2}$ with a standard deviation of $0.8 \mathrm{~m}^{2}$, a minimum of $0.5 \mathrm{~m}^{2}$, and a maximum of $4.0 \mathrm{~m}^{2}$ was obtained for bedrooms. The rooms in the living rooms tended to be smaller than those in the bedrooms. 
Table 26: Window areas for main floor living rooms [25] [26]

\begin{tabular}{|c|c|c|c|c|c|c|}
\hline \multirow[b]{2}{*}{ Home } & \multicolumn{3}{|c|}{ Pilot survey } & \multicolumn{3}{|c|}{ Extended Survey } \\
\hline & $\begin{array}{l}\text { Number } \\
\text { of } \\
\text { windows }\end{array}$ & $\begin{array}{c}\text { Area of } \\
\text { largest } \\
\text { window } \\
\left(\mathbf{m}^{2}\right)\end{array}$ & $\begin{array}{c}\text { Number } \\
\text { of } \\
\text { samples }\end{array}$ & $\begin{array}{c}\text { Number } \\
\text { of } \\
\text { windows }\end{array}$ & $\begin{array}{c}\text { Area of } \\
\text { largest } \\
\text { window } \\
\left(\mathrm{m}^{2}\right)\end{array}$ & $\begin{array}{c}\text { Number } \\
\text { of } \\
\text { samples }\end{array}$ \\
\hline 3 storey detached & 2 & 1.4 & 4 & 2 & $\overline{2.2}$ & 28 \\
\hline 2 storey detached & 2 & 2.5 & 33 & 2 & 2.6 & 231 \\
\hline Bungalow & 3 & 2.6 & 13 & 2 & 2.9 & 118 \\
\hline Duplex & 2 & 2.2 & 2 & 2 & 2.4 & 12 \\
\hline Apartment & 3 & 3.4 & 6 & 2 & 3.1 & 64 \\
\hline $\begin{array}{l}2 \text { Storey semi- } \\
\text { detached }\end{array}$ & 1 & 2.7 & 4 & 2 & 2.6 & 29 \\
\hline $\begin{array}{l}3 \text { storey town } \\
\text { home }\end{array}$ & 2 & 3.2 & 5 & 2 & 2.2 & 14 \\
\hline $\begin{array}{l}2 \text { storey town } \\
\text { home }\end{array}$ & 2 & 3.5 & 6 & 2 & 2.2 & 58 \\
\hline
\end{tabular}

Table 27: Window areas for basement living rooms [25] [26]

\begin{tabular}{|c|c|c|c|c|c|c|}
\hline \multirow[b]{2}{*}{ Home } & \multicolumn{3}{|c|}{ Pilot survey } & \multicolumn{3}{|c|}{ Extended Survey } \\
\hline & $\begin{array}{c}\text { Number } \\
\text { of } \\
\text { windows }\end{array}$ & $\begin{array}{c}\text { Area of } \\
\text { largest } \\
\text { window } \\
\left(\mathrm{m}^{2}\right)\end{array}$ & $\begin{array}{c}\text { Number } \\
\text { of } \\
\text { samples }\end{array}$ & $\begin{array}{c}\text { Number } \\
\text { of } \\
\text { windows }\end{array}$ & $\begin{array}{c}\text { Area of } \\
\text { largest } \\
\text { window } \\
\left(\mathrm{m}^{2}\right)\end{array}$ & $\begin{array}{c}\text { Number } \\
\text { of } \\
\text { samples }\end{array}$ \\
\hline 2 storey detached & 2 & 0.5 & 18 & 3 & 0.7 & 231 \\
\hline $\begin{array}{l}2 \text { storey semi- } \\
\text { detached }\end{array}$ & 2 & 0.6 & 4 & 2 & 0.6 & 29 \\
\hline 2 storey town home & 2 & 1.3 & 6 & 2 & 0.7 & 58 \\
\hline 3 storey detached & 3 & 0.1 & 2 & 3 & 0.8 & 28 \\
\hline 3 storey town home & 3 & 0.3 & 3 & 2 & 0.4 & 14 \\
\hline Bungalow & 4 & 0.9 & 11 & 4 & 0.6 & 118 \\
\hline Duplex & 6 & 1.4 & 1 & 3 & 0.6 & 12 \\
\hline
\end{tabular}




\subsection{Office Buildings}

\subsubsection{Fire Loads}

In the project [12] to validate the fire load survey methodology proposed in the NFPA (draft) Standard 557 the author found a mean fire load density for offices of $557 \mathrm{MJ} / \mathrm{m}^{2}$ with a standard deviation of $286 \mathrm{MJ} / \mathrm{m}^{2}$, an $80^{\text {th }}$ percentile value of $1077 \mathrm{MJ} / \mathrm{m}^{2}$, a $90^{\text {th }}$ percentile value of $1182 \mathrm{MJ} / \mathrm{m}^{2}$, and a $95^{\text {th }}$ percentile value of $1282 \mathrm{MJ} / \mathrm{m}^{2}$. The Design Guide- Structural Fire Safety [24] gives the mean fire loads for business offices as $\mathbf{8 0 0}$ $\mathrm{MJ} / \mathrm{m}^{2}$ and that for engineering offices as $600 \mathrm{MJ} / \mathrm{m}^{2}$. The mean value of $557 \mathrm{MJ} / \mathrm{m}^{2}$ obtained by Eduful (2012) is close to the value for engineering offices reported in the Design Guide- Structural Fire Safety [24].

Culver [11] conducted a survey of government and private offices in various regions of the United States. Factors such as location, height, age, occupancy characteristics, room use, and room size were taken into consideration. Based on the results obtained for all regions, the maximum fire load was found to be $9681 \mathrm{MJ} / \mathrm{m}^{2}$; the minimum was found to be $27.2 \mathrm{MJ} / \mathrm{m}^{2}$; and a calculated overall mean of $709 \mathrm{MJ} / \mathrm{m}^{2}$. Table 28 provides a summary of the results obtained. The standard deviations obtained were very high indicating a wide range of fire load density for the surveyed offices; this trend is observed also with the values obtained for the maximum and minimum fire load density. The maximum and minimum values obtained in this survey are much greater and smaller respectively than the values obtained by other researchers; the mean fire load densities however are comparable. 
Table 28: Fire load densities for offices in various regions of the United States [11]

\begin{tabular}{|c|c|c|c|c|c|c|}
\hline \multirow[b]{2}{*}{$\begin{array}{l}\text { Census } \\
\text { region }\end{array}$} & \multirow[b]{2}{*}{$\begin{array}{c}\text { Number } \\
\text { of } \\
\text { buildings }\end{array}$} & \multirow[b]{2}{*}{$\begin{array}{l}\text { Number } \\
\text { of rooms }\end{array}$} & \multicolumn{4}{|c|}{ Total fire load density $\mathbf{M J} / \mathrm{m}^{2}$} \\
\hline & & & Maximum & Minimum & Mean & $\begin{array}{l}\text { Standard } \\
\text { deviation }\end{array}$ \\
\hline North-east & 6 & 409 & 9680.7 & 27.2 & 690.2 & 672.0 \\
\hline North-central & 5 & 117 & 3605.3 & 45.4 & 599.4 & 499.5 \\
\hline South & 6 & 227 & 4113.8 & 36.3 & 753.7 & 599.4 \\
\hline West & 6 & 601 & 4704.1 & 45.4 & 726.5 & 599.4 \\
\hline
\end{tabular}

Table 3 shows the influence of room use on fire load as observed in the survey of office buildings by Kumar and Rao [14]. Storage and file rooms appeared to have the highest loads while the minimum fire loads were observed in the corridors. An overall maximum fire load of $1860 \mathrm{MJ} / \mathrm{m}^{2}$ observed in this survey. The mean fire load for all the rooms was found to be $348 \mathrm{MJ} / \mathrm{m}^{2}$ with a standard deviation of $262 \mathrm{MJ} / \mathrm{m}^{2}$ and the 95 th percentile was $1030 \mathrm{MJ} / \mathrm{m}^{2}$. The fire loads found for this survey appeared to decrease with increase in room floor area. The combustible materials found were classified as wood, paper, plastic, and others. The results showed that wood and paper contributed 98.7\% of fire loads in office buildings.. The reception, corridors, conference rooms, and lavatories were found to have the highest amount wood, with contributions of over $80.0 \%$ in each location. Paper contributed the most to the fire loads in storage and file rooms, with contributions of $81.9 \%$ and $74.1 \%$ respectively. Plastic contributed less than $5 \%$ to the fire load in all locations.

In 1970, a report by Baldwin et al. [30] was written providing the survey results of fire loads and the layout of two "modern" office buildings. The surveyed buildings were 
located in London. The survey was conducted to give statistical data for research on the behaviour of fires in buildings. The average fire load density was found to be $372 \mathrm{MJ} / \mathrm{m}^{2}$ which is close to the value obtained by Kumar and Rao [14]. The $95^{\text {th }}$ percentile was found to be $1097 \mathrm{MJ} / \mathrm{m}^{2}$. The maximum fire load density was found to be about 2195 $\mathrm{MJ} / \mathrm{m}^{2}$. Most of the recorded fire load density values however were on the low end.

A fire load survey of contemporary office buildings in the United States was conducted and reported by Caro and Milke [31] in 1995. The direct weighing method was used in this survey which involved both open plan office and closed/compartmented offices. Partitions were included in the calculation of fire load density. A range from 965 $\mathrm{MJ} / \mathrm{m}^{2}$ to $1986 \mathrm{MJ} / \mathrm{m}^{2}$ with a mean of $1321 \mathrm{MJ} / \mathrm{m}^{2}$ was recorded for open offices. The fire load density for open plan offices were composed of about $50 \%$ papers and books and $35 \%$ partitions. The fire load density for closed offices was found to range from 1082 $\mathrm{MJ} / \mathrm{m}^{2}$ to $1340 \mathrm{MJ} / \mathrm{m}^{2}$ with a mean of $1207 \mathrm{MJ} / \mathrm{m}^{2}$. The fire load density for closed offices consisted of about $56 \%$ papers and books, and $36 \%$ furniture. The values for open plan offices were much higher because they tended to have smaller floor areas than closed offices. The mean fire load density for all the offices surveyed was found to be $1238 \mathrm{MJ} / \mathrm{m}^{2}$. The minimum and mean values obtained in this survey are much higher than those obtained by other researchers previously discussed.

\subsubsection{Floor Areas}

In the report of the survey of offices [32] conducted by the GSA, NAS, and NBS, the author provides overall floor areas for each surveyed building, as well as, the number of rooms surveyed for each building. A total of twenty-three buildings were surveyed. 
Clerical and general office formed the bulk of the rooms surveyed in each building. Each of the areas provided was divided by the number of rooms in the building to obtain the average floor area per room for each building. The calculated floor areas ranged from $14.0 \mathrm{~m}^{2}$ to $164.0 \mathrm{~m}^{2}$ with a mean of $33.1 \mathrm{~m}^{2}$ and standard deviation of $32 \mathrm{~m}^{2}$. An inspection of the average floor areas obtained show that most of the values range between about $15.0 \mathrm{~m}^{2}$ and $40.0 \mathrm{~m}^{2}$ with only three values $\left(57.2 \mathrm{~m}^{2}, 75.8 \mathrm{~m}^{2}, 164.0 \mathrm{~m}^{2}\right)$ out of this range. These values appear unrealistically high for general and clerical office space. These high values are due to the presence of a high percentage of conference rooms (which tend to be large) compared to general and clerical offices in those buildings. Without the extreme values, the mean floor area is found to be $23.2 \mathrm{~m}^{2}$ with a standard deviation of $7.5 \mathrm{~m}^{2}$.

In the survey by Kumar and Rao [14], the total area for each room type was divided by the number of rooms in that category to obtain the average floor area. Conference rooms had the highest mean area of $71.9 \mathrm{~m}^{2}$ and lavatories had the lowest of $7.5 \mathrm{~m}^{2}$. The reception, miscellaneous office, general office, technical office, storage and file room, clerical office, and corridor had floor areas of $13.0 \mathrm{~m}^{2}, 25.1 \mathrm{~m}^{2}, 26.0 \mathrm{~m}^{2}, 29.7 \mathrm{~m}^{2}, 30.4$ $\mathrm{m}^{2}, 43.1 \mathrm{~m}^{2}$, and $53.4 \mathrm{~m}^{2}$ respectively. The mean area for all the rooms surveyed was found to be $30.2 \mathrm{~m}^{2}$. This compares favourably with the value obtained by Culver [32].

The report by Baldwin et al. [30] providing the survey results of fire loads and the layout of two "modern" office buildings reports floor areas as having a mean of $26 \mathrm{~m}^{2}$. Again this agrees with the findings by Culver [32] and Kumar and Rao [14]. Most of the surveyed rooms had floor areas between $9 \mathrm{~m}^{2}$ and $19 \mathrm{~m}^{2}$; however areas as large as 180 
$\mathrm{m}^{2}$ were reported. Caro and Milke [31] reported average floor areas of $11.7 \mathrm{~m}^{2}$ for closed offices and $5.2 \mathrm{~m}^{2}$ for open plan offices in the survey of contemporary office buildings in the United States. Eduful [12] surveyed offices with a total floor area of $935 \mathrm{~m}^{2}$. The author found that the floor areas for the surveyed enclosed offices ranged from about 3 $\mathrm{m}^{2}$ to about $27 \mathrm{~m}^{2}$. The mean floor area was $14.4 \mathrm{~m}^{2}$ with a standard deviation of $5.7 \mathrm{~m}^{2}$ and $95^{\text {th }}$ percentile value of $25.2 \mathrm{~m}^{2}$. Open plan offices were found to range in floor area between $3 \mathrm{~m}^{2}$ and $14 \mathrm{~m}^{2}$. The mean floor area was $6.3 \mathrm{~m}^{2}$ with a standard deviation of 2.0 $\mathrm{m}^{2}$, and a $95^{\text {th }}$ percentile of $11.1 \mathrm{~m}^{2}$. The floor area values obtained by Eduful [12] are comparable to those obtained by Caro and Milke [31].

\subsubsection{Summary of Fire Loads and Fire Load Densities}

The mean fire load densities found for office buildings by various authors ranged from $348 \mathrm{MJ} / \mathrm{m}^{2}$ to $1321 \mathrm{MJ} / \mathrm{m}^{2}$. The mean floor areas ranged from $5.2 \mathrm{~m}^{2}$ to $33.1 \mathrm{~m}^{2}$ per room and the mean fire loads from $3509 \mathrm{MJ}$ to $17827 \mathrm{MJ}$ per room. Where the fire loads were not provided directly by the author, they were calculated by multiplying the fire load densities by the floor areas reported. Closed offices appeared to have higher floor areas and fire loads than open offices and cubicles. The higher fire loads observed in closed offices is due to the presence of a large amount of heavy wooden furniture whereas open office typically have lighter furniture usually not made of solid wood. The peak fire load densities reported ranged from $1340 \mathrm{MJ} / \mathrm{m}^{2}$ to $9681 \mathrm{MJ} / \mathrm{m}^{2}$ and the fire loads from 10,327 MJ to $224,599 \mathrm{MJ}$. 


\subsubsection{Area of Openings}

Interestingly, not very many of the survey results included area of openings. Culver [32] presents the total area of openings as a percentage of wall area in the report on the survey of office buildings. The occupancy type is divided into government and private office buildings, and each of these divided into room use categories. For government buildings, the percentage of opening area was calculated to be $12.7 \%, 11.2 \%, 14.8 \%, 8.2 \%, 6.0 \%$, $5.5 \%$, and $7.3 \%$ for general office, clerical office, lobby, conference room, file room, storage room, and library respectively. For private buildings, the percentage of opening area was calculated to be $17.8 \%, 13.3 \%, 14.5 \%, 14.1 \%, 11.1 \%, 9.0 \%$, and $6.8 \%$ for general office, clerical office, lobby, conference room, file room, storage room, and library respectively. From the results provided, it appears that opening areas for general offices, clerical offices, conference rooms, file rooms, and storage rooms are larger in private offices than in government buildings. In the survey by Eduful [12], the surveyed enclosed offices were found to have window openings with a mean of $3.2 \mathrm{~m}^{2}$ and standard deviation of $1.3 \mathrm{~m}^{2}$ and $95^{\text {th }}$ percentile of $4.4 \mathrm{~m}^{2}$. 


\section{Chapter 4: Statistics of Fire Events}

Statistics provide a way to organise and analyse data, and to draw meaningful conclusions that can be applied to solve problems. Fire statistics give a snap-shot of the fire losses among a stock of buildings existing at a point in time and help to determine the efficiency of fire safety provisions and efforts that aim to reduce risk and damage during fire events [33]. Data on fires is collected by researchers and various agencies during surveys, and also by fire fighters who are called to the scene of fires. A study by Forintek Canada Corp. in 1999 [34] suggests that fire ranks seventh, behind suicide, vehicular accidents, accidental falls, accidental poisoning, homicide and accidental drowning, among non-medical related Canadian deaths. In 2010, the Canadian province of Ontario reported a total of 12,849 fires which caused injury, fatality, or property damage; 8,037 of these fires occurred in structures [35]. In British Columbia, a total of 5,983 fires were reported for 2010 [36]. These fires cause damages to the tune of several million dollars per province per year.

\subsection{Residential Building Fires}

Fires occur in about $0.10 \%$ of all residential structures in Ontario every year [35] [37]. Other statistics report that 2.61 fires occur for every 1000 apartment units in Ontario and 5.90 for every 1000 apartments units in the United States [38]. According to various 
studies conducted in Canada and the United States [33], the United Kingdom [39], and Taiwan [40], the majority of deaths and injuries caused by fires occur in residential buildings. This is in spite of the fact that residential buildings are typically constructed according to prescriptive building code requirements with implicit levels of fire performance [33]. Buildings in which sleeping accommodations are provided for occupants who have not been admitted to receive medical care (e.g. hospitals) or are involuntarily detained (e.g. prisons) are classified as residential by Canadian statistics [33].

Statistics provided by the Canadian Wood Council [41] state that " $85 \%$ of fire deaths occur in residential buildings, the majority of which are single-family homes". It further states that the reason for this rather high percentage is because "Canadians spend more than two-thirds of their time at home and, for a significant portion of that time, they are sleeping and thus at greater risk due to decreased awareness". This agrees closely with statistics provided by the Council of Canadian Fire Marshals and Fire Commissioners [42] which places the number of Canadian residential fire deaths for 2002 at $250,82 \%$ of the total fire deaths.

For the period from 1979 to 1997 , statistics for fire losses in Canada suggests that the total number of fires, and deaths and injuries due to fires is decreasing significantly even as the number of population and structures is increasing. The drop over the 19-year period is due to the fact that many provincial jurisdictions in Canada started to require the installation of smoke detectors in the early 1970s. In 1979, residential buildings in Canada saw $37.6 \%$ of all fires, $24.1 \%$ of property losses due to fire, $74.2 \%$ of fire related 
deaths, and $65.1 \%$ of injuries due to fire. These percentages represent the highest in each category, a trend which is also observed with current statistics on fire related deaths and injuries. Ontario statistics for 2006 to 2010 [35] also reported a continuous decline in the number of residential fires and fires in all building types (refer to Figure 11). During this period (2006- 2010) residential fires accounted for $72 \%$ of all fires in buildings that resulted in some kind of injury, fatality, or loss of property [35]. In addition, $80 \%$ of fires in buildings reported in British Columbia during 2006 occurred in residential occupancies [43].

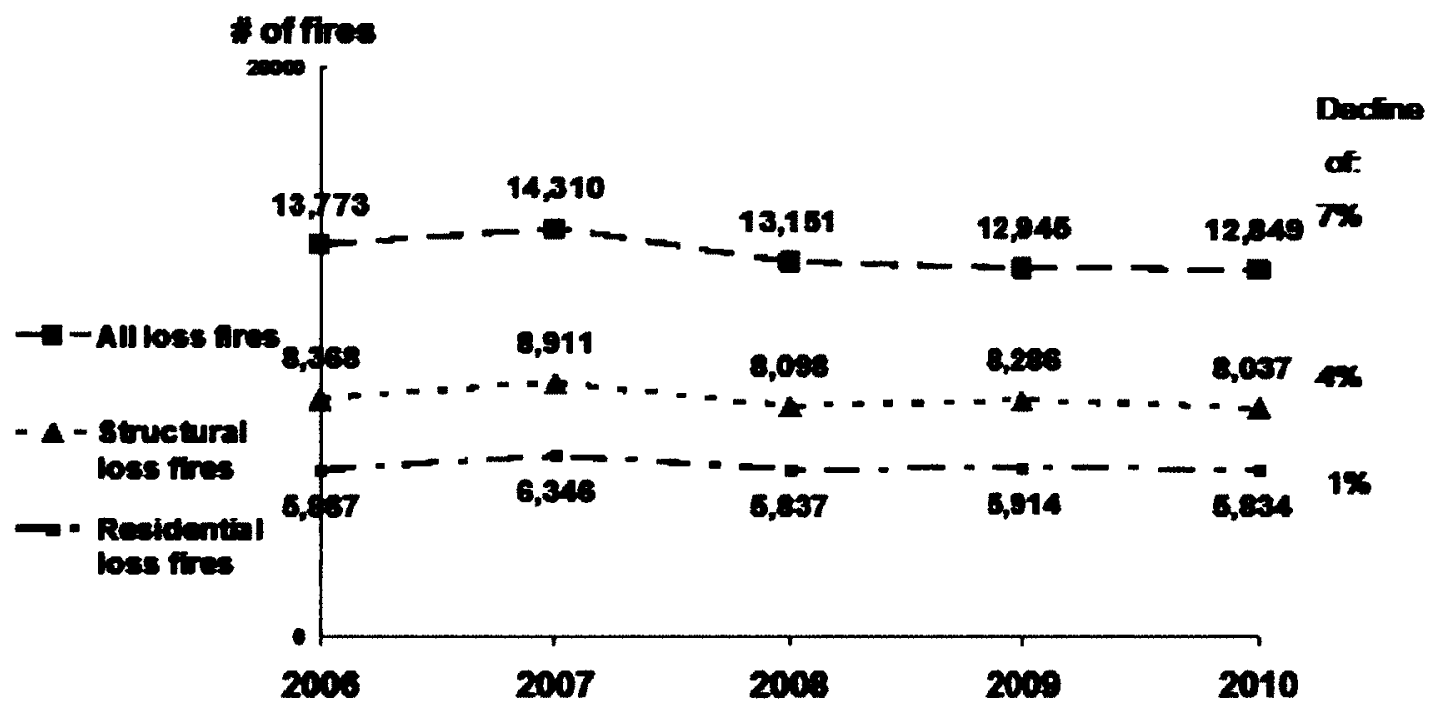

Figure 11: Annual fire losses in ontario from 2006 to 2010 [35]

A survey conducted by the National Fire Protection Association (NFPA) in the United States reported a total of 383,000 fires in 1999 , out of which $73 \%$ were fires in buildings that occurred in residential buildings [33]. The report also provides statistics for 
residential fires that occurred 1996; Table 29 lists home fires by property type in the United States in reported for this period. Most of the fires occurred in 1- and 2-family houses, but the highest number of deaths occurred in mobile homes, with most fire related injuries in apartment buildings.

Table 29: Home fires in the United States in 1996, by property type [33]

\begin{tabular}{lcccr}
\hline Property type & Number of fires & Deaths/100 fires & Injuries/100 fires & Loss/ fire \\
\hline 1- and 2-family houses & 308,000 & 0.96 & 4.0 & $\$ 12,330$ \\
Apartments* & 101,900 & 0.66 & 6.18 & $\$ 9,600$ \\
Mobile homes & 18,400 & 2.45 & 4.5 & $\$ 9,800$ \\
\hline \multicolumn{2}{c}{ "NFPA includes all multifamily homes, other than two-family houses, in this property class. }
\end{tabular}

Hotels and motels are classified as residential by NBCC. In 2001, 218 fires were reported in hotels and motels in Canada which resulted in 25 injuries, 1 death and $\$ 73,600$ in property damages per fire [16]. The United Kingdom statistical database and NFPA indicate that smoking is the major source of ignition in hotels and motel fires [16]. Table 30 presents percentages of fires in motels and hotels from 1980 to 1998 , by height of the buildings in which they occurred, and the height from grade of the origin of the fires. The table shows that about $50 \%$ of all fires occurred in one- and two-storey structures and about $70 \%$ occurred in structures no more than four storeys in height. It also shows that over $50 \%$ of all motel and hotel fires occurred at heights up to 3.0 meters above grade and about $70 \%$ up to heights of 6.1 meters above grade [34]. This shows a predisposition for fires to occur at lower levels of hotel and motel buildings rather than at higher levels. A similar kind of trend is observed with care homes for the aged. This trend is likely 
because the placement of kitchens for these facilities is the bottom floors, and fires tend to start in these locations more than anywhere else.

Table 30: Fire events in motels/hotels by building height and height of fire origin within building (extracted from [34])

\begin{tabular}{ccccc}
\hline $\begin{array}{c}\text { Height of } \\
\text { Structure }\end{array}$ & Fires (\%) & & $\begin{array}{c}\text { Level of origin } \\
\text { (above grade) }(\mathbf{m})\end{array}$ & Fires (\%) \\
\hline One-storey & 20.9 & & $0-3.0$ & 69.8 \\
Two storey & 29.3 & & $3.0-6.1$ & 11.2 \\
$3-4$ storey & 21 & $6.1-9.1$ & 3.8 \\
$5-6$ storey & 8.4 & & $9.1-15.2$ & 3 \\
$7-12$ storey & 10.7 & & $15.2-21.3$ & 1.2 \\
$13-24$ storey & 6.2 & & $>21.3$ & 1.1 \\
$25-49$ storey & 2.8 & & Below ground & 9.4 \\
\hline
\end{tabular}

Surprisingly, Canadian residential fire-loss statistics show a significantly different trend compared to the United States, in spite of similarities in culture, economic conditions and life styles, and how fires are reported [33]. For 1996, the United States reported 430 fires and 4.1 fire related deaths per 100,000 households while Canada reported only 225 and 2.6 fire related deaths per 100,000 households, a $48 \%$ and $37 \%$ difference respectively. The author provides no explanation for the noted differences. Fire related injuries per household however were reported to be the same between the two countries.

Table 31 shows common ignition sources for residential fires. Cooking activities are the leading source of ignition, causing the greatest number of injuries, followed by incendiary or suspicious sources or children playing. However, fires started as a result of smoking (e.g. cigarettes) cause the greatest number of deaths [33]. This is most likely due to the fact that smoking fires may have been started by people who fall asleep or are 
impaired in some other way by the time the fire develops. Ontario statistics [35] report the same trend with fires caused by lit smoke materials with an average of 500 fires in buildings (mostly in residential buildings) reported each year from 2006 to 2010 causing an average of 70 injuries and an average of 18 deaths per year.

Table 31: Sources of ignition in reported ${ }^{1}$ residential fires in the United States in 1996Percent of total [33]

\begin{tabular}{lcccc}
\hline Source & Fires & Property losses & Fire deaths & Fire Injuries \\
\hline Cooking & 19.6 & 6.7 & 6.5 & 21 \\
Incendiary/suspicious/children & 15 & 18.6 & 15.2 & 18.9 \\
playing & 13.8 & 12.2 & 11 & 9.2 \\
Heating system and other heat & 8.2 & 10.3 & 6.7 & 6.5 \\
Electrical distribution system & 8 & 7.1 & 4.4 & 6.1 \\
Appliances and other electrical & 8.9 & 3.5 & 7.4 \\
equipment & 5.9 & 6.2 & 17 & 10.6 \\
Open flame & 4.8 & 4.1 & & \\
Smoking & & & & \\
\hline
\end{tabular}

Statistics for the Ontario province in Canada [35] also report cooking as being the leading ignition source in residential fires for 2006 to 2010 . An average of 1400 fires in buildings were reported each year from 2006 to 2010 causing an average of 180 injuries and an average of 8 deaths; an average 1300 of these fires occurred in residential buildings.

Points of origin for residential fires include kitchen/cooking area, sleeping areas, living room/lounge areas, chimneys, laundry areas, lavatories, and building crawl spaces/substructure or basement. Both Richardson [33] and Hasofer and Thomas [44] reported kitchens to be the most frequent point $(23.5 \%)$ of origin for fires in residential

\footnotetext{
${ }^{1}$ Unknowns not apportioned.
} 
buildings. Statistics for British Columbia during 2006 - 2010 reported cooking activities to be the leading source of ignition in fires in buildings, after arson [36]. Similar results were reported by Juneja [45] in 2004 for Ontario Canada. $26.6 \%$ of all residential fires from 1995 to 2002 originated in kitchens or cooking areas, followed by $11.6 \%$ in living areas and $10.3 \%$ in sleeping areas or bedrooms. Fires originating in other areas contributed less than $6.0 \%$ each to the total number of fires in residential buildings. Consistent with other studies, Juneja reported that the highest number of injuries $(31.3 \%)$ occured in cooking areas, followed by $18.5 \%$ in sleeping areas, and $18.1 \%$ in living rooms. Less than $4.0 \%$ of injuries occurred in each of the other areas of residential occupancies. The highest numbers of injuries per 100 fires (19.4 per 100 fires) however were reported in fires that originated in sleeping areas, followed by 16.9 per 100 fires in living rooms, and 12.7 per 100 fires in cooking areas. The highest numbers of fire deaths $(40.3 \%)$ were reported in fires that originated in living rooms, followed by $17.0 \%$ in sleeping areas, and $15.9 \%$ in cooking areas. Fires that originated in other areas contributed less than $7.0 \%$ each to the fire deaths. Fires originating in attics were reported to produce the highest dollar value in damages per fire even though only $1.2 \%$ of all residential fires originated in this location. The higher dollar losses are due to the fact that fires originating in this location are not easily detectable since attics are usually used only for storage and may progress extensively before they are discovered.

Actions reported to be the primary causes of fires include leaving cooking food, appliances, and open and smouldering flames unattended, lack of proper maintenance of equipment and appliances, overloading electrical equipment, improper handling or 
disposal of fuels among other things [33], with unattended ignition sources causing the greatest number of fires [45]. Table 32 shows NFPA estimates of the annual averages from 1993-1997 of items first ignited in home fires. Fires started by the ignition of furniture result in the highest number of deaths.

Table 32: NFPA estimates 1993-1997 annual averages - first item/materials ignited in home fires (in decreasing order of deaths per 100 fires) [33]

\begin{tabular}{|c|c|c|c|c|c|c|}
\hline \multirow[b]{2}{*}{ Material first ignited } & \multirow{2}{*}{$\begin{array}{c}\begin{array}{c}\text { Fires } \\
(\mathbf{4 2 3 , 7 0 0 )}\end{array} \\
\%\end{array}$} & \multicolumn{2}{|c|}{ Deaths $(3,616)$} & \multicolumn{2}{|c|}{$\begin{array}{l}\text { Injuries } \\
(19,149)\end{array}$} & \multirow{2}{*}{$\begin{array}{c}\begin{array}{c}\text { Loss per } \\
\text { fire }\end{array} \\
\text { SUS } \\
\end{array}$} \\
\hline & & $\%$ & $\begin{array}{c}\text { Per } 100 \\
\text { fires }\end{array}$ & $\%$ & $\begin{array}{c}\text { Per } 100 \\
\text { fires }\end{array}$ & \\
\hline $\begin{array}{l}\text { Furniture (upholstered and non- } \\
\text { upholstered) }\end{array}$ & 4.0 & 20.0 & 4.3 & 10.3 & 11.6 & 17400 \\
\hline Mattress, bedding & 6.2 & 15.3 & 2.1 & 14.5 & 10.6 & 12900 \\
\hline $\begin{array}{l}\text { Flammable liquids and gases, cleaning } \\
\text { supplies, etc }\end{array}$ & 5.1 & 7.4 & 1.3 & 8.9 & 7.9 & 11300 \\
\hline Interior wall linings & 3.9 & 5.6 & 1.2 & 3.0 & 3.5 & 17500 \\
\hline Floor coverings & 2.3 & 3.2 & 1.2 & 2.5 & 4.9 & 13900 \\
\hline Unclassified or unknown material & 9.7 & 12.3 & 1.2 & 9.1 & 4.2 & 14100 \\
\hline $\begin{array}{l}\text { Decorations for special events, } \\
\text { Christmas tree, etc. }\end{array}$ & 0.3 & 0.4 & 1.1 & 0.7 & 9.9 & 17100 \\
\hline Cabinetry & 1.6 & 1.8 & 1.0 & 2.2 & 6.3 & 12200 \\
\hline Structural members, framing & 9.4 & 10.4 & 0.9 & 5.2 & 2.5 & 22100 \\
\hline Paper, paper products, books, etc & 2.7 & 2.6 & 0.8 & 2.8 & 4.7 & 9600 \\
\hline Curtain, blind, drapery, tapestry & 1.0 & 0.9 & 0.8 & 3.7 & 8.2 & 9700 \\
\hline $\begin{array}{l}\text { Clothing (not on person) and other } \\
\text { textiles }\end{array}$ & 5.3 & 4.3 & 0.7 & 6.1 & 5.2 & 9300 \\
\hline Ceiling covering & 0.5 & 0.4 & 0.6 & 0.2 & 2.1 & 13100 \\
\hline $\begin{array}{l}\text { Household supplies, stock, stored } \\
\text { materials, etc }\end{array}$ & 0.6 & 0.4 & 0.6 & 0.5 & 3.8 & 8200 \\
\hline Electrical wire, cable insulation & 7.6 & 4.0 & 0.4 & 3.9 & 2.3 & 8500 \\
\hline Exterior trim & 0.9 & 0.4 & 0.4 & 0.4 & 2.2 & 11600 \\
\hline $\begin{array}{l}\text { Appliance housing/case, special } \\
\text { electrical equipment }\end{array}$ & 1.7 & 0.6 & 0.3 & 1.1 & 2.9 & 6700 \\
\hline
\end{tabular}


Cooking materials

Exterior facade wall

Exterior roof covering

Thermalacoustical insulation

Rubbish, trash, waste
19.0

3.6

1.2

1.1

10.4
3.5

0.4

0.2

0.2

1.7
0.2

0.1

0.1

0.1

0.1
19.8

0.7

0.2

0.4

2.9

4.7

0.9

0.8

1.8

1.3
3000

11300

34200

8700

3500

NFPA estimates suggest that the risk of a fire starting in a residential building due to the ignition of structural elements or framing is higher in one- and two-family dwellings compared to one- to four-storey apartments and apartments with more than four-storeys. On average, $8.2 \%$ of fires where structural elements where the first items to ignite were in one- and two-family dwellings, compared to an average of $4.4 \%$ for one to four storey buildings, and an average of $0.8 \%$ for apartments with more than four storeys. The number of deaths and injuries in residential fires where structural elements were the first items to ignite however was no greater in one- and two-family dwellings than in one- to four-storey apartments and apartments with more than four storeys [33].

Chandler and Baldwin [39] conducted a study of domestic fires in the United Kingdom in which furniture and furnishings were the first items to be ignited. It was discovered that in $1970,20 \%$ of all dwelling fires were caused by the ignition of furniture and furnishings, but these fires accounted for only $40 \%$ of domestic fire deaths. The study also showed that almost $40 \%$ of fires that resulted in deaths actually spread beyond the room of origin. Upholstery fires were shown to be more likely to be confined to the burning item than bedding fires. 


\subsection{Non-residential Building Fires}

Data from the National Fire Incident Reporting System (NFIRS) [46] suggests that non-residential structure fires account for only $8 \%$ of all fires in the United States but lead to some of the highest costs in fire losses.
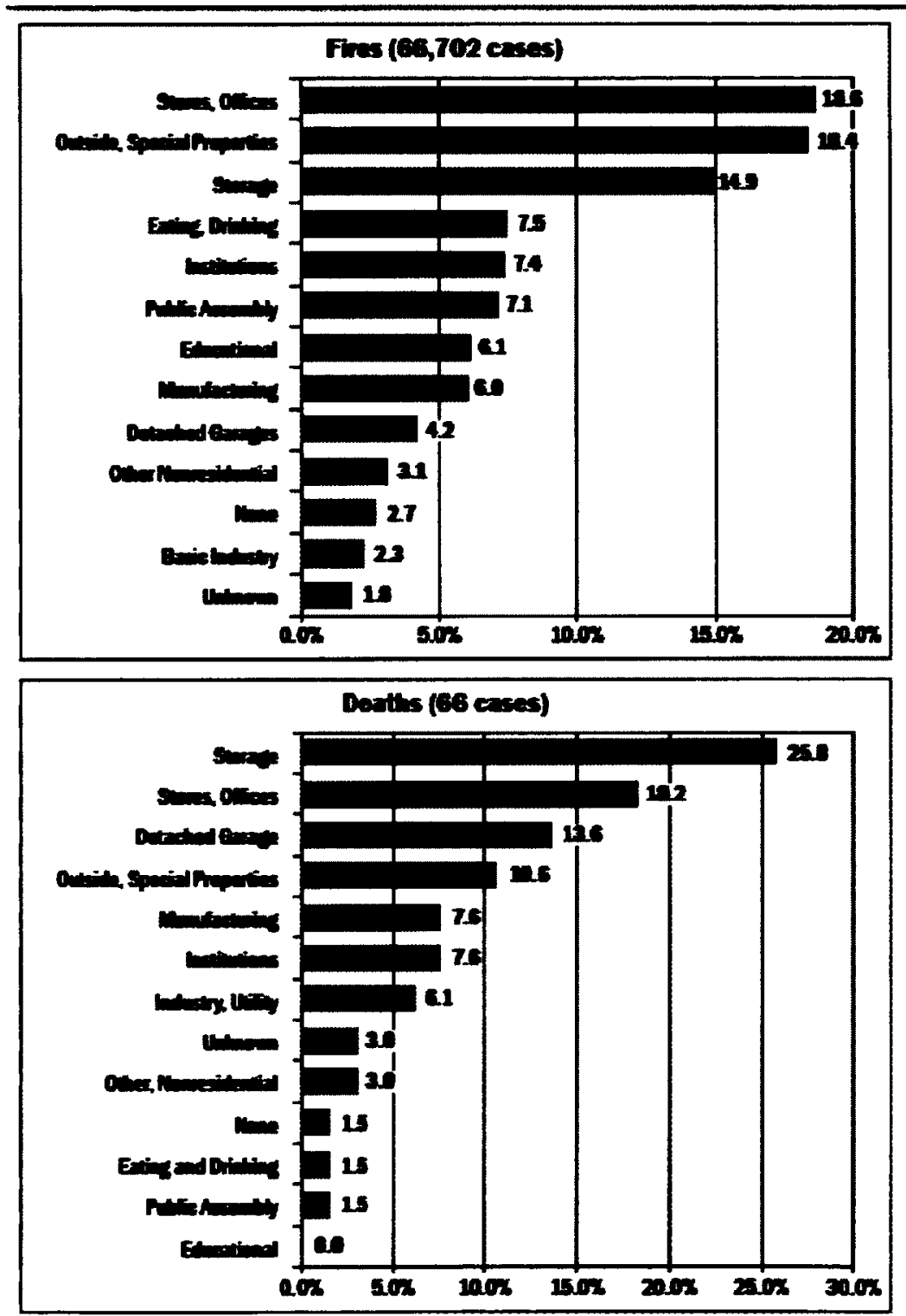

Figure 12: Non-residential building fires and fire losses by property type (2006) [47] 
In 2000 , there were 126,000 non-residential building fires in the United States which led to 90 deaths, 2,200 injuries, and $\$ 2.8$ billion in property damages. The United States Fire Administration in 2006 [47] classified non-residential buildings into 11 major categories. Figure 12 shows these categories as well as the percentage of fires reported in the various categories. It also shows the relative proportion of deaths in each category.

Stores and offices, compared to other non-residential buildings, saw the greatest percentage of fires and injuries but the greatest number of deaths was recorded in storage facilities. Stores and office buildings have been classified by the United States Fire Administration to include stores, specialty shops, personal services, and offices. In stores and office buildings, $25 \%$ of fires recorded are due to cooking, $15 \%$ to electrical malfunctions, and $10 \%$ to heating sources. The leading area where fires start in stores and office buildings is kitchens or cooking areas, followed in order by laundry rooms, offices, exterior wall surface, and equipment or service areas. Cooking is reported to be the leading cause of all non-residential building fires (26\%) as with residential fires, followed by arson. Arson was however reported to be the leading cause of deaths in non-residential building fires [47].

Juneja [45] in his research reported that from 1995 to $2002,8 \%$ of all fires in buildings in Ontario occurred in industrial occupancies, $6 \%$ in assembly occupancies, $3 \%$ in mechantile occupancies, $2 \%$ in institutional occupancies, $2 \%$ in business and personal services occupancies, and $6 \%$ in miscellaneous structures; the rest were reported in residential occupancies. The percentages reported by Juneja are very similar to those for the period from 2006 to 2010 reported by the Office of the Fire Marshal for Ontario [35] 
and also for the province of British Columbia [43]. Of all the deaths that occurred in fires in buildings, only $5 \%$ occurred in non-residential occupancies [45]; similar to results concluded from statistics for British Columbia [43]. A higher percentage of injuries was recorded for non-residential occupancies than deaths with $12 \%$ of these injuries occurring in industrial occupancies, $3 \%$ in assembly occupancies, $2 \%$ in mechantile occupancies, $2 \%$ in institutional occupancies, $1 \%$ in business and personal services occupancies, and $1 \%$ in miscellaneous structures. An even higher percentage was recorded for property damage in non-residential occupancies in terms of dollar amounts with $20 \%$ recorded for industrial occupancies, $5 \%$ for assembly occupancies, $5 \%$ for mechantile occupancies, $1 \%$ for institutional occupancies, $3 \%$ for business and personal services occupancies, and $7 \%$ for miscellaneous structures [45]. For the period from 1995 to 2002 , the areas for business and personal services occupancies in Ontario where most fires (9.2\%) originated were reported to be office areas [45] contrary to the report by the United States Fire Administration [47]. Office areas were also reported as the areas with the most number of fire related injuries. The mechanical/electrical services room was the next highest area of origin with $8.1 \%$ of fires starting there, followed by the lobby/entranceway, $6.6 \%$; laundry area, 6.5\%; exterior wall, 5.2\%; roof, 4.8\%; HVAC equipment room, 3.8\%; trash or rubbish storage, $3.0 \%$. Other areas where fires originated included storage rooms, cooking areas, washrooms, hallways, and concealed spaces. The highest percentage of property damage of $14.5 \%$ occurred in fires where the area of origin was undetermined, followed by $11.8 \%$ in office areas, and $5.9 \%$ in lobby/entranceways; fires that originated in most of the other locations contributed less than $5.0 \%$ to the total property damage 
[45]. The highest sources of ignition reported by British Columbia statistics [43] for 2006 were smokers' materials and open flames, cooking equipment, heating equipment and electrical equipment in order of decreasing likelihood.

\subsection{Fire Statistics in Buildings with and without Sprinklers}

Fire control is achieved through active and passive means [4]. Passive systems include compartmentalization which resist fire spread such as fire rated structural elements and assemblies. Active systems control the fire by human action or automatic devices such as sprinklers. Automatic sprinklers are described by Buchanan [4] as the best form of active fire protection. They are widely used and required by building codes in various types of buildings to control and extinguish fires. The fire safety requirements mandated by NBCC become more stringent as buildings get taller and larger. For example, four storey residential buildings of any type of construction are required to be sprinklered, and the structure is required to have a one-hour fire resistance rating [41]. Stricter requirements are set forth for higher buildings because of the time involved in alerting and evacuating occupants.

Sprinklers are designed to extinguish or prevent the growth of fires by spraying water over the source of heat. Sprinklers are designed to act in time since the water supply system is able to extinguish only fires of a certain size [4]. A sprinkler system usually activates a number of sprinklers surrounding the fire and this helps to reduce radiative feedback from the fire, producing steam that deprives the fire of oxygen, and also wets adjacent combustibles [34], reducing the likelihood of them igniting too. The benefits of 
sprinkler systems are intuitive and cannot be over emphasized, and over the years, experience and statistics have come to validate this notion. From 1980 to 1998 , there were 3440 fires in hotels and motels without sprinkler systems, which led to 8.7 deaths and 71 injuries per every 1000 fires, compared to 1150 fires in hotels and motels with sprinkler systems, leading to 1.7 deaths and 49 injuries per every 1000 fires [34].

A similar trend was observed for care homes for the aged during the same time period where more expensive, and likely, more severe fires were recorded in buildings without sprinklers compared to buildings with sprinklers. Table 33 shows the outcome of fires in motels and hotels and care homes for the aged of all construction types with and without sprinklers by building height. The monetary value of property lost per fire recorded was reduced by almost half with the presence of sprinklers. There was however no clear trend between building height and number of fires recorded.

Table 33: Outcomes of fire events in hotels/motels and care homes for the aged of all construction types with and without sprinklers for the period 1980 - 1998 [34]

\begin{tabular}{|c|c|c|c|c|}
\hline \multirow[b]{2}{*}{ Buildings of all construction types } & \multicolumn{2}{|c|}{ No sprinklers } & \multicolumn{2}{|c|}{ With sprinklers } \\
\hline & $\begin{array}{c}\text { Property } \\
\text { loss per } \\
\text { fire (USD) }\end{array}$ & $\begin{array}{c}\text { Injuries } \\
\text { per } 1000 \\
\text { fires }\end{array}$ & $\begin{array}{c}\text { Property } \\
\text { loss per } \\
\text { fre (USD) }\end{array}$ & $\begin{array}{c}\text { Injuries } \\
\text { per } 1000 \\
\text { fires }\end{array}$ \\
\hline One- and two-storey hotels/motels & $\begin{array}{l}10200 \\
2200 \text { fires }\end{array}$ & 52 & $\begin{array}{c}5700 \\
210 \text { fires }\end{array}$ & 43 \\
\hline Three- and four-storey hotels/motels & $\begin{array}{l}14900 \\
690 \text { fires }\end{array}$ & 114 & $\begin{array}{l}5400 \\
280 \text { fires }\end{array}$ & 61 \\
\hline $\begin{array}{l}\text { Five- to forty- nine storey } \\
\text { hotels/motels }\end{array}$ & $\begin{array}{l}8500 \\
540 \text { fires }\end{array}$ & 93 & $\begin{array}{l}4300 \\
650 \text { fires }\end{array}$ & 42 \\
\hline $\begin{array}{l}\text { One- and two-storey care homes for } \\
\text { the aged }\end{array}$ & $\begin{array}{l}3100 \\
550 \text { fires }\end{array}$ & 78 & $\begin{array}{c}1100 \\
1150 \text { fires }\end{array}$ & 77 \\
\hline
\end{tabular}


Three- and four-storey care homes for the aged

Five- to forty- nine storey care homes for the aged

\author{
1800 \\ 170 fires \\ 2000 \\ 100 fires
}

41

80
1300

380 fires

700

150 fires

\subsection{Summary}

Fires occur in all kinds of structures. According to statistics, at least one out of every thousand residential buildings catches fire every year. Fire statistics show that a high majority of fires that occur in buildings occur in residential occupancies. It was also found that these residential fires typically start due to unattended cooking. Other areas of residential buildings where fires may start include the bedroom and the living room. Fires in non-residential buildings are not as prevalent as residential building fires, but tend to cause more expensive damage. Sprinklers effectively reduce the growth and spread of fires, and thus the damage that might have been caused in their absence. 


\section{Chapter 5: Fuel Packages and Fire Scenerios}

This chapter presents information on the fuel packages found for residential and office buildings. These were determined from the fire load survey data presented by the various researchers considered for this project. Since the design fire load should be at least the load which has a less than $10 \%$ probability of being exceeded in the 50 year life of the building [4], values that will be used to establish the design fires are based on the $95^{\text {th }}$ percentile and peak values. Also presented here are the fire scenarios from which design fire scenarios may be chosen.

\subsection{Fuel Packages for Residential Buildings}

The fire load survey of residential buildings usually involves the inventory of all combustible materials in all the spaces in the residence. The research typically focuses on the fire loads in living rooms, bedrooms, kitchens, dining rooms, study areas, storage spaces, and closets. Sometimes floor areas and fire loads of closets and storage spaces are included in the floor areas and fire loads of the rooms which they are found. Rooms such as lavatories and garages are usually not surveyed during the research.

The survey of hotels and motels by Chen [16] helped to define the fuel packages for bedrooms for this study. It was found that hotel bedrooms and bedrooms in general may contain combustible items such as night table, window covering, dresser, bed, books, side 
table, stuffed toys, wooden shelves, wardrobe, upholstered chair, drawer chest, entertainment unit, and plastic storage bins. The items found in bedrooms and in residential buildings in general may be grouped broadly under cellulose-based materials which includes wood and paper products; plastics which include mattresses, as well as, foams found in chairs and sofas; and textiles. For hotels and motel bedrooms it was found that wood and mattress made up most of the fire load density of the room (refer to Table 11). It should be noted that guest luggage and therefore clothes typically found in bedrooms was not considered in Chen's research. Consequently the conclusion that mattresses make up most of the fire load density of a room may not always hold true. With the consideration of textiles, the percentage of the fire load found for bedrooms was almost evenly distributed among wood, plastics, and textiles (refer to Table 16).

Main living rooms were found to contain items listed in Figure 6 which include furniture items, electronics, paper and plastic products. Basement living rooms had the same items as in main living rooms, as well as, other items such as recreational equipment and bedroom furniture. Living rooms and bedrooms in basements may be likened to studio apartments in mid-rise buildings. Wood-based materials form about $50 \%$ to $65 \%$ of combustible materials found in the living rooms, followed by plastic materials which contribute about $30 \%$ to the fire loads; textiles form less than $5 \%$ of the total fire load.

Kitchens which are usually found to be interconnected with dining rooms and living rooms were found to have mostly wood-based products in the form of cabinets and shelves. Over $80 \%$ of the fire load is contributed by wood based products, followed by 
about $15 \%$ of plastics and less than $1 \%$ of textiles. Dining rooms, like living rooms were found to have about $65 \%$ wood-based products and about $30 \%$ plastics with textiles forming about $1 \%$ of the fire loads. Items found in dining rooms were chairs, dining table, window coverings, books, dining display unit, hutch, area rug, side table, wooden shelves, upholstered chairs, and plastic storage bins.

\subsection{Fuel Packages for Office Buildings}

Similar to residential buildings, room use has an influence on the relative amounts of various combustible materials found in office buildings. The various spaces found in office buildings include reception area, storage and file rooms, technical offices, clerical offices, general offices, conference rooms etc. Additionally there may be open offices with partitions usually without doors or enclosed offices.

The combustible materials found in office buildings comprise cellulosic materials which include paper and wood products, plastics, and other miscellaneous materials. A study conducted by Caro and Milke [31] found that books and paper contributed $20 \%$ to about $65 \%$ to fire loads in offices. They also found that the fire loads for open offices were composed of about $50 \%$ papers and books and $35 \%$ partitions, and the fire load density for closed offices consisted of about $56 \%$ papers and books, and $36 \%$ furniture. Kumar and Rao [14] found that spaces such as the lavatory, conference room, corridor, reception, and general offices had very high amounts of wood with compositions ranging from over $50 \%$ to almost $100 \%$. The storage and file rooms had about $82 \%$ paper, $18 \%$ wood, and less than $1 \%$ of plastic and other combustible materials. The clerical and 
technical offices follow the same trend with a lot more paper than wood. All the offices had a limited amount of plastic and other combustible materials.

\subsection{Fire Scenarios}

In order to develop design fires, fire scenarios have to be identified from which appropriate design fire scenarios can be selected. A fire scenario is a set of conditions that might cause a fire which may to be threatening to a building, its occupants, and contents. Each fire scenario is described by a unique set of events that influence the ignition, development, and spread of fire in a particular compartment [5]. There are usually infinite possible fire scenarios that can be developed; any change to the events of a fire scenario is likely to give rise to a different outcome, thereby creating a different fire scenario. Design fire scenarios should therefore be representative of the aim of a particular design and should include scenarios that are most likely to occur and most likely to cause the most damage, as well as those which might not occur so often but would cause extensive damage if allowed to occur.

Design fire scenarios for this project were selected based on fire statistics as well as fire load surveys conducted by various researchers and agencies. Figure 13 shows a probability chart developed from prevailing fire statistics that makes it easier to visualize where and how fires are mostly likely to occur in structures. The figure shows that fires have at least $72 \%$ probability of occurring within residential structures and at least a $15 \%$ probability of occurring in non-residential structures. Fires in buildings have about an $8 \%$ probability of occurring in industrial structures, $6 \%$ in assembly structures, $3 \%$ in mechantile structures, $2 \%$ in institutional structures, $2 \%$ in business and personal services 
structures, and $6 \%$ in other kinds of structures. Of all the fire deaths that occur in structures, there is about an $\mathbf{8 2} \%$ probability that they will occur in residential structures. This is consistent with what is expectated since a very high percentage of fires occur in residential structures.

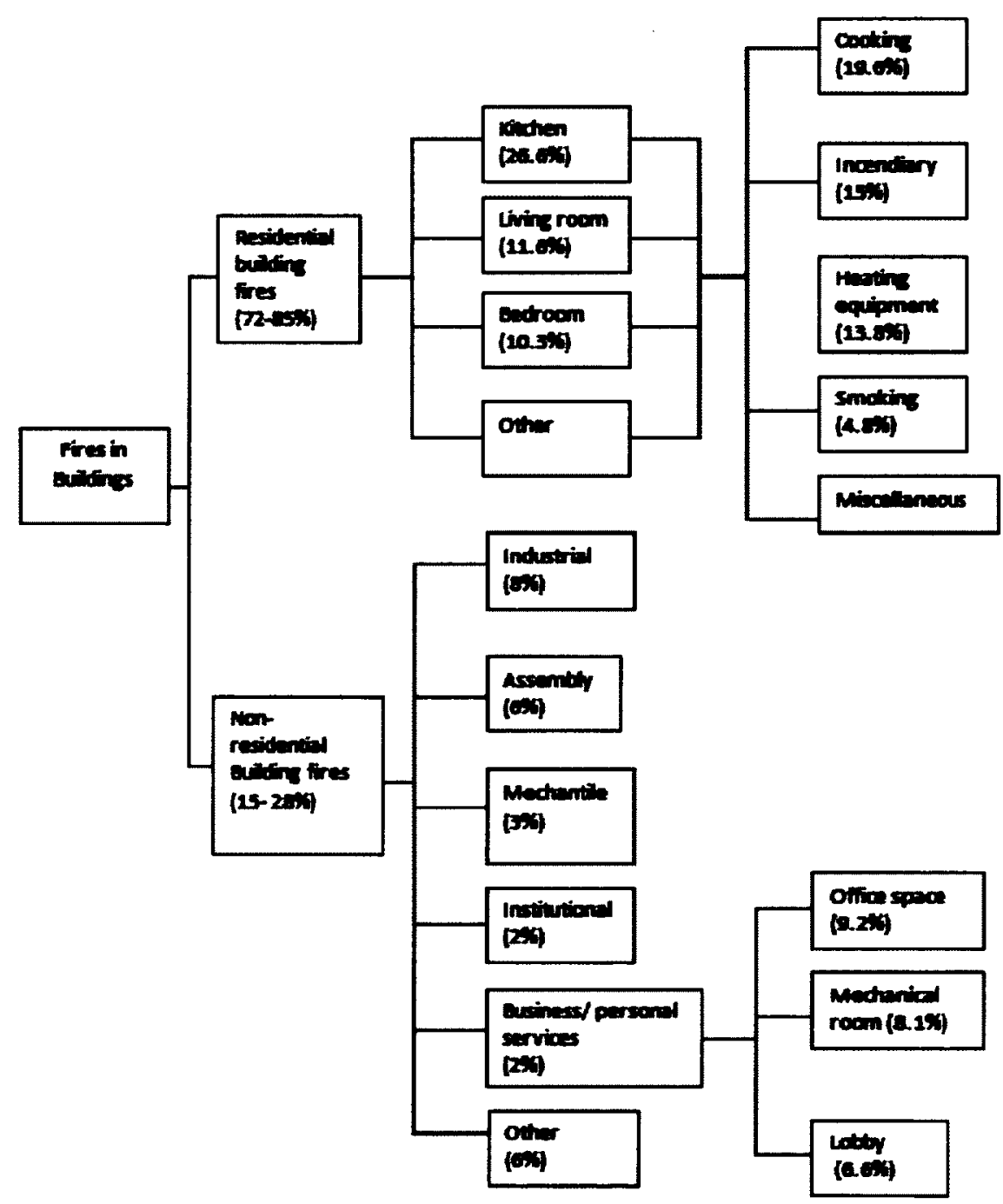

Figure 13: Probability chart developed from fire statistics 
Given that a fire occurs in a residential building, according to statistics, the most likely place for it to start is in the kitchen or cooking space (26.6\% probability). There is an $11.6 \%$ probability that it will start in the living room, and a $10.3 \%$ probability that it will start in the bedroom. The most probable source of ignition in residential structures is from cooking sources such as unattended food and open flames. Other sources with relatively high probabilities include incendiary sources such as children playing, heating equipment, and smokers' materials.

Since the most fires start in residential occupancies, the building chosen to be simulated in this project will be a residential building. Also, it was found that fires in residential buildings are most likely to start in kitchens, but may also start in the living room or bedroom. The scenarios chosen will therefore involve fires which originate in the living room, bedroom, and kitchen. 


\section{Chapter 6: CUrisk Fire Modelling}

CUrisk is a fire risk analysis model being developed at Carleton University. CUrisk's sub-model dealing with fire growth and smoke movement was used to simulate mid-rise building fires. It consists of several sub-models which are interdependent. A Microsoft Excel spreadsheet facilitates the entering of data and Microsoft Visual Basic is used in running the software. The inputs to the CUrisk model are presented in Appendix A. The objective of this modelling exercise is to develop heat release rate curves, temperature profiles, and gas production curves for the case study building.

\subsection{Building Description}

A six-storey residential building was chosen for use in this study. It is a simplified version of what a typical apartment building might look like. It was chosen because the area of the various rooms are close to average floor areas found for the web survey conducted for this study. The building has a total floor area of $3402 \mathrm{~m}^{2}, 567 \mathrm{~m}^{2}$ on each floor and a floor height of $3 \mathrm{~m}$. The building consists of six-apartments measuring $12.0 \mathrm{~m}$ x $6.0 \mathrm{~m}$ on each floor, each with two bedrooms, a living room, a kitchen, and a bathroom. The bedrooms, kitchen, and bathroom are connected to the living room via doors, and the living room to a corridor shared by each of the six apartments. Each of the doors measure $2.0 \mathrm{~m} \times 0.9 \mathrm{~m}$. The corridor is connected on both ends by a door leading to a lobby 
connecting the elevator shaft and staircase. Each bedroom has a window measuring $1.5 \mathrm{~m}$ x $1.5 \mathrm{~m}$ connecting it to the outside. Figure 14 shows dimensions for each apartment. Figures 15 to 20 show the floor plans for each floor with the location of the numbered compartments. Each of the floors is identical. To prevent errors in the model by running it with too many rooms, the number of rooms was reduced by considering each apartment as one room except the apartment with the fire room. Also each floor was identical in layout. There are a total of ninety spaces with a total of a hundred and thirty-four openings consisting of eighty-six doors and forty-eight windows.

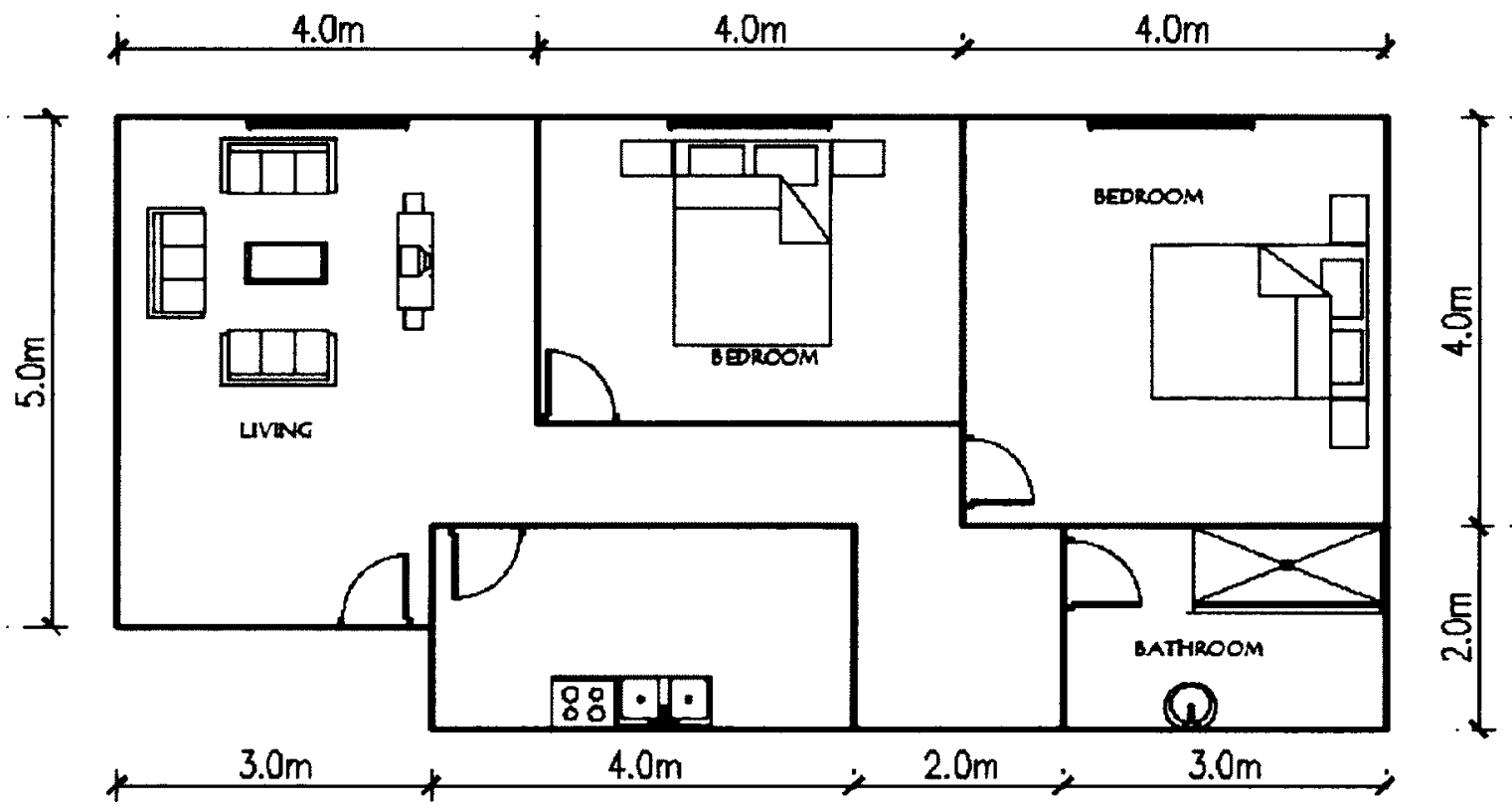

Figure 14: Dimensions for various spaces within apartment 


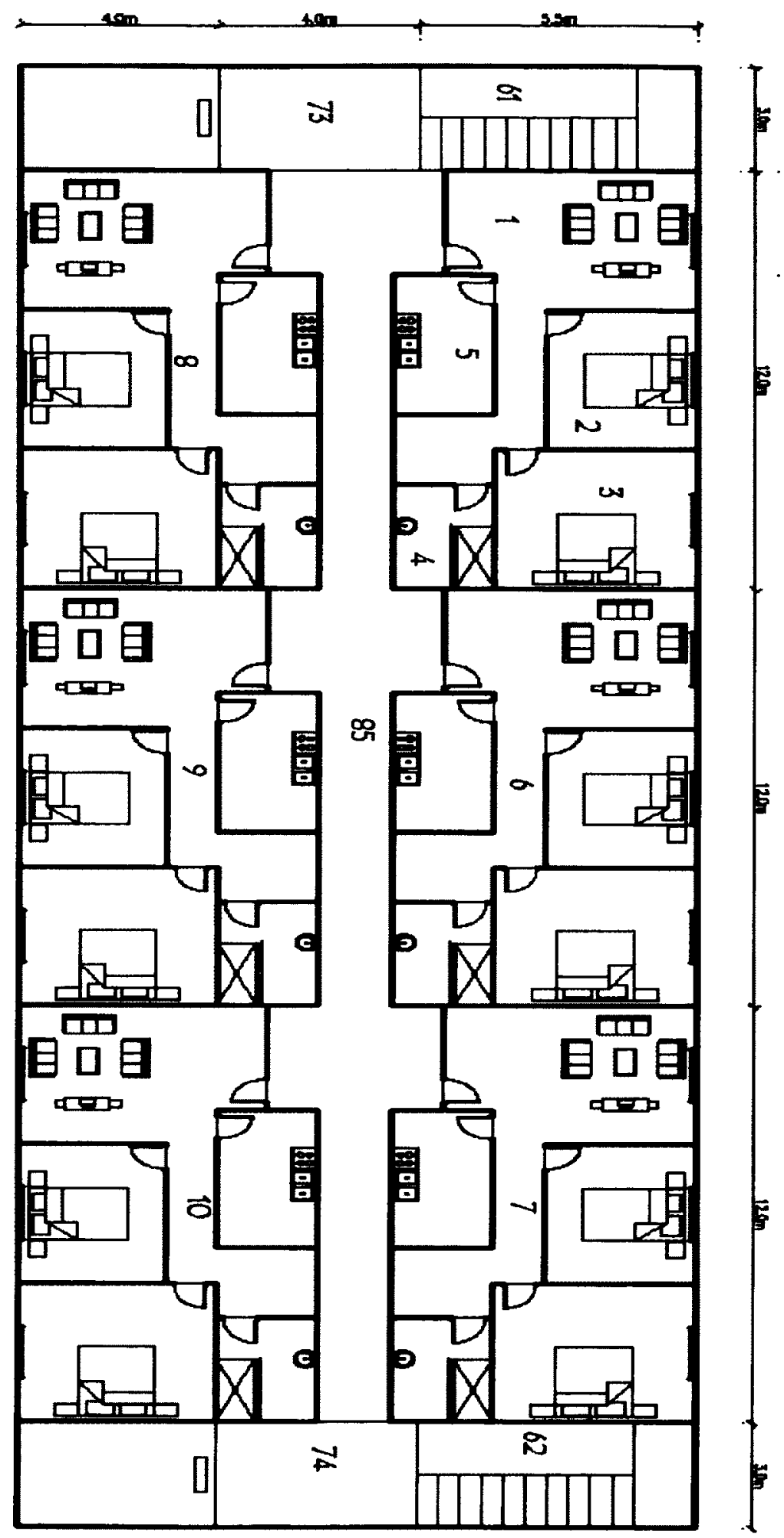

Figure 15: First floor plan with location of compartments 


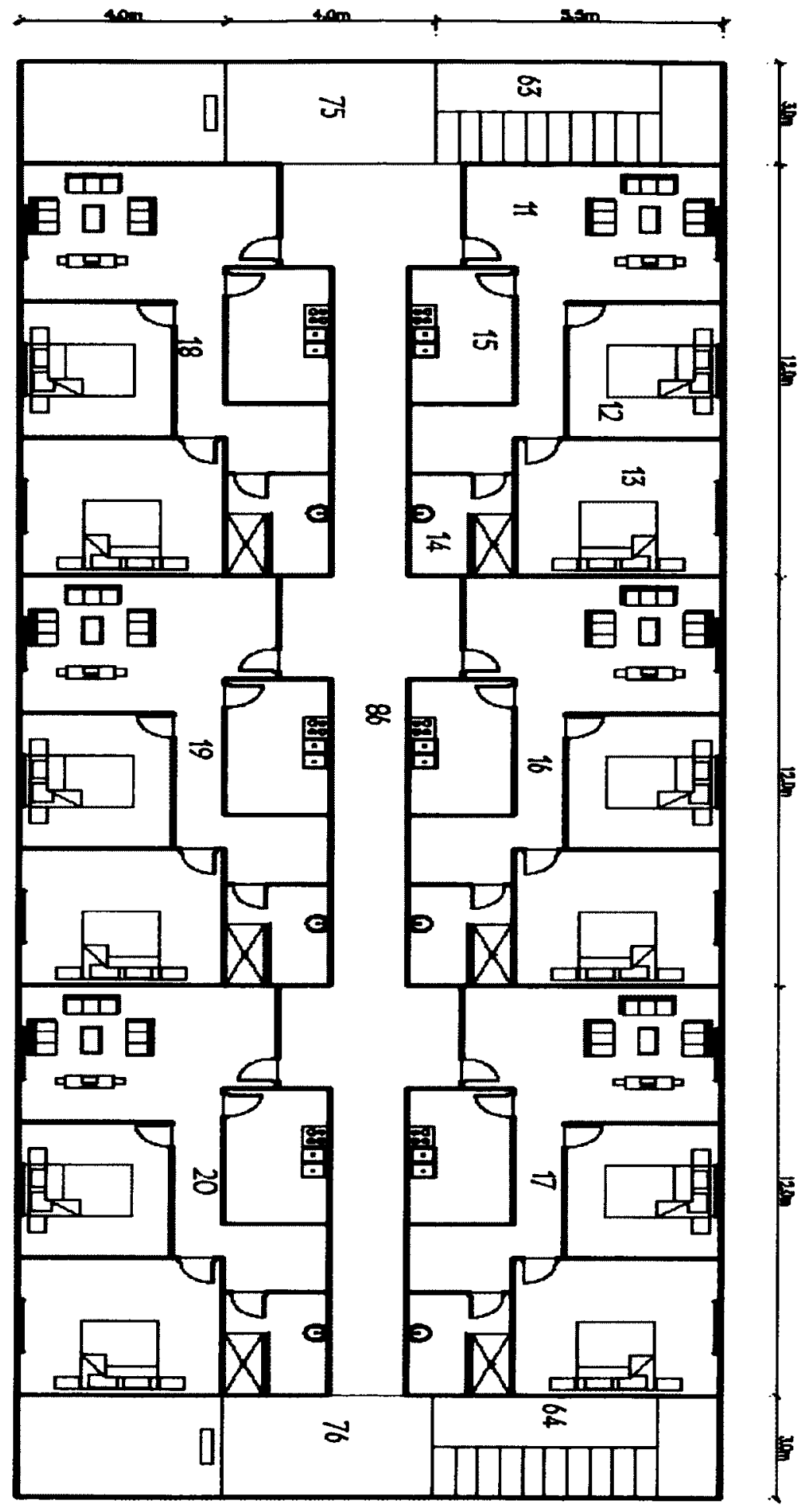

Figure 16: Second floor plan with location of compartments 

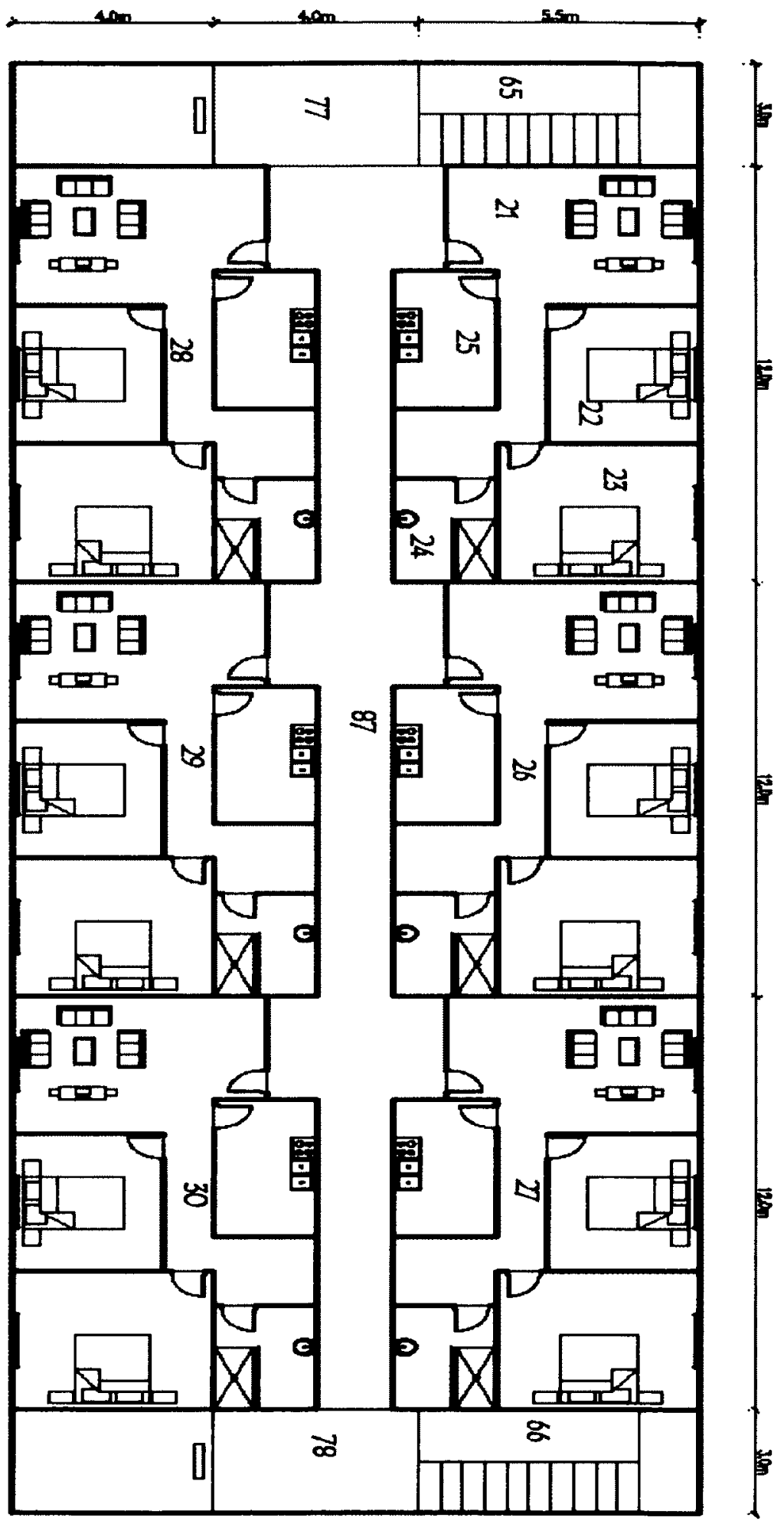

Figure 17: Third floor plan with location of compartments 


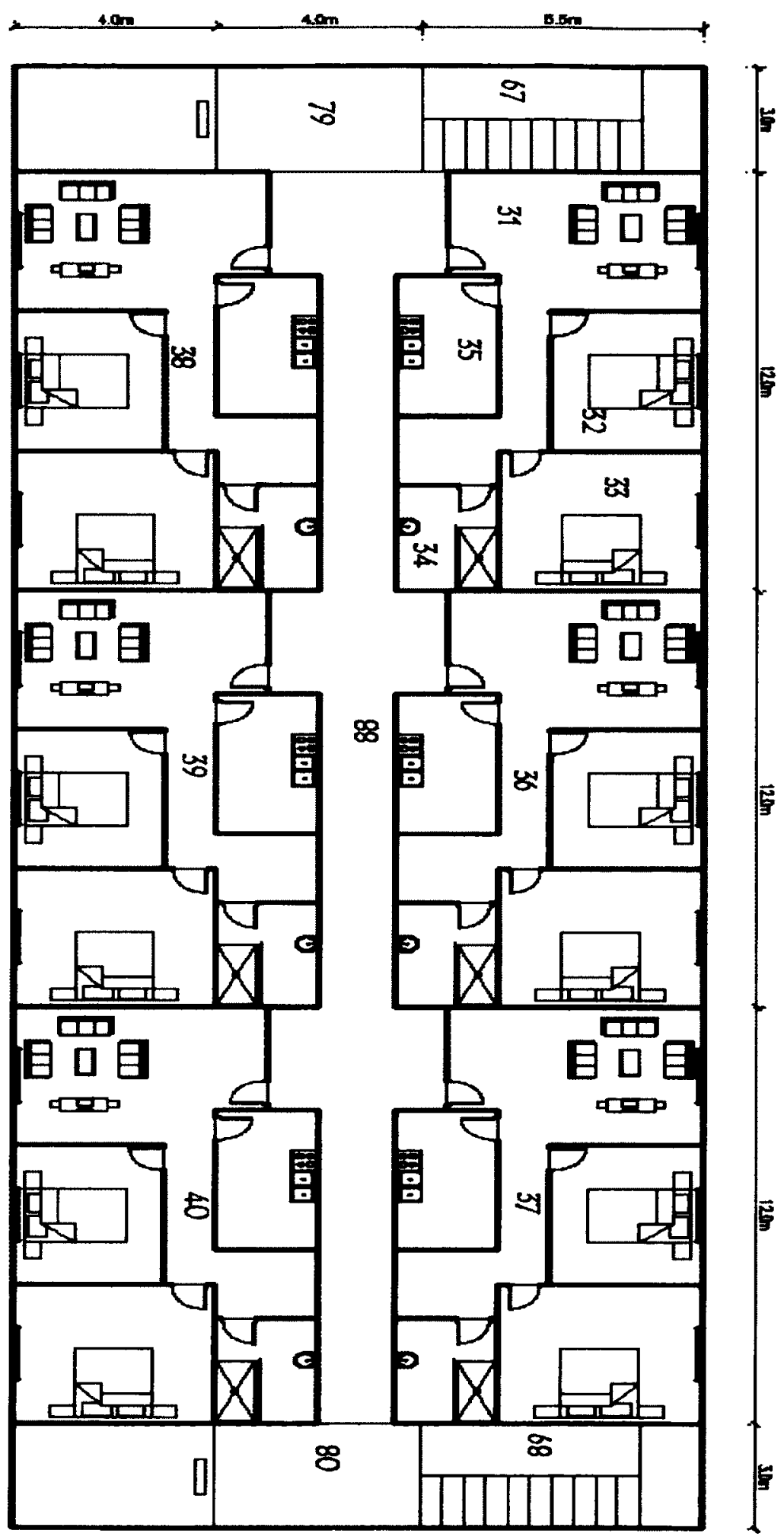

Figure 18: Fourth floor plan with location of compartments 


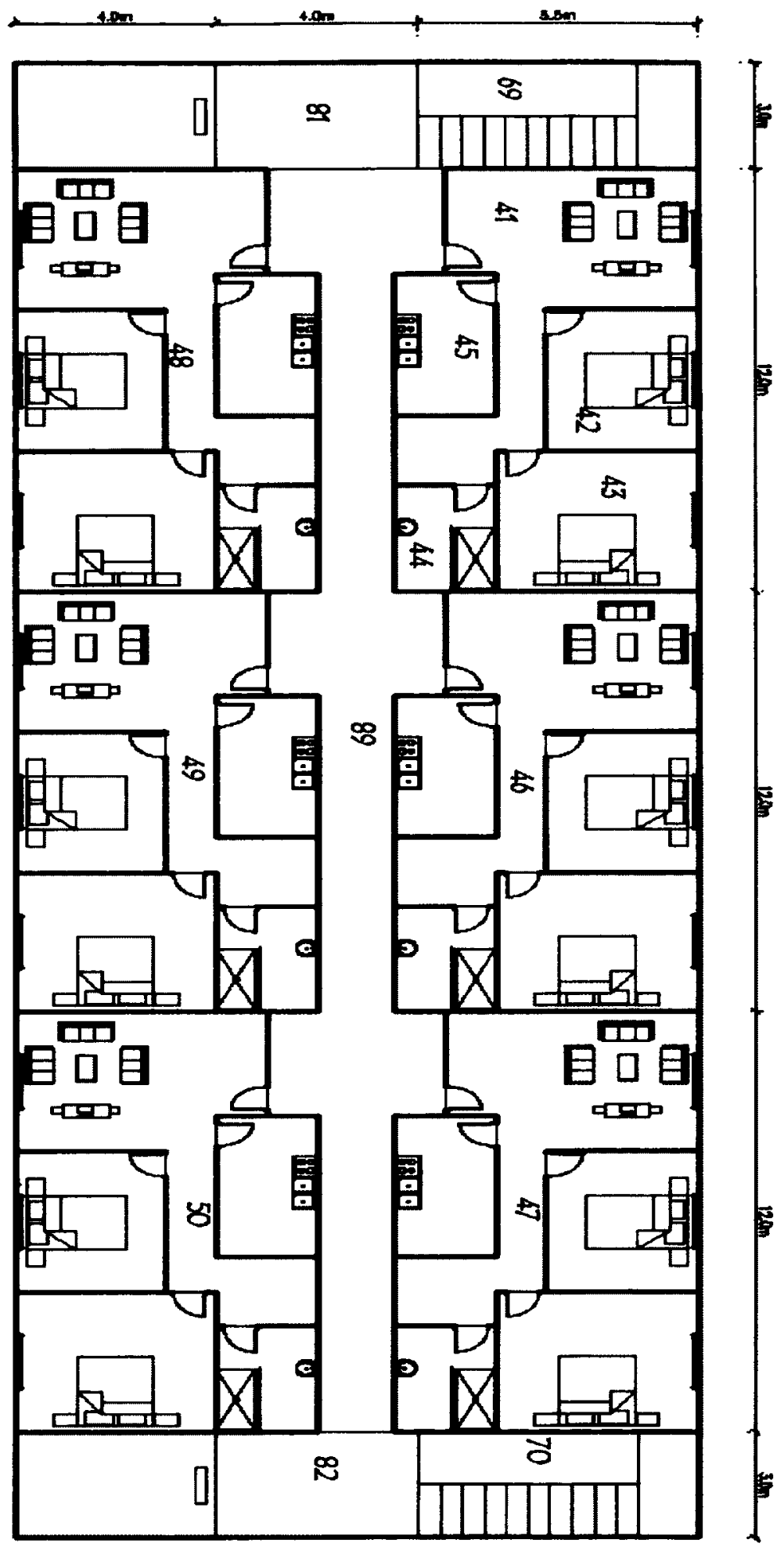

Figure 19: Fifth floor plan with location of compartments 


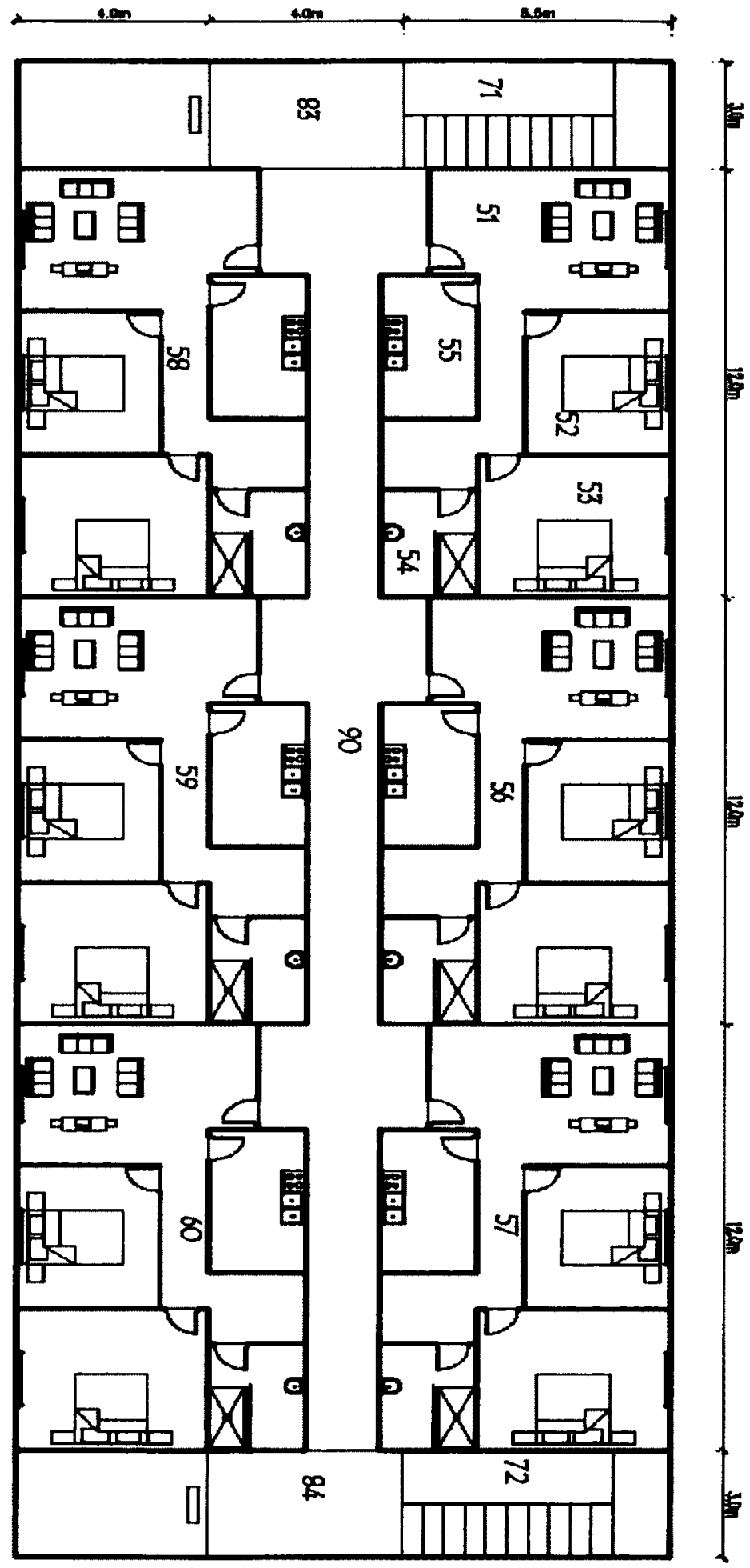

Figure 20: Sixth floor plan with location of compartments 


\subsection{Building Fire Safety Features}

The fire safety features of a building include active fire protection systems such as automatic sprinklers, passive fire protection systems such as fire rated building assemblies [4], and emergency fire protection systems such as emergency lighting [49] and firefighting equipment. In this research the design fires were developed for the worst case scenario where the only fire fighting measures accounted for were the passive fire protection systems. The floor assemblies for the second to sixth floors used in this study are one-hour fire resistance rated assemblies. For the first floor the floor is concrete. The walls and ceilings are all gypsum board protected assemblies. The building is served by two staircases on the east and west ends and two exit doors to the outside on the ground level. The fire department option was set such that there is no intervention.

\subsection{Fire Simulation Theory}

Maximum heat release rate is one of the inputs to the CUrisk model. The maximum possible heat release rate for a compartment is a function of the ventilation characteristics of the compartment. It is given by the following correlation [49]:

$$
\dot{Q}_{\max }=1518 A_{v} \sqrt{H_{v}}
$$

Where,

$$
\begin{aligned}
& \dot{Q}_{\max }=\text { Maximum possible heat release rate of fire, } \mathrm{kW} \\
& H_{v}=\text { Height of vent, } \mathrm{m}^{2} \\
& A_{v}=\text { Area of vent, } \mathrm{m}^{2}
\end{aligned}
$$


It was assumed for the calculation of the maximum heat release rates for this simulation that doors between compartments within apartments and all windows were open, and doors between units were closed. Table 34 shows the maximum heat release rates calculated for the various compartments. The maximum heat release rate for entire apartment units was taken as the highest calculated heat release rate of $8 \mathrm{MW}$. Based on the components found in each room from fire load surveys, growth rates were assumed for each room from the options provided by CUrisk (Table 34).

Table 34: Calculated marimum heat release rates and assumed growth rates

\begin{tabular}{lccc}
\hline Compartment & $\begin{array}{c}\text { Max HRR } \\
\text { (MW) }\end{array}$ & $\begin{array}{c}\text { Fire Growth } \\
\text { Rate }\end{array}$ & $\begin{array}{c}\text { Growth } \\
\text { Constant, } \mathbf{k}(4) \\
\left(\mathbf{s} / \mathbf{M W} \mathbf{W}^{1 / 2}\right)\end{array}$ \\
\hline Bedrooms & $\mathbf{8}$ & Fast & 150 \\
Kitchen & 4 & Fast & 150 \\
Bathroom & 4 & Fast & 150 \\
Living room & 4 & Medium & 300 \\
Apartment unit & $\mathbf{8}$ & Medium & 300 \\
Other areas & 4 & Fast & 150 \\
\hline
\end{tabular}

Flashover heat release rates may be estimated using the Thomas flashover equation [4] given by:

$$
\dot{Q}_{f o}=0.0078 A_{t}+0.378 A_{v} \sqrt{H_{v}}
$$

Where,

$\dot{Q}_{f o}=$ Heat release rate at flashover, MW

$A_{t}=$ Total internal surface area of the room, $\mathrm{m}^{2}$

Time to flashover for $\mathrm{at}^{2}$ design fire, may be estimated by: 


$$
t_{f o}=k \sqrt{\dot{Q}_{f o}}
$$

Where,

$$
\begin{aligned}
& t_{f o}=\text { Time to flashover } \\
& k=\text { Growth constant }
\end{aligned}
$$

Post-flashover temperatures may be predicted using empirical questions and graphs. An empirical equation developed by Law [4] allows for the calculation of maximum temperatures as a function of openings in a compartment and total area of bounding surfaces (Equation 6.4), and also based on fire load (Equation 6.5).

$$
T_{\max }=6000\left(1-e^{-0.1 \Omega}\right) / \sqrt{\Omega}
$$

Where,

$$
\Omega=\left(A_{t}-A_{v}\right) / A_{v} \sqrt{H_{v}}
$$

The maximum temperature may not be reached if the fuel load is low; the maximum temperature may be reduced using:

$$
T=T_{\max }\left(1-e^{-0.05 \Psi}\right)
$$

Where,

$$
\begin{aligned}
& \Psi=L \sqrt{A_{v}\left(A_{t}-A_{v}\right)} \\
& \mathrm{L}=\text { Fire load (kg, wood equivalent) }
\end{aligned}
$$

Table 35 shows the maximum expected post-flashover temperatures based on Law's equation, as well as the expected heat release rate at flashover and the time to flashover. Since fire spread is not considered, temperatures recorded in the fire room will be due to the heat release rate of the fire and the increase in temperature recorded in the other 
rooms will be due to smoke spread. The expected duration of the fire was estimated by dividing the maximum $95^{\text {th }}$ percentile fire load found by the maximum heat release rate. This does not give an accurate result for the duration of the fire since it does not take into consideration factors such as the growth phase of the fire and ventilation characteristics. It however provides a time at which the CUrisk model may be ended. The estimated duration of fire for the living room was estimated to be about 4000 seconds and about 2000 seconds was estimated for the bedrooms and kitchen.

Table 35: Maximum expected post-flashover temperatures, time to flashover, and HRR at flashover

\begin{tabular}{lcccccc}
\hline Compartment & $\boldsymbol{\Omega}$ & $\mathbf{T}_{\max }\left({ }^{\circ} \mathrm{C}\right)$ & $\boldsymbol{\Psi}$ & $\mathbf{T}\left({ }^{\circ} \mathrm{C}\right)$ & $\dot{\boldsymbol{Q}}_{\boldsymbol{f o}}(\mathbf{M W})$ & $\boldsymbol{t}_{\boldsymbol{f o}}(\mathbf{s})$ \\
\hline Bedroom1 & 14.3 & 1207.0 & 46.3 & 1087.8 & 2.6 & 243 \\
Bedroom2 & 11.7 & 1209.6 & 38.4 & 1032.7 & 2.5 & 238 \\
Kitchen & 19.7 & 1163.1 & 42.5 & 1024.4 & 1.4 & 175 \\
Bathroom & 15.8 & 1198.6 & 19.0 & 734.1 & 1.3 & 170 \\
Living room & 16.9 & 1190.0 & 44.5 & 1061.4 & 2.7 & 497 \\
\hline
\end{tabular}

\subsection{Simulated Fire Scenarios}

Fire statistics show that fires in residential building typically originate in the kitchen but may also start in other parts of the house such as the bedroom or living room. Based on the fire statistics data and engineering judgement, two groups consisting of five scenarios each were selected for the simulation. The rooms selected for the simulation were secondary bedrooms on the first and third floors, a primary bedroom on the third floor, a living room on the second floor, and a kitchen on the fourth floor. In group one, all doors 
between compartments within apartments were open fully, and doors between units were closed to simulate what happens if the fire and fire gases are contained in one apartment. For the scenarios in group two, the doors between compartments within apartments, and the doors between units were opened $70 \%$ of the way to simulate smoke spread. For all scenarios, the windows were initially closed and were set to break once the temperature in a compartment reaches $300^{\circ} \mathrm{C}$; according to an $\mathrm{NRCC}$ study [48], $300^{\circ} \mathrm{C}$ is a reasonable lower bound for window breakage. In scenario one for both groups, the fire starts in the center of compartment 2 (shown in Figure 15) which is a secondary bedroom on the first floor. The maximum heat release rate was calculated to be $8 \mathrm{MW}$ based on the ventilation characteristics of the room; the door connected to the living and the window to the outside. The fuel selected for the bedroom was "sofa" which has a "medium" growth rate recommended for furniture items. In scenario two, the fire starts in the center of compartment 11 (shown in Figure 16) which is a living room on the second floor. The maximum heat release rate was calculated to be $8 \mathrm{MW}$ based on the ventilation characteristics of the room; the door connected to the two bedrooms, the kitchen, and the bathroom, and the window to the outside. The fuel selected for the living room was "polyester" which has a "fast" growth rate recommended for some padded/upholstered furniture. The fire in scenario three starts in the center of compartment 23 (shown in Figure 17) which is a primary bedroom on the third floor. The maximum heat release rate was calculated to be $8 \mathrm{MW}$ based on the ventilation characteristics of the room which are the door connected to the living and the window to the outside. As with the secondary bedroom, the fuel selected for the primary bedroom was "sofa" which has a "medium" 
growth rate. In scenario four, the fire starts in the center of compartment 22 (shown in Figure 17), which is a secondary bedroom on the third floor and identical to the bedroom for scenario one. In scenario five, the fire starts in the center of compartment 35 (shown in Figure 18) which is a kitchen on the fourth floor. The maximum heat release rate was calculated to be $4 \mathrm{MW}$ based on the ventilation characteristics of the room; the door connected to the living. The fuel selected for the kitchen was "polyester" which has a "fast" growth rate since a fire in the kitchen is likely to start due to cooking materials such as oil which burn at a "fast" rate. All detectors, alarms, and sprinklers were set to not go off during the simulation. The fire department option was also set such that there will be no intervention during the simulation.

\subsection{Results and Analysis}

The simulation was run for 3600 seconds. Unfortunately CUrisk does not model the decay of fires. The simulation time was therefore chosen as a value close to the maximum expected fire duration of 4000 seconds. The results for the scenarios considered are presented in this section.

\subsubsection{Heat Release Rate}

The Thomas equation [4] (refer to equation 6.2 and Table 35) gives a relatively accurate prediction of the heat release rate at flashover for all rooms except the living room where it predicts a much lower heat release rate compared that observed with CUrisk. The HRR curves are presented in Figures 21 to 30 for the rooms of fire origin in the various fire scenarios. The room of fire origin for scenario one is a secondary bedroom on the first 
floor. Figure 21 shows the fire for scenario one of group one which grows as a medium $t^{2}$ fire until it reaches a peak HRR of $4.3 \mathrm{MW}$ at 620 seconds. The HRR declines gradually to around 3.9 MW by the end of the simulation. This data compare favourably with the results obtained by Chen [16] in the fire test he performed for hotel and motel rooms where he recorded peak heat release rates of about $3.7 \mathrm{MW}$ and 4.8 MW for the two tests he performed. The floor area of Chen's test rooms measured $3.77 \mathrm{~m} \mathrm{x} 4.17 \mathrm{~m}$ which is close to the dimension of the bedrooms in this study. The fire in scenario one of group two, which has more ventilation because the doors between units were opened $70 \%$ of the way, grows as a $t^{2}$ fire to an initial peak HRR 3.6 MW at 564 seconds (refer to Figure 22) and then climbs to a higher peak HRR of $4.3 \mathrm{MW}$ at 1050 seconds after the temperature in the living room reaches $300^{\circ} \mathrm{C}$ and the window breaks. The extra ventilation does not seem to affect the HRR; this might be because the room is "far" from the open main door. For scenario two of group one where the fire starts in the living room, the CUrisk model predicts that the fire grows as a $\mathrm{t}^{2}$ fire to a peak heat release rate of $6.4 \mathrm{MW}$ at 604 seconds after which the HRR declines gradually to $3.6 \mathrm{MW}$ by the end of the simulation (refer to Figure 23). In scenario two of group two the model predicts the fire growing to a peak heat release of $7.8 \mathrm{MW}$ rate at 416 seconds and then declines to about $6.0 \mathrm{MW}$ at the end of the simulation as shown in Figure 24. The higher peak heat release rate observed for scenario two of group two is due the extra ventilation provided by the partial open main door between the corridor and the living room. Mou [49] obtained a peak heat release rate of $6.0 \mathrm{MW}$ for the fire that started in the living room which is close to the heat release rate for the living room observed in this study. In scenario three, the fire 
starts in the primary bedroom which is slightly bigger than the secondary bedroom. In scenario three of group one, the heat release rate grows as a $\mathrm{t}^{2}$ fire to a peak of $4.1 \mathrm{MW}$ and then gradually declines to $3.6 \mathrm{MW}$ at 3600 seconds. Following the same trend observed in scenario one of group two, the heat release rate in scenario three of group two reaches and initial peak heat release rate of $3.3 \mathrm{MW}$ at 548 seconds, levels of for about 800 seconds, and then climbs to a higher peak of $4.2 \mathrm{MW}$. The heat release rate observed in scenario three is slightly lower than observed for the smaller room in scenario one; this is expected since the bigger room is likely to absorb more energy from the fire, thereby keeping the heat release rate lower. The heat release rate curves for scenario four in groups one and two are almost identical to those for scenario one; the difference in floor level does not seem to have a significant effect. The graphs for scenario five in both groups is presented in Figure 29 and Figure 30. In scenario five of group one the fire starts as a $\mathrm{t}^{2}$ fire until it reaches $1.2 \mathrm{MW}$ at 170 seconds. Since kitchen has no window, the main door and windows are closed, and the temperature in the rooms with windows never climb high enough for the windows to break, the oxygen in the fire compartment is quickly depleted. The heat release rate quickly declines and the fire is barely sustained after the $380^{\text {th }}$ second. In scenario five of group two where the main door is partially open, the fire is sustained to the end of the simulation as shown in Figure 30. 


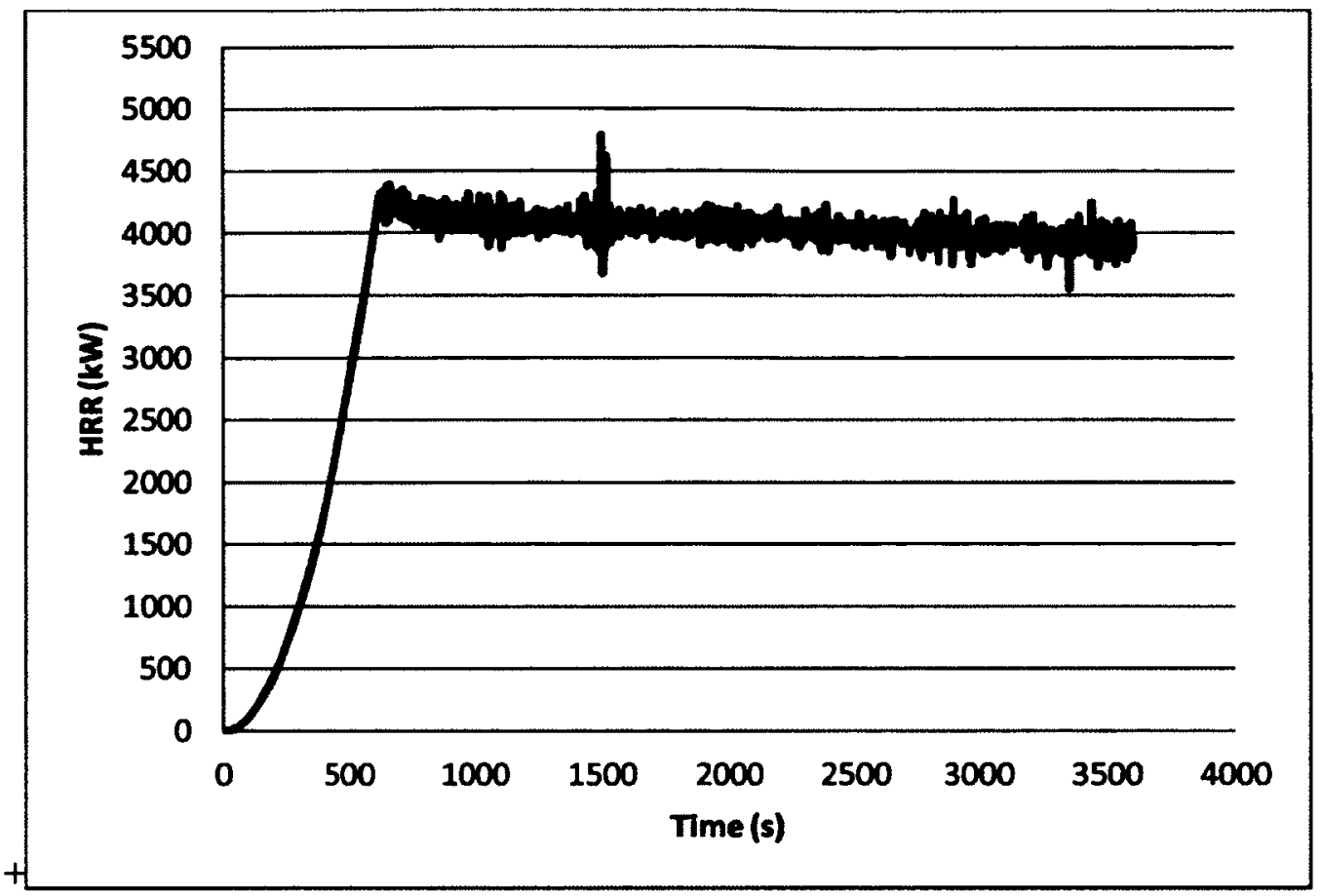

Figure 21: HRR curve for Group one Scenario one

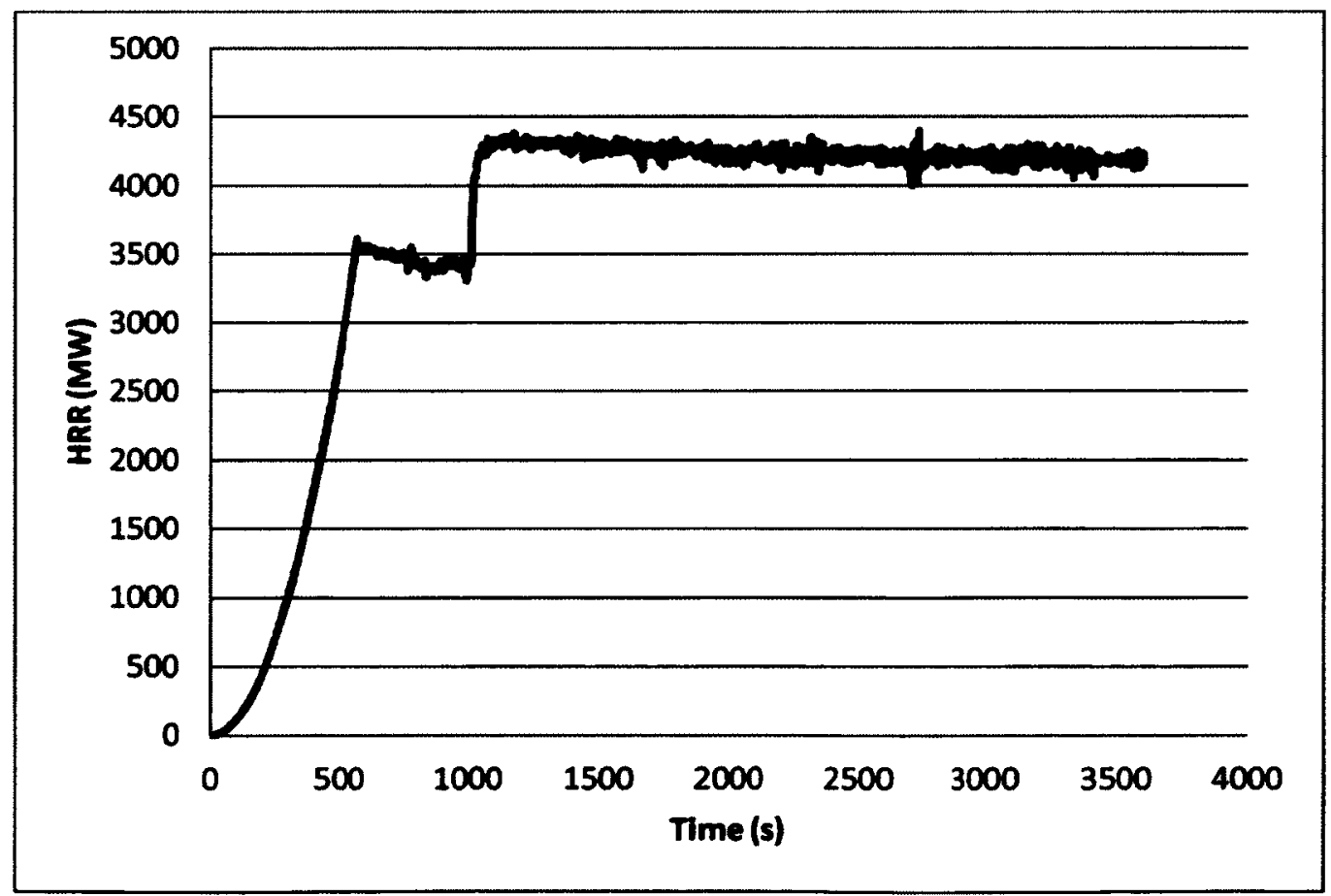

Figure 22: HRR curve for Group two Scenario one 


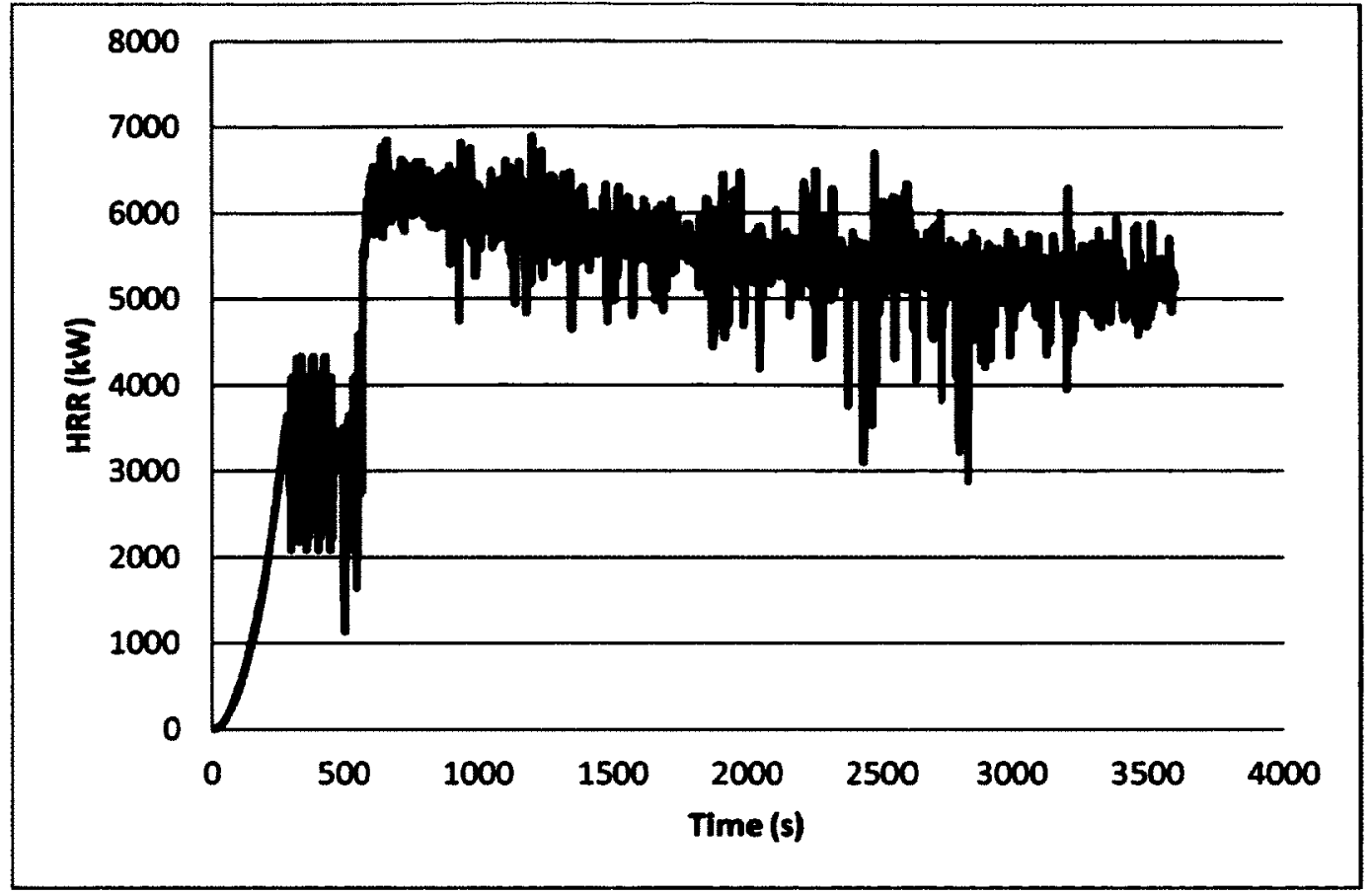

Figure 23: HRR curve for Group one Scenario two

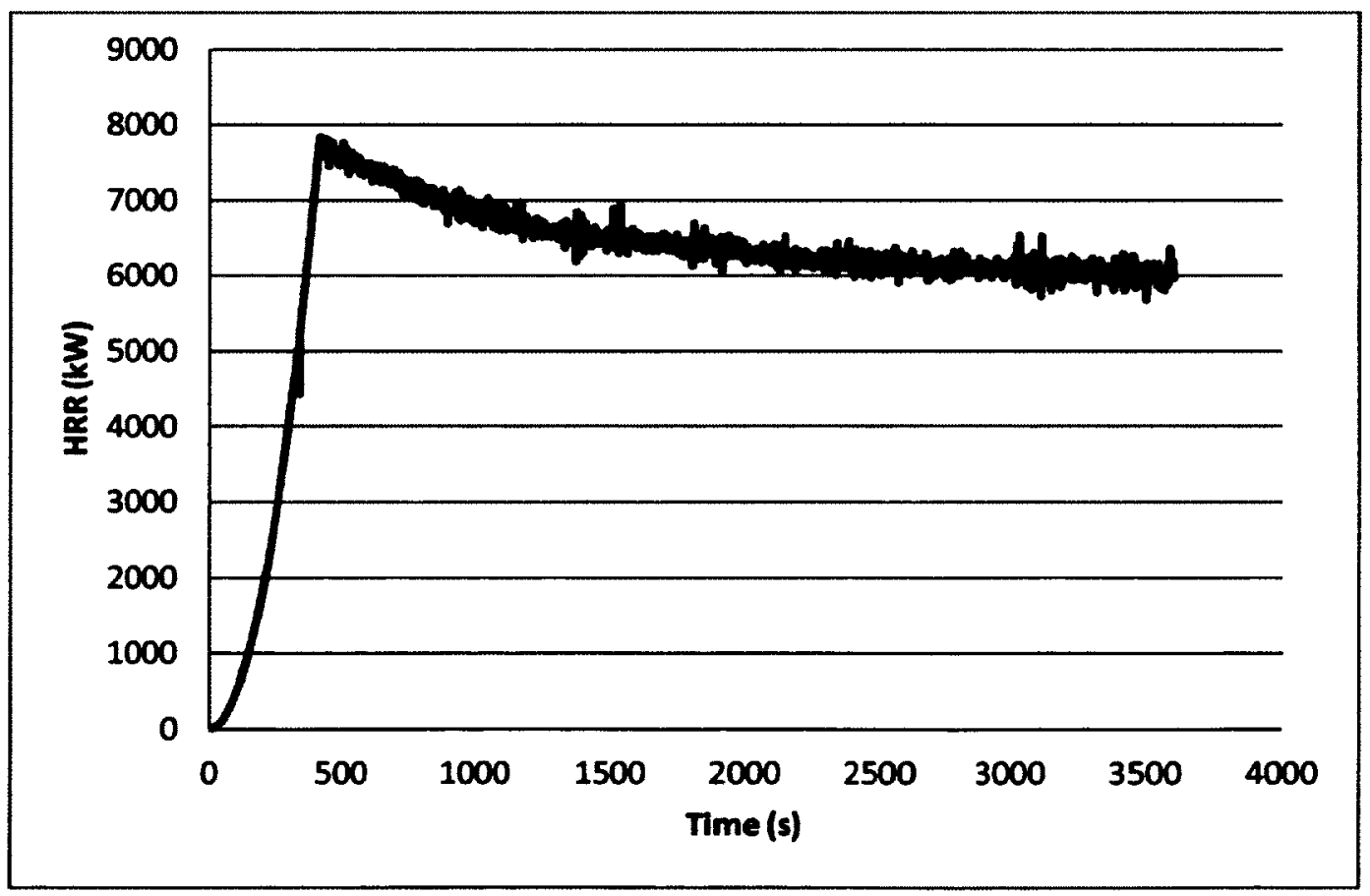

Figure 24: HRR curve for Group two Scenario two 


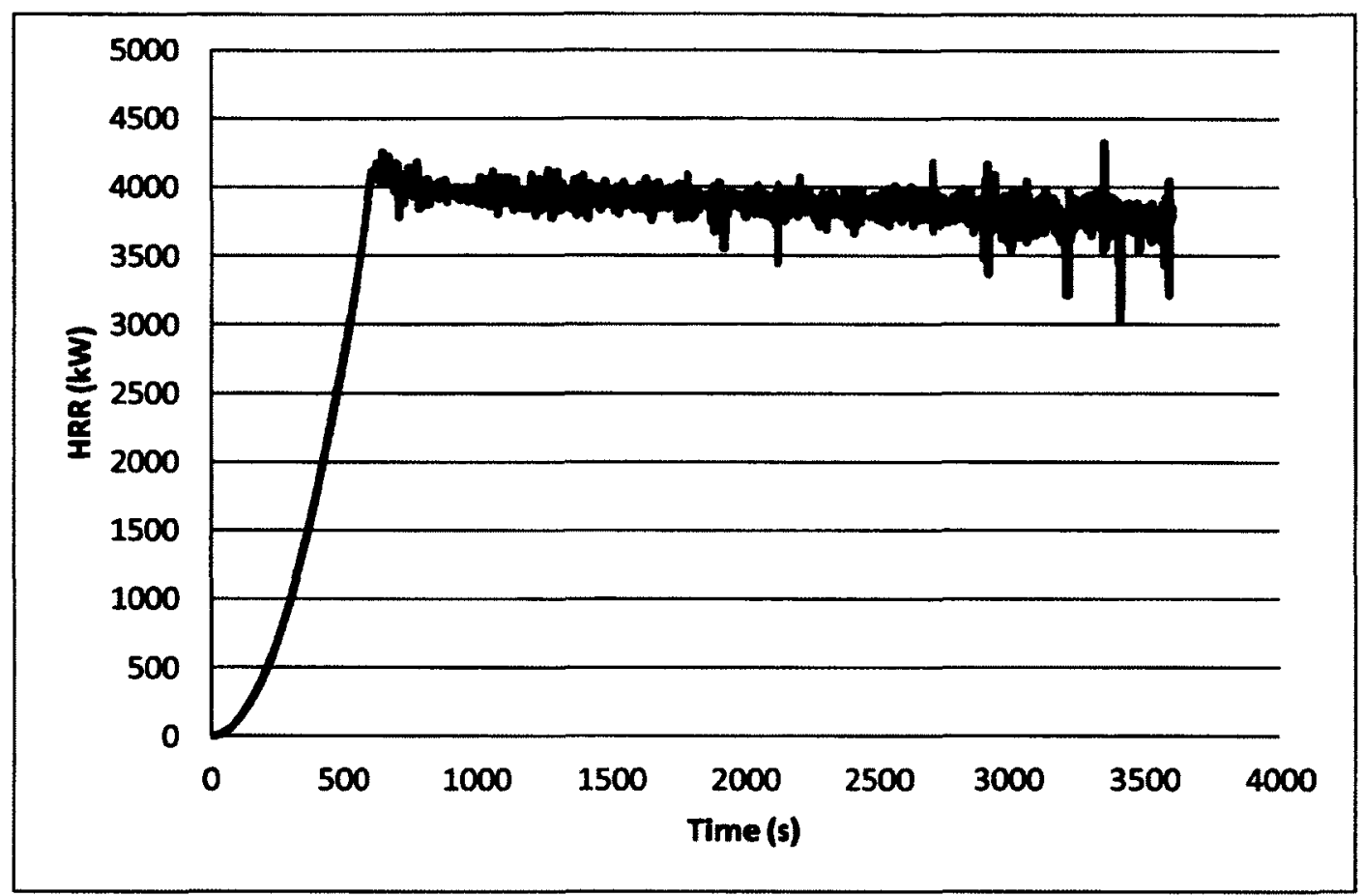

Figure 25: HRR curve for Group one Scenario three

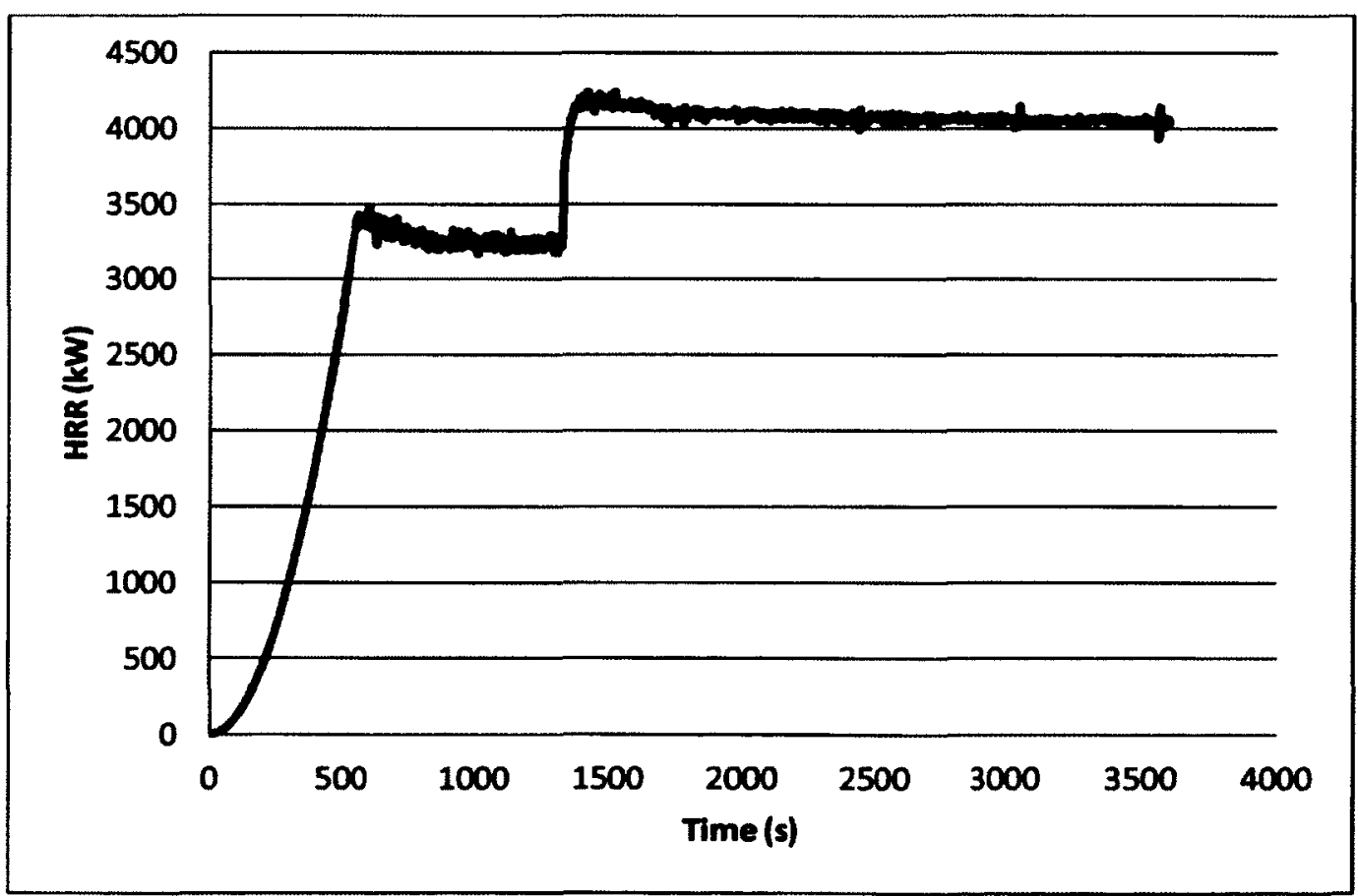

Figure 26: HRR curve for Group two Scenario three 


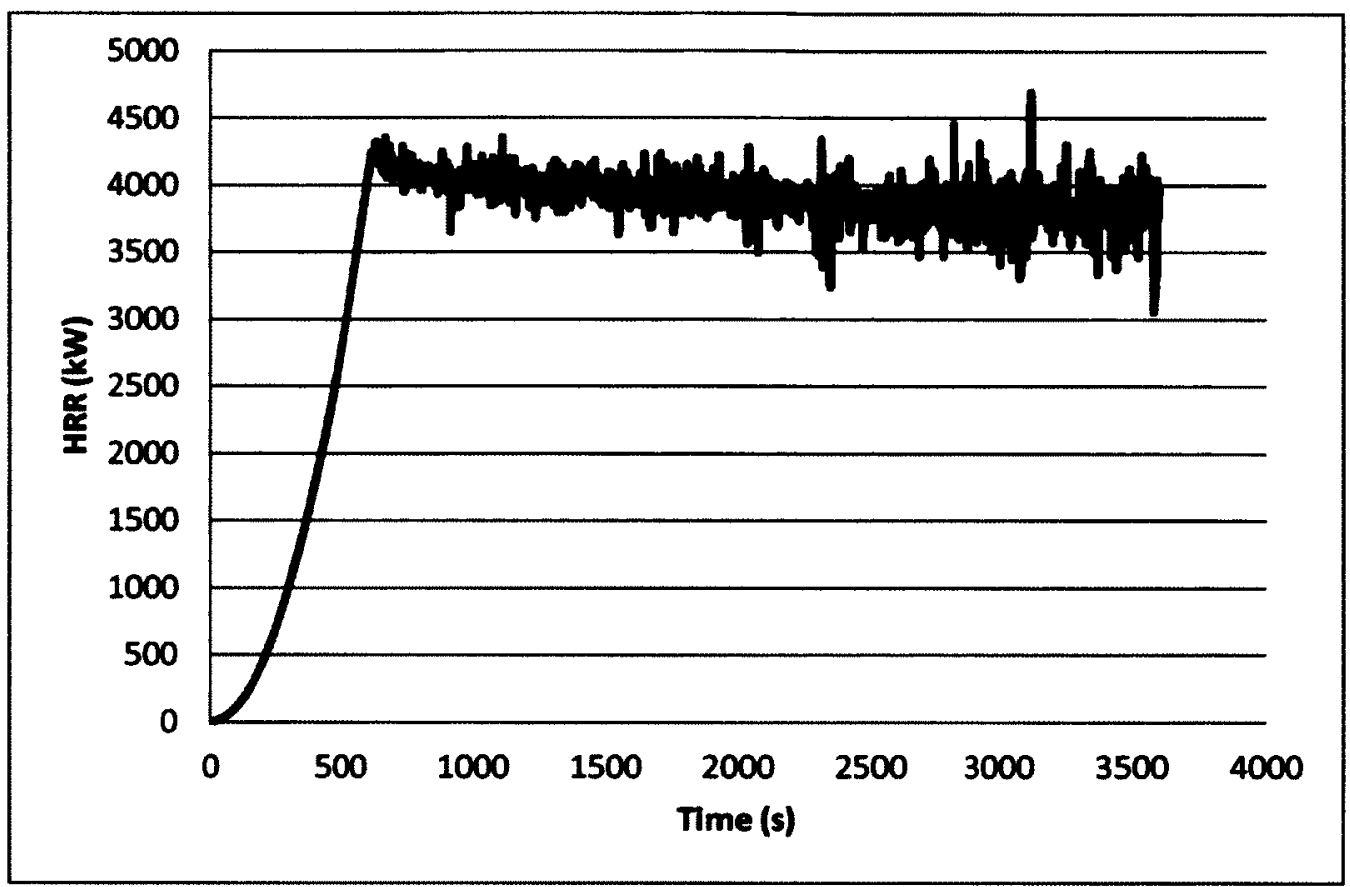

Figure 27: HRR curve for Group one Scenario four

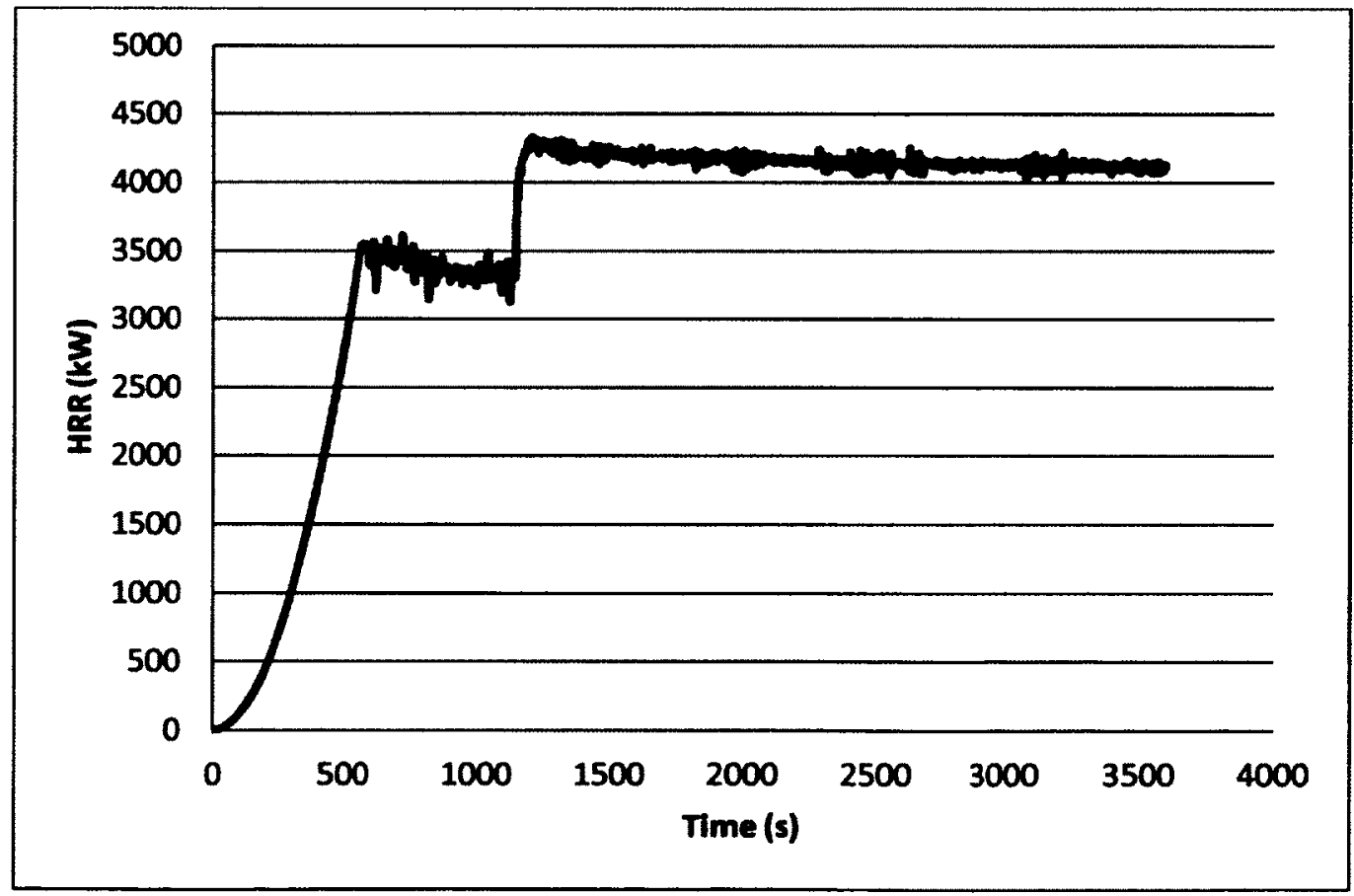

Figure 28: HRR curve for Group two Scenario four 


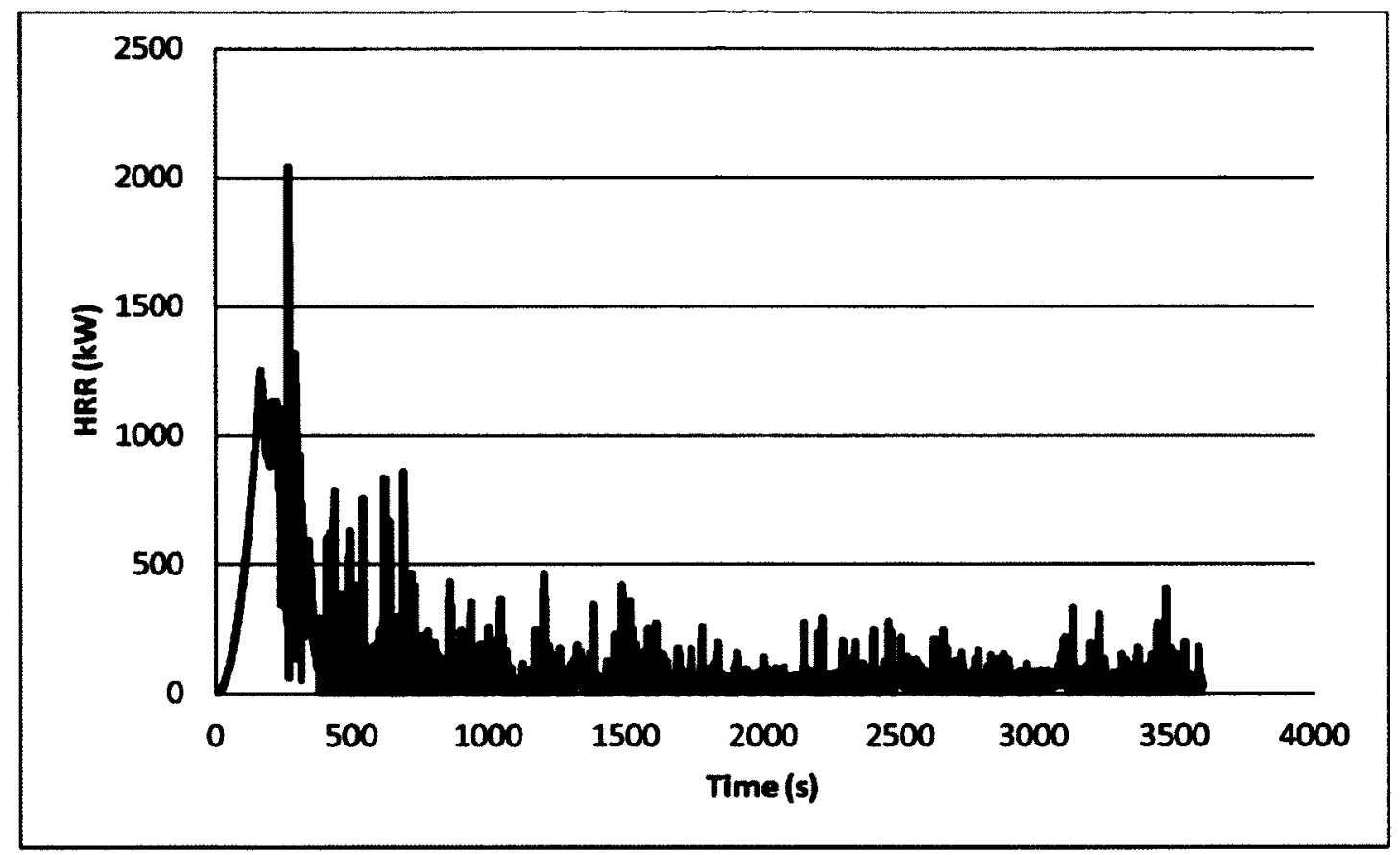

Figure 29: HRR curve for Group one Scenario five

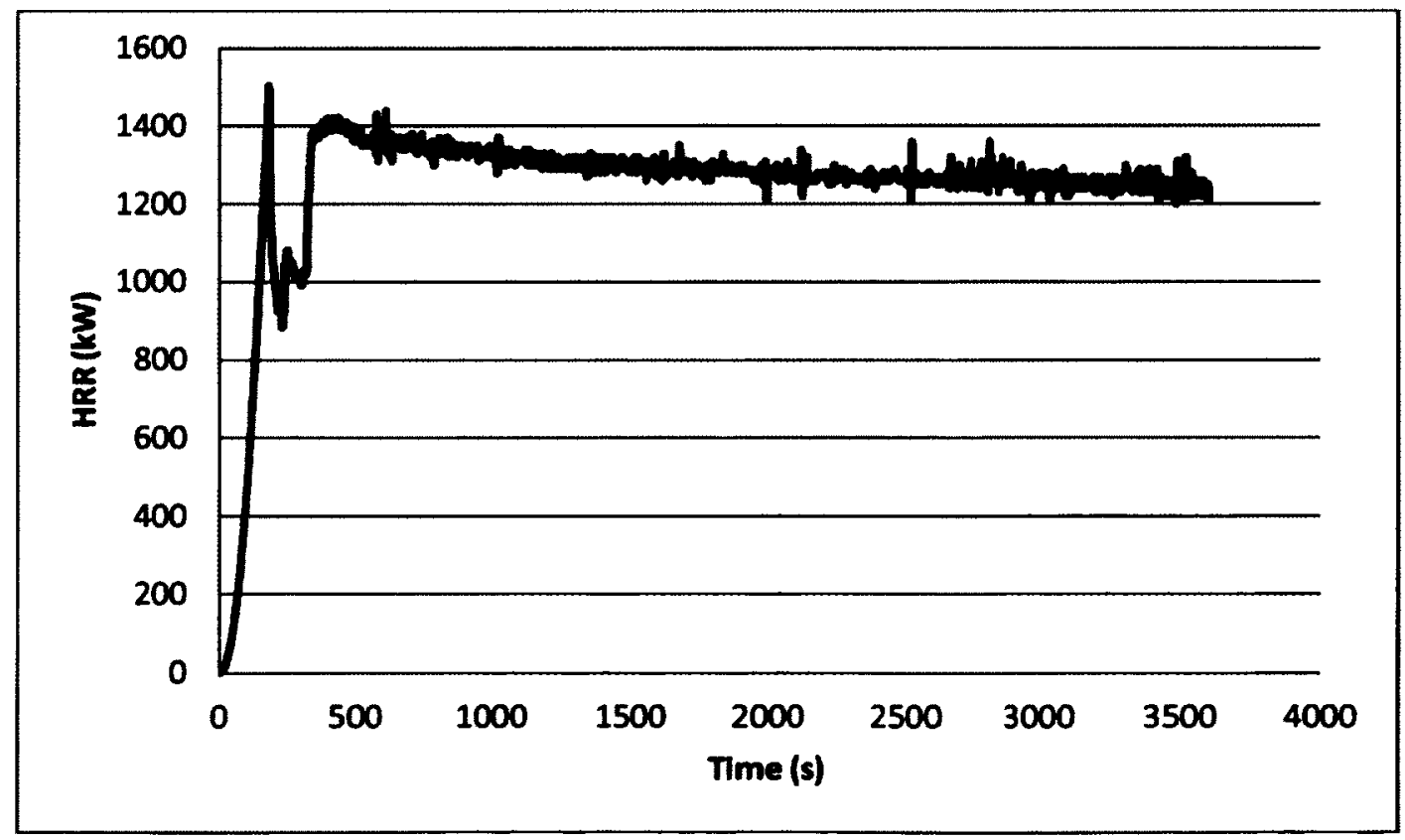

Figure 30: HRR curve for Group two Scenario five 


\subsubsection{Temperature}

As the fire grows, the temperatures in a fire compartment increase. The temperature increase recorded in the compartment of fire origin is due to convection and radiation from the fire while the temperature increase recorded for other compartments is due to smoke spread. CUrisk considers flashover to occur when the upper layer temperature reaches $600^{\circ} \mathrm{C}$. Table 36 shows the time at which flashover occurs in the model, as well as, the calculated time to flashover. As observed from the table, the time of flashover predicted by the model was higher than those estimated by calculation except for scenario two which is the living room. The maximum temperatures calculated using Law's equation [4] (refer to Table 35) were observed to be slightly lower than obtained by the model.

Table 36: Observed and predicted time to flashover for various scenarios

\begin{tabular}{lccc}
\hline & \multicolumn{3}{c}{ Time to Flashover (s) } \\
\cline { 2 - 3 } & Predicted by model & $\begin{array}{c}\text { Estimated by } \\
\text { calculation }\end{array}$ \\
\cline { 2 - 3 } & Group 1 & Group 2 & 243 \\
\hline Scenario 1 & 451 & 458 & 497 \\
Scenario 2 & 274 & 291 & 238 \\
Scenario 3 & 456 & 462 & 243 \\
Scenario 4 & 443 & 447 & 175 \\
Scenario 5 & 218 & 210 & \\
\hline
\end{tabular}

Figures 31 to 41 show the increase of the temperature of the upper layer with time for the room of fire origin, as well as, some adjacent rooms that showed increase in 
temperature. The numbers on each of the graphs refer to the numbered compartments as shown in figures 14 to 19 . Figure 31 shows the temperature profiles with time for the compartments in the apartment of fire origin for group one scenario one. The curve for the compartment of fire origin, compartment 2 , shows that temperatures in the room reaches $1360^{\circ} \mathrm{C}$ by the end of the simulation. In Chen's fire experiments for hotels and motels, the maximum temperature observed was about $1200^{\circ} \mathrm{C}$, lower than observed for this study. Smoke spread to the living room (compartment 1) caused temperatures to rise to about $550^{\circ} \mathrm{C}$. In compartments 3,4 , and 5 which are the primary bedroom, bathroom, and kitchen respectively, saw temperatures rise to about $200^{\circ} \mathrm{C}$ due to smoke spread. When the main doors are partly opened in group two scenario one, the temperature rises to $1330^{\circ} \mathrm{C}$ in the fire room by the end of the simulation (refer to Figure 32); a almost the same as when the main doors are closed. The temperature in the living room however drops slightly when the main doors are open, and the temperatures in the kitchen, secondary bedroom, and bathroom also drop. This is expected since the additional ventilation allows less hot smoke to accumulate in one compartment and also allows for the dilution of the smoke with fresh air thereby decreasing the temperature of the smoke. In scenario two of group one where the fire starts in the living room, the temperature quickly rises to $630^{\circ} \mathrm{C}$ by 280 seconds and reaches $1280^{\circ} \mathrm{C}$ by the end of the simulation. Temperatures in the bathroom and kitchen rise to $830^{\circ} \mathrm{C}$ and $790^{\circ} \mathrm{C}$ respectively. In the two bedrooms, temperatures reach $300^{\circ} \mathrm{C}$ about 450 seconds into the fire at which point windows were expected to break, providing more ventilation. By the end of the simulation, the temperatures in the bedrooms were about $560^{\circ} \mathrm{C}$. In scenario two of group 
two where the main door is open, the temperature observed in the fire room is about $1230^{\circ} \mathrm{C}$. A temporary drop in temperature is observed at the time the window breaks in the fire room in scenarios one, three, and four. In scenario five of group one where the fire is barely sustained due to oxygen depletion, the temperature in the fire compartment only reaches about $610^{\circ} \mathrm{C}$. The temperature in the fire compartment for scenario five where the main doors are partially open reaches about $1100^{\circ} \mathrm{C}$ by the end of the simulation. Figure 41 shows the temperatures recorded for compartments outside the apartment of fire origin for group two scenario one where the main doors are open. It takes 60 seconds for smoke to get from the primary bedroom, which is the room of fire origin in this scenario, to the corridor (compartment 85 ) directly in front of the apartment. This is characterized by the temperature increase observed to begin at this time. The temperature in the corridor reaches $91^{\circ} \mathrm{C}$ by the end of the simulation. It takes smoke 168 seconds to get from the fire compartment to the staircase lobbies (compartments 73 and 74) on the same floor where the temperature rises to about $35^{\circ} \mathrm{C}$ by the end of the simulation. At 166 seconds, smoke reaches the other apartments on the same floor (compartments 6, 7,8,9, and 10) where temperatures rise to about $25^{\circ} \mathrm{C}$ by the end of the simulation. At about 640 seconds smoke reaches the corridor on the second floor (floor above room of fire origin) and causes a temperature rise of less than $2^{\circ} \mathrm{C}$ by the end of the simulation. 


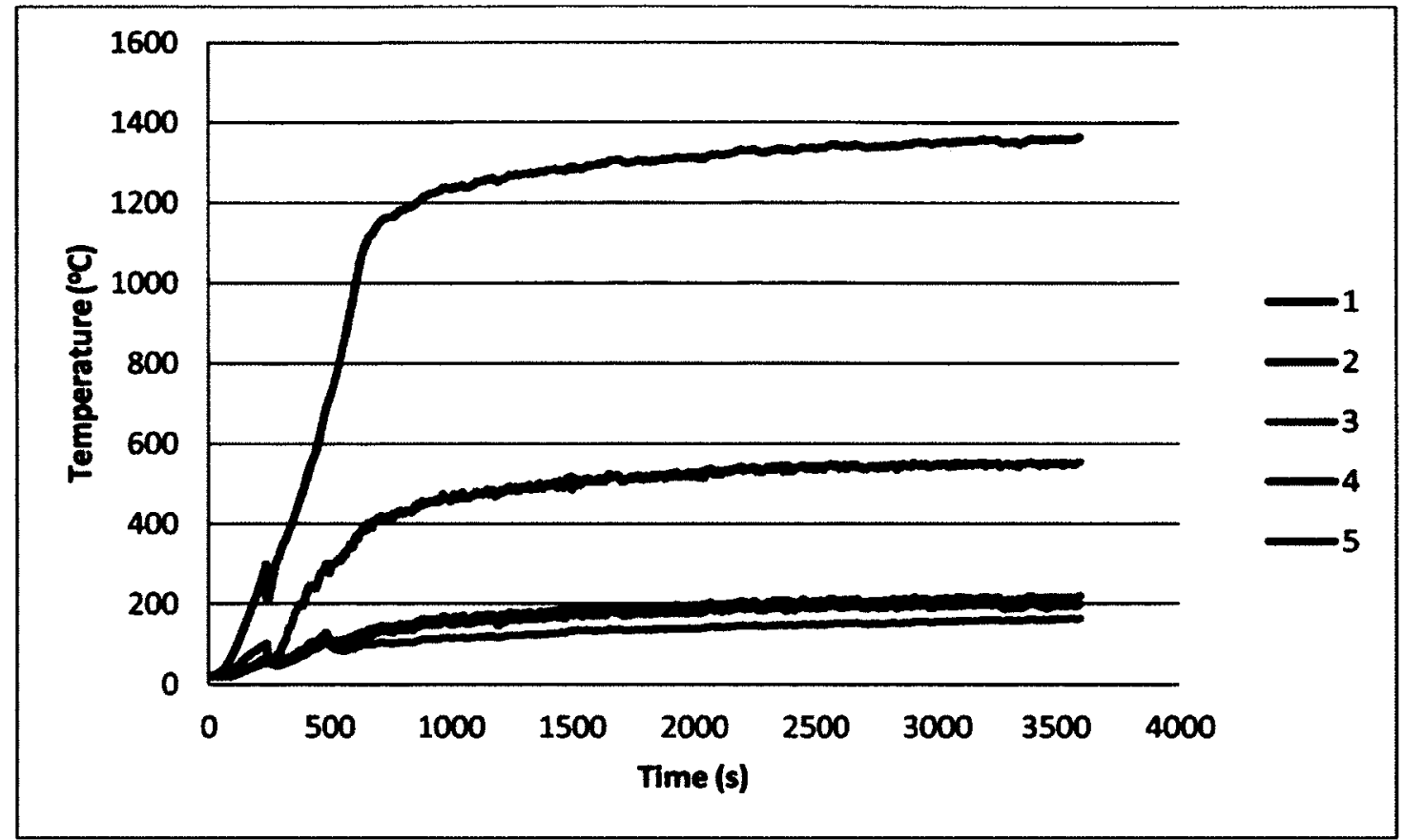

Figure 31: Upper layer temperature for compartments in apartment of fire origin for Group one Scenario one

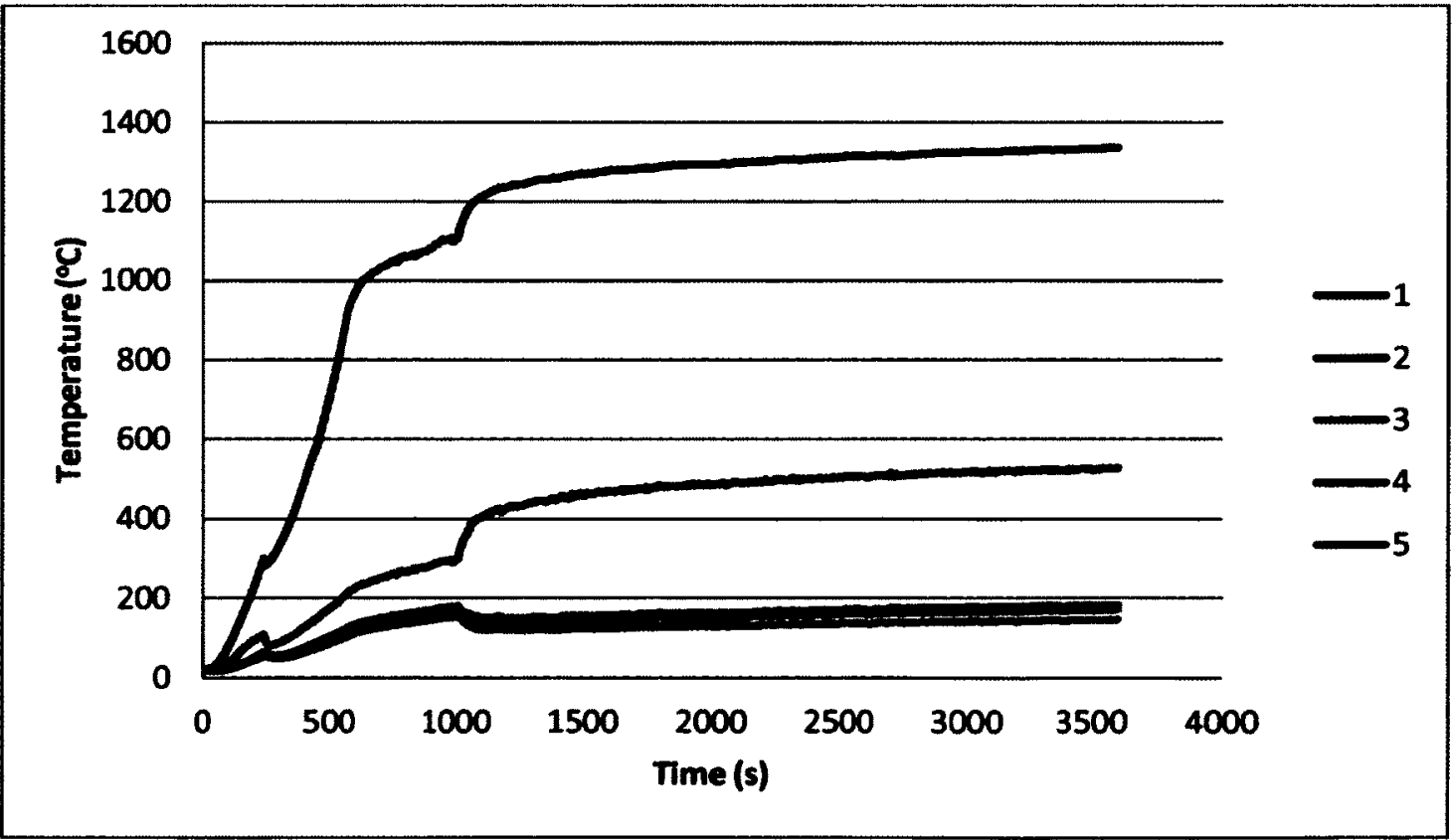

Figure 32: Upper layer temperature for compartments in apartment of fire origin for Group two Scenario one 


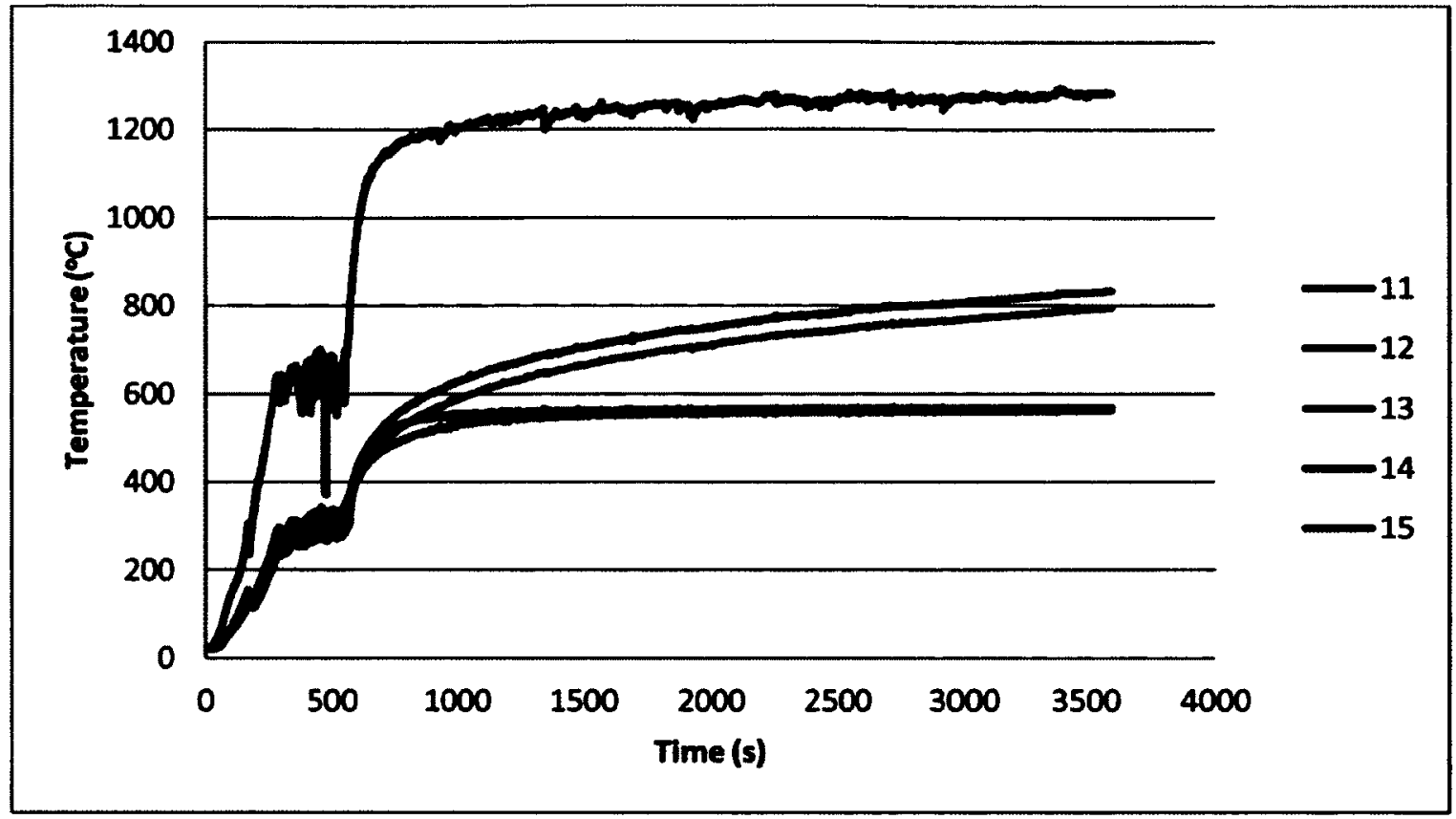

Figure 33: Upper layer temperature for compartments in apartment of fire origin for Group one Scenario two

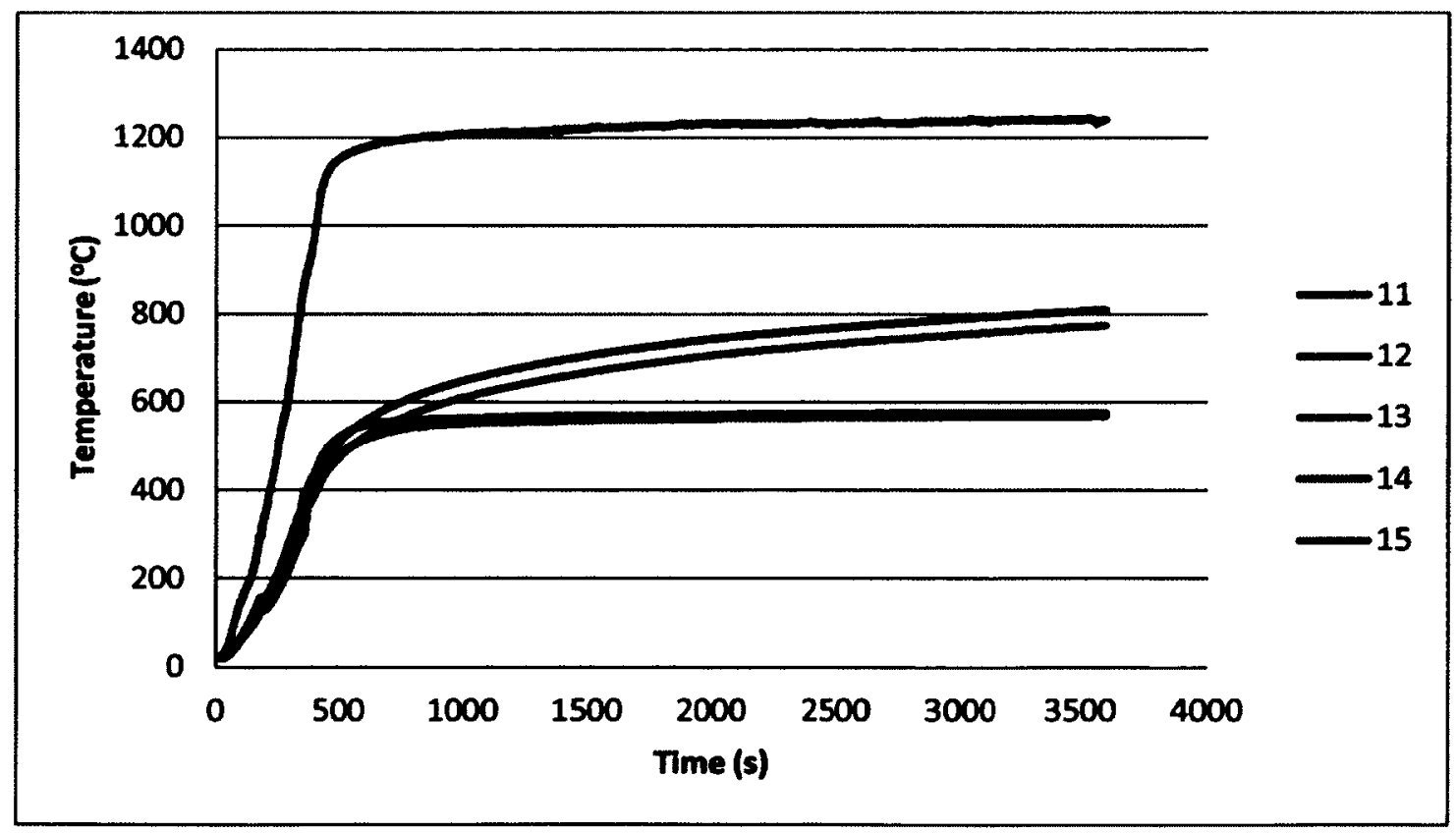

Figure 34: Upper layer temperature for compartments in apartment of fire origin for Group two Scenario two 


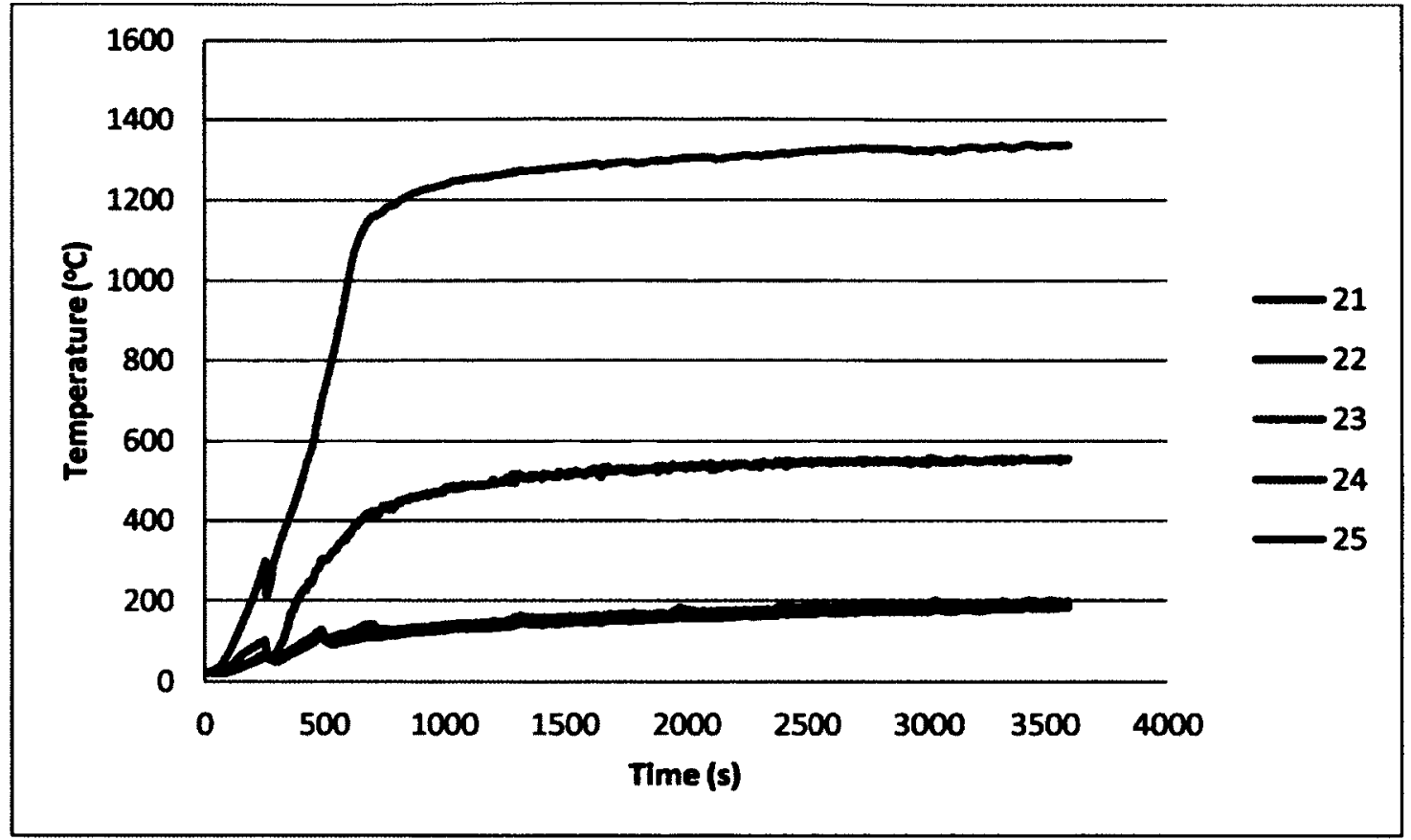

Figure 35: Upper layer temperature for compartments in apartment of fire origin for Group one Scenario three

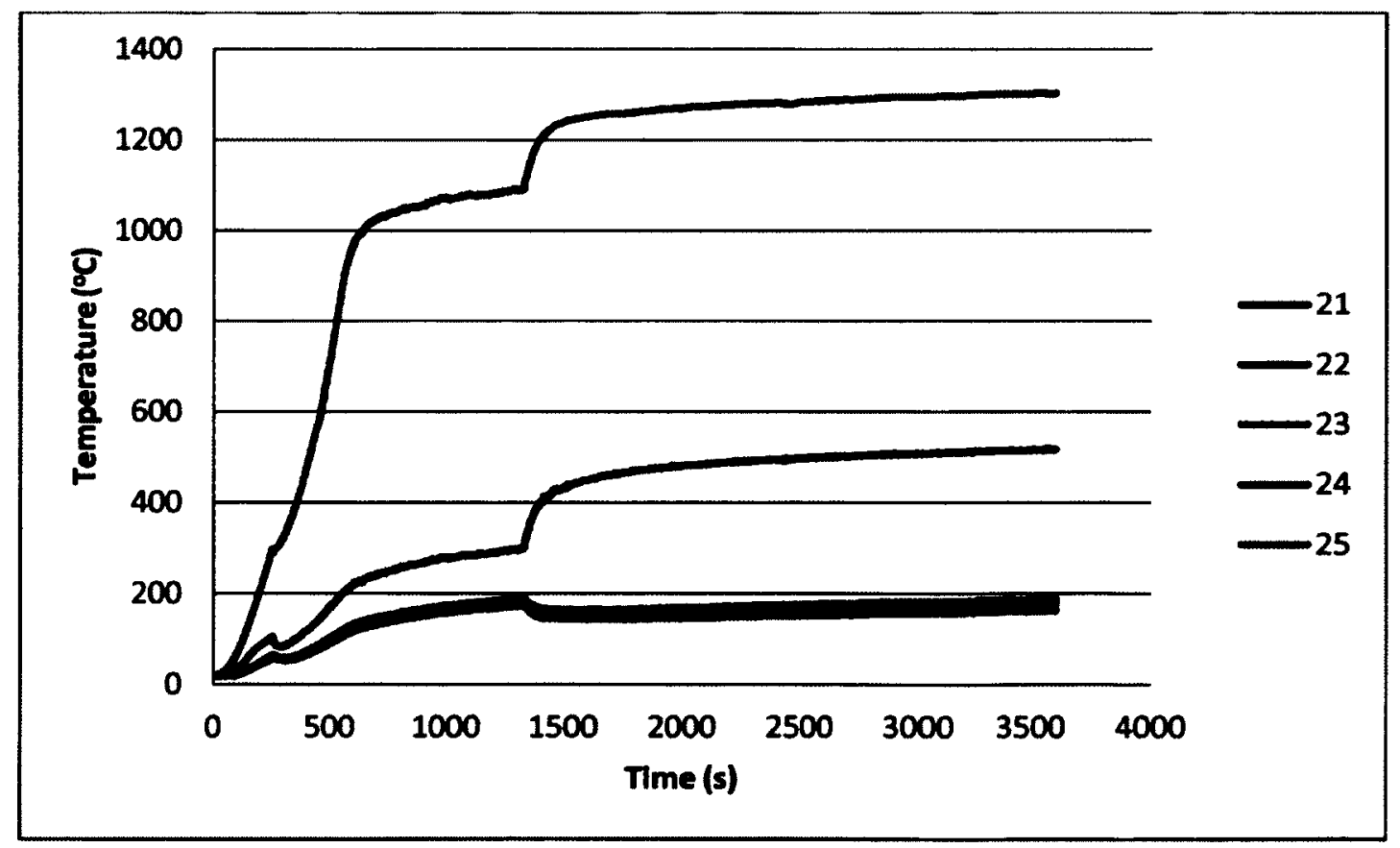

Figure 36: Upper layer temperature for compartments in apartment of fire origin for Group two Scenario three 


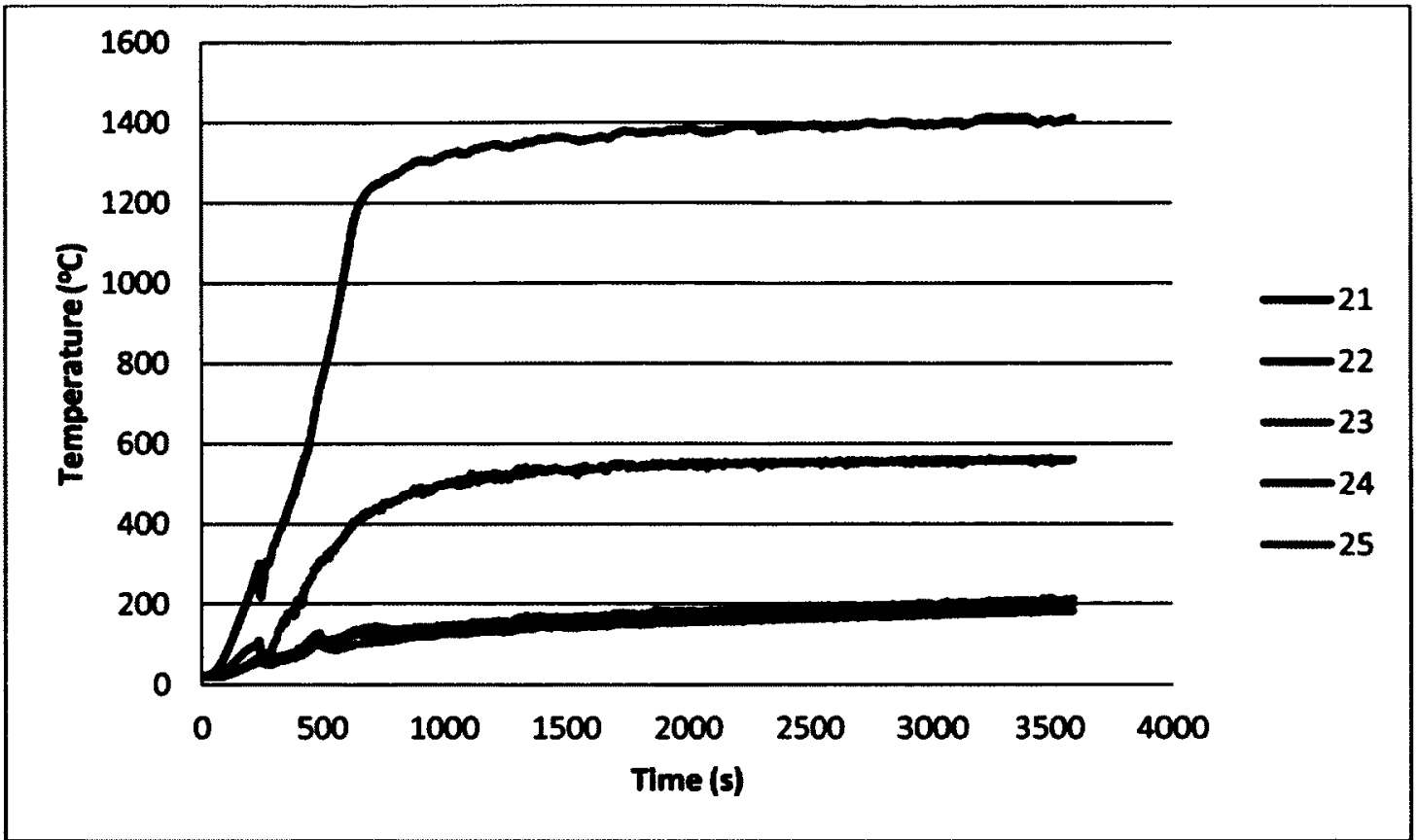

Figure 37: Upper layer temperature for compartments in apartment of fire origin for Group one Scenario four

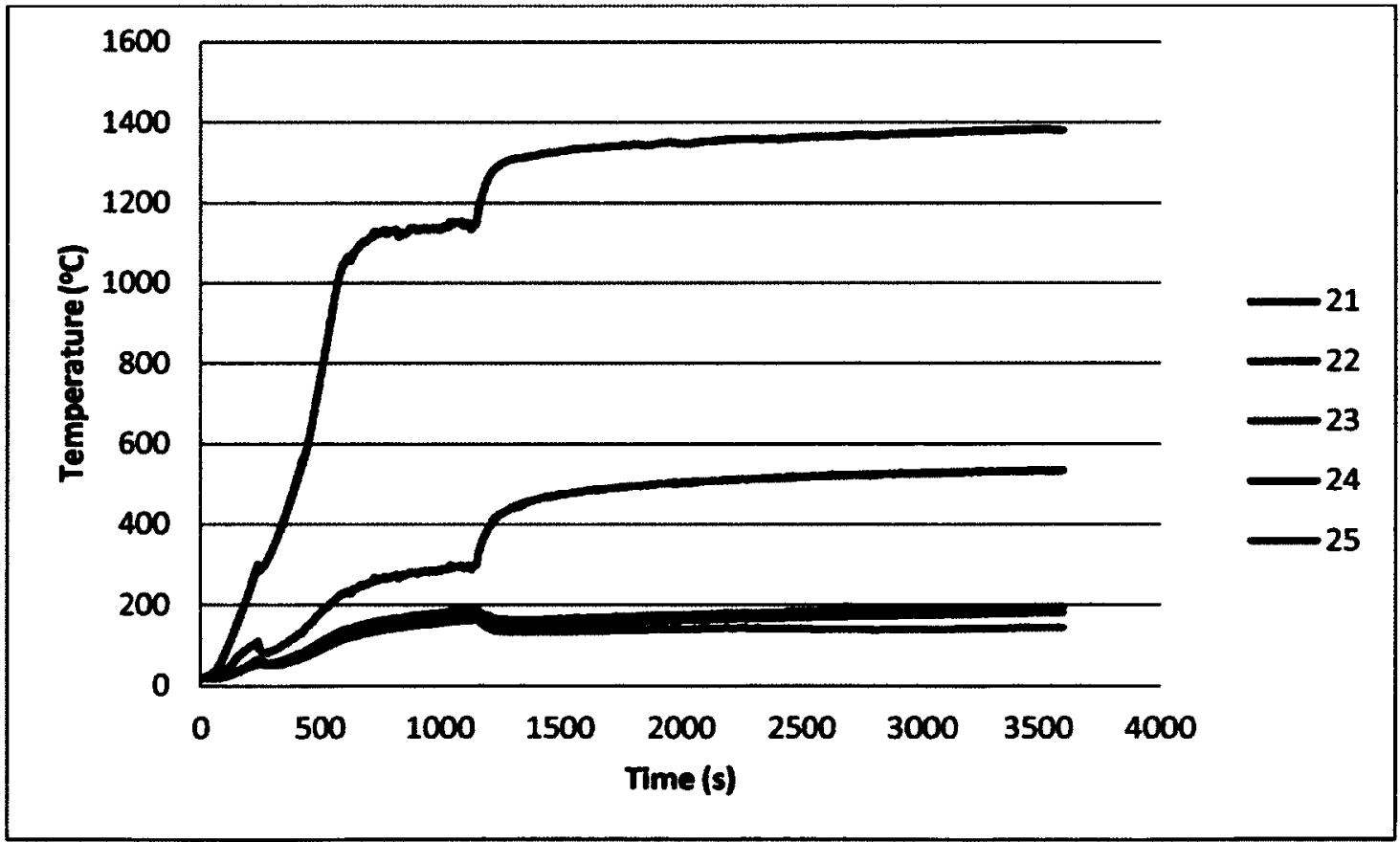

Figure 38: Upper layer temperature for compartments in apartment of fire origin for Group two Scenario four 


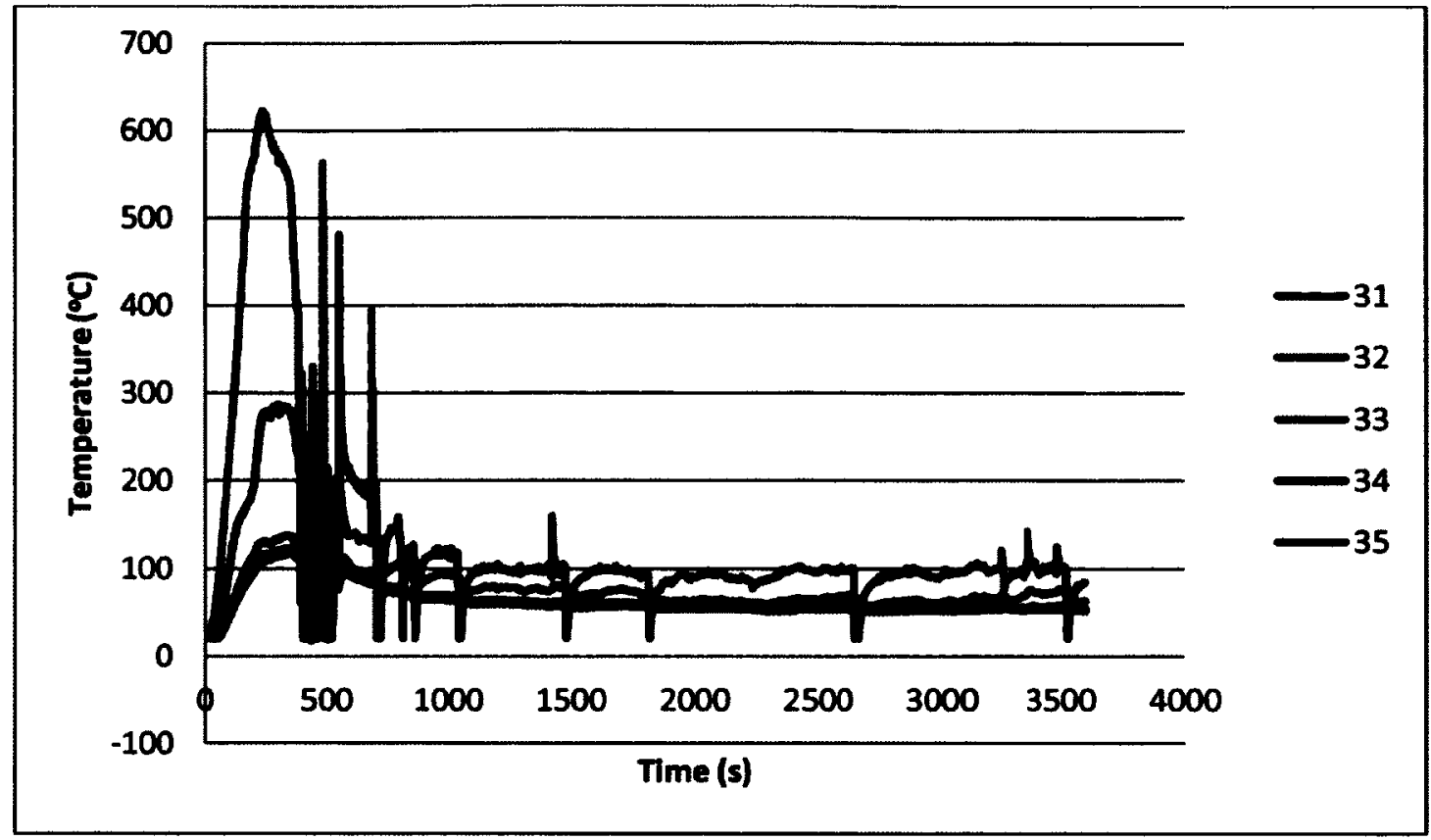

Figure 39: Upper layer temperature for compartments in apartment of fire origin for Group one Scenario five

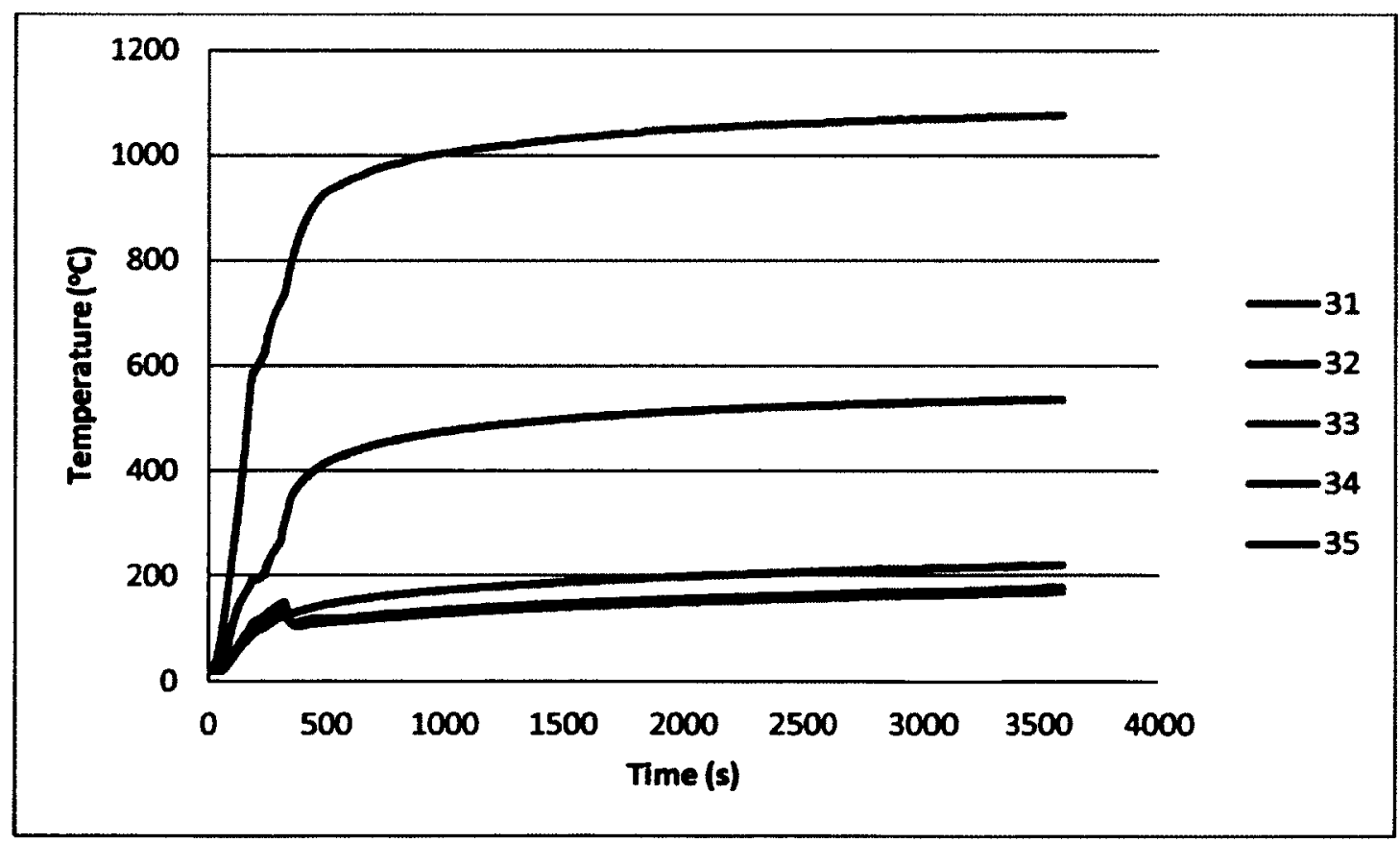

Figure 40: Upper layer temperature for compartments in apartment of fire origin for Group two Scenario five 


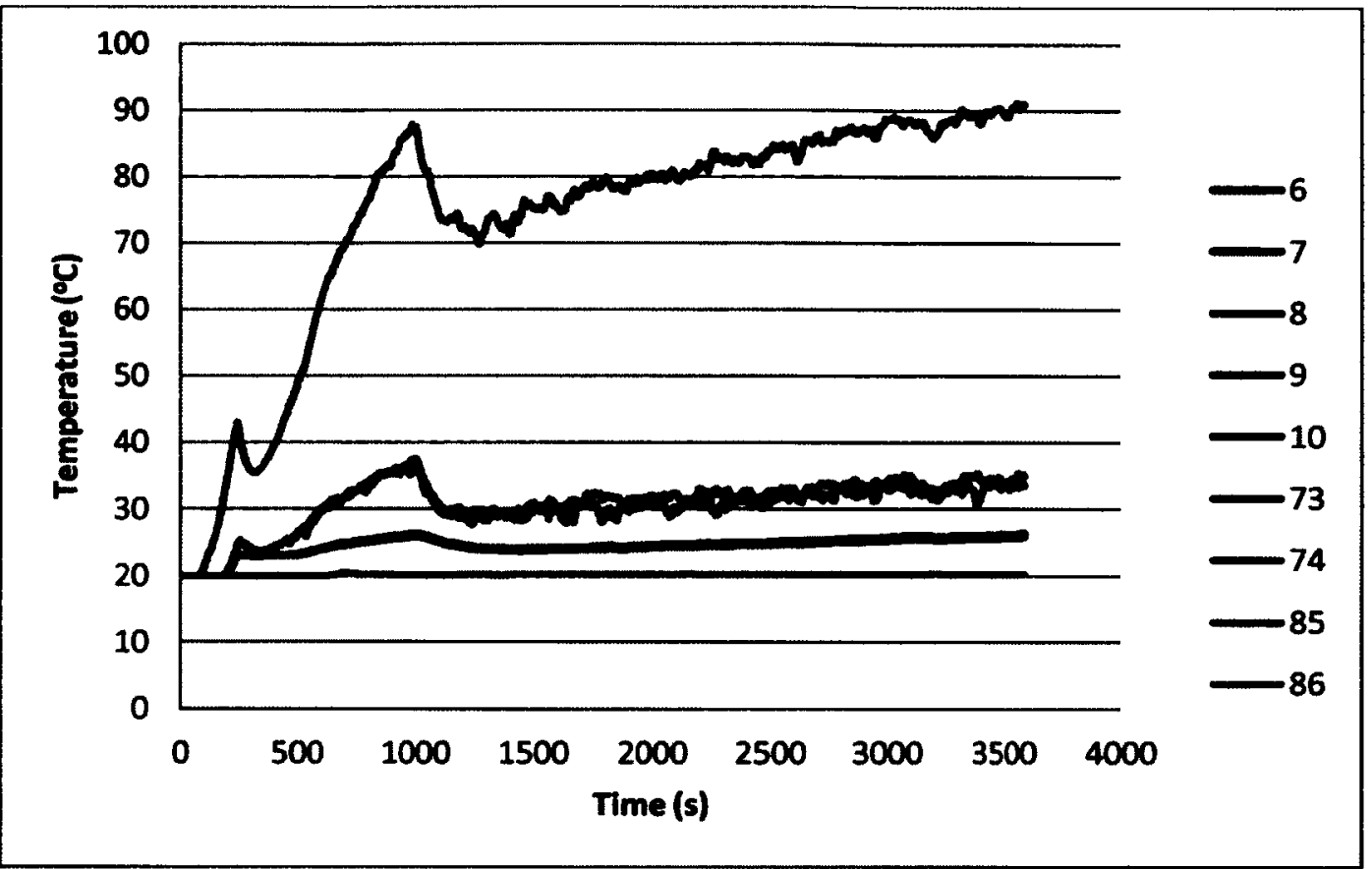

Figure 41: Upper layer temperature for selected compartments outside apartment of fire origin for Group two Scenario one

\subsubsection{Smoke Interface Height}

As the fire develops fire gases are produced which fill the upper layer of the room. As more gases are produced, the layer drops and spreads through the various compartments. Figure 42 shows the interface height with time for group one scenario one. The interface layer drops rapidly in the fire compartment (compartment 2) after ignition; the model predicts that the smoke layer drops to $2.0 \mathrm{~m}$ above the ground in only 24 seconds and to $0.7 \mathrm{~m}$ above the ground by about 220 seconds. About 230 seconds into the fire, the window in the fire compartments breaks, causing the smoke layer to rise briefly to $1.55 \mathrm{~m}$ above the ground. The smoke layer finally drops to and levels off at $0.9 \mathrm{~m}$ until the end of the simulation. The smoke layer in the living room (compartment 1) begins to drop 20 seconds into the fire, drops to $0.2 \mathrm{~m}$ at 230 seconds and finally rises to $1.8 \mathrm{~m}$ above the 
ground after the window in the bedroom breaks. Smoke levels in the primary bedroom, bathroom, and kitchen compartments begin to drop after about 60 seconds and rapidly fill the compartments. The window in the living room also breaks at about 510 seconds at which time the smoke layer in the primary bedroom, bathroom, and kitchen are observed to rise. The smoke level in the primary bedroom gradually drops again as the fire progresses. The smoke layer profiles observed for selected compartments for group two scenario two are shown in Figure 43. The fire origin in this scenario is the living room (compartment 11). Immediately following ignition the smoke layer begins to drop in the living room; it reaches $2.0 \mathrm{~m}$ above the floor in 30 seconds and drops to $0.9 \mathrm{~m}$ above the floor by the end of the simulation. Just like with scenario one, the smoke layer in this scenario rise briefly after the window in the living room breaks at 180 seconds. Smoke levels in the other compartments (compartments 12,13,14, and 15) within the apartment of fire origin begin to drop after 38 seconds. The windows in the bedrooms (compartments 12 and 13) break around 320 seconds causing the smoke layers in these compartments to rise to about $1.8 \mathrm{~m}$ by the end of the simulation. The smoke layers in the kitchen and bathroom fluctuate briefly after the windows break but smoke fills the compartments almost completely by the end of the simulation. The graph also shows the change in smoke levels with time for apartments outside the room of fire origin, as well as, for the floor above. A similar trend is observed for group two scenario five shown in Figure 44. 


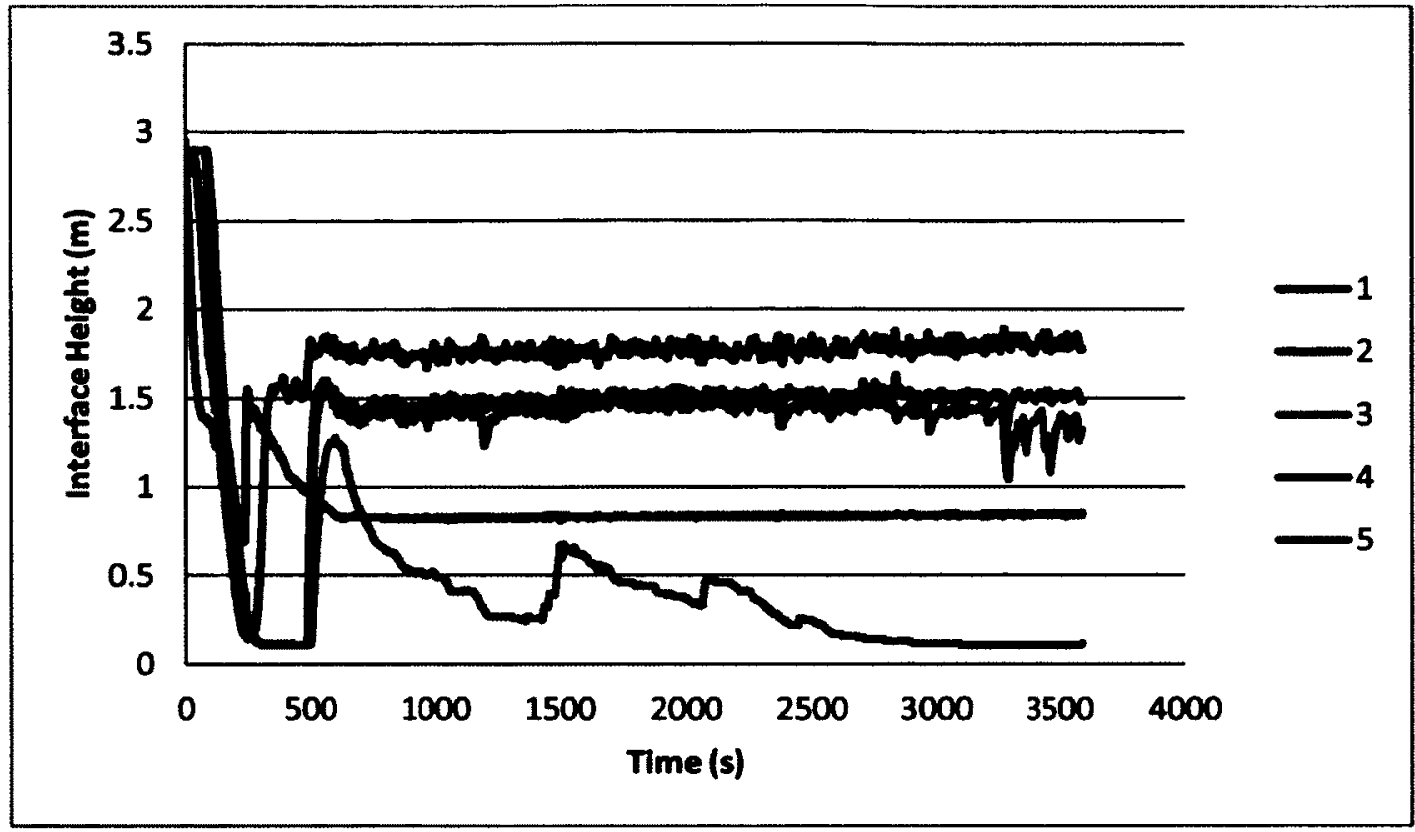

Figure 42: Interface Height for Group one Scenario one for selected compartments

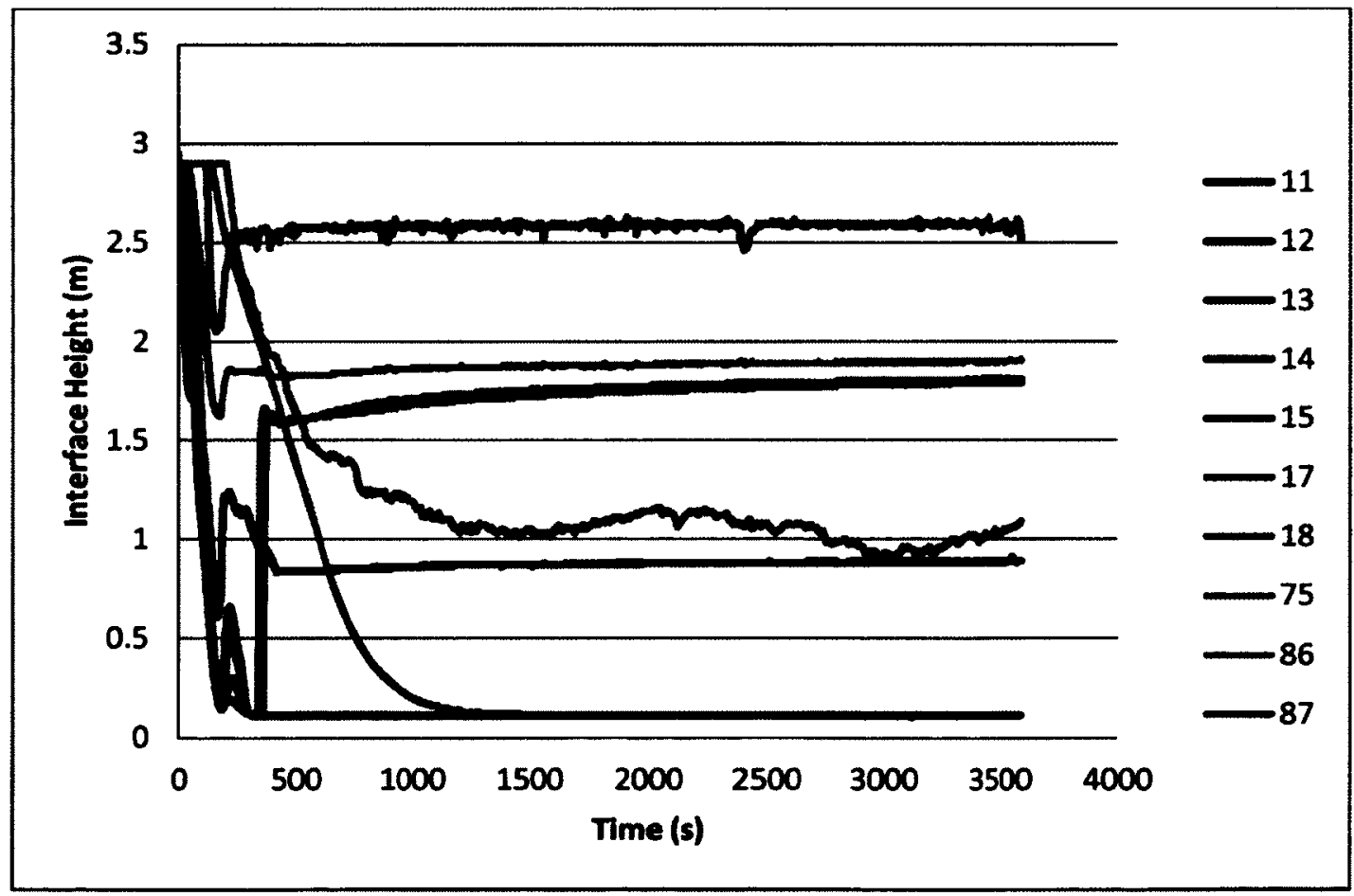

Figure 43: Interface height for Group two Scenario two for selected compartments 


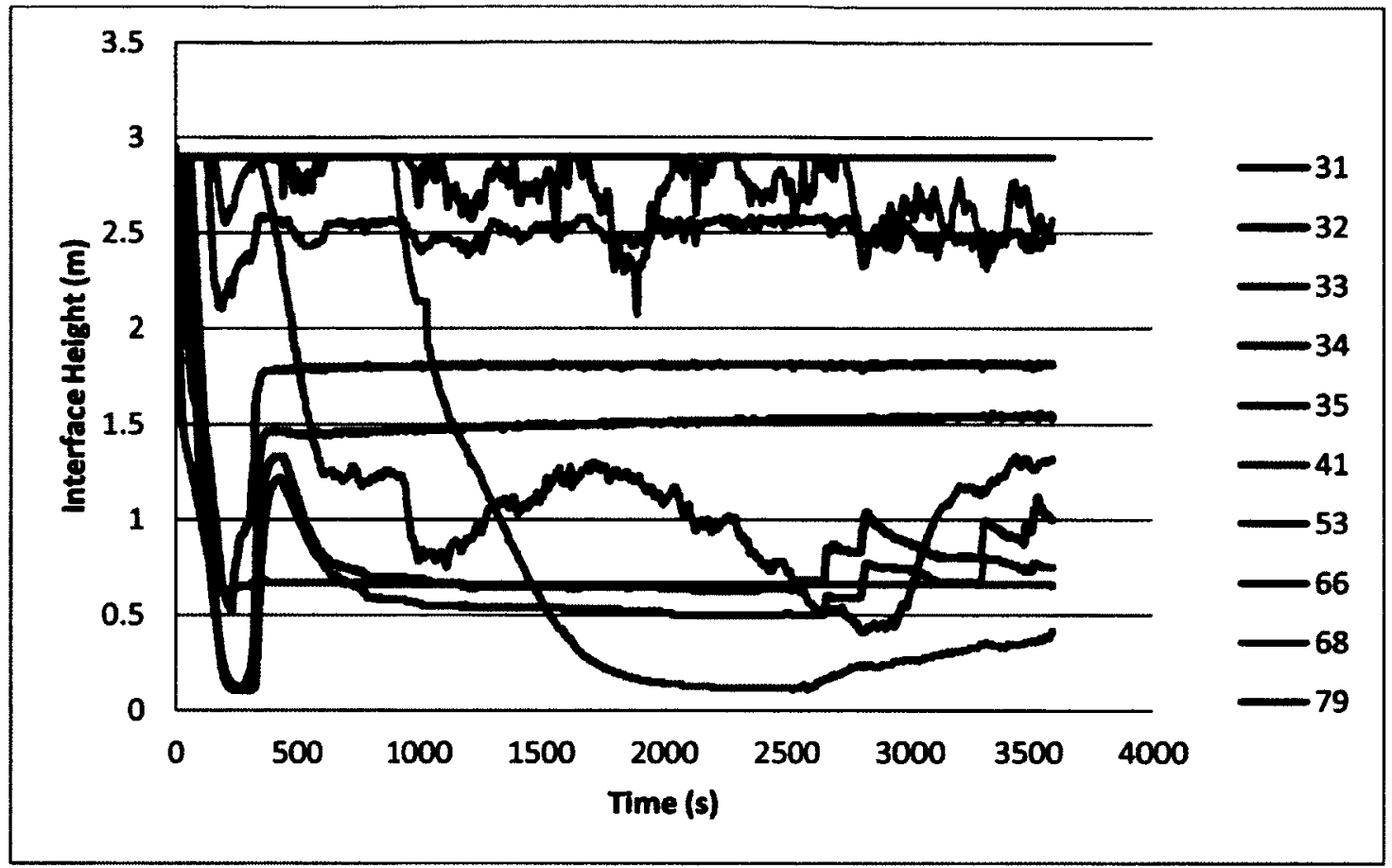

Figure 44: Interface Height for Group two Scenario five for selected compartments

\subsubsection{Oxygen Levels}

Oxygen levels begin to drop as fire progresses and smoke spreads through the various compartments. Figure 45 shows the oxygen profiles with time for group one scenario one. Oxygen levels begin to drop rapidly in the fire compartment (compartment 2) following ignition; it reduces from $23 \%$ to $4 \%$ in 620 seconds and then levels off until the end of the simulation. There are slight temporary increases in oxygen levels around 230 seconds and 510 seconds when the windows in the room of fire origin and the living room break. Oxygen levels in the living room (compartment 1) do not begin to drop until 36 seconds into the fire. Levels in the other compartments begin to drop after about 88 seconds. As expected, oxygen levels outside the apartment of fire origin remain at $23 \%$ since the main doors are closed in this scenario and smoke does not spread to those 
compartments. The oxygen profiles observed for selected compartments for scenario two of group two is shown in Figure 46. The room of fire origin in this scenario is the living room (compartment 11). Again oxygen levels in the fire compartment begin to drop immediately following ignition; it drops to $4.5 \%$ in 460 seconds and then levels off until the end of the simulation. Oxygen levels in compartments 14 and 15 begin to drop after about 30 seconds and drop just as rapidly as in the fire compartment to reach about $4.5 \%$ by the end of the simulation. Oxygen levels in the bedrooms were observed to drop to about $7.5 \%$ and then increase to $14.5 \%$ after the windows break. Oxygen levels in the corridor (compartment 86) directly in front of the apartment of fire origin begin to drop after 36 seconds and drop to $14 \%$ by end of the simulation. In compartments 17 and 18 which are apartments on the same floor as the compartment of fire origin, the oxygen levels begin to drop after 122 seconds and only drop to $18.0 \%$ by the end of the simulation; this is in spite of high levels of smoke recorded in these compartments (refer to Figure 43) implying that smoke reaching these compartments are very dilute. Oxygen in the staircase lobby (compartment 75 ) drops to $19.5 \%$ while that in the corridor (compartment 87 ) on the floor above only drops to $21 \%$. A similar trend is observed for group two scenario five shown in Figure 47. The curve for the staircase (compartment 66) on the floor below shows that the smoke does not spread to that floor. 


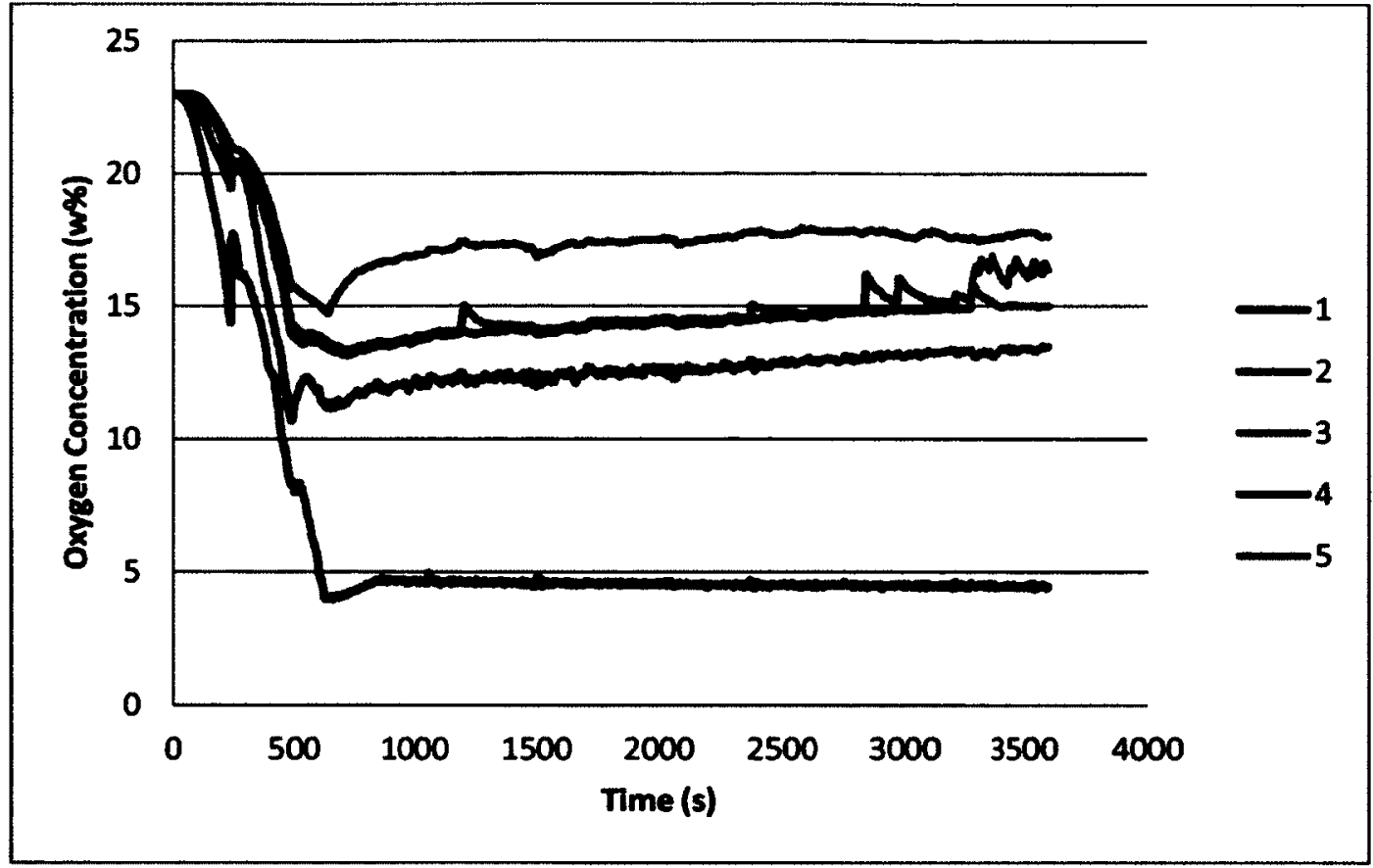

Figure 45: Oxygen concentration in upper layer for selected compartments for Group one Scenario one

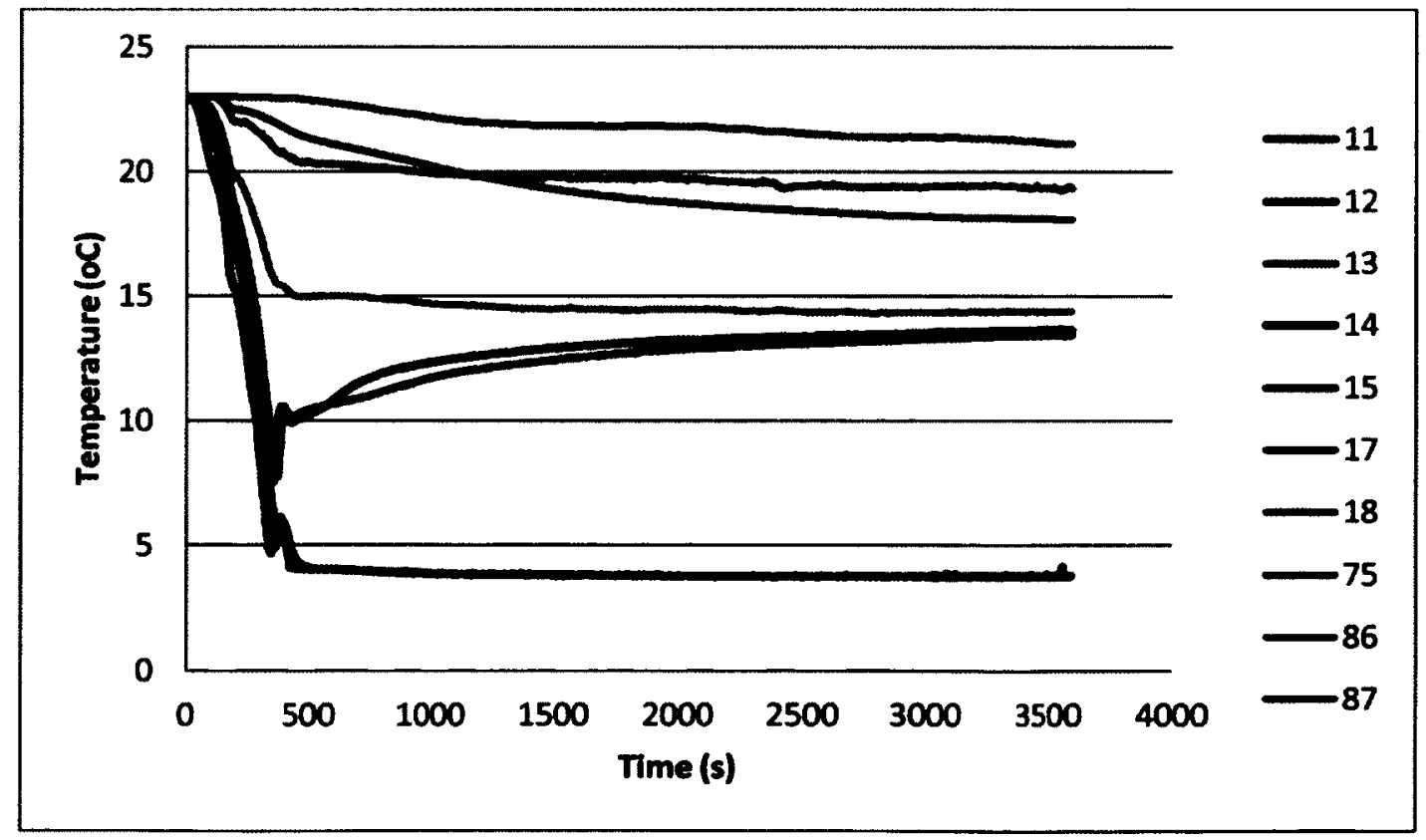

Figure 46: Orygen concentration in upper layer for selected compartments for Group two Scenario two 


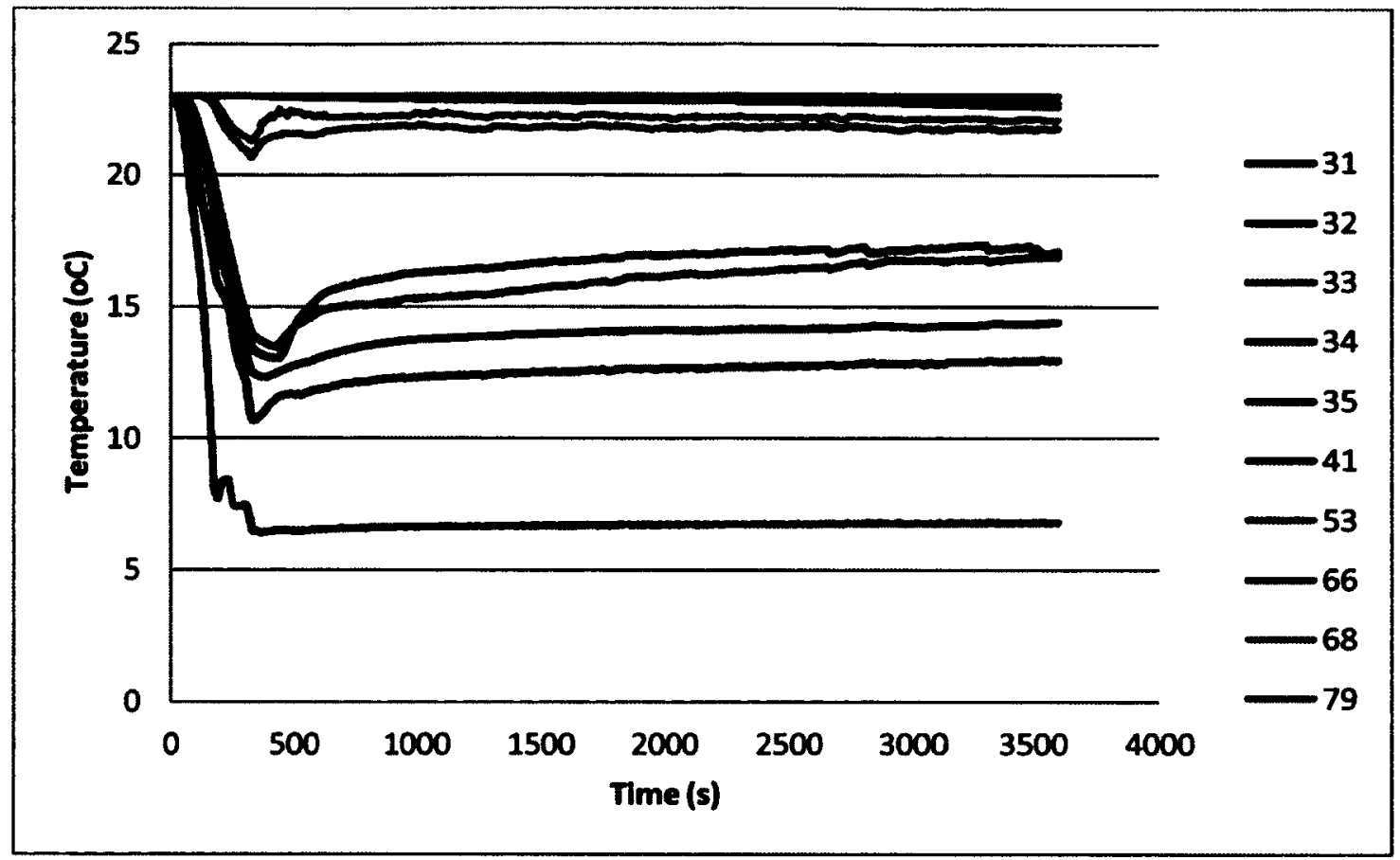

Figure 47: Oxygen concentration in upper layer for Group two Scenario five for selected compartments

\subsection{5 $\mathrm{CO}_{2}$ Concentration}

As smoke spreads through the various compartments $\mathrm{CO}_{2}$ levels rise and may reach toxic levels. Figure 48 shows the $\mathrm{CO}_{2}$ profile with time for group one scenario one. $\mathrm{CO}_{2}$ levels rise rapidly in the fire compartment (compartment 2) following ignition; it increases to $14.1 \%$ in 620 seconds, drops to $13.5 \%$, and then levels off until the end of the simulation. $\mathrm{CO}_{2}$ levels in the living room (compartment 1) begin to rise 30 seconds into the fire. Levels in the other compartments begin to rise after about 88 seconds, at the same time at which oxygen levels were observed to start dropping. Since the main doors are closed in this scenario, smoke does not spread to other compartments and therefore $\mathrm{CO}_{2}$ levels do not change outside the apartment of fire origin. The $\mathrm{CO}_{2}$ profiles observed for selected compartments for group two scenario two are shown in Figure 49. The room of fire origin 
in this scenario is the living room (compartment 11). Immediately following ignition, $\mathrm{CO}_{2}$ concentration begins to rise in the living room; it reaches to $14.5 \%$ in 340 seconds, and rise to and level off at $15 \%$ until the end of the simulation. $\mathrm{CO}_{2}$ levels in compartments 14 and 15 rise rapidly to about $13.6 \%$ in 360 seconds and reach $15 \%$ by the end of the simulation. $\mathrm{CO}_{2}$ levels in the corridor (compartment 86) directly in front of the apartment of fire origin increase to $7 \%$ by the end of the simulation. As it can be seen from the graph, the smoke spreads to compartments 17 and 18, which are apartments on the same floor as the compartment of fire origin, and also to the staircase lobby (compartment 75) as well as the floor above (compartment 87). A similar trend is observed for group two scenario four shown in Figure 50. The curve for the staircase (compartment 66) on the floor below confirms that smoke does not spread to that floor.

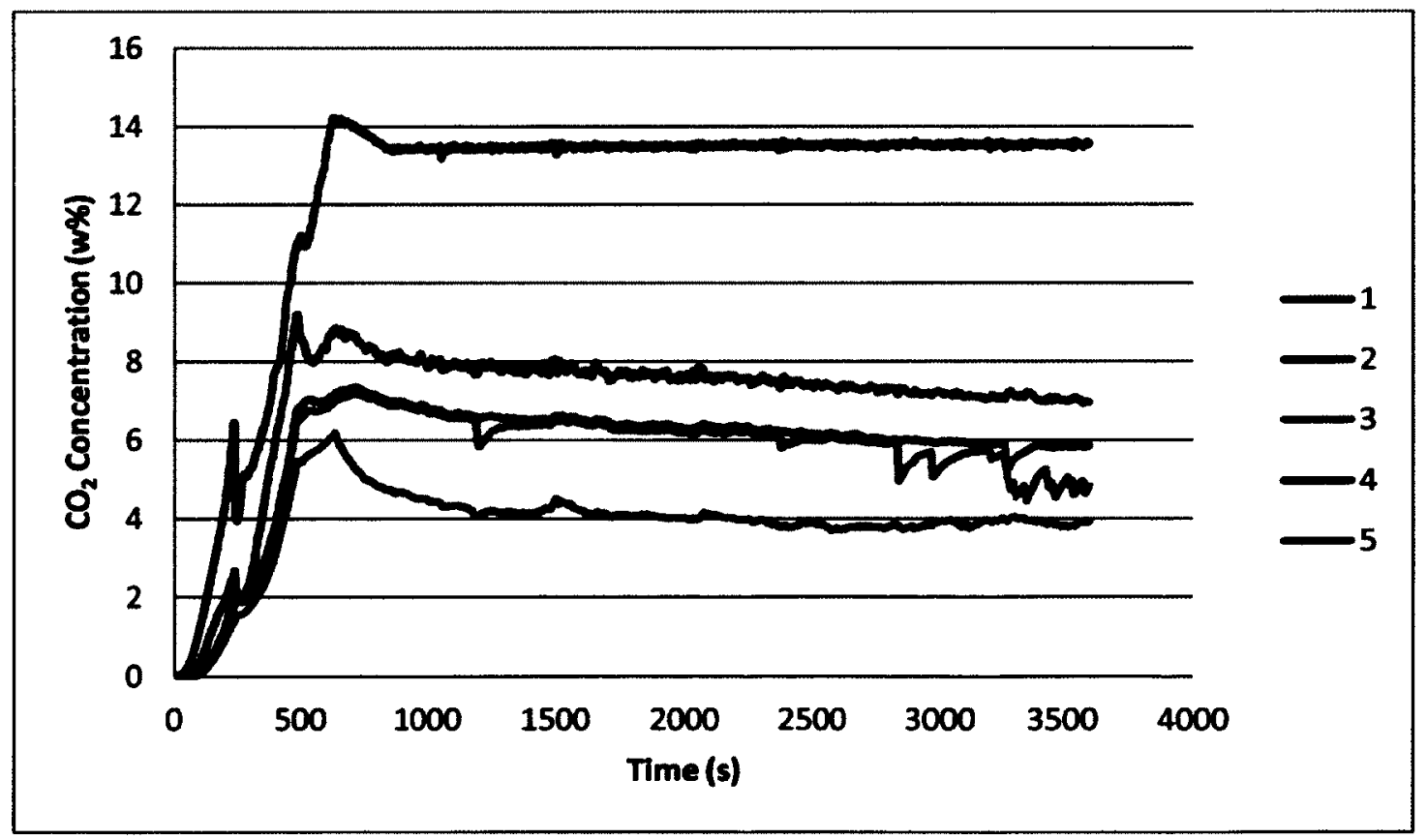

Figure 48: $\mathrm{CO}_{2}$ concentration in upper layer for Group one Scenario one for selected compartments 


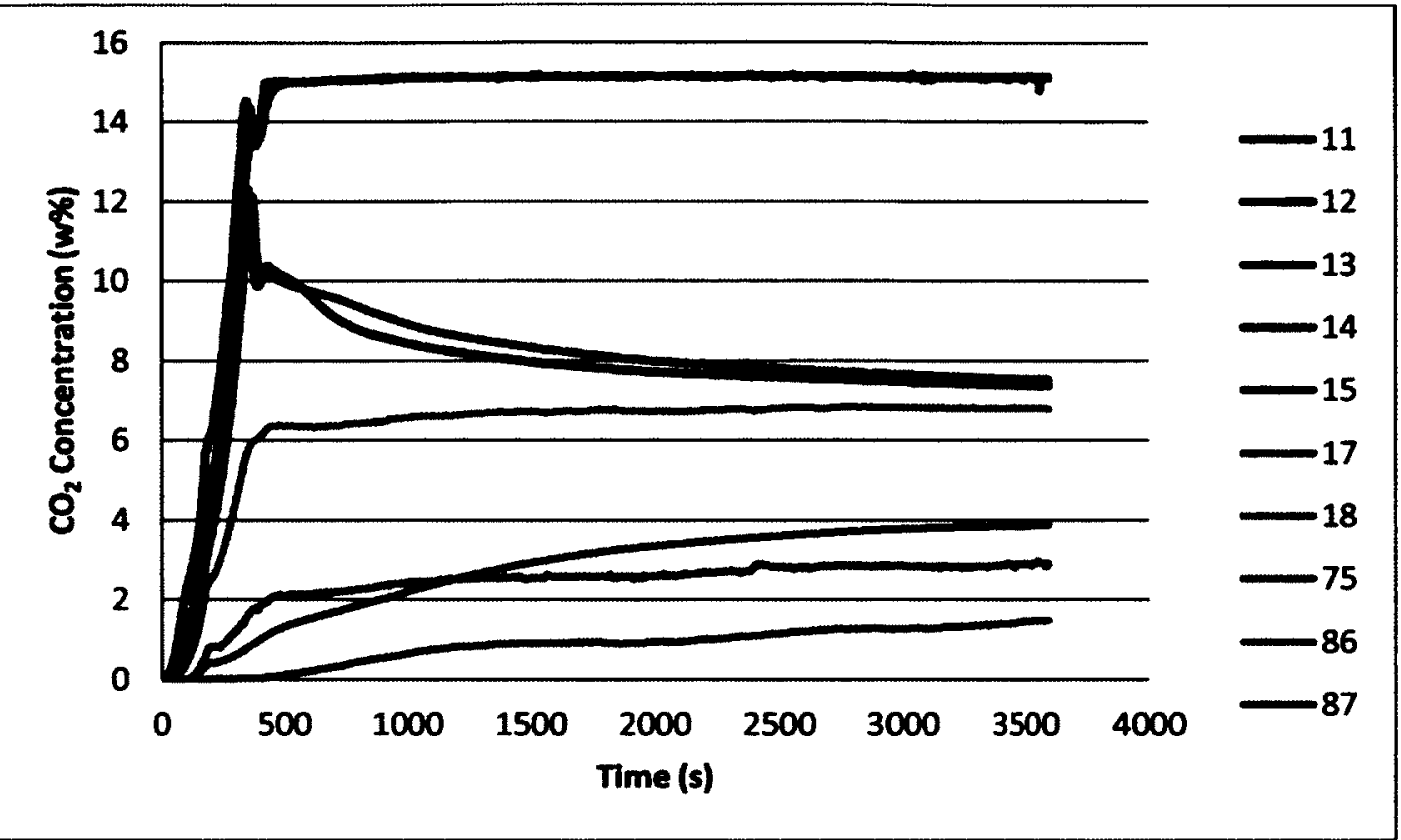

Figure 49: $\mathrm{CO}_{2}$ concentration in upper layer for Group two Scenario two for selected compartments

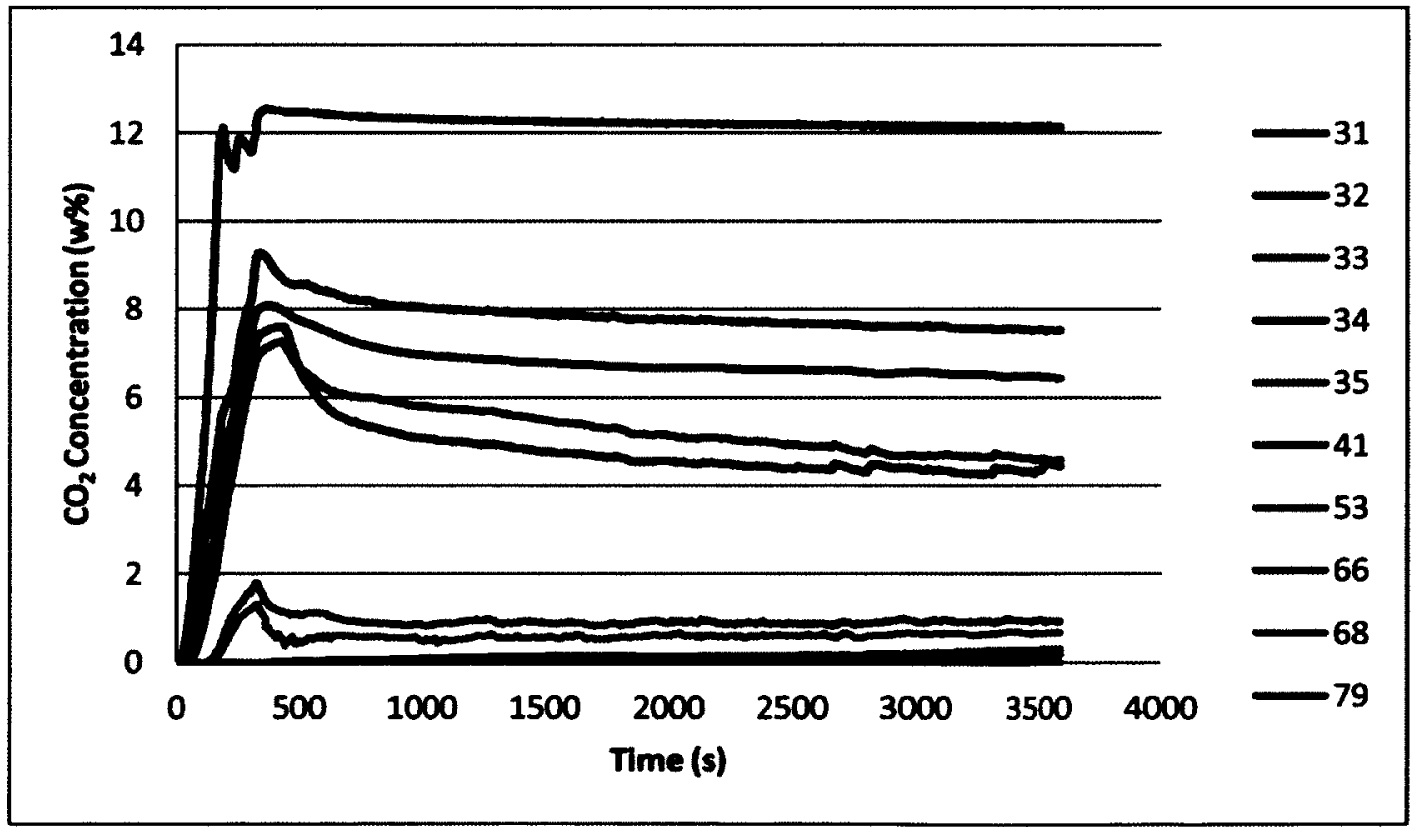

Figure 50: $\mathrm{CO}_{2}$ concentration in upper layer for Group two Scenario five for selected compartments 


\subsubsection{CO and Soot Concentrations}

Figures 51 to 56 show the amount of $\mathrm{CO}$ and soot produced during the 1800 seconds of the simulation. The curves for $\mathrm{CO}$ and soot production have the same shape as those for $\mathrm{CO}_{2}$ production. The levels increase rapidly immediately following ignition in the fire compartment and then level off as the fire reaches steady state burning. The levels of $\mathrm{CO}$ and soot in the apartment of fire origin are higher by the end of the simulation than the levels in other compartments in the building. The curves confirm that smoke does not spread to floors below the room of fire origin.

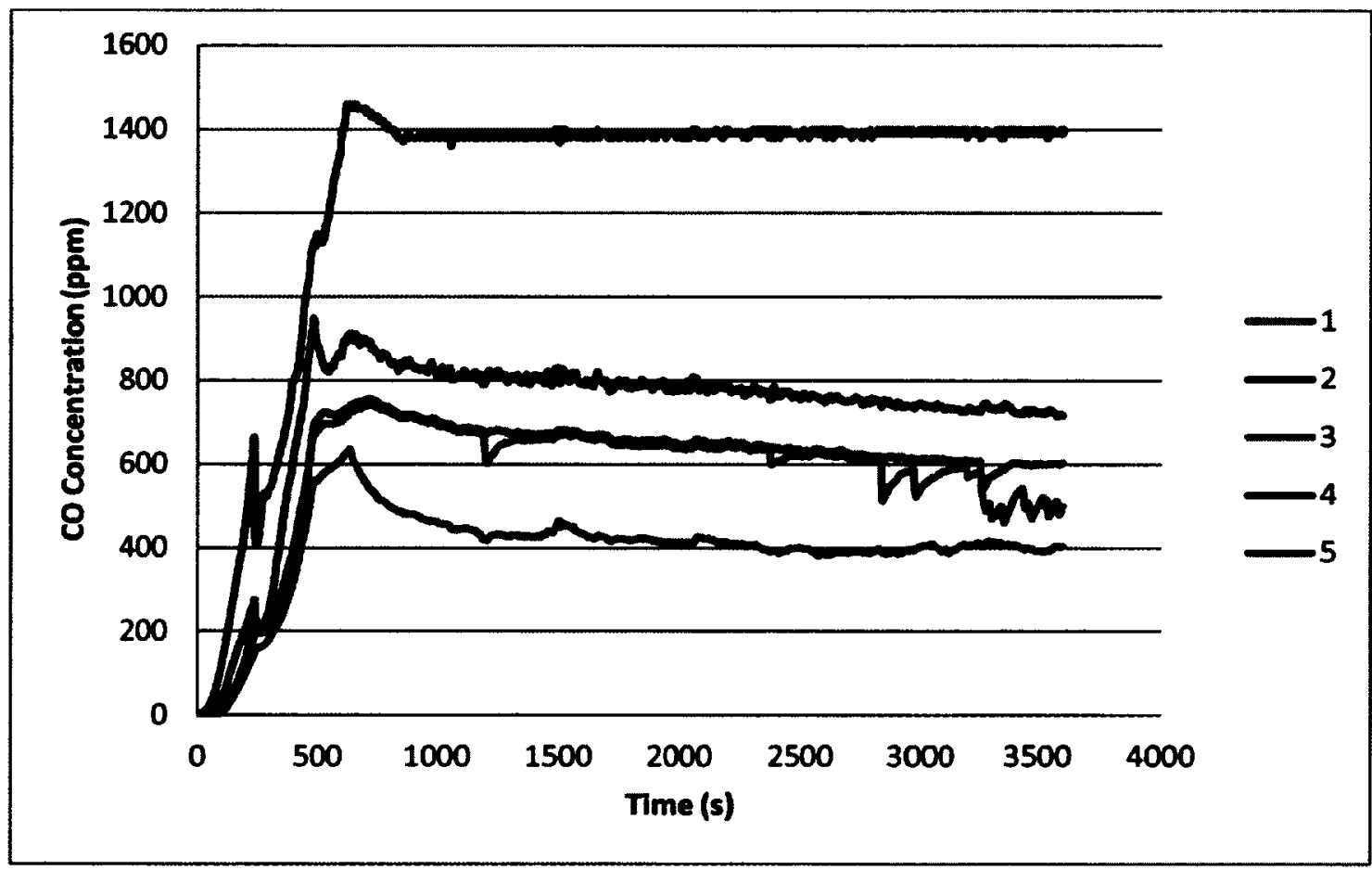

Figure 51: CO concentration in upper layer for Group one Scenario one for selected compartments 


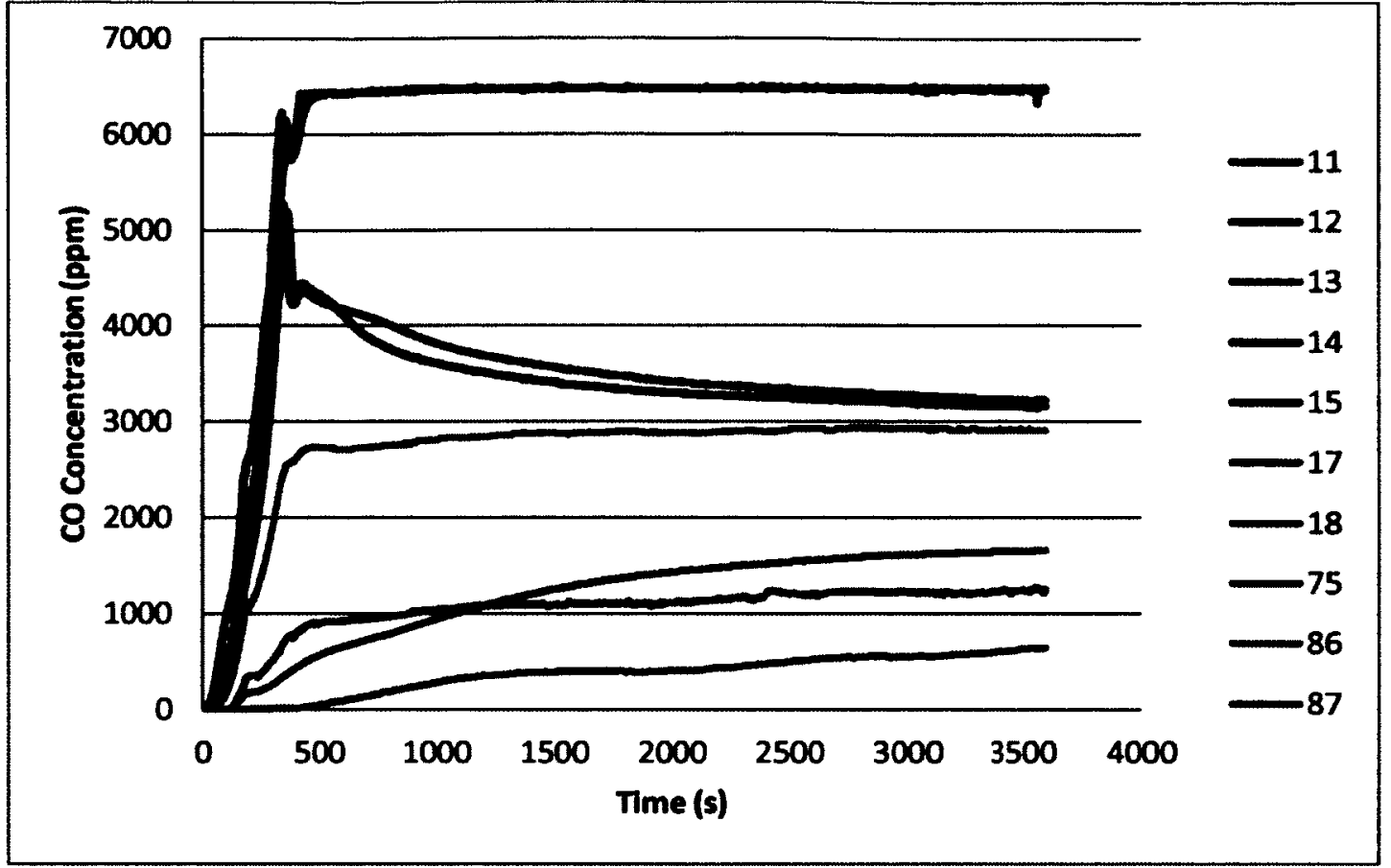

Figure 52: CO concentration in upper layer for Group two Scenario two for selected compartments

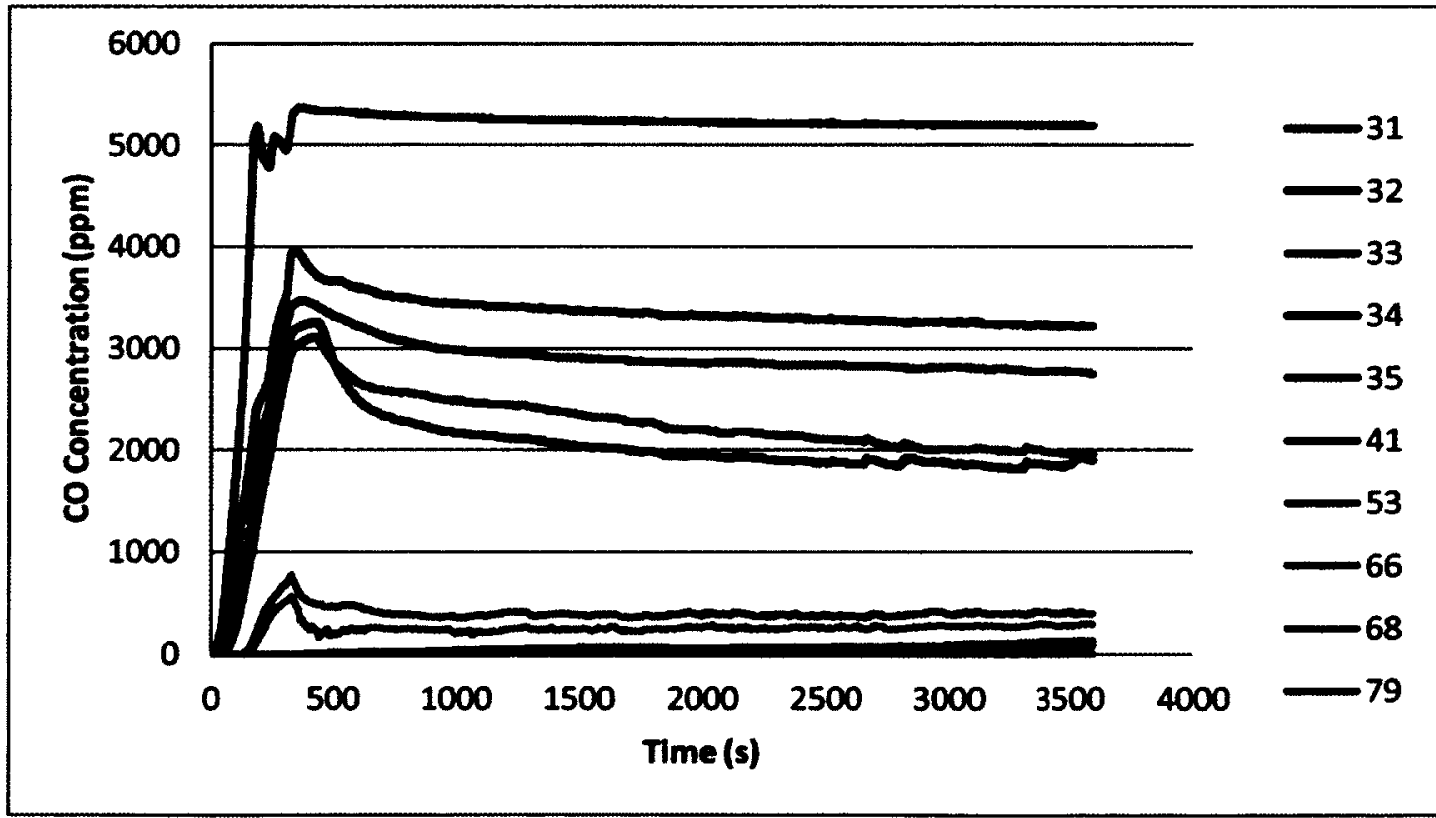

Figure 53: CO concentration in upper layer for Group two Scenario five for selected compartment 


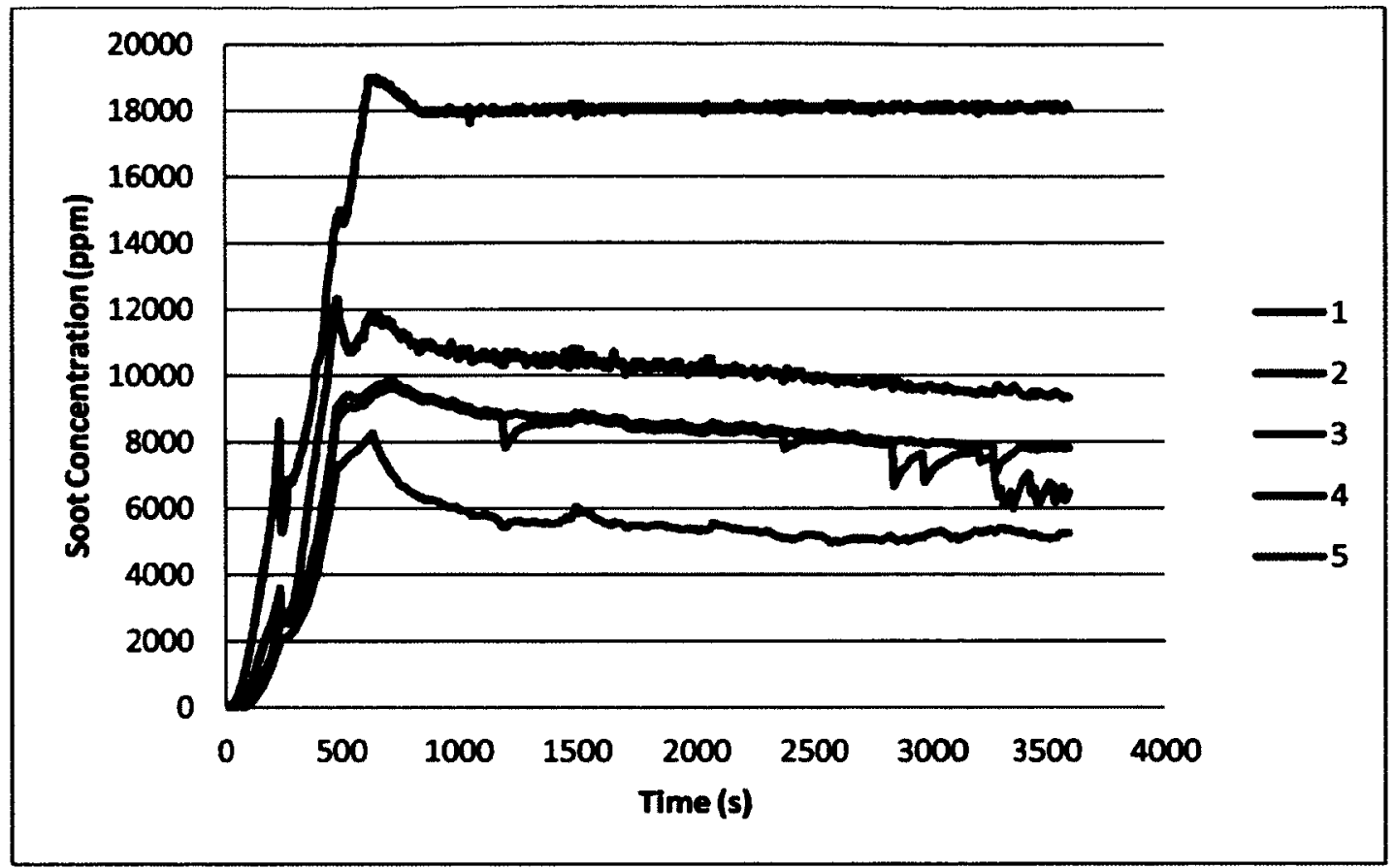

Figure 54: Soot concentration in upper layer for Group one Scenario one for selected compartments

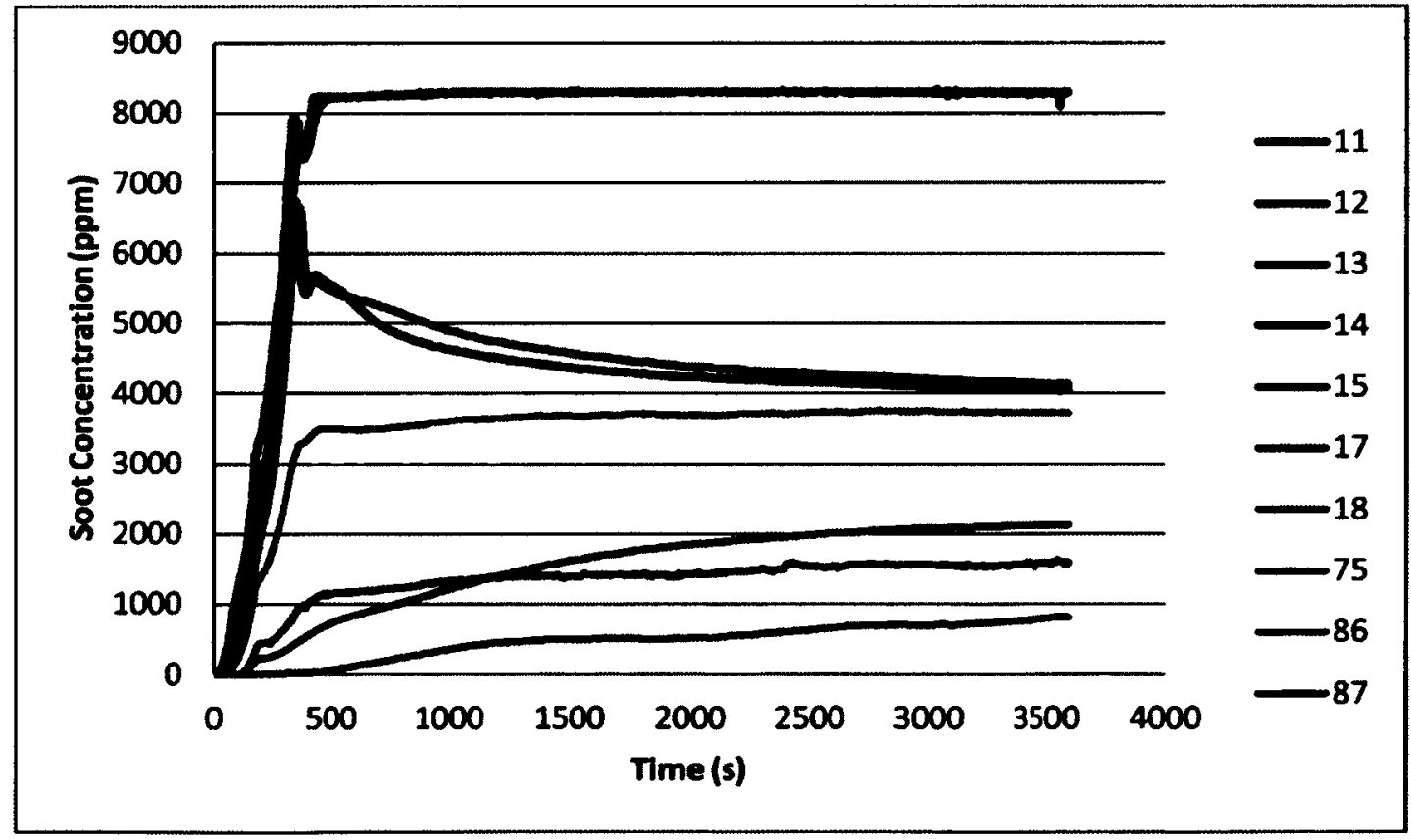

Figure 55: Soot concentration in upper layer for Group two Scenario two for selected compartments 


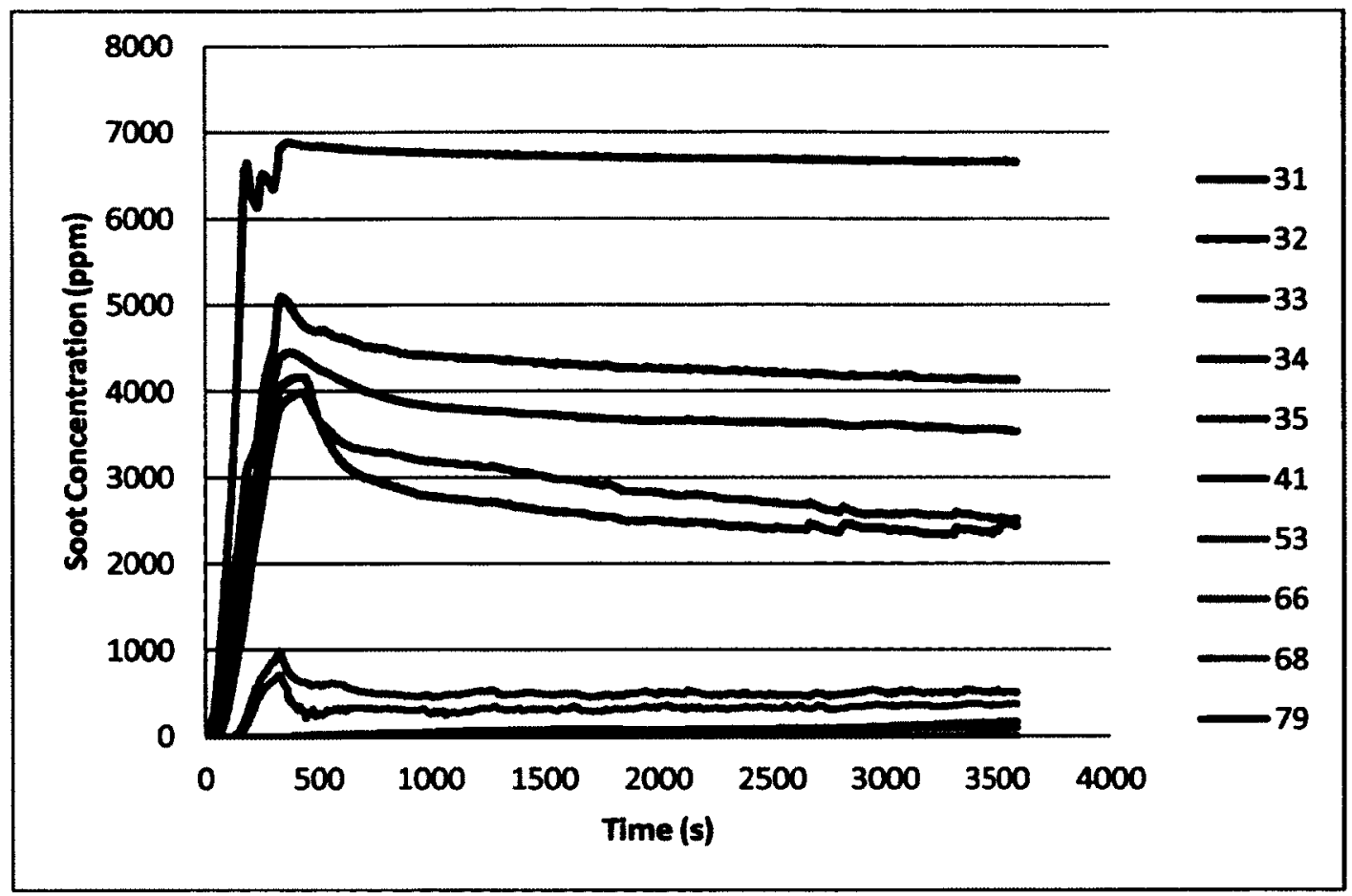

Figure 56: Soot concentration in upper layer for Group two Scenario four for selected compartments

\subsection{Design Fire Curves}

The design fire curves are presented in this section. The design curves were developed by plotting the data obtained from the CUrisk simulation in Microsoft Excel. The trend line feature in Excel was then used to find the line of best fit according to the data obtained for each compartment in order to quantify the growth rate, as well as, the heat release rate at steady state burning. The polynomial trend line option was selected to quantify each portion of the graphs. Equations for the growth rate and the heat release rate at steady state burning are displayed on the graphs. Since it is not possible to model the decay portion of a fire in CUrisk, the decay of the various design curves could not be quantified. 


\subsubsection{Design Fire Curves for Living Rooms}

The living room measures $4.0 \mathrm{~m} \times 5.0 \mathrm{~m}$ with a $1.5 \mathrm{~m} \times 1.5 \mathrm{~m}$ window connecting it to the outside, and $0.9 \mathrm{~m} \times 2.0 \mathrm{~m}$ doors connecting it to the corridor, the two bedrooms, the kitchen, and the bathroom. The maximum heat release rate for the living room was calculated to be $7.8 \mathrm{MW}$. The peak heat release rates predicted by the model in each case were lower than the calculated maximum. A fast growth rate in the initial stage of the fire was an input to the model.

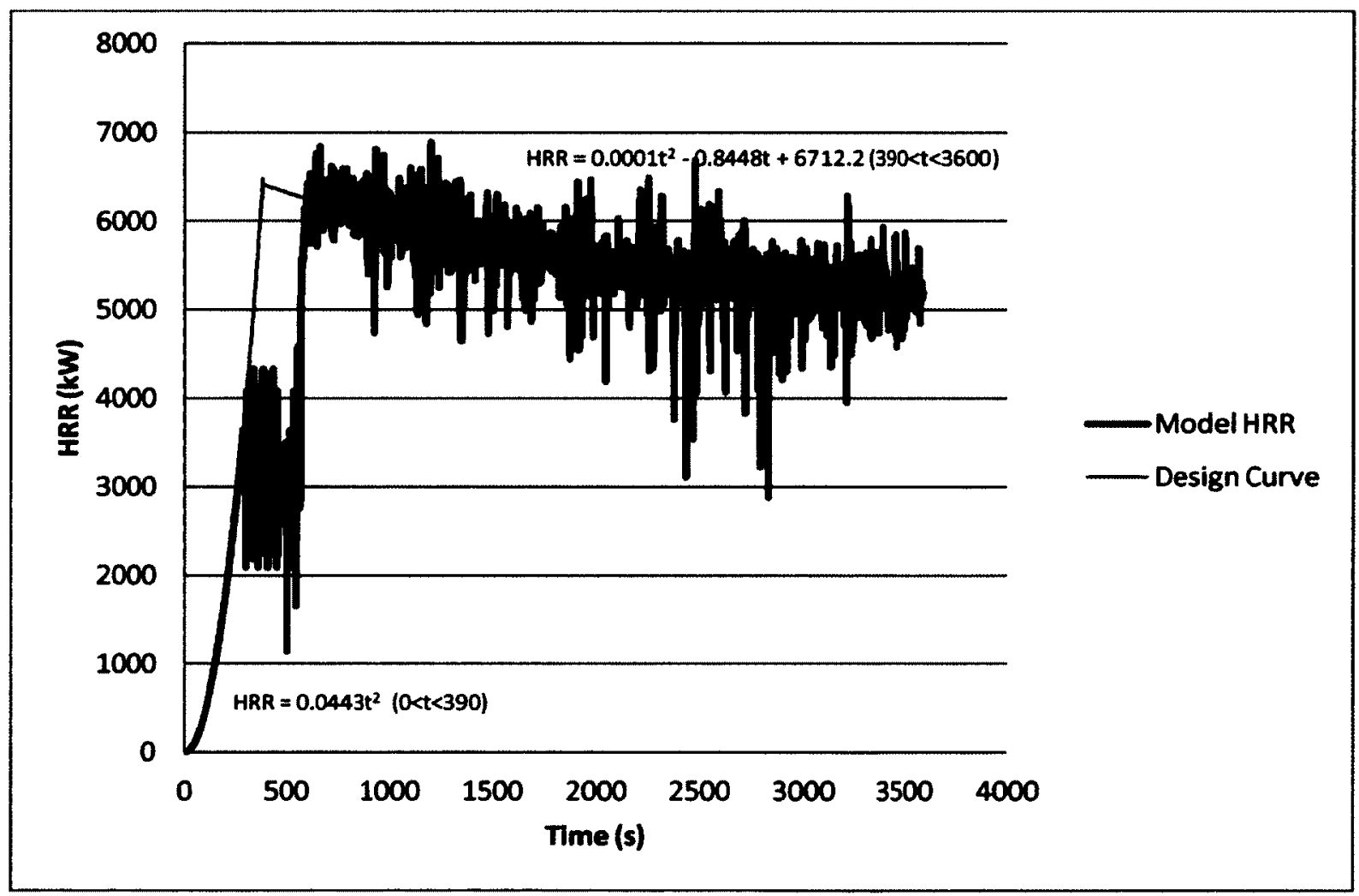

Figure 57: Design HRR curve for living room with closed main doors 


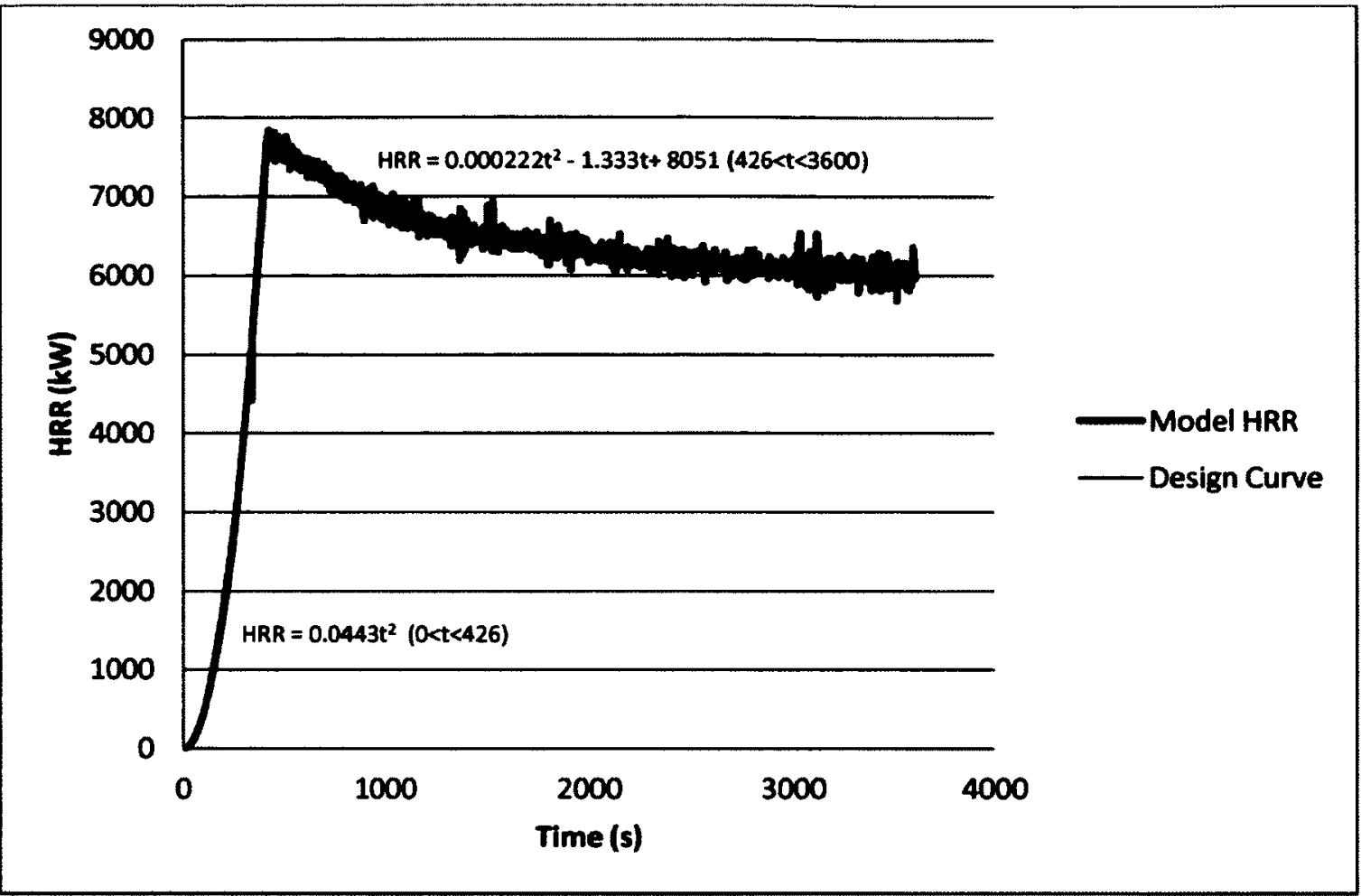

Figure 58: Design HRR curve for living room with open main doors

The design curve obtained for the living room for the scenario where the main doors were closed is presented in Figure 57. The growth rate observed as an output is one for a $\mathbf{t}^{2}$ fire with a growth coefficient of 0.0443 . This value is close to the growth coefficient for a fire with a fast growth rate. The peak heat release rate of $6.7 \mathrm{MW}$ is reached 390 seconds after ignition. In the scenario where the main doors were open, the fire grew as a $t^{2}$ fire with a fast growth rate as shown in Figure 58. The slightly higher peak heat release rate of 7.9 MW is reached 420 seconds after ignition; 30 seconds earlier than in the case with less ventilation. 


\subsubsection{Design Fire Curves for Bedrooms}

The primary bedroom measures $4.0 \mathrm{~m} \times 4.0 \mathrm{~m}$ and the secondary bedroom measures 4.0 $\mathrm{m} \times 3.0 \mathrm{~m}$. Each of the bedrooms has a window to the outside measuring $1.5 \mathrm{~m} \times 1.5 \mathrm{~m}$ and a $2.0 \mathrm{~m} \times 0.9 \mathrm{~m}$ door connecting it to the living room. Based on the ventilation characteristics, it was calculated that the maximum possible heat release rate will be 8 MW for each of the rooms. The CUrisk model however predicted peak heat release rates that were less in each scenario. A medium growth rate in the initial stage of the fire was an input to the model. Similar heat release rate curves were obtained for all the scenarios in group one where the fires started in a bedroom. The same observation was made for fires in group two that started in a bedroom. The design curves for bedrooms were therefore based on the ones that produced the highest peak heat release rate in each group. The design curve obtained for the secondary bedroom for the scenario where the main doors were closed is presented in Figure 59. The growth rate observed as an output is one for a $t^{2}$ fire with a growth rate coefficient of 0.011 . This value is close to the input of 0.012 for fires with medium growth rates. The peak heat release rate of $4.3 \mathrm{MW}$ is reached 620 seconds after ignition. The second design curve is based on scenario three of group two where the fire starts in a primary bedroom. Similar to the fire that starts in the secondary bedroom, the fire in the primary bedroom grows as a $t^{2}$ fire with a growth coefficient of 0.011 as shown in Figure 60. The peak heat release rate of $4.3 \mathrm{MW}$ is reached in 600 seconds. The extra ventilation and slight difference in floor area does not seem to affect the design curve. 


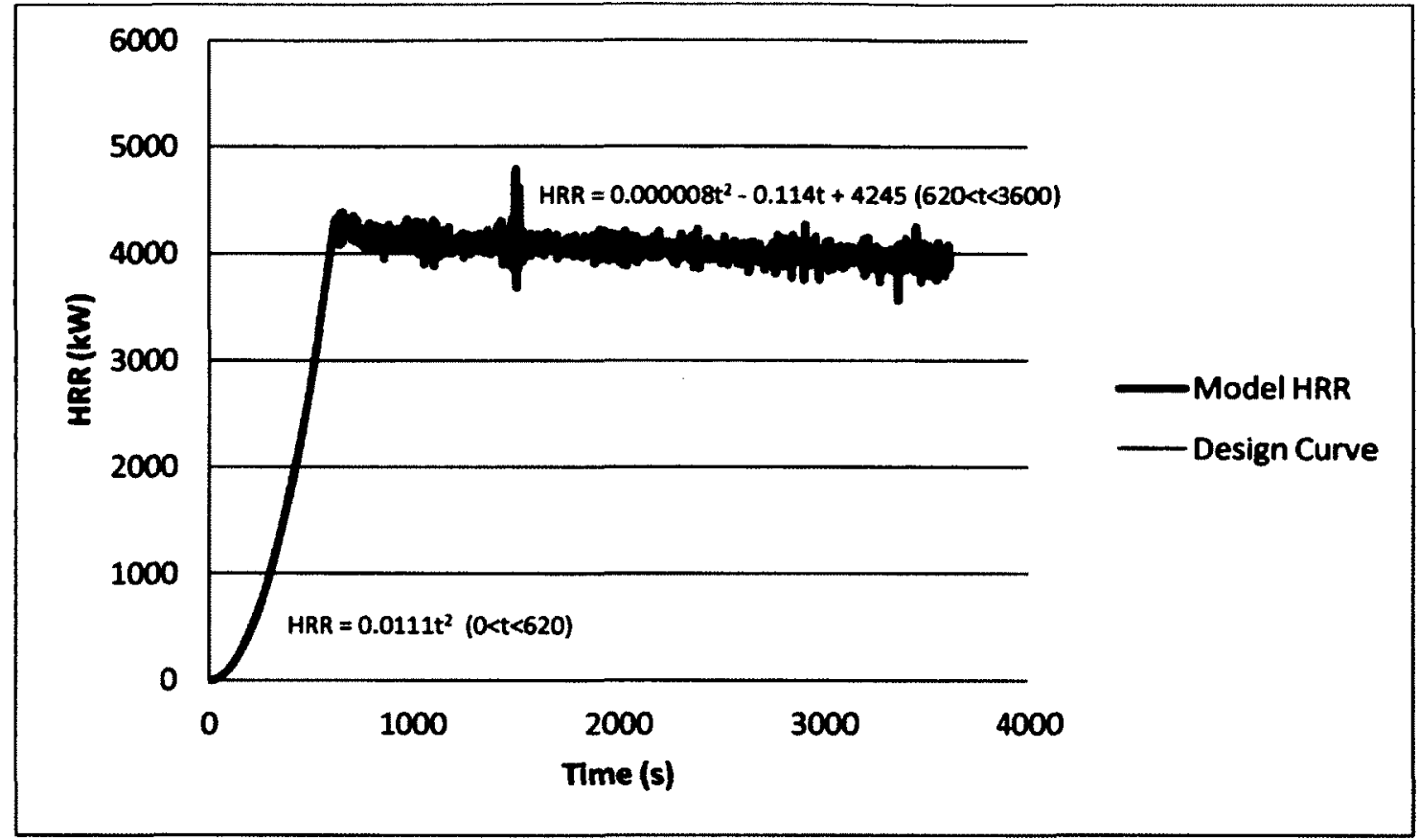

Figure 59: Design HRR curve for a secondary bedroom

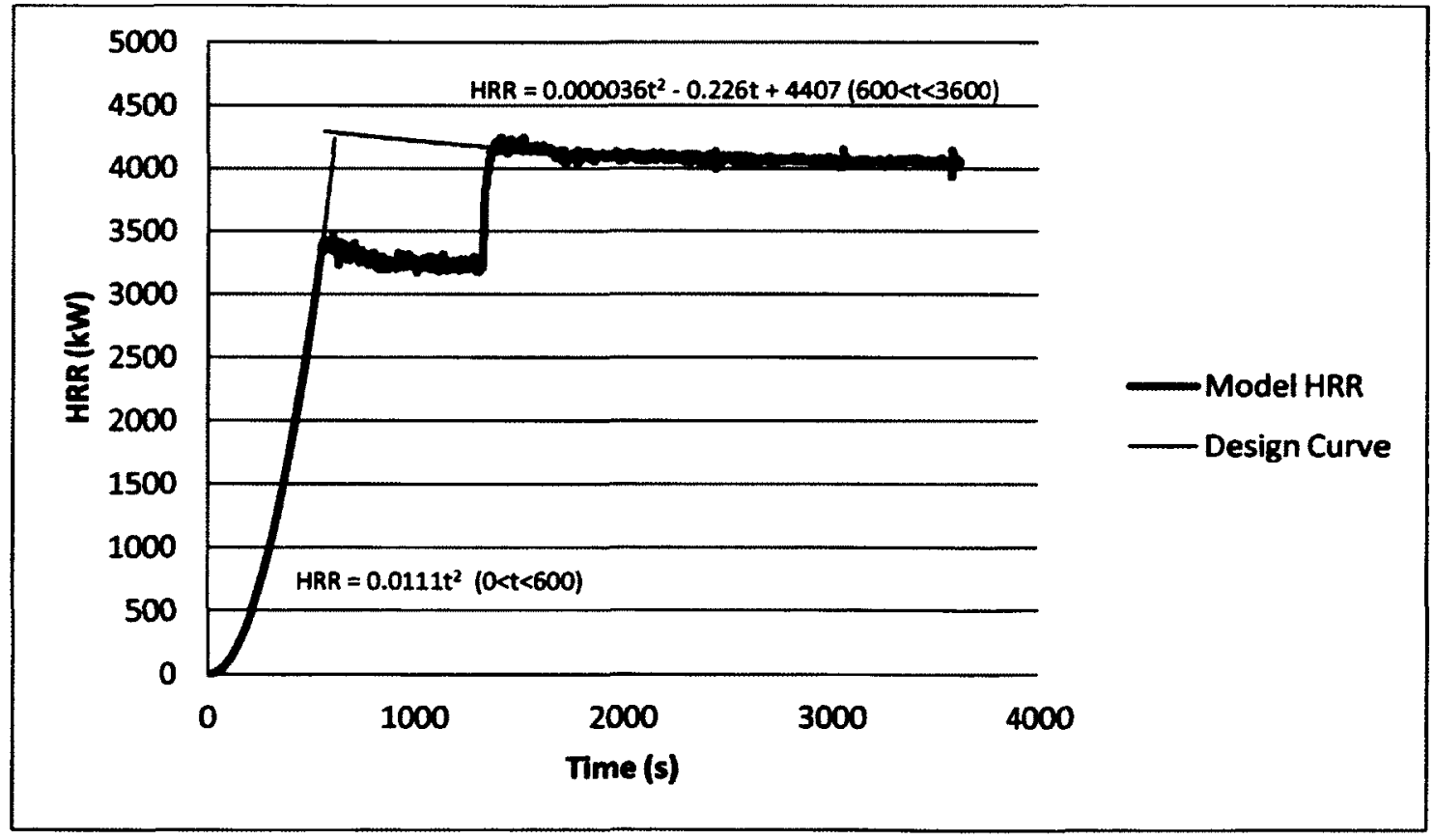

Figure 60: Design HRR curve for a primary bedroom 


\subsubsection{Design Fire Curves for Kitchens}

The kitchen has a floor area of $4.0 \mathrm{~m} \times 2.0 \mathrm{~m}$ and is connected to the living room by a 0.9 $\mathrm{m} \times 2.0 \mathrm{~m}$ door. It has no window to the outside; therefore the only source of ventilation for the fire is through the door. The maximum heat release rate for the kitchen was calculated to be $4 \mathrm{MW}$. The peak heat release rate predicted by the model was much lower than the calculated maximum. A fast growth rate in the initial stage of the fire was an input to the model. Figure 61 shows the design curve obtained for the kitchen for the scenario where the main doors were open. The growth rate observed is one for a fast $\mathbf{t}^{2}$ fire with a growth coefficient of 0.044 . The peak heat release rate of $1.5 \mathrm{MW}$ is reached 200 seconds after ignition. The fire is extinguished prematurely in the case where the main doors are closed.

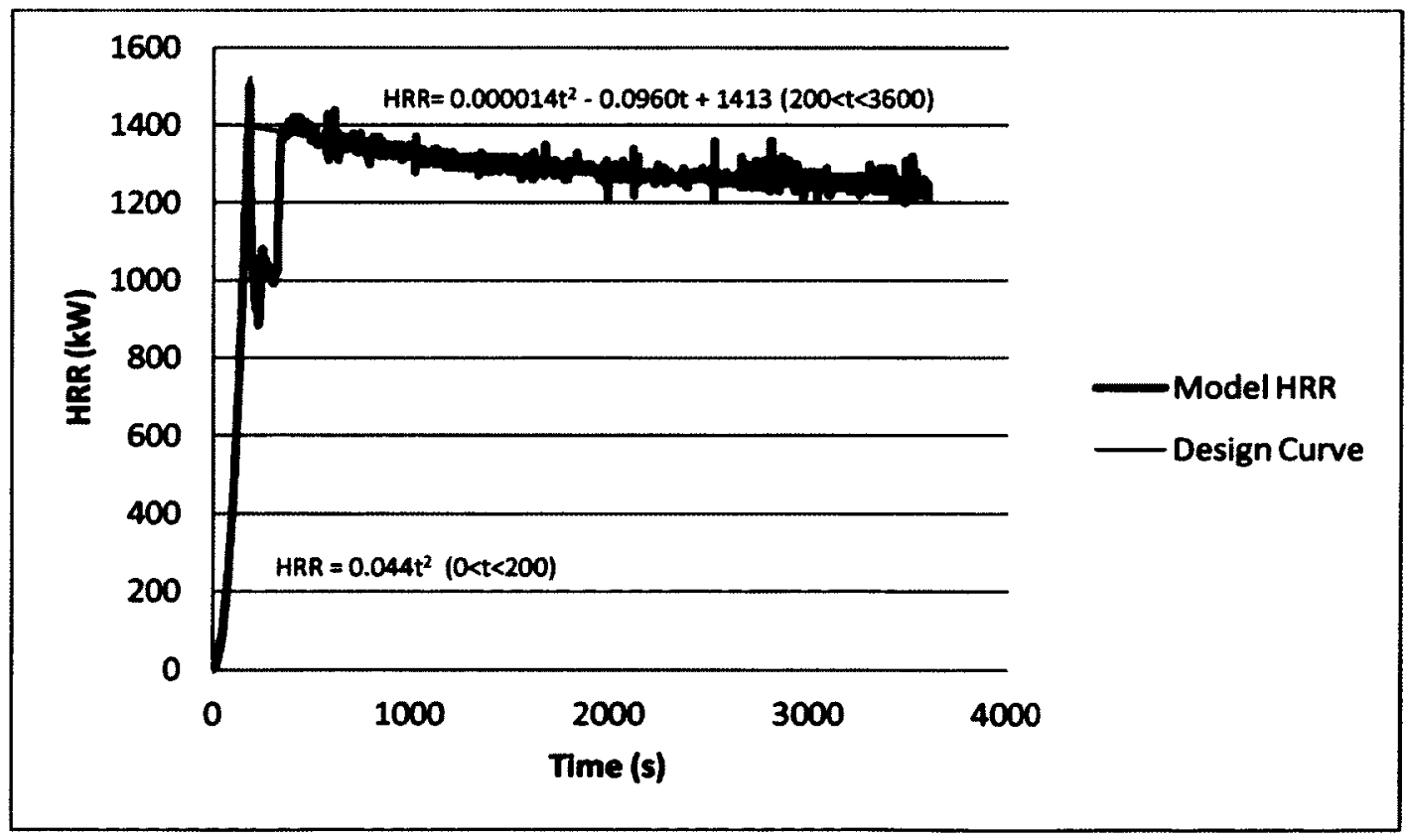

Figure 61: Design HRR curve for a kitchen 


\section{Chapter 7: Conclusions and Recommendations}

\subsection{Conclusions}

This project involved the development of fire loads and design fires for residential and non-residential mid-rise buildings. For the purposes of this project, mid-rise buildings were defined as buildings from four- to eight-storeys.

The literature review showed that most of the available surveys have usually focused on particular occupancies and not necessarily on buildings of particular heights. The best way of obtaining fire loads for mid-rise buildings for this project would have been to conduct a fire load survey of mid-rise buildings. This was not possible due to the challenges involved in doing this which were the time consuming process of obtaining permission from building owners and conducting the survey, privacy concern issues, and also a large number of buildings will need to be surveyed to establish a meaningful data set for realistic analyses. The alternative that was therefore settled on was to use data available for other surveys that have already been conducted. In the first step the appropriateness of this data for the objectives of this project was established. It was found that the contents found in rooms for particular uses do not necessarily vary because the height of a building changes. It was therefore possible to make use of the data currently available for various building occupancies to establish fire loads for mid-rise buildings. It 
was also found that average floor areas for low-rise buildings are close to those for midrise buildings but maximum floor areas in mid-rise buildings are much lower than those in low-rise buildings.

Through review of statistical data on fires, it was discovered that a large majority of fire deaths and injuries occur in residential buildings with the most number of these fires originating in the kitchen. Also, non-residential building fires account for only a small fraction of all building fires but lead to some of the highest costs in fire losses. Based on the fire load surveys and fire statistics, fuel packages were established and design fire scenarios selected.

Simulations were performed using CUrisk, a fire risk analysis computer model software currently under development at Carleton University. The modelling involved a six-storey building with six apartments per floor. Each apartment contained a living room, two bedrooms, a kitchen, and a bathroom. Design fires were established for living rooms, bedrooms, and kitchens according to the results that were obtained from the simulation. Most of the results obtained were reasonable and compared well with some previous experiments. The results show that closed doors delay if not prevent smoke spread from the compartment of fire origin allowing occupants in other areas of the building time to evacuate.

\subsection{Recommendations for Future Work}

The fire loads in this project were developed using available data that was not specifically obtained from mid-rise buildings. The assumption was made to that fire load densities found for could be multiplied by floor areas of mid-rise buildings to obtain the fire loads 
that will be contained in each compartment. This might not necessarily be accurate since it was found that maximum floor areas in mid-rise buildings are much less than maximum floor areas in low-rise buildings. Also going forward, if combustible contruction becomes acceptable for mid-rise buildings, the combustible contruction materials might end up contributing to the fire load of the building. It will therefore be worthwhile to conduct this survey for both combustible and non-combustible construction to determine whether or not type of construction affects fire loads. It will be also valuable to conduct fire load surveys for mid-rise buildings to establish types, amounts, and distribution of combustible materials found in midrise buildings as well as size and location of openings and floor areas.

Once the development of fire spread sub-model for CUrisk is complete, the simulation could be run to determine the speed and effects of fire spread on the occupants and structure of mid-rise buildings. Improvements will need to be made to CUrisk such that one can enter different fire loads for different compartments; currently one can only enter an initial growth rate of the fire and the maximum HRR. Future experiments could also be carried out using other fire simulation software such as FDS. 


\section{References}

1. Canada Commission on Building and Fire Codes. National Building Code of Canada 2005. National Research Council Canada, Institute for Research in Construction Ottawa, On., 2005

2. Wood Works (2009, December), History and Use of Midrise Buildings in Other Jurisdictions. [Online]. Available: http://www.wood-works.org/BC

3. Kruszelnicki, M., Rationalization of Life Safety - Code Requirements for Mid-Rise Buildings, M.Eng Project report, Carleton University, 2011

4. Buchanan, A.C., Structural Design for Fire Safety, University of Canterbury, New Zealand, 2002

5. Zalok, E., Design Fires For Commercial Premises, Ph. D. dissertation, Carleton University, 2006

6. City of Toronto (2005, November), Mid-Rise Residential Housing, Profile Toronto [Online]. Available: http://www.toronto.ca/planning/pdf/profile tor midrise.pdf

7. British Columbia. 2011. Mid-rise Wood Frame - Questions and Answers. [Online]. Available: http:/housing.gov.bc.ca/building/wood_frame/qanda.htm\#2-2

8. GHL Consultants Ltd. Technical and Process Risks in 5 and 6 Storey Wood-Frame Buildings of Residential Occupancy. Building and Safety Policy Branch, Ministry of Housing and Social Development, Victoria, BC, 2009

9. Culver, C. G., Survey Results for Fire Loads and Live Loads in Office Buildings, Building Science Series No. 85, National Bureau of Standards, USA, 1976, pp.1-150

10. Zalok, E, Hadjisophocleous, G., Mehaffey, J. 2009. Fire Loads in Commercial Premises, Fire and Materials, Fire Mater. 2009, 33:63-78

11. Culver, C. G., Characteristics of Fire Loads in Office Buildings, Center for Building Technology, National Bureau of Standards

12. Eduful, J., Validation of Methodologies to Determine Fire Load for Use in Structural Fire Protection, MASc. Thesis, Carleton University, 2012

13. Yii, H. W., Effect of Surface Area and Thickness on Fire Loads, Fire Engineering Research Report 2000/13, University of Canterbury, March 2000 
14. Kumar, S. and Rao C. V. S. K., Fire Loads in Office Buildings, Building and Environment, 1995, Vol.30, No.2, pp.299-305

15. Bwalya, A. C., Lougheed, J. D., Kashef, A., Saber, H. H., Survey Results of Combustible Contents and Floor Areas in Canadian Multi-Family Dwellings, Research report No. 253, October 242008

16. Chen, Z., Design Fires for Motels and Hotels, MASc. Thesis, Carleton University, 2008

17. SFPE Engineering Guide to Performance-based Fire Protection Analysis and Design of Building, Society of Fire Protection Engineers and National Fire Protection Association, USA, 2000

18. Bwalya, A. C., An Overview of Design Fires for Building Compartments, Fire Technology, 2008, 44, pp.167-184

19. Drysdale, D. 1998. An Introduction of Fire Dynamics. $2^{\text {nd }}$ edition. Chichester, U.K: John Wiley \& Sons

20. http://www.bfrl.nist.gov/IAQanalysis/CONTAM/overview/1.htm.

CONTAM Multizone Airflow and Contaminant Transport Analysis Software, NIST Multizone Modeling Website, accessed: November, 2011.

21. McGrattan, K., McDermott, R., Hostikka, S., Floyd, J., Fire Dynamics Simulator User's Guide Version 5, NIST Special Publication 1019-5, October, 2010

22. Forney, G. P., User's Guide for Smokeview Version 5 - A Tool for Visualizing Fire Dynamics Simulator Data, NIST Special Publication 1017-1, January, 2008

23. Hadjisophocleous, G., and Fu, Z., Report On The Fire Risk Assessment System Model, Internal Report, Carleton University, 2002

24. Thomas, P. H. 1986. Design Guide: Structural Fire Safety CIB W14 workshop report. Fire Safety Journal, Vol. 10, No. 2, pp 77-137

25. Bwalya, A. C., Sultan, M. A., and Benichou, N., A Pilot Survery of Fire Loads in Canadian Homes, Research report No. 159, National Research Council Canada, March 92004

26. Bwalya, A. C., An Extended Survey of Combustible Contents in Canadian Residential Living Rooms, Research report No. 176, National Research Council Canada, November 82004

27. Anon, P, (1942). Building Materials and Science structures - Fire Resistance Classification of Building Construction, Report of Subcommittee on Fire Resistance Classification of Central Housing Committee on Research, Design and Construction, Report BMS92, National Bureau of Standards, Washington

28. http://www.royallepage.ca/. Royal LePage Real Estate Services, Real-estate website, accessed: November, 2011. 
29. http://www.grapevine.on.ca/. The Grape Vine Home Marketing Consultants, Realestate website, accessed: November, 2011.

30. Baldwin, R., Law, M., Allen, G., and Griffiths, L. G., (1970). Survey of Fire-Loads in Modern Office Buildings - Some Preliminary Results', JFRO, Fire Research Note No. 808

31. Caro, T. and Milke, J., (1996). 'A Survey of Fire Loads in Contemporary Office Building', NIST Report GCR-96-697, NIST, Gaithersburg, MD

32. Culver, C. G., Survey Results for Fire Loads and Live Loads in Office Buildings, NBS Building Science Series 85, May 1976

33. Richardson, L. R., , What Fire Statistics Tell Us About Our Fire and Building Codes for Housing and Small Buildings and Fire Risk for Occupants of those Structure, Fire and Materials, $v 25,2001$, pp.255-271

34. Richardson, L. R., Fire Losses in Selected Property Classifications of Non-residential, Commercial, and Residential Wood Buildings. Part 1: Hotels/motels and Care Homes for Aged, Fire and Materials, v 31, 2007, pp.97-123

35. Ontario Office of the Fire Marshal, Fire Statistics, http://www.ofm.gov.on.ca/en/, Feb. 3, 2012 [March 2012]

36. British Columbia Office of the Fire Commissioner, 2009 and 2010 Fire Reportings, http://www.pssg.gov.bc.ca/firecom/statistics/index.htm, January 2011 [January 2012]

37. Statistics Canada. 2012. Ottawa, Ontario (Code 3506008) and Ontario (Code 35) (table). Census Profile. 2011 Census. Statistics Canada Catalogue no. 98-316-XWE. Ottawa. http://www12.statcan.ca/census-recensement/2011/dp$\mathrm{pd} /$ prof/index.cfm?Lang $=\mathrm{E}$ (accessed January, 2012)

38. Gaskin, J. and Yung, D., Canadian and U.S.A. Fire Statistics for Use in the Risk-Cost Assessment Model, Internal report No. 637, National Research Council Canada, January 1993

39. Chandler, S. E. and Baldwin, R., Furniture and Furnishings in the Home - Some Fire Statistics, Fire and Materials, 1976, pp.76-82

40. Lin, Y., Life Risk Analysis in Residential Building Fires, Central Police University, Taiwan, July 10, 2003

41. Canadian Wood Council. Fire safety in resisdential buildings, Building Performance Series No. 2, 2000

42. Council of Canadian Fire Marshals and Fire Commissioners, Annual Report 2000, Fire Losses in Canada, 2000

43. British Columbia Office of the Fire Commissioner, Annual Statistical Report 2006, http://www.pssg.gov.bc.ca/firecom/statistics/pdf/2006stats.pdf, [January 2012] 
44. Hasofer, A. M. and Thomas, I., Analysis of fatalities and injuries in building fire statistics. Fire Safety Journal 41 (2006) pp.2-14

45. Juneja, C.S., Analysis of Ontario Fires and Reliability of Active Fire Protection Systems, MASc. Thesis, Carleton University, 2004

46. U.S. Fire Administration. Non-Residential Structure Fires in 2000, Topical Fire Research Series, Vol. 3, Issue 10, June 2004

47. U.S. Fire Administration. Nonresidential Building Fires, FEMA, April 2010

48. Babrauskas, V., Glass Breakage in Fires, Fire Science \& Technology Inc., Issaquah, WA, USA http://www.doctorfire.com/glass.html ; accessed August 2012

49. Mou, X., Quantitative Fire Risk Analysis Case Study Using CUrisk, MASc. Thesis, Carleton University, 2009 


\section{Appendix A}

Input Data for Scenarios in Group One

\section{General Text}

Date and Time:15/06/2012 9:44:47 AM

Description:Input file Creatorl.xlsm

01):Annual fire frequency

0.00317

02):Population of the building

144

03):Design life of the building in years

50

04):Threshold of injury

0.1

05):Threshold of death

0.8

06):Number of scenarios

5

07):Number of compartments

90

08):Step size for risk assessment in seconds

2

09):Start time of risk assessment in seconds

0

10):End time of risk assessment in seconds 3600

11):Scenario Probability

11

21

31

41

5

Scenario Generation Input Data

Setup For Scenario Generation

Note that items with question mark ? should be input with Yes or No

$\forall * * * * * * * * * * * * * * * * * * * * * *$

Data for Fire Department

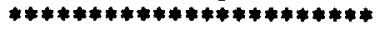

Number of Response Options

1

Option No, Notification Time S, Response Time S, Set Up Time S 
$1,3600,60,300$

$* * * * * * * * * * * * * * * * * * * * *$

Data for Sprinkler

$* * * * * * * * * * * * * * * * * * * * * *$

Act Temperature C, Spray Density $(\mathrm{mm} / \mathrm{S})$, Effectiveness

$150,0.1,0.9$

$* * * * * * * * * * * * * * * * * * * * *$

Data for each scenario

$* * * * * * * * * * * * * * * * * * * * * * *$

Number of scenarios

5

-Scenario ID-...

1

1):FireRoomNo, |Center|Wal||Comer|,FuelName, |Slow|Medium|Fast|Ultra|, MaxHRRMW, FDoption

2 ,Center,Sofa,Medium, 8,1

2):LocalSprinkler?, LocalHeatDetector?, OtherHeatDetector?

No,No,No

3):LocalSmokeDetector?, HVAC/CorridorSmokeDetector?, Stairwell/ElevatorSmokeDetector?

No,No,No

4):LocalAlarm?, Central Alarm?, VoiceAlarm?, CentralAlarmConnectedToFireDepartment?

No,No,No,No

-ScenariolD-...

2

1):FireRoomNo, |Center|Wall|Corner|,FuelName, |Slow|Medium|Fast|Ultra|, MaxHRRMW, FDoption

11 ,Center,Polyester,Fast, 8,1

2):LocalSprinkler?, LocalHeatDetector?, OtherHeatDetector?

No,No,No

3):LocalSmokeDetector?, HVAC/CorridorSmokeDetector?, Stairwell/ElevatorSmokeDetector?

No,No,No

4):LocalAlarm?, CentralAlarm?, VoiceAlarm?, CentralAlarmConnectedToFireDepartment?

No,No,No,No

-ScenariolD--

3

1):FireRoomNo, |Center|Wall|Corner|,FuelName, |Slow|Medium|Fast|Ultra|, MaxHRRMW, FDoption

23 ,Center,Sofa,Medium, 8 , 1

2):LocalSprinkler?, LocalHeatDetector?, OtherHeatDetector?

No,No,No

3):LocalSmokeDetector?, HVAC/CorridorSmokeDetector?, Stairwell/ElevatorSmokeDetector?

No,No,No

4):LocalAlarm?, Central Alarm?, VoiceAlarm?, CentralAlarmConnectedToFireDepartment?

No,No,No,No

-.ScenarioID....

4

1):FireRoomNo, |Center|Wall|Corner|,FuelName, |Slow|Medium|Fast|Ultra|, MaxHRRMW, FDoption

22 ,Center,Sofa,Medium, 8,1

2):LocalSprinkler?, LocalHeatDetector?, OtherHeatDetector?

No,No,No

3):LocalSmokeDetector?, HVAC/CorridorSmokeDetector?, Stairwell/ElevatorSmokeDetector?

No,No,No

4):LocalAlarm?, CentralAlarm?, VoiceAlarm?, CentralAlarmConnectedToFireDepartment?

No,No,No,No

-ScenariolD-.

5

1):FireRoomNo, |Center|Wall|Corner|,FuelName, |Slow|Medium|Fast|Ultra|, MaxHRRMW, FDoption

35 ,Center,Polyester,Fast, 4,1

2):LocalSprinkler?, LocalHeatDetector?, OtherHeatDetector?

No,No,No

3):LocalSmokeDetector?, HVAC/CorridorSmokeDetector?, Stairwell/ElevatorSmokeDetector? 
No,No,No

4):LocalAlarm?, CentralAlarm?, VoiceAlarm?, CentralAlarmConnectedToFireDepartment? No,No,No,No

Fire Growth Generation Imput Data

$\forall * * * * * * * * * * * * * * * * * * * * * * * *$

Setup For Fire Growth Generation

$* * * * * * * * * * * * * * * * * * * * * * *$

Number of compartments

90

-CompartmentID--

1

FuelName, |Center|Wal||Corner|, |Slow|Medium|Fast|Ultra|, MaxHRRMW

Polyester,Center,Fast, 4

-CompartmentID-

2

FuelName, |Center|Wal||Comer|, |Slow|Medium|Fast|Ultra|, MaxHRRMW

Sofa,Center,Medium, 8

-CompartmentIID-

3

FuelName, |Center|Wal||Comer|, |Slow|Medium|Fast|Ultra|, MaxHRRMW

Sofa,Center,Medium, 8

-CompartmentID.

4

FuelName, |Center|Wal||Corner|, |Slow|Medium|Fast|Ultra|, MaxHRRMW

Polyester,Center,Fast, 4

-CompartmentID--

5

FuelName, |Center|Wall|Comer|, |Slow|Medium|Fast|Ultra|, MaxHRRMW

Polyester,Center,Fast, 4

--CompartmentID--

6

FuelName, |Center|Wall|Corner|, |Slow|Medium|Fast|Ultra|, MaxHRRMW

Sofa,Center,Medium, 8

-CompartmentID--

7

FuelName, |Center|Wall|Corner|, |Slow|Medium|Fast|Ultra|, MaxHRRMW

Sofa, Center,Medium, 8

-CompartmentID-.

8

FuelName, |Center|Wall|Corner|, |Slow|Medium|Fast|Ultra|, MaxHRRMW Sofa, Center,Medium, 8

-CompartmentID-

9

FuelName, |Center|Wall|Corner|, |Slow|Medium|Fast|Ultra|, MaxHRRMW

Sofa,Center,Medium, 8

-CompartmentID-

10

FuelName, |Center|Wall|Comer|, |Slow|Medium|Fast|Ultra|, MaxHRRMW

Sofa, Center,Medium, 8

-CompartmentID-

11

FuelName, |Center|Wall|Corner|, |Slow|Medium|Fast|Ultra|, MaxHRRMW

Polyester, Center,Fast, 4

-CompartmentID-

12 
FuelName, |Center|Wal||Corner|, |Slow|Medium|Fast|Ultra|, MaxHRRMW Sofa,Center,Medium, 8

-CompartmentID-

13

FuelName, |Center|Wall|Comer|, |Slow|Medium|Fast|Ultra|, MaxHRRMW

Sofa,Center,Medium, 8

-CompartmentID.

14

FuelName, |Center|Wall|Corner|, |Slow|Medium|Fast|Ultra|, MaxHRRMW

Polyester,Center,Fast, 4

-CompartmentID-

15

FuelName, |Center|Wall|Corner|, |Slow|Medium|Fast|Ultra|, MaxHRRMW

Polyester,Center,Fast, 4

-CompartmentID-

16

FuelName, |Center|Wall|Comer|, |Slow|Medium|Fast|Ultra|, MaxHRRMW

Sofa,Center,Medium, 8

-CompartmentID--

17

FuelName, |Center|Wall|Comer|, |Slow|Medium|Fast|Ultra|, MaxHRRMW Sofa,Center,Medium, 8

-CompartmentID--

18

FuelName, |Center|Wall|Corner|, |Slow|Medium|Fast|Ultra|, MaxHRRMW

Sofa,Center,Medium, 8

-CompartmentID--

19

FuelName, |Center|Wall|Corner|, |Slow|Medium|Fast|Ultra|, MaxHRRMW Sofa, Center,Medium, 8

-CompartmentID--

20

FuelName, |Center|Wall|Corner|, |Slow|Medium|Fast|Ultra|, MaxHRRMW

Sofa, Center,Medium, 8

-CompartmentID-.

21

FuelName, |Center|Wall|Corner|, |Slow|Medium|Fast|Ultra|, MaxHRRMW

Polyester,Center,Fast, 4

-CompartmentID-

22

FuelName, |Center|Wal||Corner|, |Slow|Medium|Fast|Ultra|, MaxHRRMW

Sofa, Center,Medium, 8

-CompartmentiD--

23

FuelName, |Center|Wal||Corner|, |Slow|Medium|Fast|Ultra|, MaxHRRMW

Sofa,Center,Medium, 8

-CompartmentID-.

24

FuelName, |Center|Wal||Corner|, |Slow|Medium|Fast|Ultra|, MaxHRRMW

Polyester,Center,Fast, 4

-CompartmentID.

25

FuelName, |Center|Wal||Corner|, |Slow|Medium|Fast|Ultra|, MaxHRRMW

Polyester,Center,Fast, 4

-CompartmentID.

26

FuelName, |Center|Wall|Comer|, |Slow|Medium|Fast|Ultra|, MaxHRRMW

Sofa,Center,Medium, 8 
-CompartmentID-

27

FuelName, |Center|Wall|Corner|, |Slow|Medium|Fast|Ultra|, MaxHRRMW

Sofa,Center,Medium, 8

-CompartmentID-

28

FuelName, |Center|Wal||Comer|, |Slow|Medium|Fast|Ultra|, MaxHRRMW

Sofa,Center,Medium, 8

-CompartmentID-

29

FuelName, |Center|Wall|Comer|, |Slow|Medium|Fast|Ultra|, MaxHRRMW

Sofa, Center,Medium, 8

-CompartmentID--

30

FuelName, |Center|Wall|Corner|, |Slow|Medium|Fast|Ultral, MaxHRRMW

Sofa,Center,Medium, 8

-CompartmentID-

31

FuelName, |Center|Wall|Corner|, |Slow|Medium|Fast|Ultra|, MaxHRRMW

Polyester,Center,Fast, 4

-CompartmentID-

32

FuelName, |Center|Wall|Comer|, |Slow|Medium|Fast|Ultra|, MaxHRRMW

Sofa,Center,Medium, 8

-CompartmentID--

33

FuelName, |Center|Wall|Corner|, |Slow|Medium|Fast|Ultra|, MaxHRRMW

Sofa,Center,Medium, 8

-CompartmentID--

34

FuelName, |Center|Wal||Corner|, |Slow|Medium|Fast|Ultra|, MaxHRRMW

Polyester,Center,Fast, 4

-CompartmentiD-.

35

FuelName, |Center|Wal||Corner|, |Slow|Medium|Fast|Ultra|, MaxHRRMW

Polyester,Center,Fast, 4

-CompartmentiD-

36

FuelName, |Center|Wall|Corner|, |Slow|Medium|Fast|Ultra|, MaxHRRMW

Sofa,Center,Medium, 8

-CompartmentID--

37

FuelName, |Center|Wall|Corner|, |Slow|Medium|Fast|Ultra|, MaxHRRMW

Sofa,Center,Medium, 8

-CompartmentID-

38

FuelName, |Center|Wall|Corner|, |Slow|Medium|Fast|Ultra|, MaxHRRMW

Sofa,Center,Medium, 8

-CompartmentID-

39

FuelName, |Center|Wall|Corner|, |Slow|Medium|Fast|Ultra|, MaxHRRMW

Sofa,Center,Medium, 8

-CompartmentID-

40

FuelName, |Center|Wall|Corner|, |Slow|Medium|Fast|Ultra|, MaxHRRMW

Sofa,Center,Medium, 8

-CompartmentID-

41 
FuelName, |Center|Wall|Corner|, |Slow|Medium|Fast|Ultra|, MaxHRRMW Polyester,Center,Fast, 4

-CompartmentID-

42

FuelName, |Center|Wall|Corner|, |Slow|Medium|Fast|Ultra|, MaxHRRMW

Sofa,Center,Medium, 8

-CompartmentID.

43

FuelName, |Center|Wall|Comer|, |Slow|Medium|Fast|Ultra|, MaxHRRMW

Sofa, Center,Medium, 8

-CompartmentID-

44

FuelName, |Center|Wall|Comer|, |Slow|Medium|Fast|Ultra|, MaxHRRMW

Polyester, Center, Fast, 4

-CompartmentID-

45

FuelName, |Center|Wall|Corner|, |Slow|Medium|Fast|Ultra|, MaxHRRMW

Polyester,Center,Fast, 4

-CompartmentID-

46

FuelName, |Center|Wall|Corner|, |Slow|Medium|Fast|Ultra|, MaxHRRMW

Sofa,Center,Medium, 8

-CompartmentID-

47

FuelName, |Center|Wall|Comer|, |Slow|Medium|Fast|Ultra|, MaxHRRMW

Sofa,Center,Medium, 8

-CompartmentID.

48

FuelName, |Center|Wall|Corner|, |Slow|Medium|Fast|Ultra|, MaxHRRMW

Sofa, Center,Medium, 8

-CompartmentID-

49

FuelName, |Center|Wall|Corner|, |Slow|Medium|Fast|Ultra|, MaxHRRMW

Sofa,Center,Medium, 8

-CompartmentID--

50

FuelName, |Center|Wall|Corner|, |Slow|Medium|Fast|Ultra|, MaxHRRMW

Sofa, Center,Medium, 8

-CompartmentID-

51

FuelName, |Center|Wall|Corner|, |Slow|Medium|Fast|Ultra|, MaxHRRMW

Polyester,Center,Fast, 4

-CompartmentID-

52

FuelName, |Center|Wall|Comer|, |Slow|Medium|Fast|Ultra|, MaxHRRMW

Sofa,Center,Medium, 8

-CompartmentID-.

53

FuelName, |Center|Wall|Corner|, |Slow|Medium|Fast|Ultra|, MaxHRRMW

Sofa,Center,Medium, 8

-CompartmentID-

54

FuelName, |Center|Wall|Corner|, |Slow|Medium|Fast|Ultra|, MaxHRRMW

Polyester,Center,Fast, 4

- CompartmentID--

55

FuelName, |Center|Wall|Comer|, |Slow|Medium|Fast|Ultra|, MaxHRRMW

Polyester,Center,Fast, 4 
-CompartmentID-

56

FuelName, |Center|Wall|Corner|, |Slow|Medium|Fast|Ultra|, MaxHRRMW

Sofa,Center,Medium, 8

- CompartmentID.

57

FuelName, |Center|Wall|Corner|, |Slow|Medium|Fast|Ultra|, MaxHRRMW

Sofa,Center,Medium, 8

-CompartmentID-.

58

FuelName, |Center|Wal||Corner|, |Slow|Medium|Fast|Ultra|, MaxHRRMW

Sofa,Center,Medium, 8

-CompartmentID.

59

FuelName, |Center|Wall|Corner|, |Slow|Medium|Fast|Ultra|, MaxHRRMW

Sofa, Center,Medium, 8

-CompartmentID-.

60

FuelName, |Center|Wall|Corner|, |Slow|Medium|Fast|Ultra|, MaxHRRMW

Sofa,Center,Medium, 8

-CompartmentID.-

61

FuelName, |Center|Wall|Corner|, |Slow|Medium|Fast|Ultra|, MaxHRRMW

Sofa,Center,Medium, 4

-CompartmentID.

62

FuelName, |Center|Wall|Corner|, |Slow|Medium|Fast|Ultral, MaxHRRMW

Sofa, Center,Medium, 4

-CompartmentID--

63

FuelName, |Center|Wall|Corner|, |Slow|Medium|Fast|Ultra|, MaxHRRMW

Sofa,Center,Medium, 4

-CompartmentID-

64

FuelName, |Center|Wall|Corner|, |Slow|Medium|Fast|Ultra|, MaxHRRMW

Sofa,Center,Medium, 4

-CompartmentID-

65

FueIName, |Center|Wall|Corner|, |Slow|Medium|Fast|Ultra|, MaxHRRMW

Sofa,Center,Medium, 4

-CompartmentID-

66

FuelName, |Center|Wall|Comer|, |Slow|Medium|Fast|Ultra|, MaxHRRMW

Sofa,Center,Medium, 4

-CompartmentID-

67

FueIName, |Center|Wall|Corner|, |Slow|Medium|Fast|Ultra|, MaxHRRMW

Sofa,Center,Medium, 4

-CompartmentID-.

68

FuelName, |Center|Wall|Corner|, |Slow|Medium|Fast|Ultra|, MaxHRRMW

Sofa,Center,Medium, 4

-CompartmentID.-

69

FueIName, |Center|Wall|Corner|, |Slow|Medium|Fast|Ultra|, MaxHRRMW

Sofa,Center,Medium, 4

- CompartmentID-

70 
FuelName, |Center|Wal||Corner|, |Slow|Medium|Fast|Ultra|, MaxHRRMW Sofa,Center,Medium, 4

-CompartmentID-

71

FuelName, |Center|Wall|Comer|, |Slow|Medium|Fast|Ultra|, MaxHRRMW

Sofa, Center,Medium, 4

-CompartmentID--

72

FuelName, |Center|Wall|Corner|, |Slow|Medium|Fast|Ultra|, MaxHRRMW

Sofa,Center,Medium, 4

-CompartmentID.

73

FuelName, |Center|Wal||Corner|, |Slow|Medium|Fast|Ultra|, MaxHRRMW

Sofa, Center,Medium, 4

-CompartmentID.

74

FuelName, |Center|Wall|Comer|, |Slow|Medium|Fast|Ultra|, MaxHRRMW

Sofa, Center,Medium, 4

-CompartmentiD--

75

FuelName, |Center|Wall|Corner|, |Slow|Medium|Fast|Ultral, MaxHRRMW Sofa,Center,Medium, 4

-CompartmentID.

76

FuelName, |Center|Wall|Corner|, |Slow|Medium|Fast|Ultra|, MaxHRRMW

Sofa, Center,Medium, 4

-CompartmentID-

77

FuelName, |Center|Wall|Corner|, |Slow|Medium|Fast|Ultra|, MaxHRRMW

Sofa, Center,Medium, 4

-CompartmentID.

78

FuelName, |Center|Wall|Corner|, |Slow|Medium|Fast|Ultra|, MaxHRRMW

Sofa,Center,Medium, 4

-CompartmentID.

79

FuelName, |Center|Wall|Corner|, |Slow|Medium|Fast|Ultra|, MaxHRRMW

Sofa,Center,Medium, 4

-CompartmentID--

80

FuelName, |Center|Wall|Corner|, |Slow|Medium|Fast|Ultra|, MaxHRRMW Sofa, Center,Medium, 4

-CompartmentID-

81

FuelName, |Center|Wall|Corner|, |Slow|Medium|Fast|Ultra|, MaxHRRMW

Sofa, Center,Medium, 4

-CompartmentID--

82

FuelName, |Center|Wall|Comer|, |Slow|Medium|Fast|Ultra|, MaxHRRMW

Sofa,Center,Medium, 4

-CompartmentID -

83

FuelName, |Center|Wall|Corner|, |Slow|Medium|Fast|Ultra|, MaxHRRMW

Sofa,Center,Medium, 4

-CompartmentID-

84

FuelName, |Center|Wall|Comer|, |Slow|Medium|Fast|Ultra|, MaxHRRMW

Sofa,Center,Medium, 4 
-CompartmentID.

85

FuelName, |Center|Wall|Corner|, |Slow|Medium|Fast|Ultra|, MaxHRRMW

Sofa, Center,Medium, 4

-CompartmentID-

86

FuelName, |Center|Wal||Comer|, |Slow|Medium|Fast|Ultra|, MaxHRRMW

Sofa, Center, Medium, 4

-CompartmentID-

87

FuelName, |Center|Wall|Corner|, |Slow|Medium|Fast|Ultra|, MaxHRRMW

Sofa, Center,Medium, 4

-CompartmentID-

88

FuelName, |Center|Wal||Corner|, |Slow|Medium|Fast|Ultra|, MaxHRRMW

Sofa, Center, Medium, 4

-CompartmentID--

89

FuelName, |Center|Wall|Corner|, |Slow|Medium|Fast|Ultra, MaxHRRMW

Sofa, Center, Medium, 4

-CompartmentID.

90

FuelName, |Center|Wall|Corner|, |Slow|Medium|Fast|Ultra|, MaxHRRMW

Sofa, Center,Medium, 4

\section{Building Description Input Data}

The 1st three lines can be anything for description.

1story building, 3 Room, 2 door and 2 windows

Date: June 4, 2004, Time: 10:00 AM

01):ReCT03, BY04, DV05, CCV06, RCV07, SCV08, MV09, FS10, TsimuS, TmaxS, StepSizeS

$90,3,134,0,0,10,0,1,3600,3600,2$

02):HrefM, PambPa, TambC, LoopSize|L|M|S|, Plume|Mc|He|

$0,101325,20, \mathrm{M}, \mathrm{Mc}$

03):CTid, TiniC, WidtM, DeptM, CeilM, FlooM, Cc, Ff, We, Ws, Ww, Wn

$1,20,4,5,3,0,1,3,1,1,1,1$

$2,20,4,3,3,0,1,3,1,1,1,1$

$3,20,4,4,3,0,1,3,1,1,1,1$

$4,20,3,2,3,0,1,3,1,1,1,1$

$5,20,4,2,3,0,1,3,1,1,1,1$

$6,20,8,8,3,0,1,3,1,1,1,1$

$7,20,12,6,3,0,1,3,1,1,1,1$

$8,20,12,6,3,0,1,3,1,1,1,1$

$9,20,12,6,3,0,1,3,1,1,1,1$

$10,20,12,6,3,0,1,3,1,1,1,1$

$11,20,4,5,3,3,1,2,1,1,1,1$

$12,20,4,3,3,3,1,2,1,1,1,1$

$13,20,4,4,3,3,1,2,1,1,1,1$

$14,20,3,2,3,3,1,2,1,1,1,1$

$15,20,4,2,3,3,1,2,1,1,1,1$

$16,20,8,8,3,3,1,2,1,1,1,1$

$17,20,12,6,3,3,1,2,1,1,1,1$

$18,20,12,6,3,3,1,2,1,1,1,1$

$19,20,12,6,3,3,1,2,1,1,1,1$

$20,20,12,6,3,3,1,2,1,1,1,1$

$21,20,4,5,3,6,1,2,1,1,1,1$

$22,20,4,3,3,6,1,2,1,1,1,1$ 
車

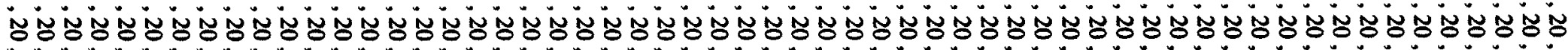

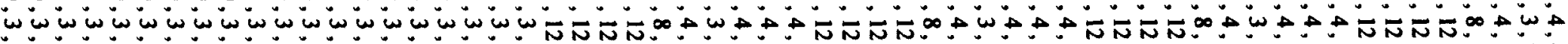

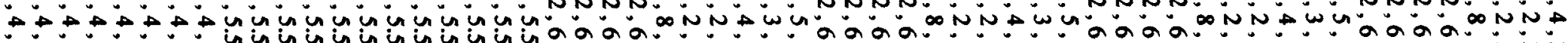
w

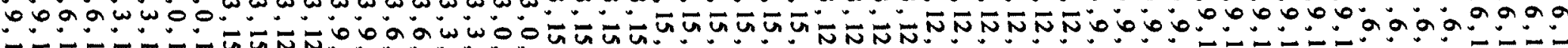
- - - - NNNNNNNN-

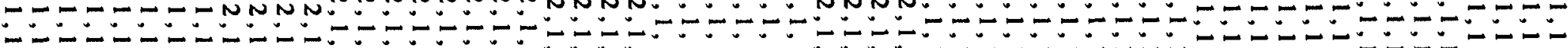

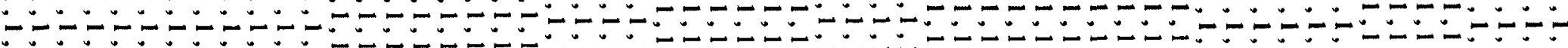

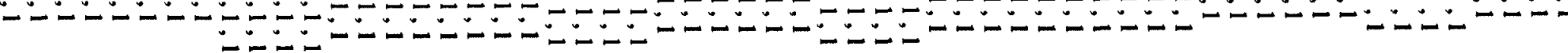


$81,20,3,4,3,12,1,2,1,1,1,1$

$82,20,3,4,3,12,1,2,1,1,1,1$

$83,20,3,4,3,15,1,2,1,1,1,1$

$84,20,3,4,3,15,1,2,1,1,1,1$

$85,20,36,1.5,3,0,1,2,1,1,1,1$

$86,20,36,1.5,3,3,1,2,1,1,1,1$

$87,20,36,1.5,3,6,1,2,1,1,1,1$

$88,20,36,1.5,3,9,1,2,1,1,1,1$

$89,20,36,1.5,3,12,1,2,1,1,1,1$

$90,20,36,1.5,3,15,1,2,1,1,1,1$

04):BYid, BYdesc,BYthicM,BYcond(W/M.K),BYdens(kg/M3),BYspec(J/KgK),BYemis

1, Gypsum, $0.1,0.17,790,900,0.9$

2 ,Floor.WLJ-1.1, $0.292,0.093,204,1146,0.9$

3 ,Concrete, $0.2,0.76,1900,880,0.9$

05A):DVid, DVnol,DVno2,DVsoffM,DVsillM,DVwidtM, WindV(M/S), BreakTempC, DotNo (Dvtimes)

$1,1,85,2,0,0.9,0,10000,2$

05B):DVtimeS

0,3600

05C):OpeningFactor

0,0

05A):DVid, DVnol,DVno2,DVsoftM,DVsillM,DVwidtM, WindV(M/S), BreakTempC, DotNo (Dvtimes)

$2,1,2,2,0,0.9,0,10000,2$

05B):DVtimeS

0,3600

05C):OpeningFactor

1,1

05A):DVid, DVnol,DVno2,DVsoffM,DVsillM,DVwidtM, WindV(M/S), BreakTempC, DotNo (Dvtimes)

$3,1,3,2,0,0.9,0,10000,2$

05B):DVtimeS

0,3600

05C):OpeningFactor

1,1

05A):DVid, DVnol,DVno2,DVsoftM,DVsillM,DVwidtM, WindV(M/S), BreakTempC, DotNo (Dvtimes)

$4,1,4,2,0,0.9,0,10000,2$

05B):DVtimeS

0,3600

05C):OpeningFactor

1,1

05A):DVid, DVno1,DVno2,DVsoffM,DVsillM,DVwidtM, WindV(M/S), BreakTempC, DotNo (Dvtimes)

$5,1,5,2,0,0.9,0,10000,2$

05B):DVtimeS

0,3600

05C):OpeningFactor

1,1

05A):DVid, DVnol,DVno2,DVsoffM,DVsillM,DVwidtM, WindV(M/S), BreakTempC, DotNo (Dvtimes) $6,6,85,2,0,0.9,0,10000,2$

05B):DVtimeS

0,3600

05C).OpeningFactor

0,0

0SA):DVid, DVno1,DVno2,DVsoffM,DVsillM,DVwidtM, WindV(M/S), BreakTempC, DotNo (Dvtimes) $7,7,85,2,0,0.9,0,10000,2$

05B):DVtimeS

0,3600

05C):OpeningFactor

0,0

05A):DVid, DVnol,DVno2,DVsoffM,DVsillM,DVwidtM, WindV(M/S), BreakTempC, DotNo (Dvtimes) $8,8,85,2,0,0.9,0,10000,2$ 
05B):DVtimeS

0,3600

05C):OpeningFactor

0,0

05A):DVid, DVno1,DVno2,DVsoffM,DVsillM,DVwidtM, WindV(M/S), BreakTempC, DotNo (Dvtimes)

$9,9,85,2,0,0.9,0,10000,2$

05B):DVtimes

0,3600

05C):OpeningFactor

0,0

05A):DVid, DVno1,DVno2,DVsoffM,DVsillM,DVwidtM, WindV(M/S), BreakTempC, DotNo (Dvtimes)

$10,10,85,2,0,0.9,0,10000,2$

05B):DVtimeS

0,3600

05C):OpeningFactor

0,0

05A):DVid, DVno1,DVno2,DVsoftM,DVsillM,DVwidtM, WindV(M/S), BreakTempC, DotNo (Dvtimes)

$11,11,86,2,0,0.9,0,10000,2$

05B):DVtimeS

0,3600

05C).OpeningFactor

0,0

05A):DVid, DVno1,DVno2,DVsoffM,DVsillM,DVwidtM, WindV(M/S), BreakTempC, DotNo (Dvtimes)

$12,11,12,2,0,0.9,0,10000,2$

05B):DVtimeS

0,3600

05C):OpeningFactor

1,1

05A):DVid, DVnol,DVno2,DVsoffM,DVsillM,DVwidtM, WindV(M/S), BreakTempC, DotNo (Dvtimes)

$13,11,13,2,0,0.9,0,10000,2$

05B):DVtimeS

0,3600

05C):OpeningFactor

1,1

05A):DVid, DVno1,DVno2,DVsoffM,DVsillM,DVwidtM, WindV(M/S), BreakTempC, DotNo (Dvtimes)

$14,11,14,2,0,0.9,0,10000,2$

05B):DVtimeS

0,3600

05C).OpeningFactor

1,1

05A):DVid, DVnol,DVno2,DVsoftM,DVsillM,DVwidtM, WindV(M/S), BreakTempC, DotNo (Dvtimes)

$15,11,15,2,0,0.9,0,10000,2$

05B):DVtimeS

0,3600

05C):OpeningFactor

1,1

05A):DVid, DVno1,DVno2,DVsoftM,DVsillM,DVwidtM, WindV(M/S), BreakTempC, DotNo (Dvtimes)

$16,16,86,2,0,0.9,0,10000,2$

05B):DVtimeS

0,3600

05C):OpeningFactor

0,0

05A):DVid, DVno1,DVno2,DVsoftM,DVsillM,DVwidtM, WindV(M/S), BreakTempC, DotNo (Dvtimes)

$17,17,86,2,0,0.9,0,10000,2$

05B):DVtimeS

0,3600

05C):OpeningFactor

0,0 
05A):DVid, DVnol,DVno2,DVsoffM,DVsillM,DVwidtM, WindV(M/S), BreakTempC, DotNo (Dvtimes) $18,18,86,2,0,0.9,0,10000,2$

05B):DVtimeS

0,3600

05C).OpeningFactor

0,0

05A):DVid, DVno1,DVno2,DVsoffM,DVsillM,DVwidtM, WindV(M/S), BreakTempC, DotNo (Dvtimes)

$19,19,86,2,0,0.9,0,10000,2$

05B):DVtimeS

0,3600

05C):OpeningFactor

0,0

05A):DVid, DVnol,DVno2,DVsoffM,DVsillM,DVwidtM, WindV(M/S), BreakTempC, DotNo (Dvtimes)

$20,20,86,2,0,0.9,0,10000,2$

05B):DVtimeS

0,3600

05C):OpeningFactor

0,0

05A):DVid, DVnol,DVno2,DVsoffM,DVsillM,DVwidtM, WindV(M/S), BreakTempC, DotNo (Dvtimes)

$21,21,87,2,0,0.9,0,10000,2$

05B):DVtimeS

0,3600

05C):OpeningFactor

0,0

05A):DVid, DVno1,DVno2,DVsoffM,DVsillM,DVwidtM, WindV(M/S), BreakTempC, DotNo (Dvtimes)

$22,21,22,2,0,0.9,0,10000,2$

05B):DVtimeS

0,3600

05C):OpeningFactor

1,1

05A):DVid, DVno1,DVno2,DVsoffM,DVsillM,DVwidtM, WindV(M/S), BreakTempC, DotNo (Dvtimes)

$23,21,23,2,0,0.9,0,10000,2$

05B):DVtimeS

0,3600

05C):OpeningFactor

1,1

05A):DVid, DVnol,DVno2,DVsoffM,DVsillM,DVwidtM, WindV(M/S), BreakTempC, DotNo (Dvtimes)

$24,21,24,2,0,0.9,0,10000,2$

05B):DVtimeS

0,3600

05C):OpeningFactor

1,1

05A):DVid, DVno1,DVno2,DVsoffM,DVsillM,DVwidtM, WindV(M/S), BreakTempC, DotNo (Dvtimes)

$25,21,25,2,0,0.9,0,10000,2$

05B):DVtimeS

0,3600

05C):OpeningFactor

1,1

05A):DVid, DVno1,DVno2,DVsoffM,DVsillM,DVwidtM, WindV(M/S), BreakTempC, DotNo (Dvtimes)

$26,26,87,2,0,0.9,0,10000,2$

05B):DVtimeS

0,3600

05C):OpeningFactor

0,0

05A):DVid, DVnol,DVno2,DVsoffM,DVsillM,DVwidtM, WindV(M/S), BreakTempC, DotNo (Dvtimes)

$27,27,87,2,0,0.9,0,10000,2$

05B):DVtimeS

0,3600 
05C):OpeningFactor

0,0

05A):DVid, DVnol,DVno2,DVsoffM,DVsillM,DVwidtM, WindV(M/S), BreakTempC, DotNo (Dvtimes)

$28,28,87,2,0,0.9,0,10000,2$

05B):DVtimeS

0,3600

05C):OpeningFactor

0,0

05A):DVid, DVnol,DVno2,DVsoffM,DVsillM,DVwidtM, WindV(M/S), BreakTempC, DotNo (Dvtimes)

$29,29,87,2,0,0.9,0,10000,2$

05B):DVtimeS

0,3600

05C):OpeningFactor

0,0

05A):DVid, DVno1,DVno2,DVsoffM,DVsillM,DVwidtM, WindV(M/S), BreakTempC, DotNo (Dvtimes) $30,30,87,2,0,0.9,0,10000,2$

05B):DVtimeS

0,3600

05C):OpeningFactor

0,0

05A):DVid, DVno1,DVno2,DVsoffM,DVsillM,DVwidtM, WindV(M/S), BreakTempC, DotNo (Dvtimes) $31,31,88,2,0,0.9,0,10000,2$

05B):DVtimeS

0,3600

05C):OpeningFactor

0,0

05A):DVid, DVno1,DVno2,DVsoffM,DVsillM,DVwidtM, WindV(M/S), BreakTempC, DotNo (Dvtimes)

$32,31,32,2,0,0.9,0,10000,2$

05B):DVtimeS

0,3600

05C):OpeningFactor

1,1

05A):DVid, DVno1,DVno2,DVsoffM,DVsillM,DVwidtM, WindV(M/S), BreakTempC, DotNo (Dvtimes)

$33,31,33,2,0,0.9,0,10000,2$

05B):DVtimes

0,3600

05C):OpeningFactor

1,1

05A):DVid, DVno1,DVno2,DVsoffM,DVsillM,DVwidtM, WindV(M/S), BreakTempC, DotNo (Dvtimes)

$34,31,34,2,0,0.9,0,10000,2$

05B):DVtimeS

0,3600

05C):OpeningFactor

1,1

05A):DVid, DVnol,DVno2,DVsoftM,DVsillM,DVwidtM, WindV(M/S), BreakTempC, DotNo (Dvtimes)

$35,31,35,2,0,0.9,0,10000,2$

05B):DVtimeS

0,3600

05C):OpeningFactor

1,1

05A):DVid, DVnol,DVno2,DVsoffM,DVsillM,DVwidtM, WindV(M/S), BreakTempC, DotNo (Dvtimes)

$36,36,88,2,0,0.9,0,10000,2$

05B):DVtimeS

0,3600

05C).OpeningFactor

0,0

05A):DVid, DVnol,DVno2,DVsoffM,DVsillM,DVwidtM, WindV(M/S), BreakTempC, DotNo (Dvtimes)

$37,37,88,2,0,0.9,0,10000,2$ 
05B):DVtimeS

0,3600

05C).OpeningFactor

0,0

05A):DVid, DVnol,DVno2,DVsoffM,DVsillM,DVwidtM, WindV(M/S), BreakTempC, DotNo (Dvtimes)

$38,38,88,2,0,0.9,0,10000,2$

05B):DVtimeS

0,3600

05C).OpeningFactor

0,0

05A):DVid, DVno1,DVno2,DVsoffM,DVsillM,DVwidtM, WindV(M/S), BreakTempC, DotNo (Dvtimes)

$39,38,88,2,0,0.9,0,10000,2$

05B):DVtimeS

0,3600

05C):OpeningFactor

0,0

05A):DVid, DVnol,DVno2,DVsoffM,DVsillM,DVwidtM, WindV(M/S), BreakTempC, DotNo (Dvtimes)

$40,40,88,2,0,0.9,0,10000,2$

05B):DVtimeS

0,3600

05C):OpeningFactor

0,0

05A):DVid, DVnol,DVno2,DVsoffM,DVsillM,DVwidtM, WindV(M/S), BreakTempC, DotNo (Dvtimes)

$41,41,89,2,0,0.9,0,10000,2$

05B):DVtimeS

0,3600

05C):OpeningFactor

0,0

0SA):DVid, DVnol,DVno2,DVsoffM,DVsillM,DVwidtM, WindV(M/S), BreakTempC, DotNo (Dvtimes)

$42,41,42,2,0,0.9,0,10000,2$

05B):DVtimeS

0,3600

05C):OpeningFactor

1,1

05A):DVid, DVnol,DVno2,DVsoffM,DVsillM,DVwidtM, WindV(M/S), BreakTempC, DotNo (Dvtimes)

$43,41,43,2,0,0.9,0,10000,2$

05B):DVtimeS

0,3600

05C):OpeningFactor

1,1

05A):DVid, DVno1,DVno2,DVsoffM,DVsillM,DVwidtM, WindV(M/S), BreakTempC, DotNo (Dvtimes)

$44,41,44,2,0,0.9,0,10000,2$

05B):DVtimeS

0,3600

05C).OpeningFactor

1,1

05A):DVid, DVnol,DVno2,DVsoffM,DVsillM,DVwidtM, WindV(M/S), BreakTempC, DotNo (Dvtimes)

$45,41,45,2,0,0.9,0,10000,2$

05B):DVtimes

0,3600

05C):OpeningFactor

1,1

05A):DVid, DVnol,DVno2,DVsoffM,DVsillM,DVwidtM, WindV(M/S), BreakTempC, DotNo (Dvtimes)

$46,46,89,2,0,0.9,0,10000,2$

05B):DVtimeS

0,3600

05C).OpeningFactor

$\mathbf{0}, \mathbf{0}$ 
05A):DVid, DVnol,DVno2,DVsoffM,DVsillM,DVwidtM, WindV(M/S), BreakTempC, DotNo (Dvtimes) $47,47,89,2,0,0.9,0,10000,2$

05B):DVtimeS

0,3600

0SC):OpeningFactor

0,0

05A):DVid, DVnol,DVno2,DVsoffM,DVsillM,DVwidtM, WindV(M/S), BreakTempC, DotNo (Dvtimes) $48,48,89,2,0,0.9,0,10000,2$

05B):DVtimeS

0,3600

05C):OpeningFactor

0,0

05A):DVid, DVnol,DVno2,DVsoffM,DVsillM,DVwidtM, WindV(M/S), BreakTempC, DotNo (Dvtimes) $49,49,89,2,0,0.9,0,10000,2$

05B):DVtimeS

0,3600

05C):OpeningFactor

$\mathbf{0}, \mathbf{0}$

05A):DVid, DVno1,DVno2,DVsoftM,DVsillM,DVwidtM, WindV(M/S), BreakTempC, DotNo (Dvtimes) $50,50,89,2,0,0.9,0,10000,2$

05B):DVtimeS

0,3600

05C):OpeningFactor

0,0

05A):DVid, DVno1,DVno2,DVsoffM,DVsillM,DVwidtM, WindV(M/S), BreakTempC, DotNo (Dvtimes)

$51,51,90,2,0,0.9,0,10000,2$

05B):DVtimeS

0,3600

05C):OpeningFactor

0,0

05A):DVid, DVno1,DVno2,DVsoffM,DVsillM,DVwidtM, WindV(M/S), BreakTempC, DotNo (Dvtimes)

$52,51,52,2,0,0.9,0,10000,2$

05B):DVtimeS

0,3600

05C):OpeningFactor

1,1

05A):DVid, DVnol,DVno2,DVsoffM,DVsillM,DVwidtM, WindV(M/S), BreakTempC, DotNo (Dvtimes)

$53,51,53,2,0,0.9,0,10000,2$

05B):DVtimeS

0,3600

05C):OpeningFactor

1,1

05A):DVid, DVno1,DVno2,DVsoffM,DVsillM,DVwidtM, WindV(M/S), BreakTempC, DotNo (Dvtimes)

$54,51,54,2,0,0.9,0,10000,2$

05B):DVtimeS

0,3600

05C):OpeningFactor

1,1

05A):DVid, DVnol,DVno2,DVsoffM,DVsillM,DVwidtM, WindV(M/S), BreakTempC, DotNo (Dvtimes) $55,51,55,2,0,0.9,0,10000,2$

05B):DVtimeS

0,3600

05C):OpeningFactor

1,1

05A):DVid, DVnol,DVno2,DVsoftM,DVsillM,DVwidtM, WindV(M/S), BreakTempC, DotNo (Dvtimes) $56,56,90,2,0,0.9,0,10000,2$

05B):DVtimeS

0,3600 
05C):OpeningFactor

0,0

05A):DVid, DVnol,DVno2,DVsoffM,DVsillM,DVwidtM, WindV(M/S), BreakTempC, DotNo (Dvtimes)

$57,57,90,2,0,0.9,0,10000,2$

05B):DVtimeS

0,3600

05C):OpeningFactor

0,0

05A):DVid, DVnol,DVno2,DVsoffM,DVsillM,DVwidtM, WindV(M/S), BreakTempC, DotNo (Dvtimes)

$58,58,90,2,0,0.9,0,10000,2$

05B):DVtimeS

0,3600

05C):OpeningFactor

0,0

05A):DVid, DVno1,DVno2,DVsoffM,DVsillM,DVwidtM, WindV(M/S), BreakTempC, DotNo (Dvtimes)

$59,59,90,2,0,0.9,0,10000,2$

05B):DVtimeS

0,3600

05C):OpeningFactor

0,0

05A):DVid, DVno1,DVno2,DVsoftM,DVsillM,DVwidtM, WindV(M/S), BreakTempC, DotNo (Dvtimes) $60,60,90,2,0,0.9,0,10000,2$

OSB):DVtimeS

0,3600

05C):OpeningFactor

0,0

05A):DVid, DVno1,DVno2,DVsoftM,DVsillM,DVwidtM, WindV(M/S), BreakTempC, DotNo (Dvtimes)

$61,73,85,2,0,0.9,0,10000,2$

05B):DVtimeS

0,3600

05C):OpeningFactor

0,0

05A):DVid, DVnol,DVno2,DVsoffM,DVsillM,DVwidtM, WindV(M/S), BreakTempC, DotNo (Dvtimes)

$62,74,85,2,0,0.9,0,10000,2$

05B):DVtimeS

0,3600

05C):OpeningFactor

0,0

05A):DVid, DVnol,DVno2,DVsoffM,DVsillM,DVwidtM, WindV(M/S), BreakTempC, DotNo (Dvtimes)

$63,75,86,2,0,0.9,0,10000,2$

05B):DVtimeS

0,3600

05C):OpeningFactor

0,0

05A):DVid, DVnol,DVno2,DVsoffM,DVsillM,DVwidtM, WindV(M/S), BreakTempC, DotNo (Dvtimes)

$64,76,86,2,0,0.9,0,10000,2$

05B):DVtimeS

0,3600

05C):OpeningFactor

0,0

05A):DVid, DVnol,DVno2,DVsoffM,DVsillM,DVwidtM, WindV(M/S), BreakTempC, DotNo (Dvtimes)

$65,77,87,2,0,0.9,0,10000,2$

05B):DVtimeS

0,3600

05C):OpeningFactor

0,0

05A):DVid, DVnol,DVno2,DVsoffM,DVsillM,DVwidtM, WindV(M/S), BreakTempC, DotNo (Dvtimes)

$66,78,87,2,0,0.9,0,10000,2$ 
05B):DVtimeS

0,3600

05C):OpeningFactor

0,0

0SA):DVid, DVnol,DVno2,DVsoffM,DVsillM,DVwidtM, WindV(M/S), BreakTempC, DotNo (Dvtimes)

$67,79,88,2,0,0.9,0,10000,2$

05B):DVtimeS

0,3600

05C):OpeningFactor

0,0

05A):DVid, DVnol,DVno2,DVsoffM,DVsillM,DVwidtM, WindV(M/S), BreakTempC, DotNo (Dvtimes)

$68,80,88,2,0,0.9,0,10000,2$

05B):DVtimeS

0,3600

05C):OpeningFactor

0,0

05A):DVid, DVno1,DVno2,DVsoffM,DVsillM,DVwidtM, WindV(M/S), BreakTempC, DotNo (Dvtimes)

$69,81,89,2,0,0.9,0,10000,2$

05B):DVtimeS

0,3600

05C):OpeningFactor

0,0

05A):DVid, DVno1,DVno2,DVsoffM,DVsillM,DVwidtM, WindV(M/S), BreakTempC, DotNo (Dvtimes)

$70,82,89,2,0,0.9,0,10000,2$

05B):DVtimeS

0,3600

05C):OpeningFactor

0,0

05A):DVid, DVnol,DVno2,DVsoffM,DVsillM,DVwidtM, WindV(M/S), BreakTempC, DotNo (Dvtimes)

$71,83,90,2,0,0.9,0,10000,2$

05B):DVtimeS

0,3600

05C):OpeningFactor

0,0

05A):DVid, DVnol,DVno2,DVsoffM,DVsillM,DVwidtM, WindV(M/S), BreakTempC, DotNo (Dvtimes)

$72,84,90,2,0,0.9,0,10000,2$

05B):DVtimeS

0,3600

05C):OpeningFactor

0,0

05A):DVid, DVnol,DVno2,DVsoffM,DVsillM,DVwidtM, WindV(M/S), BreakTempC, DotNo (Dvtimes)

$73,61,73,3,0,3,0,10000,2$

0SB):DVtimeS

0,3600

05C):OpeningFactor

1,1

05A):DVid, DVnol,DVno2,DVsoftM,DVsillM,DVwidtM, WindV(M/S), BreakTempC, DotNo (Dvtimes)

$74,62,74,3,0,3,0,10000,2$

05B):DVtimeS

0,3600

05C):OpeningFactor

1,1

05A):DVid, DVnol,DVno2,DVsoftM,DVsillM,DVwidtM, WindV(M/S), BreakTempC, DotNo (Dvtimes)

$75,63,75,3,0,3,0,10000,2$

05B):DVtimeS

0,3600

05C):OpeningF actor

1,1 
05A):DVid, DVnol,DVno2,DVsoffM,DVsillM,DVwidtM, WindV(M/S), BreakTempC, DotNo (Dvtimes) $76,64,76,3,0,3,0,10000,2$

05B):DVtimeS

0,3600

05C).OpeningFactor

1,1

05A):DVid, DVnol,DVno2,DVsoffM,DVsillM,DVwidtM, WindV(M/S), BreakTempC, DotNo (Dvtimes) $77,65,77,3,0,3,0,10000,2$

05B):DVtimes

0,3600

05C):OpeningFactor

1,1

05A):DVid, DVnol,DVno2,DVsoffM,DVsillM,DVwidtM, WindV(M/S), BreakTempC, DotNo (Dvtimes) $78,66,78,3,0,3,0,10000,2$

05B):DVtimeS

0,3600

05C):OpeningFactor

1,1

0SA):DVid, DVnol,DVno2,DVsoffM,DVsillM,DVwidtM, WindV(M/S), BreakTempC, DotNo (Dvtimes) $79,67,79,3,0,3,0,10000,2$

05B):DVtimeS

0,3600

05C):OpeningFactor

1,1

05A):DVid, DVnol,DVno2,DVsoffM,DVsillM,DVwidtM, WindV(M/S), BreakTempC, DotNo (Dvtimes) $80,68,80,3,0,3,0,10000,2$

05B):DVtimeS

0,3600

05C):OpeningFactor

1,1

05A):DVid, DVno1,DVno2,DVsoftM,DVsillM,DVwidtM, WindV(M/S), BreakTempC, DotNo (Dvtimes)

$81,69,81,3,0,3,0,10000,2$

05B):DVtimeS

0,3600

05C):OpeningFactor

1,1

05A):DVid, DVnol,DVno2,DVsoffM,DVsillM,DVwidtM, WindV(M/S), BreakTempC, DotNo (Dvtimes)

$82,70,82,3,0,3,0,10000,2$

05B):DVtimeS

0,3600

05C).OpeningFactor

1,1

05A):DVid, DVnol,DVno2,DVsoffM,DVsillM,DVwidtM, WindV(M/S), BreakTempC, DotNo (Dvtimes)

$83,71,83,3,0,3,0,10000,2$

05B):DVtimeS

0,3600

05C).OpeningFactor

1,1

05A):DVid, DVnol,DVno2,DVsoffM,DVsillM,DVwidtM, WindV(M/S), BreakTempC, DotNo (Dvtimes)

$84,72,84,3,0,3,0,10000,2$

05B):DVtimeS

0,3600

05C):OpeningFactor

1,1

05A):DVid, DVnol,DVno2,DVsoffM,DVsillM,DVwidtM, WindV(M/S), BreakTempC, DotNo (Dvtimes)

$85,73,91,2,0,1.8,0,10000,2$

05B):DVtimeS

0,3600 
05C).OpeningFactor

0,0

05A):DVid, DVnol,DVno2,DVsoftM,DVsillM,DVwidtM, WindV(M/S), BreakTempC, DotNo (Dvtimes)

$86,74,91,2,0,1.8,0,10000,2$

05B):DVtimeS

0,3600

05C):OpeningFactor

0,0

05A):DVid, DVnol,DVno2,DVsoffM,DVsillM,DVwidtM, WindV(M/S), BreakTempC, DotNo (Dvtimes)

$87,1,91,2.5,1,1.5,0,300,2$

05B):DVtimeS

0,3600

05C):OpeningFactor

0,1

05A):DVid, DVnol,DVno2,DVsoftM,DVsillM,DVwidtM, WindV(M/S), BreakTempC, DotNo (Dvtimes)

$88,2,91,2.5,1,1.5,0,300,2$

05B):DVtimeS

0,3600

05C):OpeningFactor

0,1

05A):DVid, DVno1,DVno2,DVsoffM,DVsillM,DVwidtM, WindV(M/S), BreakTempC, DotNo (Dvtimes)

$89,3,91,2.5,1,1.5,0,300,2$

05B):DVtimeS

0,3600

05C):OpeningFactor

0,1

05A):DVid, DVnol,DVno2,DVsoftM,DVsillM,DVwidtM, WindV(M/S), BreakTempC, DotNo (Dvtimes)

$90,6,91,2.5,1,3,0,300,2$

05B):DVtimeS

0,3600

05C):OpeningFactor

0,1

05A):DVid, DVno1,DVno2,DVsofm,DVsillM,DVwidtM, WindV(M/S), BreakTempC, DotNo (Dvtimes)

$91,7,91,2.5,1,3,0,300,2$

05B):DVtimeS

0,3600

0SC):OpeningFactor

0,1

05A):DVid, DVnol,DVno2,DVsoftM,DVsillM,DVwidtM, WindV(M/S), BreakTempC, DotNo (Dvtimes)

$92,8,91,2.5,1,3,0,300,2$

05B):DVtimeS

0,3600

05C):OpeningFactor

0,1

05A):DVid, DVnol,DVno2,DVsoffM,DVsillM,DVwidtM, WindV(M/S), BreakTempC, DotNo (Dvtimes) $93,9,91,2.5,1,3,0,300,2$

05B):DVtimeS

0,3600

05C):OpeningFactor

0,1

05A):DVid, DVnol,DVno2,DVsoftM,DVsillM,DVwidtM, WindV(M/S), BreakTempC, DotNo (Dvtimes)

$94,10,91,2.5,1,3,0,300,2$

05B):DVtimeS

0,3600

05C):OpeningFactor

0,1

05A):DVid, DVno1,DVno2,DVsoffM,DVsillM,DVwidtM, WindV(M/S), BreakTempC, DotNo (Dvtimes) $95,11,91,2.5,1,1.5,0,300,2$ 
05B):DVtimeS

0,3600

05C):OpeningFactor

0,1

05A):DVid, DVnol ,DVno2,DVsoftM,DVsillM,DVwidtM, WindV(M/S), BreakTempC, DotNo (Dvtimes)

$96,12,91,2.5,1,1.5,0,300,2$

05B):DVtimeS

0,3600

05C):OpeningFactor

0,1

05A):DVid, DVnol,DVno2,DVsoffM,DVsillM,DVwidtM, WindV(M/S), BreakTempC, DotNo (Dvtimes) $97,13,91,2.5,1,1.5,0,300,2$

05B):DVtimeS

0,3600

05C):OpeningFactor

0,1

05A):DVid, DVno1,DVno2,DVsoftM,DVsillM,DVwidtM, WindV(M/S), BreakTempC, DotNo (Dvtimes) $98,16,91,2.5,1,3,0,300,2$

05B):DVtimeS

0,3600

05C).OpeningFactor

0,1

05A):DVid, DVnol,DVno2,DVsoffM,DVsillM,DVwidtM, WindV(M/S), BreakTempC, DotNo (Dvtimes) $99,17,91,2.5,1,3,0,300,2$

05B):DVtimeS

0,3600

05C):OpeningFactor

0,1

05A):DVid, DVnol,DVno2,DVsoffM,DVsillM,DVwidtM, WindV(M/S), BreakTempC, DotNo (Dvtimes) $100,18,91,2.5,1,3,0,300,2$

05B):DVtimeS

0,3600

05C):OpeningFactor

0,1

05A):DVid, DVno1,DVno2,DVsoffM,DVsillM,DVwidtM, WindV(M/S), BreakTempC, DotNo (Dvtimes)

$101,19,91,2.5,1,3,0,300,2$

05B):DVtimeS

0,3600

05C):OpeningFactor

0,1

05A):DVid, DVno1,DVno2,DVsoffM,DVsillM,DVwidtM, WindV(M/S), BreakTempC, DotNo (Dvtimes)

$102,20,91,2.5,1,3,0,300,2$

05B):DVtimeS

0,3600

05C):OpeningFactor

0,1

05A):DVid, DVnol,DVno2,DVsoffM,DVsillM,DVwidtM, WindV(M/S), BreakTempC, DotNo (Dvtimes)

$103,21,91,2.5,1,1.5,0,300,2$

05B):DVtimeS

0,3600

05C).OpeningFactor

0,1

05A):DVid, DVnol,DVno2,DVsoffM,DVsillM,DVwidtM, WindV(M/S), BreakTempC, DotNo (Dvtimes)

$104,22,91,2.5,1,1.5,0,300,2$

05B):DVtimeS

0,3600

05C).OpeningFactor

0,1 
05A):DVid, DVnol,DVno2,DVsoffM,DVsillM,DVwidtM, WindV(M/S), BreakTempC, DotNo (Dvtimes) $105,23,91,2.5,1,1.5,0,300,2$

05B):DVtimeS

0,3600

05C).OpeningFactor

0,1

05A):DVid, DVnol,DVno2,DVsoffM,DVsillM,DVwidtM, WindV(M/S), BreakTempC, DotNo (Dvtimes) $106,26,91,2.5,1,3,0,300,2$

05B):DVtimeS

0,3600

05C):OpeningFactor

0,1

05A):DVid, DVnol,DVno2,DVsoffM,DVsillM,DVwidtM, WindV(M/S), BreakTempC, DotNo (Dvtimes) $107,27,91,2.5,1,3,0,300,2$

05B):DVtimeS

0,3600

05C):OpeningFactor

0,1

05A):DVid, DVnol,DVno2,DVsoffM,DVsillM,DVwidtM, WindV(M/S), BreakTempC, DotNo (Dvtimes) $108,28,91,2.5,1,3,0,300,2$

05B):DVtimeS

0,3600

05C):OpeningFactor

0,1

05A):DVid, DVno1,DVno2,DVsoffM,DVsillM,DVwidtM, WindV(M/S), BreakTempC, DotNo (Dvtimes) $109,29,91,2.5,1,3,0,300,2$

05B):DVtimeS

0,3600

05C):OpeningFactor

0,1

05A):DVid, DVnol,DVno2,DVsoftM,DVsillM,DVwidtM, WindV(M/S), BreakTempC, DotNo (Dvtimes) $110,30,91,2.5,1,3,0,300,2$

05B):DVtimeS

0,3600

0SC):OpeningFactor

0,1

05A):DVid, DVnol,DVno2,DVsoffM,DVsillM,DVwidtM, WindV(M/S), BreakTempC, DotNo (Dvtimes)

$111,31,91,2.5,1,1.5,0,300,2$

05B):DVtimeS

0,3600

05C):OpeningFactor

0,1

05A):DVid, DVnol,DVno2,DVsoffM,DVsillM,DVwidtM, WindV(M/S), BreakTempC, DotNo (Dvtimes)

$112,32,91,2.5,1,1.5,0,300,2$

05B):DVtimeS

0,3600

05C):OpeningFactor

0,1

0SA):DVid, DVno1,DVno2,DVsoffM,DVsillM,DVwidtM, WindV(M/S), BreakTempC, DotNo (Dvtimes)

$113,33,91,2.5,1,1.5,0,300,2$

05B):DVtimeS

0,3600

05C):OpeningFactor

0,1

05A):DVid, DVno1,DVno2,DVsoffM,DVsillM,DVwidtM, WindV(M/S), BreakTempC, DotNo (Dvtimes)

$114,36,91,2.5,1,3,0,300,2$

05B):DVtimeS

0,3600 
0SC):OpeningFactor

0,1

05A):DVid, DVnol,DVno2,DVsoffM,DVsillM,DVwidtM, WindV(M/S), BreakTempC, DotNo (Dvtimes)

$115,37,91,2.5,1,3,0,300,2$

05B):DVtimeS

0,3600

05C):OpeningFactor

0,1

05A):DVid, DVnol,DVno2,DVsoffM,DVsillM,DVwidtM, WindV(M/S), BreakTempC, DotNo (Dvtimes)

$116,38,91,2.5,1,3,0,300,2$

05B):DVtimeS

0,3600

05C):OpeningFactor

0,1

05A):DVid, DVno1,DVno2,DVsoffM,DVsillM,DVwidtM, WindV(M/S), BreakTempC, DotNo (Dvtimes)

$117,39,91,2.5,1,3,0,300,2$

05B):DVtimeS

0,3600

0SC):OpeningFactor

0,1

05A):DVid, DVnol,DVno2,DVsoffM,DVsillM,DVwidtM, WindV(M/S), BreakTempC, DotNo (Dvtimes)

$118,40,91,2.5,1,3,0,300,2$

05B):DVtimeS

0,3600

05C).OpeningFactor

0,1

05A):DVid, DVnol,DVno2,DVsoffM,DVsillM,DVwidtM, WindV(M/S), BreakTempC, DotNo (Dvtimes)

$119,41,91,2.5,1,1.5,0,300,2$

05B):DVtimeS

0,3600

05C).OpeningFactor

0,1

05A):DVid, DVno1,DVno2,DVsoffM,DVsillM,DVwidtM, WindV(M/S), BreakTempC, DotNo (Dvtimes)

$120,42,91,2.5,1,1.5,0,300,2$

05B):DVtimeS

0,3600

05C).OpeningFactor

0,1

05A):DVid, DVnol,DVno2,DVsoftM,DVsillM,DVwidtM, WindV(M/S), BreakTempC, DotNo (Dvtimes)

$121,43,91,2.5,1,1.5,0,300,2$

05B):DVtimeS

0,3600

05C).OpeningFactor

0,1

05A):DVid, DVnol,DVno2,DVsoffM,DVsillM,DVwidtM, WindV(M/S), BreakTempC, DotNo (Dvtimes)

$122,46,91,2.5,1,3,0,300,2$

05B):DVtimeS

0,3600

05C):OpeningFactor

0,1

05A):DVid, DVnol,DVno2,DVsoftM,DVsillM,DVwidtM, WindV(M/S), BreakTempC, DotNo (Dvtimes)

$123,47,91,2.5,1,3,0,300,2$

05B):DVtimeS

0,3600

05C).OpeningFactor

0,1

05A):DVid, DVnol,DVno2,DVsoffM,DVsillM,DVwidtM, WindV(M/S), BreakTempC, DotNo (Dvtimes)

$124,48,91,2.5,1,3,0,300,2$ 
05B):DVtimeS

0,3600

05C).OpeningFactor

0,1

05A):DVid, DVno1,DVno2,DVsoffM,DVsillM,DVwidtM, WindV(M/S), BreakTempC, DotNo (Dvtimes)

$125,49,91,2.5,1,3,0,300,2$

05B):DVtimeS

0,3600

05C).OpeningFactor

0,1

05A):DVid, DVnol,DVno2,DVsoffM,DVsillM,DVwidtM, WindV(M/S), BreakTempC, DotNo (Dvtimes)

$126,50,91,2.5,1,3,0,300,2$

05B):DVtimeS

0,3600

05C).OpeningFactor

0,1

05A):DVid, DVnol,DVno2,DVsoffM,DVsillM,DVwidtM, WindV(M/S), BreakTempC, DotNo (Dvtimes)

$127,51,91,2.5,1,1.5,0,300,2$

05B):DVtimeS

0,3600

05C):OpeningFactor

0,1

05A):DVid, DVnol,DVno2,DVsoffM,DVsillM,DVwidtM, WindV(M/S), BreakTempC, DotNo (Dvtimes)

$128,52,91,2.5,1,1.5,0,300,2$

05B):DVtimeS

0,3600

05C).OpeningFactor

0,1

05A):DVid, DVno1,DVno2,DVsoffM,DVsillM,DVwidtM, WindV(M/S), BreakTempC, DotNo (Dvtimes)

$129,53,91,2.5,1,1.5,0,300,2$

05B):DVtimeS

0,3600

05C):OpeningFactor

0,1

05A):DVid, DVnol,DVno2,DVsoftM,DVsillM,DVwidtM, WindV(M/S), BreakTempC, DotNo (Dvtimes)

$130,56,91,2.5,1,3,0,300,2$

05B):DVtimeS

0,3600

05C):OpeningFactor

0,1

05A):DVid, DVnol,DVno2,DVsoffM,DVsillM,DVwidtM, WindV(M/S), BreakTempC, DotNo (Dvtimes)

$131,57,91,2.5,1,3,0,300,2$

05B):DVtimeS

0,3600

05C):OpeningFactor

0,1

05A):DVid, DVno1,DVno2,DVsoffM,DVsillM,DVwidtM, WindV(M/S), BreakTempC, DotNo (Dvtimes)

$132,58,91,2.5,1,3,0,300,2$

05B):DVtimeS

0,3600

05C):OpeningFactor

0,1

05A):DVid, DVnol,DVno2,DVsoffM,DVsillM,DVwidtM, WindV(M/S), BreakTempC, DotNo (Dvtimes)

$133,59,91,2.5,1,3,0,300,2$

05B):DVtimeS

0,3600

05C):OpeningFactor

0,1 
05A):DVid, DVnol,DVno2,DVsoftM,DVsillM,DVwidtM, WindV(M/S), BreakTempC, DotNo (Dvtimes)

$134,60,91,2.5,1,3,0,300,2$

05B):DVtimeS

0,3600

05C):OpeningFactor

0,1

06):CCVid, CnoTop, CnoBot, CthicM, CdiamM

07):RCVid, RnoTop, RnoBot, RthicM, RwidtM, RdeptM

08):SCVid, SCVctNo, SCVtopNo, Sdensity(Persons/M2), |Open/Closed|

$1,61,63,1.3$, Open

$2,62,64,1.3$, Open

$3,63,65,1.3$, Open

$4,64,66,1.3$, Open

$5,65,67,1.3$, Open

$6,66,68,1.3$, Open

$7,67,69,1.3$, Open

$8,68,70,1.3$, Open

$9,69,71,1.3$, Open

$10,70,72,1.3$, Open

09A):MVid, CTid, OpenExtM, TstartS, TendS, DotNo, |Dis|Con|, |M3/S|kg/S|cfin|

09B):MVtimeS

09C):(Out+)|M3/S|kg/S|cfm|

Input Data for Scenarios in Group Two

General Text

Date and Time:15/06/2012 9:45:27 AM

Description:Input file Creator2.xlsm

01):Annual fire frequency

0.00317

02):Population of the building

144

03):Design life of the building in years

50

04):Threshold of injury

0.1

05):Threshold of death

0.8

06):Number of scenarios

5

07):Number of compartments

90

08):Step size for risk assessment in seconds

2

09):Start time of risk assessment in seconds

0

10): End time of risk assessment in seconds

3600

11):Scenario Probability

1 


$\begin{array}{ll}3 & 1 \\ 4 & 1 \\ 5 & 1\end{array}$

\section{Scenario Generation Input Data}

Refer to scenario generation input data for scenarios in group one

\section{Fire Growth Generation Input Data}

Refer to Fire Growth Generation Input Data for scenarios in group one

\section{Building Description Input Data}

The 1st three lines can be anything for description.

1 story building, 3 Room, 2door and 2 windows

Date: June 4, 2004, Time: 10:00 AM

01):ReCT03, BY04, DV05, CCV06, RCV07, SCV08, MV09, FS10, TsimuS, TmaxS, StepSizeS

$90,3,134,0,0,10,0,1,3600,3600,2$

02):HrefM, PambPa, TambC, LoopSize|L|M|S|, Plume|Mc|He|

$0,101325,20, \mathrm{M}, \mathrm{Mc}$

03):CTid, TiniC, WidtM, DeptM, CeilM, FlooM, Cc, Ff, We, Ws, Ww, Wn

$1,20,4,5,3,0,1,3,1,1,1,1$

$2,20,4,3,3,0,1,3,1,1,1,1$

$3,20,4,4,3,0,1,3,1,1,1,1$

$4,20,3,2,3,0,1,3,1,1,1,1$

$5,20,4,2,3,0,1,3,1,1,1,1$

$6,20,8,8,3,0,1,3,1,1,1,1$

$7,20,12,6,3,0,1,3,1,1,1,1$

$8,20,12,6,3,0,1,3,1,1,1,1$

$9,20,12,6,3,0,1,3,1,1,1,1$

$10,20,12,6,3,0,1,3,1,1,1,1$

$11,20,4,5,3,3,1,2,1,1,1,1$

$12,20,4,3,3,3,1,2,1,1,1,1$

$13,20,4,4,3,3,1,2,1,1,1,1$

$14,20,3,2,3,3,1,2,1,1,1,1$

$15,20,4,2,3,3,1,2,1,1,1,1$

$16,20,8,8,3,3,1,2,1,1,1,1$

$17,20,12,6,3,3,1,2,1,1,1,1$

$18,20,12,6,3,3,1,2,1,1,1,1$

$19,20,12,6,3,3,1,2,1,1,1,1$

$20,20,12,6,3,3,1,2,1,1,1,1$

$21,20,4,5,3,6,1,2,1,1,1,1$

$22,20,4,3,3,6,1,2,1,1,1,1$

$23,20,4,4,3,6,1,2,1,1,1,1$

$24,20,3,2,3,6,1,2,1,1,1,1$

$25,20,4,2,3,6,1,2,1,1,1,1$ 


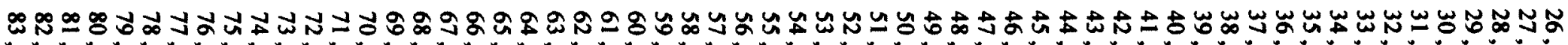

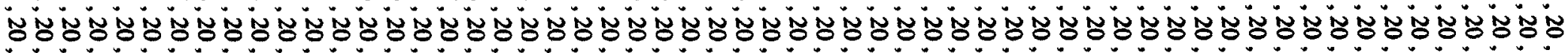

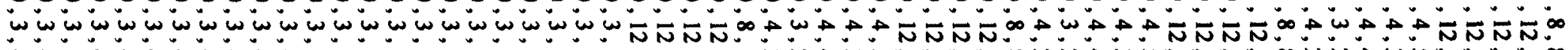

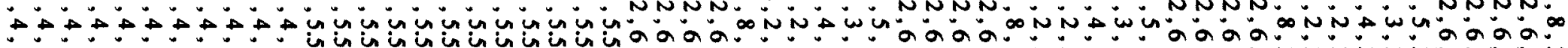

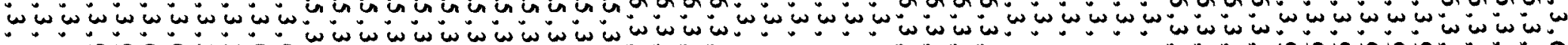

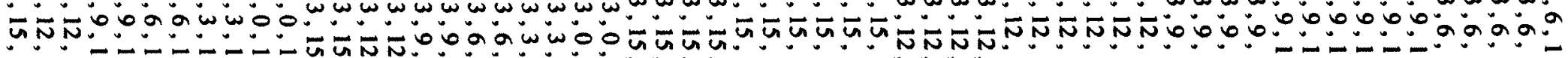
$---N_{N}$

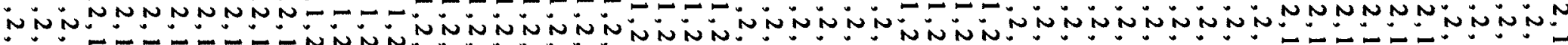

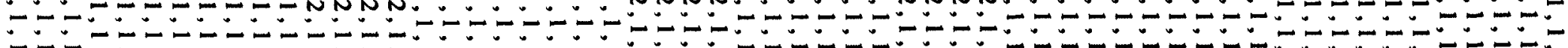

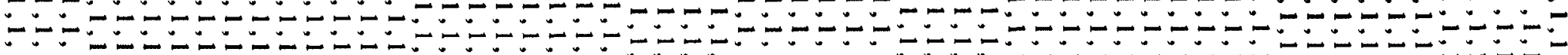

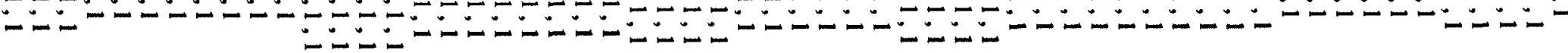


$84,20,3,4,3,15,1,2,1,1,1,1$

$85,20,36,1.5,3,0,1,2,1,1,1,1$

$86,20,36,1.5,3,3,1,2,1,1,1,1$

$87,20,36,1.5,3,6,1,2,1,1,1,1$

$88,20,36,1.5,3,9,1,2,1,1,1,1$

$89,20,36,1.5,3,12,1,2,1,1,1,1$

$90,20,36,1.5,3,15,1,2,1,1,1,1$

04):BYid, BYdesc,BYthicM,BYcond(W/M.K),BYdens(kg/M3),BYspec(J/KgK),BYemis

1 ,Gypsum, $0.1,0.17,790,900,0.9$

2 ,Floor.WL-1.1, $0.292,0.093,204,1146,0.9$

3 ,Concrete, $0.2,0.76,1900,880,0.9$

05A):DVid, DVno1,DVno2,DVsoffM,DVsillM,DVwidtM, WindV(M/S), BreakTempC, DotNo (Dvtimes)

$1,1,85,2,0,0.9,0,10000,2$

05B):DVtimeS

0,3600

05C):OpeningFactor

$0.7,0.7$

05A):DVid, DVnol,DVno2,DVsoffM,DVsillM,DVwidtM, WindV(M/S), BreakTempC, DotNo (Dvtimes)

$2,1,2,2,0,0.9,0,10000,2$

05B):DVtimeS

0,3600

05C).OpeningFactor

1,1

05A):DVid, DVnol,DVno2,DVsoftM,DVsillM,DVwidtM, WindV(M/S), BreakTempC, DotNo (Dvtimes)

$3,1,3,2,0,0.9,0,10000,2$

05B):DVtimeS

0,3600

05C).OpeningFactor

1,1

05A):DVid, DVno1,DVno2,DVsoffM,DVsillM,DVwidtM, WindV(M/S), BreakTempC, DotNo (Dvtimes)

$4,1,4,2,0,0.9,0,10000,2$

05B):DVtimeS

0,3600

05C):OpeningFactor

1,1

05A):DVid, DVnol,DVno2,DVsoffM,DVsillM,DVwidtM, WindV(M/S), BreakTempC, DotNo (Dvtimes)

$5,1,5,2,0,0.9,0,10000,2$

05B):DVtimeS

0,3600

05C):OpeningFactor

1,1

05A):DVid, DVno1,DVno2,DVsoffM,DVsillM,DVwidtM, WindV(M/S), BreakTempC, DotNo (Dvtimes)

$6,6,85,2,0,0.9,0,10000,2$

05B):DVtimeS

0,3600

05C).OpeningFactor

$0.7,0.7$

05A):DVid, DVnol,DVno2,DVsoftM,DVsillM,DVwidtM, WindV(M/S), BreakTempC, DotNo (Dvtimes)

$7,7,85,2,0,0.9,0,10000,2$

05B):DVtimes

0,3600

05C).OpeningFactor

$0.7,0.7$

05A):DVid, DVnol,DVno2,DVsoffM,DVsillM,DVwidtM, WindV(M/S), BreakTempC, DotNo (Dvtimes)

$8,8,85,2,0,0.9,0,10000,2$

05B):DVtimeS

0,3600

05C):OpeningFactor 
$0.7,0.7$

05A):DVid, DVno1,DVno2,DVsoffM,DVsillM,DVwidtM, WindV(M/S), BreakTempC, DotNo (Dvtimes) $9,9,85,2,0,0.9,0,10000,2$

05B):DVtimeS

0,3600

05C):OpeningFactor

$0.7,0.7$

05A):DVid, DVnol,DVno2,DVsoffM,DVsillM,DVwidtM, WindV(M/S), BreakTempC, DotNo (Dvtimes)

$10,10,85,2,0,0.9,0,10000,2$

05B):DVtimes

0,3600

05C).OpeningFactor

$0.7,0.7$

05A):DVid, DVnol,DVno2,DVsoffM,DVsillM,DVwidtM, WindV(M/S), BreakTempC, DotNo (Dvtimes)

$11,11,86,2,0,0.9,0,10000,2$

05B):DVtimeS

0,3600

05C):OpeningFactor

$0.7,0.7$

05A):DVid, DVnol,DVno2,DVsoffM,DVsillM,DVwidtM, WindV(M/S), BreakTempC, DotNo (Dvtimes)

$12,11,12,2,0,0.9,0,10000,2$

05B):DVtimeS

0,3600

05C):OpeningFactor

1,1

05A):DVid, DVnol,DVno2,DVsoffM,DVsillM,DVwidtM, WindV(M/S), BreakTempC, DotNo (Dvtimes)

$13,11,13,2,0,0.9,0,10000,2$

05B):DVtimeS

0,3600

05C):OpeningFactor

1,1

05A):DVid, DVno1,DVno2,DVsoffM,DVsillM,DVwidtM, WindV(M/S), BreakTempC, DotNo (Dvtimes)

$14,11,14,2,0,0.9,0,10000,2$

05B):DVtimes

0,3600

05C):OpeningFactor

1,1

05A):DVid, DVnol,DVno2,DVsoffM,DVsillM,DVwidtM, WindV(M/S), BreakTempC, DotNo (Dvtimes)

$15,11,15,2,0,0.9,0,10000,2$

05B):DVtimeS

0,3600

05C):OpeningFactor

1,1

05A):DVid, DVnol,DVno2,DVsoffM,DVsillM,DVwidtM, WindV(M/S), BreakTempC, DotNo (Dvtimes)

$16,16,86,2,0,0.9,0,10000,2$

05B):DVtimeS

0,3600

05C):OpeningFactor

$0.7,0.7$

05A):DVid, DVnol,DVno2,DVsoffM,DVsillM,DVwidtM, WindV(M/S), BreakTempC, DotNo (Dvtimes)

$17,17,86,2,0,0.9,0,10000,2$

05B):DVtimeS

0,3600

05C):OpeningFactor

$0.7,0.7$

05A):DVid, DVno1,DVno2,DVsoffM,DVsillM,DVwidtM, WindV(M/S), BreakTempC, DotNo (Dvtimes)

$18,18,86,2,0,0.9,0,10000,2$

05B):DVtimeS 
0,3600

05C):OpeningFactor

$0.7,0.7$

05A):DVid, DVnol,DVno2,DVsofm,DVsillM,DVwidtM, WindV(M/S), BreakTempC, DotNo (Dvtimes)

$19,19,86,2,0,0.9,0,10000,2$

05B):DVtimeS

0,3600

05C):OpeningFactor

$0.7,0.7$

05A):DVid, DVno1,DVno2,DVsoffM,DVsillM,DVwidtM, WindV(M/S), BreakTempC, DotNo (Dvtimes)

$20,20,86,2,0,0.9,0,10000,2$

05B):DVtimeS

0,3600

05C):OpeningFactor

$0.7,0.7$

05A):DVid, DVnol,DVno2,DVsoffM,DVsillM,DVwidtM, WindV(M/S), BreakTempC, DotNo (Dvtimes)

$21,21,87,2,0,0.9,0,10000,2$

05B):DVtimeS

0,3600

05C):OpeningFactor

$0.7,0.7$

05A):DVid, DVno1,DVno2,DVsoffM,DVsillM,DVwidtM, WindV(M/S), BreakTempC, DotNo (Dvtimes)

$22,21,22,2,0,0.9,0,10000,2$

05B):DVtimeS

0,3600

05C):OpeningFactor

1,1

05A):DVid, DVno1,DVno2,DVsoffM,DVsillM,DVwidtM, WindV(M/S), BreakTempC, DotNo (Dvtimes)

$23,21,23,2,0,0.9,0,10000,2$

05B):DVtimes

0,3600

05C):OpeningFactor

1,1

05A):DVid, DVnol,DVno2,DVsoffM,DVsillM,DVwidtM, WindV(M/S), BreakTempC, DotNo (Dvtimes)

$24,21,24,2,0,0.9,0,10000,2$

05B):DVtimeS

0,3600

05C):OpeningFactor

1,1

05A):DVid, DVnol,DVno2,DVsoffM,DVsillM,DVwidtM, WindV(M/S), BreakTempC, DotNo (Dvtimes)

$25,21,25,2,0,0.9,0,10000,2$

05B):DVtimeS

0,3600

05C):OpeningFactor

1,1

05A):DVid, DVnol,DVno2,DVsoffM,DVsillM,DVwidtM, WindV(MS), BreakTempC, DotNo (Dvtimes)

$26,26,87,2,0,0.9,0,10000,2$

05B):DVtimeS

0,3600

05C):OpeningFactor

$0.7,0.7$

05A):DVid, DVno1,DVno2,DVsoffM,DVsillM,DVwidtM, WindV(M/S), BreakTempC, DotNo (Dvtimes)

$27,27,87,2,0,0.9,0,10000,2$

05B):DVtimeS

0,3600

05C):OpeningFactor

$0.7,0.7$

05A):DVid, DVnol,DVno2,DVsoftM,DVsillM,DVwidtM, WindV(M/S), BreakTempC, DotNo (Dvtimes) 
$28,28,87,2,0,0.9,0,10000,2$

05B):DVtimeS

0,3600

05C):OpeningFactor

$0.7,0.7$

05A):DVid, DVnol,DVno2,DVsoffM,DVsillM,DVwidtM, WindV(M/S), BreakTempC, DotNo (Dvtimes)

$29,29,87,2,0,0.9,0,10000,2$

05B):DVtimeS

0,3600

05C).OpeningFactor

$0.7,0.7$

05A):DVid, DVno1,DVno2,DVsoffM,DVsillM,DVwidtM, WindV(M/S), BreakTempC, DotNo (Dvtimes)

$30,30,87,2,0,0.9,0,10000,2$

05B):DVtimeS

0,3600

05C):OpeningFactor

$0.7,0.7$

05A):DVid, DVno1,DVno2,DVsoffM,DVsillM,DVwidtM, WindV(M/S), BreakTempC, DotNo (Dvtimes)

$31,31,88,2,0,0.9,0,10000,2$

05B):DVtimeS

0,3600

05C):OpeningFactor

$0.7,0.7$

05A):DVid, DVnol,DVno2,DVsoffM,DVsillM,DVwidtM, WindV(M/S), BreakTempC, DotNo (Dvtimes)

$32,31,32,2,0,0.9,0,10000,2$

05B):DVtimeS

0,3600

05C).OpeningFactor

1,1

05A):DVid, DVno1,DVno2,DVsoffM,DVsillM,DVwidtM, WindV(M/S), BreakTempC, DotNo (Dvtimes)

$33,31,33,2,0,0.9,0,10000,2$

05B):DVtimeS

0,3600

05C):OpeningFactor

1,1

05A):DVid, DVno1,DVno2,DVsoffM,DVsillM,DVwidtM, WindV(M/S), BreakTempC, DotNo (Dvtimes)

$34,31,34,2,0,0.9,0,10000,2$

05B):DVtimeS

0,3600

05C):OpeningFactor

1,1

05A):DVid, DVnol,DVno2,DVsoffM,DVsillM,DVwidtM, WindV(M/S), BreakTempC, DotNo (Dvtimes)

$35,31,35,2,0,0.9,0,10000,2$

05B):DVtimeS

0,3600

05C):OpeningFactor

1,1

05A):DVid, DVnol,DVno2,DVsoffM,DVsillM,DVwidtM, WindV(M/S), BreakTempC, DotNo (Dvtimes)

$36,36,88,2,0,0.9,0,10000,2$

05B):DVtimeS

0,3600

05C):OpeningFactor

$0.7,0.7$

05A):DVid, DVnol,DVno2,DVsoffM,DVsillM,DVwidtM, WindV(M/S), BreakTempC, DotNo (Dvtimes)

$37,37,88,2,0,0.9,0,10000,2$

05B):DVtimeS

0,3600

05C).OpeningFactor 
$0.7,0.7$

05A):DVid, DVno1,DVno2,DVsoffM,DVsillM,DVwidtM, WindV(M/S), BreakTempC, DotNo (Dvtimes)

$38,38,88,2,0,0.9,0,10000,2$

05B):DVtimeS

0,3600

05C):OpeningFactor

$0.7,0.7$

05A):DVid, DVnol,DVno2,DVsoffM,DVsillM,DVwidtM, WindV(M/S), BreakTempC, DotNo (Dvtimes)

$39,38,88,2,0,0.9,0,10000,2$

05B):DVtimeS

0,3600

05C):OpeningFactor

$0.7,0.7$

05A):DVid, DVnol,DVno2,DVsoffM,DVsillM,DVwidtM, WindV(M/S), BreakTempC, DotNo (Dvtimes)

$40,40,88,2,0,0.9,0,10000,2$

05B):DVtimeS

0,3600

05C):OpeningFactor

$0.7,0.7$

05A):DVid, DVno1,DVno2,DVsoftM,DVsillM,DVwidtM, WindV(M/S), BreakTempC, DotNo (Dvtimes)

$41,41,89,2,0,0.9,0,10000,2$

05B):DVtimeS

0,3600

05C):OpeningFactor

$0.7,0.7$

05A):DVid, DVnol,DVno2,DVsoffM,DVsillM,DVwidtM, WindV(M/S), BreakTempC, DotNo (Dvtimes)

$42,41,42,2,0,0.9,0,10000,2$

05B):DVtimeS

0,3600

05C):OpeningFactor

1,1

05A):DVid, DVno1,DVno2,DVsoffM,DVsillM,DVwidtM, WindV(M/S), BreakTempC, DotNo (Dvtimes)

$43,41,43,2,0,0.9,0,10000,2$

05B):DVtimeS

0,3600

05C):OpeningFactor

1,1

05A):DVid, DVno1,DVno2,DVsoffM,DVsillM,DVwidtM, WindV(M/S), BreakTempC, DotNo (Dvtimes)

$44,41,44,2,0,0.9,0,10000,2$

05B):DVtimeS

0,3600

05C):OpeningFactor

1,1

05A):DVid, DVno1,DVno2,DVsoffM,DVsillM,DVwidtM, WindV(M/S), BreakTempC, DotNo (Dvtimes)

$45,41,45,2,0,0.9,0,10000,2$

05B):DVtimeS

0,3600

05C):OpeningFactor

1,1

05A):DVid, DVno1,DVno2,DVsoffM,DVsillM,DVwidtM, WindV(M/S), BreakTempC, DotNo (Dvtimes) $46,46,89,2,0,0.9,0,10000,2$

05B):DVtimeS

0,3600

05C):OpeningFactor

$0.7,0.7$

05A):DVid, DVno1,DVno2,DVsoffM,DVsillM,DVwidtM, WindV(M/S), BreakTempC, DotNo (Dvtimes) $47,47,89,2,0,0.9,0,10000,2$

05B):DVtimeS 
0,3600

05C):OpeningFactor

$0.7,0.7$

05A):DVid, DVnol,DVno2,DVsoffM,DVsillM,DVwidtM, WindV(M/S), BreakTempC, DotNo (Dvtimes)

$48,48,89,2,0,0.9,0,10000,2$

05B):DVtimeS

0,3600

05C):OpeningFactor

$0.7,0.7$

05A):DVid, DVno1,DVno2,DVsoffM,DVsillM,DVwidtM, WindV(M/S), BreakTempC, DotNo (Dvtimes) $49,49,89,2,0,0.9,0,10000,2$

05B):DVtimeS

0,3600

05C):OpeningFactor

$0.7,0.7$

05A):DVid, DVno1,DVno2,DVsoffM,DVsillM,DVwidtM, WindV(M/S), BreakTempC, DotNo (Dvtimes) $50,50,89,2,0,0.9,0,10000,2$

05B):DVtimeS

0,3600

0SC):OpeningFactor

$0.7,0.7$

05A):DVid, DVno1,DVno2,DVsoffM,DVsillM,DVwidtM, WindV(M/S), BreakTempC, DotNo (Dvtimes)

$51,51,90,2,0,0.9,0,10000,2$

05B):DVtimeS

0,3600

05C):OpeningFactor

$0.7,0.7$

05A):DVid, DVno1,DVno2,DVsoffM,DVsillM,DVwidtM, WindV(M/S), BreakTempC, DotNo (Dvtimes)

$52,51,52,2,0,0.9,0,10000,2$

05B):DVtimeS

0,3600

05C):OpeningFactor

1,1

05A):DVid, DVnol,DVno2,DVsoffM,DVsillM,DVwidtM, WindV(M/S), BreakTempC, DotNo (Dvtimes)

$53,51,53,2,0,0.9,0,10000,2$

05B):DVtimeS

0,3600

05C):OpeningFactor

1,1

05A):DVid, DVno1,DVno2,DVsoffM,DVsillM,DVwidtM, WindV(M/S), BreakTempC, DotNo (Dvtimes)

$54,51,54,2,0,0.9,0,10000,2$

05B):DVtimeS

0,3600

05C).OpeningFactor

1,1

05A):DVid, DVno1,DVno2,DVsoffM,DVsillM,DVwidtM, WindV(M/S), BreakTempC, DotNo (Dvtimes)

$55,51,55,2,0,0.9,0,10000,2$

05B):DVtimeS

0,3600

05C):OpeningFactor

1,1

05A):DVid, DVnol,DVno2,DVsoftM,DVsillM,DVwidtM, WindV(M/S), BreakTempC, DotNo (Dvtimes)

$56,56,90,2,0,0.9,0,10000,2$

05B):DVtimeS

0,3600

05C):OpeningFactor

$0.7,0.7$

05A):DVid, DVno1,DVno2,DVsoffM,DVsillM,DVwidtM, WindV(M/S), BreakTempC, DotNo (Dvtimes) 
$57,57,90,2,0,0.9,0,10000,2$

05B):DVtimeS

0,3600

05C):OpeningFactor

$0.7,0.7$

0SA):DVid, DVnol,DVno2,DVsoffM,DVsillM,DVwidtM, WindV(M/S), BreakTempC, DotNo (Dvtimes)

$58,58,90,2,0,0.9,0,10000,2$

05B):DVtimeS

0,3600

05C):OpeningFactor

$0.7,0.7$

05A):DVid, DVnol,DVno2,DVsoffM,DVsillM,DVwidtM, WindV(M/S), BreakTempC, DotNo (Dvtimes)

$59,59,90,2,0,0.9,0,10000,2$

05B):DVtimeS

0,3600

05C):OpeningFactor

$0.7,0.7$

05A):DVid, DVnol,DVno2,DVsoffM,DVsillM,DVwidtM, WindV(M/S), BreakTempC, DotNo (Dvtimes) $60,60,90,2,0,0.9,0,10000,2$

05B):DVtimeS

0,3600

05C):OpeningFactor

$0.7,0.7$

05A):DVid, DVnol,DVno2,DVsoffM,DVsillM,DVwidtM, WindV(M/S), BreakTempC, DotNo (Dvtimes)

$61,73,85,2,0,0.9,0,10000,2$

05B):DVtimeS

0,3600

05C):OpeningFactor

$0.7,0.7$

05A):DVid, DVnol,DVno2,DVsoffM,DVsillM,DVwidtM, WindV(M/S), BreakTempC, DotNo (Dvtimes)

$62,74,85,2,0,0.9,0,10000,2$

05B):DVtimeS

0,3600

05C):OpeningFactor

$0.7,0.7$

05A):DVid, DVno1,DVno2,DVsoftM,DVsillM,DVwidtM, WindV(M/S), BreakTempC, DotNo (Dvtimes) $63,75,86,2,0,0.9,0,10000,2$

05B):DVtimeS

0,3600

05C):OpeningFactor

$0.7,0.7$

05A):DVid, DVno1,DVno2,DVsoffM,DVsillM,DVwidtM, WindV(M/S), BreakTempC, DotNo (Dvtimes)

$64,76,86,2,0,0.9,0,10000,2$

05B):DVtimeS

0,3600

05C):OpeningFactor

$0.7,0.7$

05A):DVid, DVnol,DVno2,DVsoffM,DVsillM,DVwidtM, WindV(M/S), BreakTempC, DotNo (Dvtimes)

$65,77,87,2,0,0.9,0,10000,2$

05B):DVtimes

0,3600

05C):OpeningFactor

$0.7,0.7$

05A):DVid, DVnol,DVno2,DVsoffM,DVsillM,DVwidtM, WindV(M/S), BreakTempC, DotNo (Dvtimes)

$66,78,87,2,0,0.9,0,10000,2$

05B):DVtimeS

0,3600

05C):OpeningFactor 
$0.7,0.7$

05A):DVid, DVnol,DVno2,DVsoftM,DVsillM,DVwidtM, WindV(M/S), BreakTempC, DotNo (Dvtimes)

$67,79,88,2,0,0.9,0,10000,2$

05B):DVtimeS

0,3600

05C).OpeningFactor

$0.7,0.7$

05A):DVid, DVno1,DVno2,DVsoffM,DVsillM,DVwidtM, WindV(M/S), BreakTempC, DotNo (Dvtimes)

$68,80,88,2,0,0.9,0,10000,2$

05B):DVtimeS

0,3600

05C):OpeningFactor

$0.7,0.7$

05A):DVid, DVnol,DVno2,DVsoffM,DVsillM,DVwidtM, WindV(M/S), BreakTempC, DotNo (Dvtimes)

$69,81,89,2,0,0.9,0,10000,2$

OSB):DVtimeS

0,3600

05C).OpeningFactor

$0.7,0.7$

05A):DVid, DVnol,DVno2,DVsoffM,DVsillM,DVwidtM, WindV(M/S), BreakTempC, DotNo (Dvtimes)

$70,82,89,2,0,0.9,0,10000,2$

05B):DVtimeS

0,3600

05C):OpeningFactor

$0.7,0.7$

05A):DVid, DVnol,DVno2,DVsoffM,DVsillM,DVwidtM, WindV(M/S), BreakTempC, DotNo (Dvtimes)

$71,83,90,2,0,0.9,0,10000,2$

05B):DVtimeS

0,3600

05C). OpeningFactor

$0.7,0.7$

05A):DVid, DVnol,DVno2,DVsoffM,DVsillM,DVwidtM, WindV(M/S), BreakTempC, DotNo (Dvtimes)

$72,84,90,2,0,0.9,0,10000,2$

05B):DVtimeS

0,3600

05C):OpeningFactor

$0.7,0.7$

05A):DVid, DVno1,DVno2,DVsoffM,DVsillM,DVwidtM, WindV(M/S), BreakTempC, DotNo (Dvtimes)

$73,61,73,3,0,3,0,10000,2$

05B):DVtimeS

0,3600

05C):OpeningFactor

1,1

05A):DVid, DVno1,DVno2,DVsoffM,DVsillM,DVwidtM, WindV(M/S), BreakTempC, DotNo (Dvtimes)

$74,62,74,3,0,3,0,10000,2$

05B):DVtimeS

0,3600

05C):OpeningFactor

1,1

05A):DVid, DVnol,DVno2,DVsoffM,DVsillM,DVwidtM, WindV(M/S), BreakTempC, DotNo (Dvtimes) $75,63,75,3,0,3,0,10000,2$

05B):DVtimeS

0,3600

05C):OpeningFactor

1,1

05A):DVid, DVnol,DVno2,DVsoffM,DVsillM,DVwidtM, WindV(M/S), BreakTempC, DotNo (Dvtimes) $76,64,76,3,0,3,0,10000,2$

05B):DVtimeS 
0,3600

05C).OpeningFactor

1,1

05A):DVid, DVnol,DVno2,DVsoffM,DVsillM,DVwidtM, WindV(M/S), BreakTempC, DotNo (Dvtimes)

$77,65,77,3,0,3,0,10000,2$

05B):DVtimeS

0,3600

05C):OpeningFactor

1,1

05A):DVid, DVno1,DVno2,DVsoffM,DVsillM,DVwidtM, WindV(M/S), BreakTempC, DotNo (Dvtimes)

$78,66,78,3,0,3,0,10000,2$

05B):DVtimeS

0,3600

05C).OpeningFactor

1,1

05A):DVid, DVno1,DVno2,DVsoftM,DVsillM,DVwidtM, WindV(M/S), BreakTempC, DotNo (Dvtimes) $79,67,79,3,0,3,0,10000,2$

05B):DVtimeS

0,3600

05C):OpeningFactor

1,1

05A):DVid, DVno1,DVno2,DVsoffM,DVsillM,DVwidtM, WindV(M/S), BreakTempC, DotNo (Dvtimes) $80,68,80,3,0,3,0,10000,2$

05B):DVtimeS

0,3600

05C):OpeningFactor

1,1

05A):DVid, DVno1,DVno2,DVsoffM,DVsillM,DVwidtM, WindV(M/S), BreakTempC, DotNo (Dvtimes) $81,69,81,3,0,3,0,10000,2$

05B):DVtimeS

0,3600

05C).OpeningFactor

1,1

05A):DVid, DVnol,DVno2,DVsoffM,DVsillM,DVwidtM, WindV(M/S), BreakTempC, DotNo (Dvtimes) $82,70,82,3,0,3,0,10000,2$

05B):DVtimeS

0,3600

05C):OpeningFactor

1,1

05A):DVid, DVnol,DVno2,DVsoffM,DVsillM,DVwidtM, WindV(M/S), BreakTempC, DotNo (Dvtimes)

$83,71,83,3,0,3,0,10000,2$

05B):DVtimeS

0,3600

05C):OpeningFactor

1,1

05A):DVid, DVnol,DVno2,DVsoffM,DVsillM,DVwidtM, WindV(M/S), BreakTempC, DotNo (Dvtimes)

$84,72,84,3,0,3,0,10000,2$

05B):DVtimeS

0,3600

05C):OpeningFactor

1,1

05A):DVid, DVnol,DVno2,DVsoffM,DVsillM,DVwidtM, WindV(M/S), BreakTempC, DotNo (Dvtimes)

$85,73,91,2,0,1.8,0,10000,2$

05B):DVtimeS

0,3600

05C):OpeningFactor

0,0

05A):DVid, DVnol,DVno2,DVsoffM,DVsillM,DVwidtM, WindV(M/S), BreakTempC, DotNo (Dvtimes) 
$86,74,91,2,0,1.8,0,10000,2$

05B):DVtimeS

0,3600

05C).OpeningFactor

0,0

05A):DVid, DVnol,DVno2,DVsoffM,DVsillM,DVwidtM, WindV(M/S), BreakTempC, DotNo (Dvtimes)

$87,1,91,2.5,1,1.5,0,300,2$

05B):DVtimeS

0,3600

05C):OpeningFactor

0,1

05A):DVid, DVno1,DVno2,DVsoffM,DVsillM,DVwidtM, WindV(M/S), BreakTempC, DotNo (Dvtimes)

$88,2,91,2.5,1,1.5,0,300,2$

05B):DVtimeS

0,3600

05C).OpeningFactor

0,1

05A):DVid, DVnol,DVno2,DVsoftM,DVsillM,DVwidtM, WindV(M/S), BreakTempC, DotNo (Dvtimes)

$89,3,91,2.5,1,1.5,0,300,2$

05B):DVtimeS

0,3600

05C):OpeningFactor

0,1

05A):DVid, DVnol,DVno2,DVsoffM,DVsillM,DVwidtM, WindV(M/S), BreakTempC, DotNo (Dvtimes)

$90,6,91,2.5,1,3,0,300,2$

05B):DVtimeS

0,3600

05C):OpeningFactor

0,1

05A):DVid, DVnol,DVno2,DVsoffM,DVsillM,DVwidtM, WindV(M/S), BreakTempC, DotNo (Dvtimes)

$91,7,91,2.5,1,3,0,300,2$

05B):DVtimeS

0,3600

05C):OpeningFactor

0,1

05A):DVid, DVno1,DVno2,DVsoffM,DVsillM,DVwidtM, WindV(M/S), BreakTempC, DotNo (Dvtimes)

$92,8,91,2.5,1,3,0,300,2$

05B):DVtimeS

0,3600

05C):OpeningFactor

0,1

05A):DVid, DVno1,DVno2,DVsoffM,DVsillM,DVwidtM, WindV(M/S), BreakTempC, DotNo (Dvtimes)

$93,9,91,2.5,1,3,0,300,2$

05B):DVtimeS

0,3600

05C):OpeningFactor

0,1

05A):DVid, DVnol,DVno2,DVsoftM,DVsillM,DVwidtM, WindV(M/S), BreakTempC, DotNo (Dvtimes)

$94,10,91,2.5,1,3,0,300,2$

05B):DVtimeS

0,3600

05C):OpeningFactor

0,1

05A):DVid, DVnol,DVno2,DVsoftM,DVsillM,DVwidtM, WindV(M/S), BreakTempC, DotNo (Dvtimes)

$95,11,91,2.5,1,1.5,0,300,2$

05B):DVtimeS

0,3600

05C).OpeningFactor 
$\mathbf{0}, 1$

05A):DVid, DVnol,DVno2,DVsoffM,DVsillM,DVwidtM, WindV(M/S), BreakTempC, DotNo (Dvtimes)

$96,12,91,2.5,1,1.5,0,300,2$

05B):DVtimeS

0,3600

05C):OpeningFactor

0,1

05A):DVid, DVnol,DVno2,DVsoffM,DVsillM,DVwidtM, WindV(M/S), BreakTempC, DotNo (Dvtimes)

$97,13,91,2.5,1,1.5,0,300,2$

05B):DVtimeS

0,3600

05C).OpeningFactor

0,1

05A):DVid, DVno1,DVno2,DVsoffM,DVsillM,DVwidtM, WindV(M/S), BreakTempC, DotNo (Dvtimes)

$98,16,91,2.5,1,3,0,300,2$

05B):DVtimeS

0,3600

05C).OpeningFactor

0,1

05A):DVid, DVnol,DVno2,DVsoftM,DVsillM,DVwidtM, WindV(M/S), BreakTempC, DotNo (Dvtimes)

$99,17,91,2.5,1,3,0,300,2$

05B):DVtimeS

0,3600

05C):OpeningFactor

0,1

05A):DVid, DVnol,DVno2,DVsofm,DVsillM,DVwidtM, WindV(M/S), BreakTempC, DotNo (Dvtimes)

$100,18,91,2.5,1,3,0,300,2$

05B):DVtimeS

0,3600

05C):OpeningFactor

0,1

05A):DVid, DVno1,DVno2,DVsoffM,DVsillM,DVwidtM, WindV(M/S), BreakTempC, DotNo (Dvtimes)

$101,19,91,2.5,1,3,0,300,2$

05B):DVtimeS

0,3600

05C).OpeningFactor

0,1

05A):DVid, DVno1,DVno2,DVsoffM,DVsillM,DVwidtM, WindV(M/S), BreakTempC, DotNo (Dvtimes)

$102,20,91,2.5,1,3,0,300,2$

05B):DVtimeS

0,3600

05C).OpeningFactor

0,1

05A):DVid, DVnol,DVno2,DVsoffM,DVsillM,DVwidtM, WindV(M/S), BreakTempC, DotNo (Dvtimes)

$103,21,91,2.5,1,1.5,0,300,2$

05B):DVtimeS

0,3600

05C):OpeningFactor

0,1

05A):DVid, DVnol,DVno2,DVsoffM,DVsillM,DVwidtM, WindV(M/S), BreakTempC, DotNo (Dvtimes)

$104,22,91,2.5,1,1.5,0,300,2$

05B):DVtimeS

0,3600

05C).OpeningFactor

0,1

05A):DVid, DVnol,DVno2,DVsoftM,DVsillM,DVwidtM, WindV(M/S), BreakTempC, DotNo (Dvtimes) $105,23,91,2.5,1,1.5,0,300,2$

05B):DVtimeS 
0,3600

05C).OpeningFactor

0,1

0SA):DVid, DVnol,DVno2,DVsoffM,DVsillM,DVwidtM, WindV(M/S), BreakTempC, DotNo (Dvtimes) $106,26,91,2.5,1,3,0,300,2$

05B):DVtimeS

0,3600

05C):OpeningFactor

0,1

05A):DVid, DVnol,DVno2,DVsoffM,DVsillM,DVwidtM, WindV(M/S), BreakTempC, DotNo (Dvtimes) $107,27,91,2.5,1,3,0,300,2$

05B):DVtimeS

0,3600

05C):OpeningFactor

0,1

05A):DVid, DVnol,DVno2,DVsoffM,DVsillM,DVwidtM, WindV(M/S), BreakTempC, DotNo (Dvtimes) $108,28,91,2.5,1,3,0,300,2$

05B):DVtimeS

0,3600

05C):OpeningFactor

0,1

05A):DVid, DVnol,DVno2,DVsoffM,DVsillM,DVwidtM, WindV(M/S), BreakTempC, DotNo (Dvtimes) $109,29,91,2.5,1,3,0,300,2$

05B):DVtimeS

0,3600

05C):OpeningFactor

0,1

05A):DVid, DVnol,DVno2,DVsoffM,DVsillM,DVwidtM, WindV(M/S), BreakTempC, DotNo (Dvtimes) $110,30,91,2.5,1,3,0,300,2$

05B):DVtimeS

0,3600

05C):OpeningFactor

0,1

0SA):DVid, DVnol,DVno2,DVsoffM,DVsillM,DVwidtM, WindV(M/S), BreakTempC, DotNo (Dvtimes)

$111,31,91,2.5,1,1.5,0,300,2$

05B):DVtimeS

0,3600

05C):OpeningFactor

0,1

05A):DVid, DVnol,DVno2,DVsoffM,DVsillM,DVwidtM, WindV(M/S), BreakTempC, DotNo (Dvtimes)

$112,32,91,2.5,1,1.5,0,300,2$

05B):DVtimeS

0,3600

05C):OpeningFactor

0,1

05A):DVid, DVnol,DVno2,DVsoffM,DVsillM,DVwidtM, WindV(M/S), BreakTempC, DotNo (Dvtimes)

$113,33,91,2.5,1,1.5,0,300,2$

05B):DVtimeS

0,3600

05C).OpeningFactor

0,1

05A):DVid, DVnol,DVno2,DVsofm,DVsillM,DVwidtM, WindV(M/S), BreakTempC, DotNo (Dvtimes)

$114,36,91,2.5,1,3,0,300,2$

05B):DVtimeS

0,3600

05C):OpeningFactor

0,1

05A):DVid, DVnol,DVno2,DVsoffM,DVsillM,DVwidtM, WindV(M/S), BreakTempC, DotNo (Dvtimes) 
$115,37,91,2.5,1,3,0,300,2$

05B):DVtimeS

0,3600

05C):OpeningFactor

0,1

05A):DVid, DVnol,DVno2,DVsoffM,DVsillM,DVwidtM, WindV(M/S), BreakTempC, DotNo (Dvtimes)

$116,38,91,2.5,1,3,0,300,2$

05B):DVtimeS

0,3600

05C):OpeningFactor

0,1

05A):DVid, DVnol,DVno2,DVsoffM,DVsillM,DVwidtM, WindV(M/S), BreakTempC, DotNo (Dvtimes)

$117,39,91,2.5,1,3,0,300,2$

05B):DVtimeS

0,3600

05C):OpeningFactor

0,1

05A):DVid, DVnol,DVno2,DVsoffM,DVsillM,DVwidtM, WindV(M/S), BreakTempC, DotNo (Dvtimes)

$118,40,91,2.5,1,3,0,300,2$

05B):DVtimeS

0,3600

05C):OpeningFactor

0,1

05A):DVid, DVnol,DVno2,DVsoffM,DVsillM,DVwidtM, WindV(M/S), BreakTempC, DotNo (Dvtimes)

$119,41,91,2.5,1,1.5,0,300,2$

05B):DVtimeS

0,3600

05C):OpeningFactor

0,1

05A):DVid, DVnol,DVno2,DVsoffM,DVsillM,DVwidtM, WindV(M/S), BreakTempC, DotNo (Dvtimes) $120,42,91,2.5,1,1.5,0,300,2$

05B):DVtimeS

0,3600

05C):OpeningFactor

0,1

05A):DVid, DVnol,DVno2,DVsoftM,DVsillM,DVwidtM, WindV(M/S), BreakTempC, DotNo (Dvtimes) $121,43,91,2.5,1,1.5,0,300,2$

05B):DVtimeS

0,3600

05C):OpeningFactor

0,1

05A):DVid, DVno1,DVno2,DVsoffM,DVsillM,DVwidtM, WindV(M/S), BreakTempC, DotNo (Dvtimes) $122,46,91,2.5,1,3,0,300,2$

05B):DVtimeS

0,3600

05C):OpeningFactor

0,1

05A):DVid, DVnol,DVno2,DVsoffM,DVsillM,DVwidtM, WindV(M/S), BreakTempC, DotNo (Dvtimes)

$123,47,91,2.5,1,3,0,300,2$

05B):DVtimeS

0,3600

05C).OpeningFactor

0,1

05A):DVid, DVnol,DVno2,DVsoffM,DVsillM,DVwidtM, WindV(M/S), BreakTempC, DotNo (Dvtimes)

$124,48,91,2.5,1,3,0,300,2$

05B):DVtimes

0,3600

05C).OpeningFactor 
0,1

05A):DVid, DVnol,DVno2,DVsoffM,DVsillM,DVwidtM, WindV(M/S), BreakTempC, DotNo (Dvtimes) $125,49,91,2.5,1,3,0,300,2$

0SB):DVtimeS

0,3600

05C).OpeningFactor

0,1

05A):DVid, DVnol,DVno2,DVsoffM,DVsillM,DVwidtM, WindV(M/S), BreakTempC, DotNo (Dvtimes)

$126,50,91,2.5,1,3,0,300,2$

05B):DVtimeS

0,3600

05C):OpeningFactor

0,1

05A):DVid, DVno1,DVno2,DVsoffM,DVsillM,DVwidtM, WindV(M/S), BreakTempC, DotNo (Dvtimes)

$127,51,91,2.5,1,1.5,0,300,2$

05B):DVtimeS

0,3600

05C):OpeningFactor

0,1

05A):DVid, DVnol,DVno2,DVsoffM,DVsillM,DVwidtM, WindV(M/S), BreakTempC, DotNo (Dvtimes)

$128,52,91,2.5,1,1.5,0,300,2$

05B):DVtimeS

0,3600

05C):OpeningFactor

0,1

05A):DVid, DVnol,DVno2,DVsoffM,DVsillM,DVwidtM, WindV(M/S), BreakTempC, DotNo (Dvtimes)

$129,53,91,2.5,1,1.5,0,300,2$

05B):DVtimeS

0,3600

05C):OpeningFactor

0,1

05A):DVid, DVnol,DVno2,DVsoftM,DVsillM,DVwidtM, WindV(M/S), BreakTempC, DotNo (Dvtimes)

$130,56,91,2.5,1,3,0,300,2$

05B):DVtimeS

0,3600

05C):OpeningFactor

0,1

05A):DVid, DVno1,DVno2,DVsoffM,DVsillM,DVwidtM, WindV(M/S), BreakTempC, DotNo (Dvtimes)

$131,57,91,2.5,1,3,0,300,2$

05B):DVtimeS

0,3600

05C):OpeningFactor

0,1

05A):DVid, DVno1,DVno2,DVsoffM,DVsillM,DVwidtM, WindV(M/S), BreakTempC, DotNo (Dvtimes)

$132,58,91,2.5,1,3,0,300,2$

05B):DVtimeS

0,3600

05C):OpeningFactor

0,1

05A):DVid, DVnol,DVno2,DVsoffM,DVsillM,DVwidtM, WindV(M/S), BreakTempC, DotNo (Dvtimes)

$133,59,91,2.5,1,3,0,300,2$

05B):DVtimeS

0,3600

05C):OpeningFactor

0,1

05A):DVid, DVnol,DVno2,DVsoffM,DVsillM,DVwidtM, WindV(M/S), BreakTempC, DotNo (Dvtimes) $134,60,91,2.5,1,3,0,300,2$

05B):DVtimeS 
0,3600

05C):OpeningFactor

0,1

06):CCVid, CnoTop, CnoBot, CthicM, CdiamM

07):RCVid, RnoTop, RnoBot, RthicM, RwidtM, RdeptM

08):SCVid, SCVctNo, SCVtopNo, Sdensity(Persons/M2), |Open|Closed

$1,61,63,1.3$, Open

$2,62,64,1.3$, Open

$3,63,65,1.3$, Open

$4,64,66,1.3$, Open

$5,65,67,1.3$, Open

$6,66,68,1.3$, Open

$7,67,69,1.3$, Open

$8,68,70,1.3$, Open

$9,69,71,1.3$, Open

$10,70,72,1.3$,Open

09A):MVid, CTid, OpenExtM, TstartS, TendS, DotNo, |Dis|Con|, |M3/S|kg/S|cfm|

09B):MVtimeS

09C):(Out+)|M3/S|kg/S|cfm| 